\title{
GAMIFICACIÓN EN AMBIENTES \\ MASIVOS DE INNOVACION ABIERTA \\ EN EL ÁREA DE SUSTENTABILIDAD \\ ENERGÉTICA
}

\section{Tesis Doctoral}

Doctoranda:

Elvira G. Rincón Flores

Directores:

Dra. María S. Ramírez Montoya Dr. Juanjo Mena
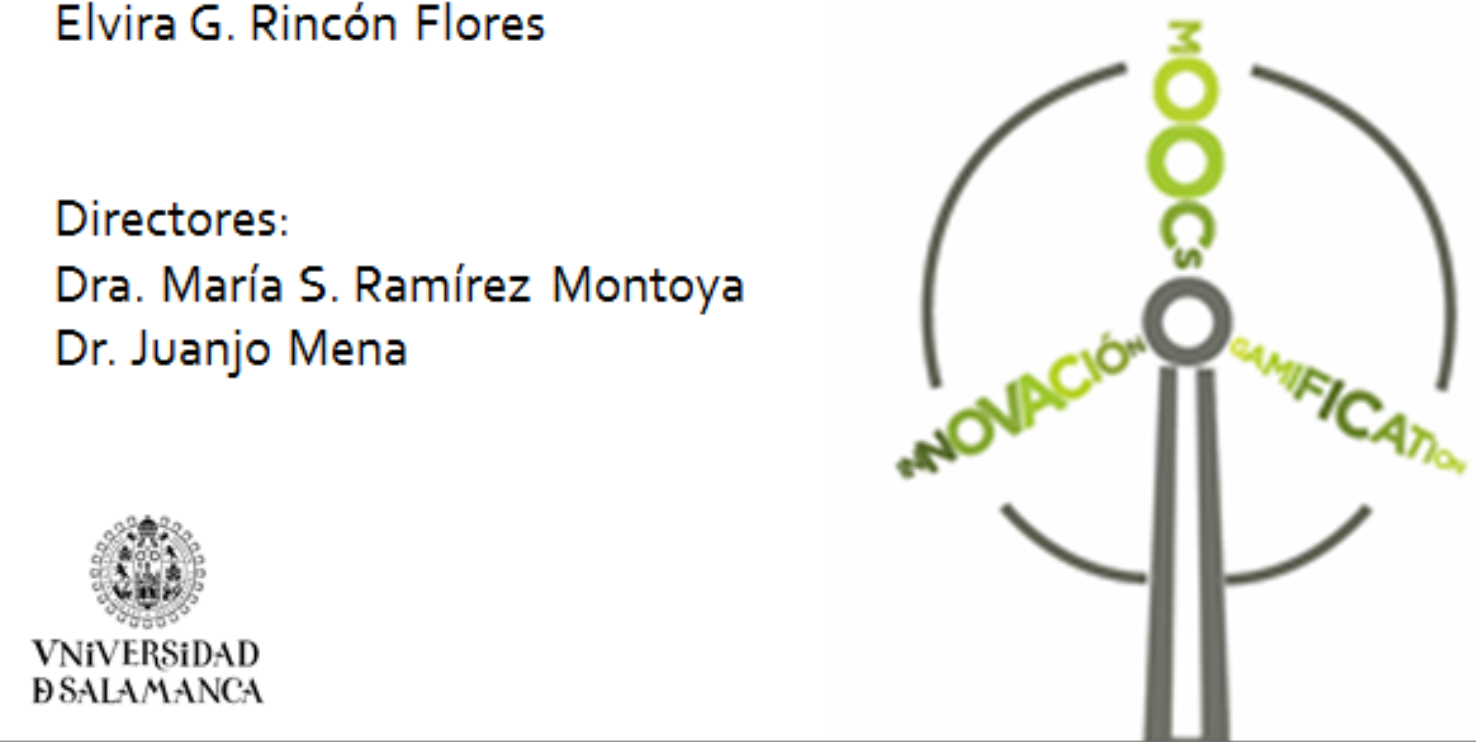
Programa de Doctorado Formación en la

Sociedad del Conocimiento (RD 99/2011)

GAMIFICACIÓN EN AMBIENTES MASIVOS DE INNOVACION ABIERTA EN EL ÁREA DE SUSTENTABILIDAD ENERGÉTICA

Tesis doctoral

Doctoranda:

Elvira G. Rincón Flores

Directores:

Dra. María Soledad Ramírez Montoya

Dr. Juanjo Mena

Diciembre 2018

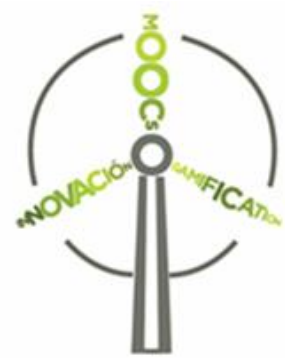


Rincón-Flores, E.G. (2018). Gamificación en ambientes masivos de innovacion abierta en el área de sustentabilidad energética (Tesis doctoral). Universidad de Salamanca, España. 


\section{AGRADECIMIENTOS}

El desarrollo de este trabajo de investigación se realizó dentro del marco del proyecto Laboratorio Binacional para la gestión inteligente de la sustentabilidad energética y la formación tecnológica, dentro del sub-proyecto Innovación abierta, colaborativa e interdisciplinaria para formar en sustentabilidad energética a través de Cursos masivos, abiertos y en línea, por lo que agradezco a la Dra. Marisol Ramírez por invitarme a formar parte de este proyecto tan importante para mí país, así como por su acompañamiento. También, agradezco el acompañamiento, las enseñanzas y las cálidas palabras de aliento del Dr. Juanjo Mena, gracias directores.

Sin duda, este proyecto no lo hubiera podido terminar sin la ayuda de mi familia, mi esposo Thibaut y mi hijo Francisco Javier, gracias por su amor y paciencia.

A mis queridos amigos: Liz, Alicia, Mónica, María, Eunice, Arturo y Ricardo, quienes siempre tuvieron tiempo para escuchar y animar, gracias por su apoyo y cariño.

El estudio se registra en el marco del Proyecto 266632 "Laboratorio Binacional para la Gestión Inteligente de la Sustentabilidad Energética y la Formación Tecnológica", con financiamiento del Fondo de Sustentabilidad Energética CONACYT-SENER (Convocatoria: S0019-2014-01). Se agradece el apoyo al CONACYT y al Tecnológico de Monterrey como responsable del proyecto. 


\section{RESUMEN}

Una de las principales preocupaciones que atañen a las sociedades de todo el mundo, gira en torno al tema de la energía y su sustentabilidad. Pues al igual que cualquier organismo biológico, las naciones requieren de este componente para vivir, desarrollarse y crecer. Ante esta necesidad, ha habido un creciente desarrollo tecnológico en las últimas décadas para cambiar el uso y obtención de energías convencionales por energías limpias y sustentables.

Los procesos para transformar las energías convencionales a limpias y sustentables ha generado cambios que han afectado a los sectores político, social, económico y educativo. Tal es el caso de México, diversos expertos consideran que la Reforma Energética ha sido uno de los cambios más importantes en los últimos 70 años, debido a las implicaciones en los ámbitos económico, político, social y educativo, tanto en el sector hidrocarburos como en el sector eléctrico.

Una de las acciones promulgadas a raíz de la Reforma Energética fue la del Programa Estratégico de Formación de Recursos Humanos en Materia Energética, pues a mediano plazo se espera la creación de 135 mil empleos directos y 365 mil empleos indirectos dentro del sector energético. Es otras palabras, México está en un proceso de cambio hacia el uso de nuevas tecnologías en el que se requiere de personas capacitadas para poder operarlas.

Y no solo eso, también se requiere de personas que comprendan la Reforma iii 
Energética y sus implicaciones para atender con mayor eficiencia los procesos administrativos derivados de dicha Reforma, así como para desarrollar oportunidades de negocios. Al mismo tiempo, es importante que la sociedad en general conozca la necesidad e implicaciones de la Reforma Energética para que el proceso de cambio fluya en la mejor armonía posible.

En este sentido, y ante la urgente necesidad de masificar la educación en cuanto a la Reforma Energética, así como en temas de energía y sustentabilidad, se lanzó en el 2016 el proyecto "Laboratorio Binacional para Gestión Inteligente de la Sustentabilidad Energética y la Formación Tecnológica" (Proyecto 266632/ Acuerdo: S0019-2014ᄀ01) cuyo objetivo es apoyar a la implementación de la Reforma Energética para crear un sector competitivo y de clase mundial.

En el proyecto participaron la Secretaría de Energía, el Consejo Nacional de Ciencia y Tecnología y el Tecnológico de Monterrey como ente educativo. El proyecto consta de trece sub-proyectos, uno de ellos corresponde al de Innovación abierta, interdisciplinaria y colaborativa para formar en sustentabilidad energética a través de Cursos masivos, abiertos y en línea, mejor conocidos como MOOC (por sus siglas en inglés).

Este sub-proyecto tuvo como propósito impactar a las comunidades académicas, empresariales y sociales de México, creando conciencia en cuanto a la necesidad de una reforma energética, así como de las opciones energéticas sustentables. Para iv 
cumplir el objetivo, se desarrollaron doce cursos MOOC, de los cuales el curso Energías Convencionales, Limpias y su Tecnología se utilizó para fines de esta investigación.

Dentro de los objetivos de diseño de los MOOC fue que incluyera estrategias didácticas innovadoras como la gamificación con el propósito de favorecer la motivación y el aprendizaje de los participantes.

Por lo que, se focalizó en la estrategia de gamificación basada en retos y su relación con las variables socio demográficas y académicas, con el propósito de generar un modelo que pueda ser transferible en el diseño, desarrollo y aplicación de esta, u otras estrategias didácticas en ambientes de innovación abierta, como los MOOC. Para cumplir con los objetivos de la investigación se optó por desarrollar un marco teórico formado por los constructos: Innovación abierta, interdisciplinaria y colaborativa, los MOOC como ambientes de innovación abierta y el papel de la Gamificación en la educación.

Así mismo, se optó por un enfoque metodológico mixto, con predominancia en la parte cuantitativa (CUAN $\rightarrow$ Cual) que siguió dos fases. En la primera se hizo la recolección de los datos cuantitativos y en la segunda, con base en los resultados cuantitativos se desarrolló la fase cualitativa. En el curso Energías Convencionales, Limpias y su Tecnología, se inscribieron 4819 alumnos y se trabajó con una muestra de 1209, los cuales correspondieron a los participantes que al menos hicieron una actividad durante el curso. Los instrumentos y estrategias de recolección de datos $\mathrm{v}$ 
consistieron en cuestionarios, entrevistas, análisis significativo de las respuestas alternativas al Reto Gamificado por parte de los estudiantes y las analíticas del curso. Como resultado de la investigación se propone un modelo para el diseño, desarrollo, implementación y evaluación de estrategias didácticas innovadoras, tales como la gamificación, en ambientes de innovación abierta (MOOCs). El cual tiene como propósito dar un aporte al conocimiento científico, de tal forma que sea un punto de referencia para el desarrollo de la arquitectura pedagógica en este tipo de ambientes educativos.

Palabras clave: Reforma energética, Energías limpias, Trabajo colaborativo e interdisciplinario, xMOOC, Gamificación basada en retos, Dinámicas, Mecánicas, Componentes, Innovación disruptiva, Innovación incremental, Modelo de innovación. 


\section{ABSTRACT}

One of the main concerns affecting societies worldwide revolves around the theme of energy and sustainability. Like any biological organism, nations require to pay attention to this component to live, develop and grow. In response to this need, an increasing technological development has taken place in the last decades to change the use and production of conventional energy for clean and sustainable energy.

The processes to transform the conventional clean and sustainable energy have brought changes that have affected the political, social, economic and educational sectors. Such is the case of Mexico. Some experts have considered that the energy reform (both in the hydrocarbons sector as well as in the electricity sector) has been one of the most critical changes in the country for the last 70 years, due to its implications in the economic, political, social, and educational sectors.

One the actions taken was the strategic training program of human resources around energy themes was the creation of 135 thousand direct jobs and 365 thousand indirect jobs within the energy sector. In this sense, Mexico is under a profound reform towards the use of new technologies and specialized trainning.

Additionally, this reform requires citizens to understand the energy reform and its implications to serve with more efficient administrative processes derived from this reform, as well as to develop business opportunities. At the same time, it is important 
that society in general meet the need and the implications of the energy reform so that the change process flow in the best possible harmony.

In this sense, and given the urgent need to massively education in terms of the energy reform, as well as on issues of energy and sustainability, the project "bi-national laboratory for intelligent management of energy sustainability" as well as its" Technological training program" was launched in 2016 with the purpose to set a world class competitive sector.

The project involved the Mexican Secretary of Energy, the National Council of Science and Technology, and the Tecnologico de Monterrey as an educational entity. The project consists of thirteen sub-projects, one of them corresponds to the open, interdisciplinary, and collaborative innovation to teach about sustainable energy through massive, open and courses (MOOCs).

This sub-project have definetly impacted the academic, business and social communities of Mexico, raising awareness of the need for an energy reform, as well as the sustainable energy options. To meet this goal, there were twelve MOOC courses, but only one of them: conventional energies, clean and its technology was used for the purposes of the present research.

Within the MOOC design goals was to include innovative teaching strategies such as the gamification in order to promote the motivation and learning of the participants. 
So, focused on the strategy of Gamification challenges and its relation with the variable partner-based demographic and academic, with the purpose of creating a model that can be transferable in the design, development and implementation of this, or other strategies teaching in open innovation, as the MOOC environments. To meet the objectives of the research, it was decided to develop a theoretical framework formed by the constructs: open, interdisciplinary, and collaborative innovation the $\mathrm{MOOC}$ as environments of open innovation and the role of the Gamification in education.

Likewise, we opted for a mixed method approach, with a predominance of quantitative methods (QUAN $\rightarrow$ Qual). During the course Conventional energies, clean and its technology, 4819 students were enrolled and it was carried out with a sample of 1209, which corresponded to the participants who at least made an activity during the course. The instruments and strategies for data collection consisted of questionnaires, interviews, meaningful analysis of the alternative responses to the challenge gamificated by students and the analyses of the course.

As a result of the research, proposes a model for the design, development, implementation and evaluation of innovative teaching strategies, such as the gamification, in environments of open innovation (MOOCs). Which aims to give a contribution to scientific knowledge, in such a way that a point of reference for the development of architecture teaching in this type of educational environments. 
Keywords: Energy reform, Clean energy, Interdisciplinary and collaborative work, xMOOC, Gamification based on challenges, Dynamics, Mechanics, Components, Disruptive innovation, Incremental innovation, Innovation model. 
NATURALEZA Y DIMENSIÓN DEL TEMA DE INVESTIGACIÓN ......................................................

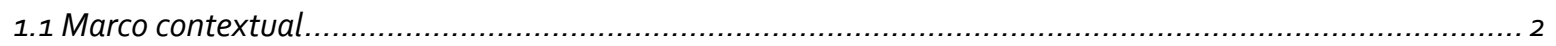

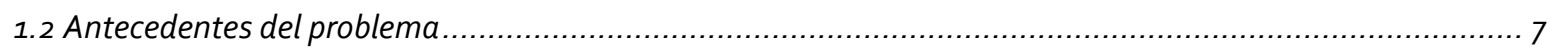

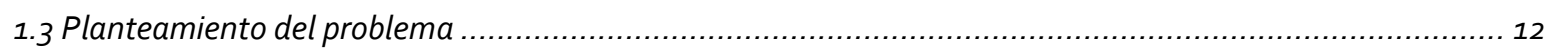

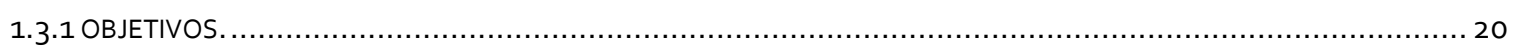

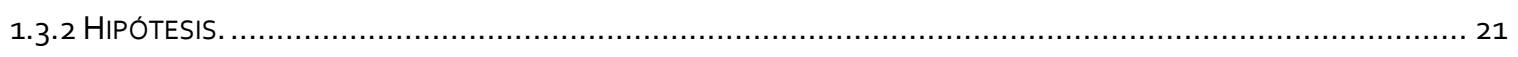

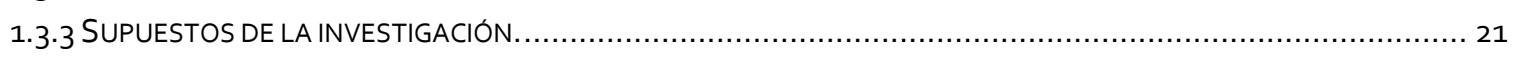

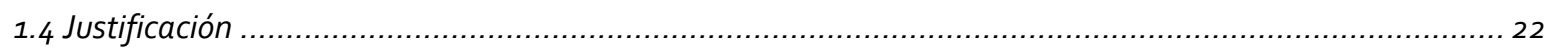

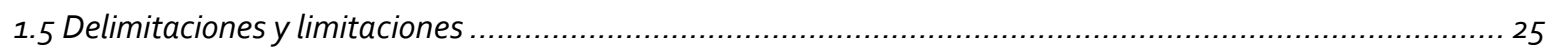

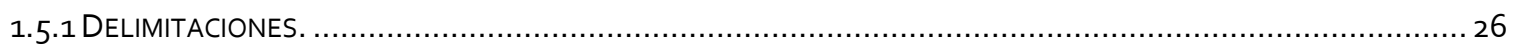

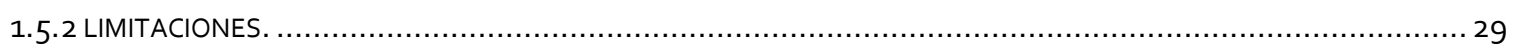

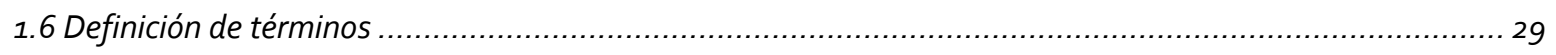

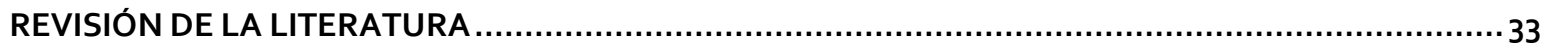

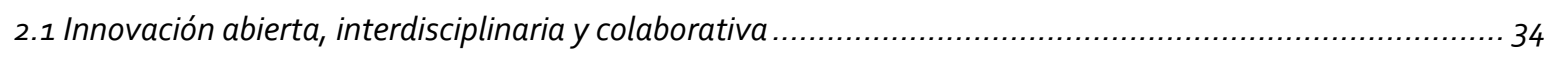

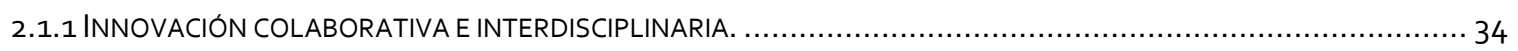

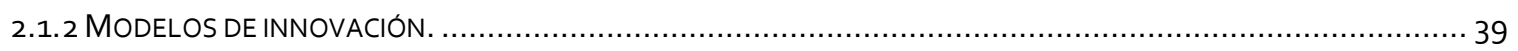

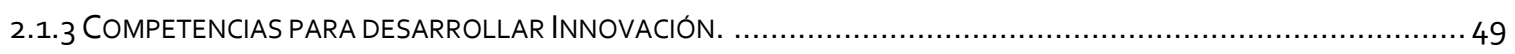

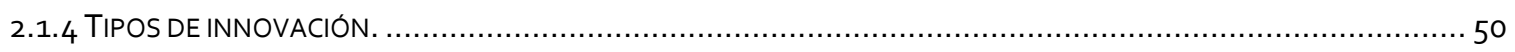

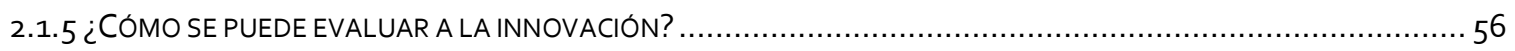

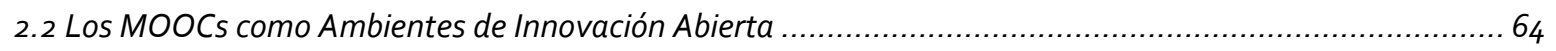

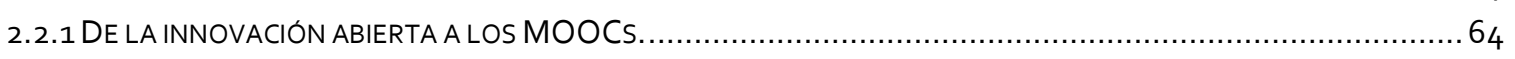

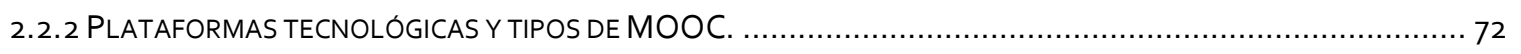

2.2.3 IMPACTO DE LOS MOOCS EN LA EDUCACIÓN ALREDEDOR DEL MUNDO Y SUS ÁREAS DE OPORTUNIDAD.............77

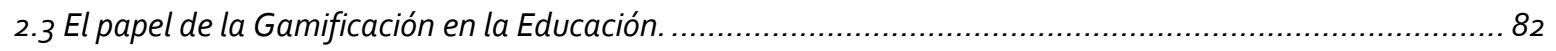

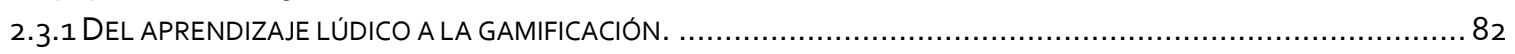

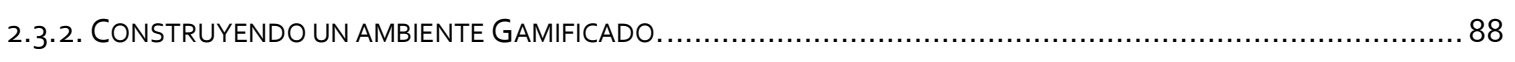

2.3.3 ENGANCHE Y FLUJO (ENGAGEMENT Y FLOW) COMO ELEMENTOS INHERENTES A LA GAMIFICACIÓN.................... 90

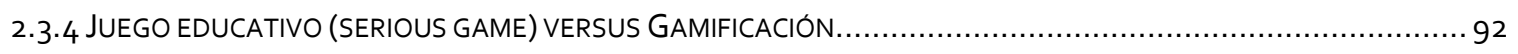

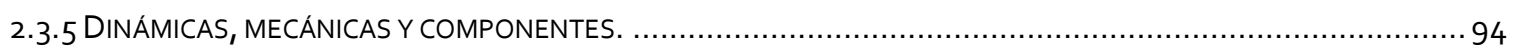

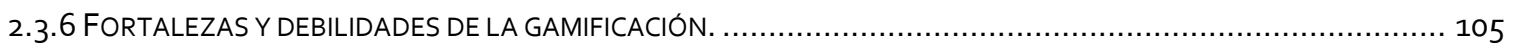

2.3.7 MECÁNICAS DE RETOS COMO ELEMENTO COGNITIVO DE UN AMBIENTE GAMIFICADO. ...............................112

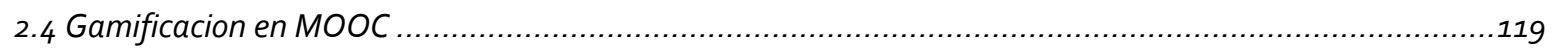

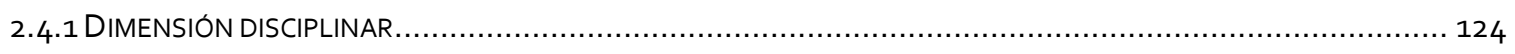

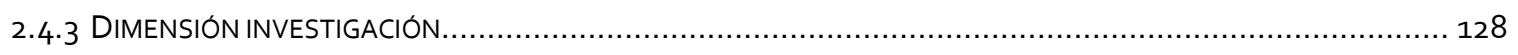

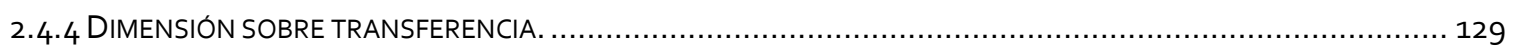

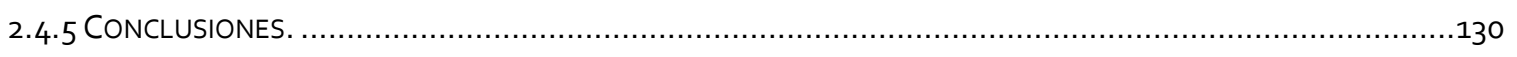

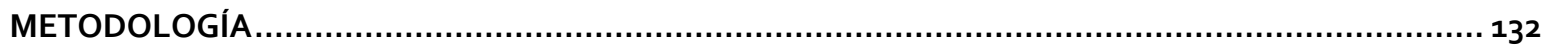

3.1 Situación educativa del marco de la investigación ....................................................................133

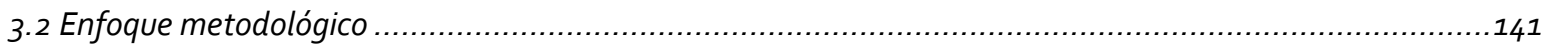

xi 


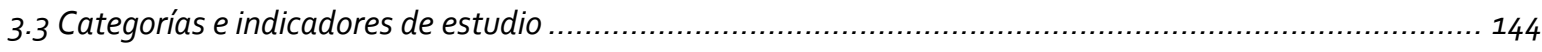

3.3.1 INDICADORES DE LA CATEGORÍA 1: INNOVACIÓN ABIERTA, INTERDISCIPLINARIA Y COLABORATIVA ................146

3.3.2 INDICADORES DE LA CATEGORÍA 2: EL PAPEL DE LA GAMIFICACIÓN EN LA EDUCACIÓN............................149

3.3.3 INDICADORES DE LA CATEGORÍA 3: ALCANCE DISRUPTIVO DEL XMOOC-ENERGÍA.................................151

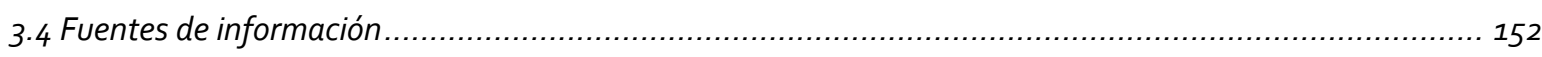

3.5 Instrumentos y estrategias de recolección de datos ......................................................... 156

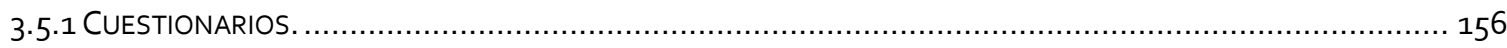

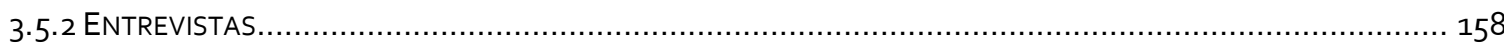

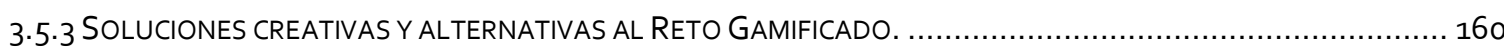

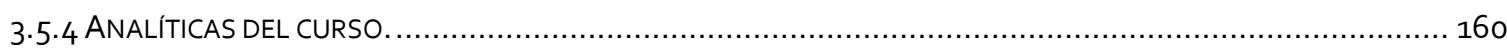

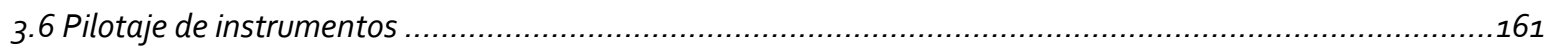

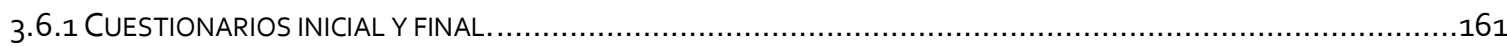

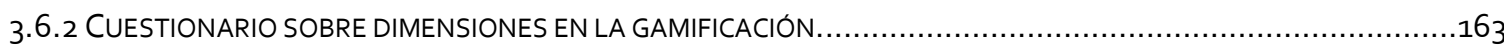

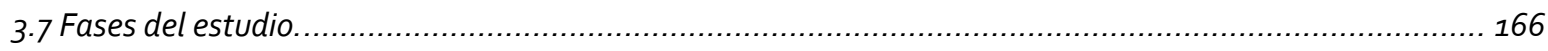

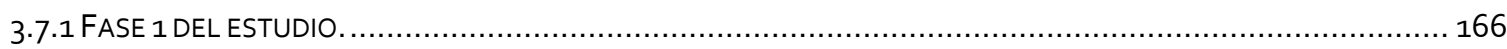

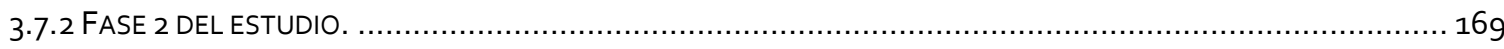

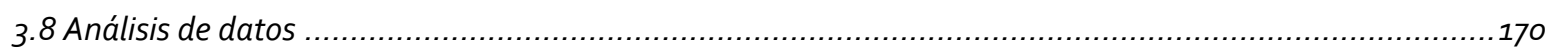

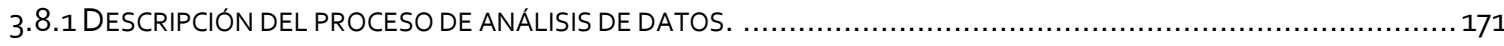

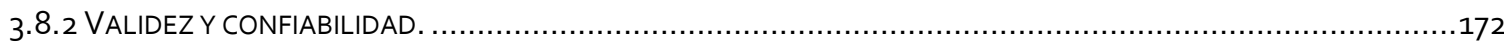

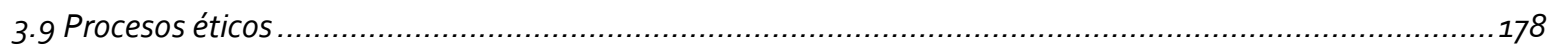

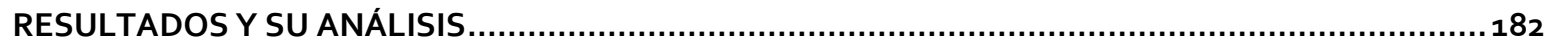

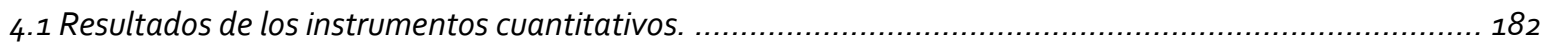

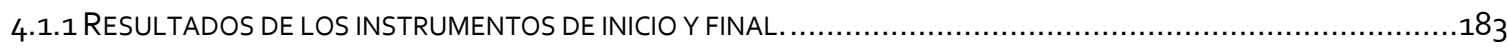

4.1.2 RESULTADOS DEL INSTRUMENTO SOBRE LAS DIMENSIONES DE LA GAMIFICACIÓN: COGNITIVA, SOCIAL Y

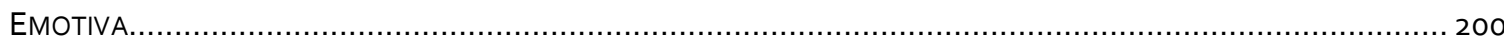

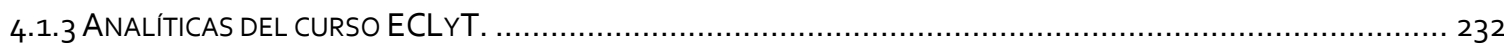

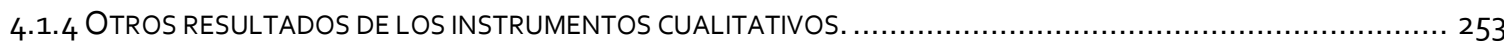

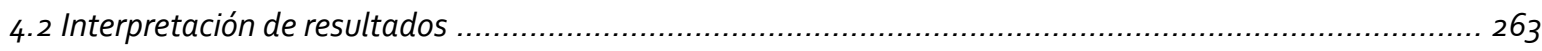

4.2.1 ANÁLISIS SOBRE LA ESTRATEGIA DIDÁCTICA GAMIFICACIÓN BASADA EN RETOS EN EL CURSO XMOOC ECLYT.263

4.2.2 EL RETO GAMIFICADO COMO BUENA PRÁCTICA EN EL XMOOC ECLYT .....................................268

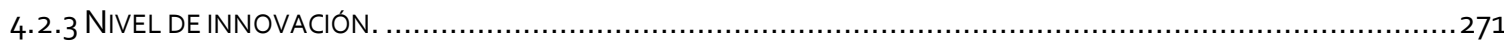

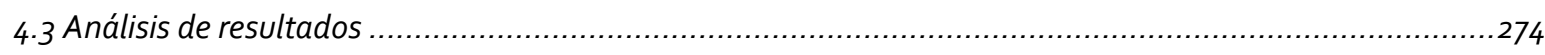

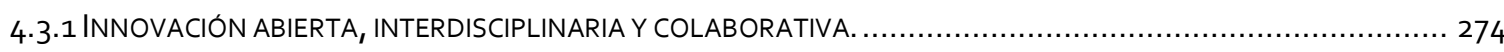

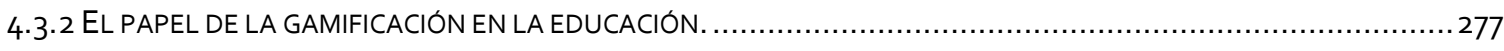

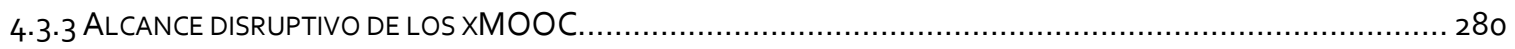

MODELO DE INNOVACIÓN EDUCATIVA INCREMENTAL PARA EL DISEÑO DE GAMIFICACIÓN

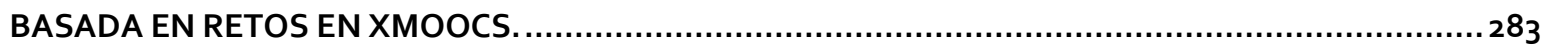

5.1 Trabajo colaborativo, interdisciplinario y vinculación. ............................................................284

5.2 Elementos de la gamificación basada en retos aplicada en xMOOC ...........................................289

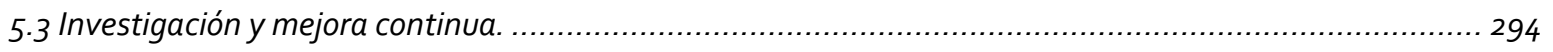

5.4 Modelo de innovación educativa incremental para el diseño de Gamificación basada en retos para

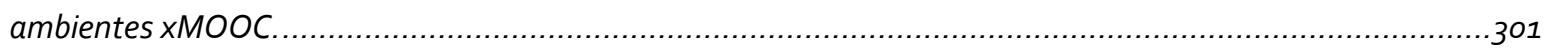

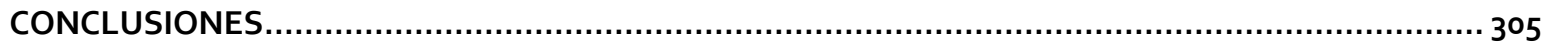

xii 


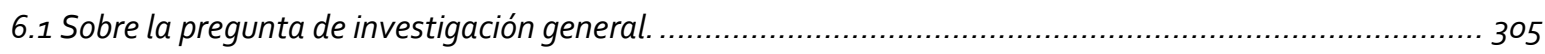

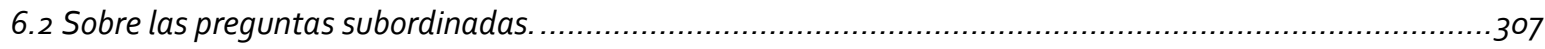

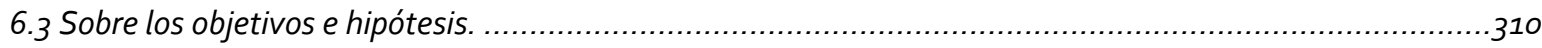

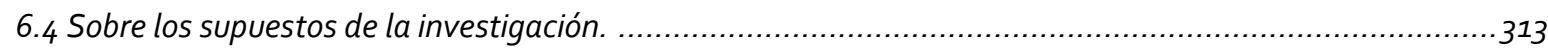

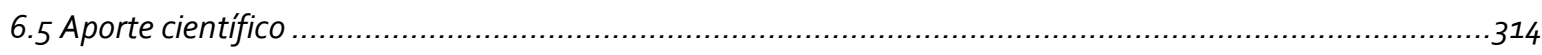

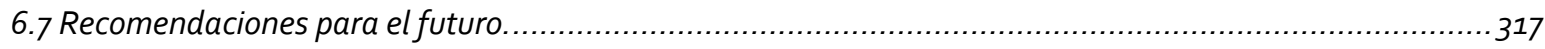

APÉNDICE I. MUESTRA DE ÍTEMS UTILIZADOS EN EL MAPPING. ........................................... 322

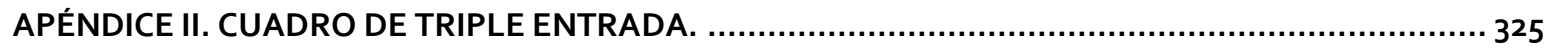

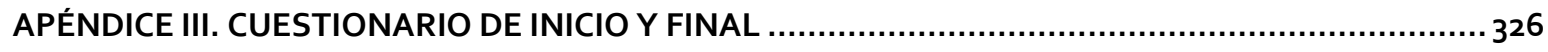

APÉNDICE IV. CUESTIONARIO SOBRE DIMENSIONES DE LA GAMIFICACIÓN (INSTRUMENTO

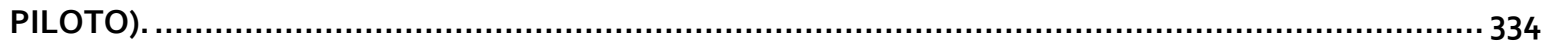

APÉNDICE V. CUESTIONARIO SOBRE DIMENSIONES DE LA GAMIFICACIÓN (INSTRUMENTO

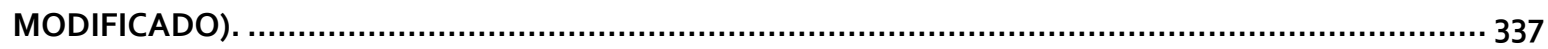

APÉNDICE VI. FORMATO PARA LA SOLICITUD DE ARCHIVOS DE DATOS DE LA PLATAFORMA

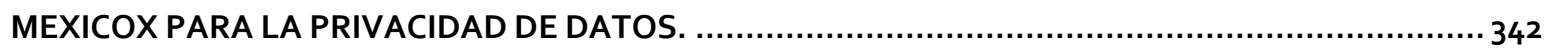

APÉNDICE VII. RÚBRICA PARA ANÁLISIS SIGNIFICATIVO DE LAS RESPUESTAS ALTERNATIVAS AL

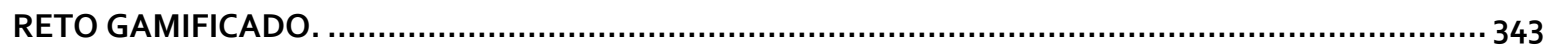

APÉNDICE VIII. RESPUESTAS SINTETIZADAS DE LAS ENTREVISTAS A EXPERTOSEX................... 345

APÉNDICE IX. TRANSCRIPCIONES DE LAS ENTREVISTAS REALIZADAS A EXPERTOS. ..................346

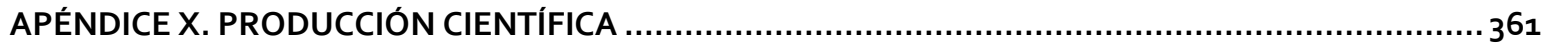

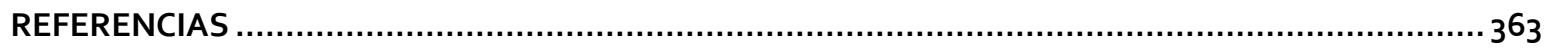




\section{ÍNDICE DE FIGURAS}

Figura 1.Oferta de curos MOOC-Energía y secuencia sugerida. 14

Figura 2.Modelo Instruccional del Sub-proyecto: Innovación abierta, interdisciplinaria y colaborativa para formar en sustentabilidad energética a través de MOOC ........................................................ 16

Figura 3. Lienzo de gamificación del Modelo Instruccional para los XMOOC - Energía .......................... 18

Figura 4. Imagen de la oferta del curso ECLyT dentro de la plataforma MéxicoX..................................28

Figura 5. Modelo de innovación y eficiencia propuesto por Schwartz, Bransford y Sears. .....................59

Figura 6. Esquema gráfico del constructo de Innovación. ..................................................................... 63

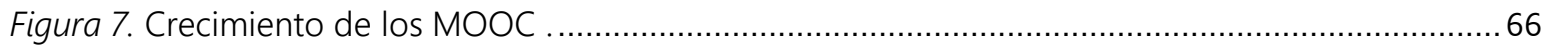

Figura 8. Número de usuarios (en miles) de diversas plataformas. .................................................... 76

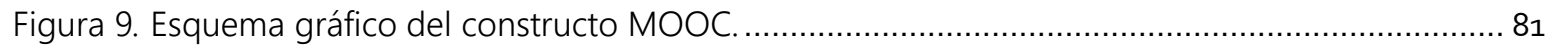

Figura 10. Elementos de la Gamificación según Werbach y Hunter ................................................ 93

Figura 11. Esquema gráfico del constructo Gamificación. ..............................................................119

Figura 12. Resumen de los resultados de búsqueda en diversas bases de datos ............................... 122

Figura 13. Distribución de las dinámicas, mecánicas y componentes. …....................................... 125

Figura 14. Distribución sobre el tipo de participantes en MOOCs con gamificación.............................. 128

Figura 15. Algunas actividades de los XMOOC-Energía ..................................................................134

Figura 16. Mirada parcial del Reto Gamificado del curso ECLyT ........................................................139

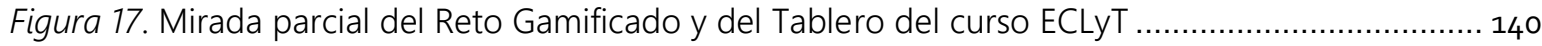

Figura 18. Diseño de investigación mixta tipo explicativa secuencial en dos fases de nuestro estudio 143

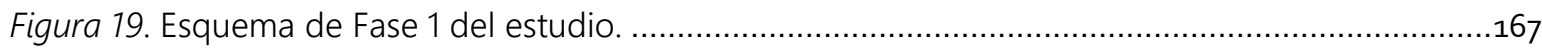

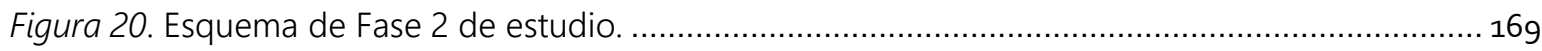

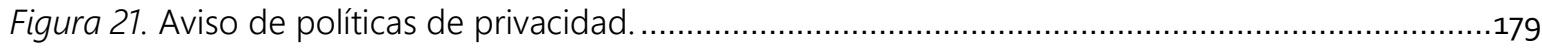

Figura 22. Proporción de hombres y mujeres que respondieron la encuesta de inicio y proporciones de

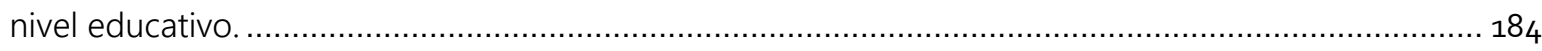

Figura 23. Resultados de la pregunta 1 tanto del cuestionario de inicio como el cuestionario final. ... 189

Figura 24. Resultados de la pregunta 2 tanto del cuestionario de inicio como el cuestionario final. ...191

Figura 25. Resultados de la pregunta 3 tanto del cuestionario de inicio como el cuestionario final. ... 194

Figura 26. Resultados de la pregunta 4 tanto del cuestionario de inicio como el cuestionario final. .. 196

Figura 27. Resultados de la pregunta 5 tanto del cuestionario de inicio como el cuestionario final. .. 199 xiv 
Figura 28. Resultados de la dimensión cognitiva global.

Figura 29. Distribución general de la dimensión social. ...................................................................213

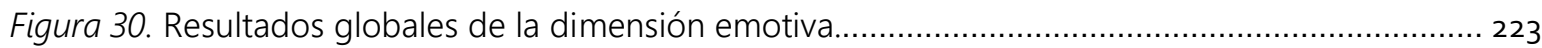

Figura 31. Distribución de los participantes extranjeros en el curso ECLyT por país............................. 238

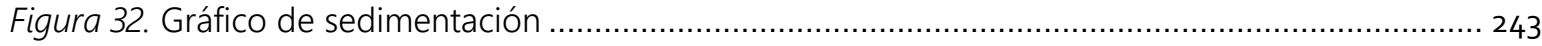

Figura 33. Gráfico Biplot de correlación con las componentes F1 y F2 ........................................... 245

Figura 34. Gráfico Biplot de correlación con las componentes F1 y F3.......................................... 247

Figura 35. Scatter-plot de la etiqueta género con respecto a las variables cuantitativas. .....................248

Figura 36. Prueba t-student para la diferencia de medias entre las calificaciones finales de los hombre y

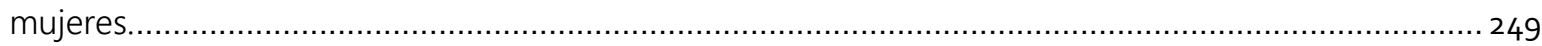

Figura 37. Scatter-plot de la etiqueta edad con respecto a las variables cuantitativas......................... 250

Figura 38. Scatter-plot de la etiqueta nivel educativo con respecto a las variables cuantitativas......... 251

Figura 39. Resultados de la Categoría 1. Opinión general del reto gamificado .................................... 253

Figura 40. Resultados de la Categoría 2. Contenido del reto gamificado. ........................................ 254

Figura 41. Resultados de la Categoría 3. Diseño del reto gamificado............................................... 256

Figura 42. Nivel de innovación logrado por género........................................................................... 260

Figura 43. Nivel de innovación por nivel educativo............................................................................ 261

Figura 44. Trabajo colaborativo, interdisciplinario y vinculación en el sub-proyecto............................ 286

Figura 45. Trabajo colaborativo, interdisciplinario y vinculación en el sub-proyecto........................... 290

Figura 46. Imagen parcial del reto gamificado "Combustibles para iluminación en caso de emergencia" del curso ECLYT

Figura 47. Evaluación y mejora continua de la innovación didáctica Gamificación basada en retos en xMOOC-energía

Figura 48. Modelo de innovación educativa incremental para el diseño de Gamificación basada en retos para $\mathrm{xMOOC}$. 


\section{ÍNDICE DE TABLAS}

Tabla 1. Cuadro comparativo ente los modelos analítico e interpretativo propuesto por Lester y Piore ... 41

Tabla 2.Modelos de innovación educativa según Zabalza y Zabalza .................................................... 45

Tabla 3. Modelos basados en la teoría Schumpeter ..................................................................... 47

Tabla 4. Actividades y competencias en el proceso de innovación ......................................................... 50

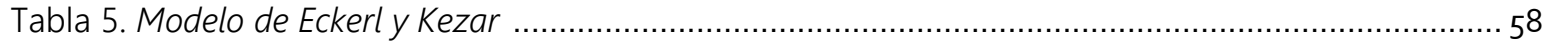

Tabla 6. Comparativo entre XMOOC y CMOOC a través de las cinco Ps ..............................................73

Tabla 7. Clasificaciones de los MOOCs según Coughlan...........................................................................74

Tabla 8. Ejemplo sobre diseño de un ambiente gamificado basado en la propuesta de Werbach y Hunter. 98

Tabla 9 .Tipos de dinámicas de acuerdo con Bunchball Inc.. 99

Tabla 10.Descripción y ejemplos de los componentes propuestos en un sistema gamificado, con base en los modelos de Werbach y Hunter., Kocadere y Caglar y Bunchball .................................................... 104

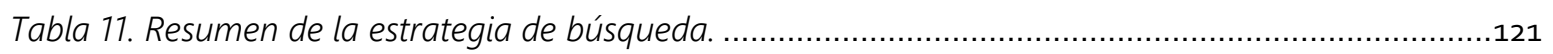

Tabla 12. Preguntas subordinadas de investigación del estudio. ........................................................123

Tabla 13. Distribución de las dinámicas, componentes y mecánicas a partir de los 30 ítems.................. 126

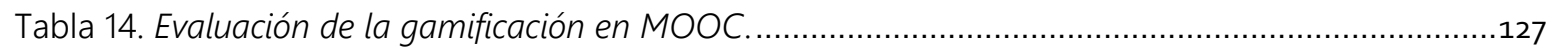

Tabla 15. Fuentes y técnicas de recolección de datos. .......................................................................155

Tabla 16. Técnica de recolección de datos cuantitativos. .................................................................... 158

Tabla 17. Alfa de Conbrach y Análisis factorial de los cuestionarios de inicio y final. .............................162

Tabla 18. Cambios realizados en los cuestionarios de inicio y final. .....................................................163

Tabla 19. Resultados del análisis de confiabilidad realizado en el software Minitab............................... 164

Tabla 20. Preguntas agregadas en el instrumento sobre dimensiones............................................... 165

Tabla 21. Conteo de mujeres y hombres según el nivel educativo.................................................... 184

Tabla 22. Preguntas del cuestionario de inicio y de fin del curso xMOOC ECLYT.................................. 186

Tabla 23. Tabla de contingencia de la pregunta 1 de los cuestionarios de inicio y final del XMOOC ECLYT. 188

Tabla 24. Prueba de Chi-cuadrada de la pregunta 1 del cuestionario de inicio y final del MOOC ECLyT. 188

Tabla 25. Tabla de contingencia de la pregunta 2 de los cuestionarios de inicio y final del XMOOC ECLYT. 190 
Tabla 26. Prueba de Chi-cuadrada de la Pregunta 2 del cuestionario de inicio y final del XMOOC ECLyT. 191

Tabla 27. Tabla de contingencia de la pregunta 3 de los cuestionarios de inicio y final del XMOOC ECLyT. 192

Tabla 28. Prueba de Chi-cuadrada de la Pregunta 3 del cuestionario de inicio y final del MOOC ECLYT193 Tabla 29. Tabla de contingencia de la pregunta 4 de los cuestionarios de inicio y final del XMOOC ECLYT 195

Tabla 30. Prueba Chi-cuadrada de la pregunta 4 del cuestionario de inicio y final del XMOOC ECLyT. . 196 Tabla 31. Tabla de contingencia de la pregunta 5 de los cuestionarios de inicio y final del MOOC ECLyT.

Tabla 32. Prueba Chi-cuadrada de la pregunta 5 del cuestionario de inicio y final del MOOC ECLYT.... 198

Tabla 33. Resultados sociodemográficos del instrumento sobre dimensiones de la gamificación. ........... 201

Tabla 34. Preguntas relacionadas a la dimensión cognitiva................................................................. 202

Tabla 35. Frecuencias relativas y promedio de la dimensión cognitiva, por pregunta y por género. ...... 204

Tabla 36. Prueba Chi-cuadrada y tabla de contingencia para género y dimensión cognitiva. ............... 205

Tabla 37. Frecuencias relativas de la dimensión cognitiva por nivel educativo. .................................... 206

Tabla 38. Prueba Chi-cuadrada y tabla de contingencia para nivel educativo y dimensión cognitiva.... 208

Tabla 39. Frecuencias relativas de la dimensión cognitiva por edad. ................................................. 209

Tabla 40. Prueba Chi-cuadrada y tabla de contingencia por nivel educativo y dimensión cognitiva...... 210

Tabla 41. Preguntas relacionadas a la dimensión social. .................................................................. 212

Tabla 42. Respuestas de las preguntas por género y dimensión social. ................................................ 214

Tabla 43. Prueba Chi-cuadrada y tabla de contingencia para género y dimensión social. ..................... 215

Tabla 44. Frecuencias relativas de la dimensión social por nivel educativo........................................... 216

Tabla 45.Prueba Chi-cuadrada y tabla de contingencia por nivel educativo y dimensión social. .............217

Tabla 46. Respuestas por edad para la dimensión social. ................................................................. 218

Tabla 47. Respuestas por edad para la dimensión social. .................................................................... 220

Tabla 48. Preguntas relacionadas a la dimensión emotiva. .............................................................. 222

Tabla 49. Respuestas de las preguntas nueve a la doce por género................................................... 224

Tabla 50. Prueba Chi-cuadrada y tabla de contingencia por género y dimensión emotiva....................226

Tabla 51. Respuestas de las preguntas nueve a la doce por nivel educativo........................................... 226

Tabla 52. Prueba Chi-Cuadrada y tabla de contingencia por nivel educativo y dimensión emotiva. ..... 228

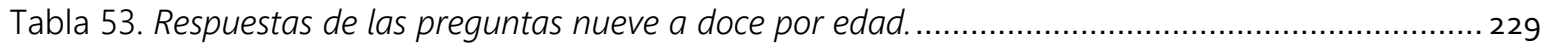

Tabla 54. Prueba Chi-Cuadrada y tabla de contingencia por edad y dimensión emotiva. ......................231 xvii 
Tabla 55. Número de mujeres y hombres que hicieron el reto por nivel educativo. 234

Tabla 56. Número de mujeres y hombres aprobados que hicieron el reto por nivel educativo. 235

Tabla 57. Resultados de los participantes aprobados y no aprobados que hicieron el reto gamificado por nivel educativo. 235

Tabla 58. Estudiantes extranjeros que hicieron o que no hicieron el $R G$ por nivel educativo. 237

Tabla 59. Participantes mexicanos aprobados y no aprobados que hicieron el reto. 239

Tabla 60. Distribución de porcentajes de aprobados y realización del RG por Estado. 240

Tabla 61. Resultados descriptivos de las variables involucradas en el estudio 242

Tabla 62. Correlaciones de las variables involucradas en el estudio. 243

Tabla 63. Cosenos cuadrados del ACP1 con respecto a los componentes F1, F2, F3 y F4..................... 246

Tabla 64. Tasa terminal y promedio de calificaciones de hombres y mujeres del curso ECLYT. 249

Tabla 65. Promedios de cada actividad con respecto el nivel educativo 251

Tabla 66. Algunas opiniones sobre el reto gamificado del curso Enegías Limpias y su Tecnología dentro de la categoría 1.

Tabla 67. Algunas opiniones sobre el reto gamificado del curso Enegías Limpias y su Tecnología dentro de la categoría 2. 255

Tabla 68. Algunas opiniones sobre el reto gamificado del curso Enegías Limpias y su Tecnología dentro de la categoría 3. 256

Tabla 69. Distribución de participantes por edad y nivel educativo. ................................................... 258

Tabla 70. Algunas respuestas alternativas al $R G$. 259

Tabla 71. Cursos XMOOC energía desarrollados dentro del subproyecto Innovación abierta, interdisciplinaria y colaborativa para formar en sustentabilidad energética a través de MOOCs 291

Tabla 72. Algunas respuestas de los participantes del curso ECLyT impartido en la primera emisión. ... 296 Tabla 73. Algunas respuestas alternativas al reto gamificado del curso ECLYT. 298 


\section{NATURALEZA Y DIMENSIÓN DEL TEMA DE INVESTIGACIÓN}

La creciente transición de energías convencionales a limpias y su desarrollo tecnológico son temas de gran interés mundial. Diversas naciones están afrontando cambios sustanciales en la manera de obtener energía, haciendola más asequible, limpia y sustentable. Al mismo tiempo, se han generado reformas político-económicas así como educativas, para facilitar y regular esta transición, tal es el caso de México y la polémica Reforma Enegética.

El presente capítulo presenta un breve recorrido histórico del papel de la energía en el mundo, para luego situar al lector en las investigaciones actuales en torno a los temas de energía en diversos países, incluyendo México. Esto con el propósito de resaltar la importancia educativa de estos temas y lo que están haciendo en otras universidades del mundo para luego dirigir la atención en lo que se está haciendo en México, lo que marcó la pauta para desarrollar y justificar la presente investigación.

En el capítulo además se presentan, la pregunta de investigación y objetivos, los supuestos y la justificación de la investigación así como las delimitaciones que enmarcaron el campo de la investigación y las limitaciones que se encontraron en el camino. 


\subsection{Marco contextual}

La historia ha mostrado que el motor que mueve el desarrollo y progreso económico de un país es la energía. Desde la revolución industrial (siglos XVIII-XIX), con una energía producida con base a la combustión del carbón se dio paso a la electricidad, evento que permitió transportar la energía desde distintos puntos geográficos, facilitando así la vida de las personas (Cunningham, 2003; Mendoza, 2016a).

A finales del siglo XIX surgió la energía fósil (petróleo), la cuál revolucionó la economía a nivel mundial y dio lugar a un desarrollo más sofisticado y masivo del sistema de transporte (Mendoza, 2016b). Así, el uso del petróleo como recurso energético fue un factor clave para el desarrollo global, ya que los ciudadanos comenzaron a moverse más rápidamente y con ello las economías de los países se desarrollaron en consonancia (Rifkin, 2012; Schoijet, 2002). Sin embargo, el uso del petróleo ha generado conflictos tanto políticos como bélicos entre algunas naciones ya que este recurso cubre el 97\% de la transportación mundial (López, 2017a). Por lo que el petróleo tiene una gran influencia en la economía globalizada y aunque, se han desarrollado sistemas eléctricos para el transporte, aun no son suficientes para satisfacer las demandas de hoy en día. 
Actualmente, el consumo de energía ya sea eléctrica o de hidrocarburos, constituye poco más del cincuenta porciento que en el siglo pasado, lo que ha generado nuevas problemáticas y reflexiones (World Council Energy, 2014) dado que para que el desarrollo de las naciones siga creciendo es importante contar con energía abundante (o barata).

Por lo que no contar con energía barata supone que la estructura económica y social se desestibilizaría (Casilda, 2002; Sanabria, 2018). Así que ante las problemáticas sociales, económicas y ambientales generadas por los asuntos energéticos, diversos países se han sumado el desarrollo de energías sustentables, lo que ha implicado una serie de reformas y alianzas alrededor del mundo. Por ejemplo, en México, la Reforma Energética (en adelante, RE) surgió ante una necesidad inminente que se resume en tres factores: de tipo geológico, problemáticas internas y el desarrollo internacional (Morales, 2016). El factor geológico se refiere a que el petroleo mexicano se encuentra en aguas profundas y no se cuenta con la tecnología para su extracción.

Las problemáticas internas están vinculadas a PEMEX (Petroleos Mexicanos) y CFE (Comisión Federal de Electricidad), las cuales tienen que ver con asuntos de corrupción y errores de índole administrativo que han impedido el desarrollo tanto de PEMEX como de la CFE (Serra, 2017a). El tercer factor se refiere al desarrollo energético 
a nivel internacional, lo que ha llevado a que diversas naciones estén transformando su sector energética para ser más competitivas.

Desde la nacionalización del petróleo, la mayoría de la producción mexicana era producida desde campos baratos, es decir, con un precio de 20 dólares por barril pero desde el año 2004 la producción comenzó a decaer (Carbonell, 2013). A principios de los años ochenta se había pronosticado que la reserva de petróleo alcanzaría para los próximos 60 años.

No obstante, actualmente existen reservas de este hidrocarburo para menos de 10 años (Aguilera, Alejo, Navarrete y Torres, 2016), por lo que la energía considerada barata (López, 2017b) se está agotando, mientras que las demandas de energía de la sociedad e industria mexicana, están creciendo de manera más acelerada (RosasFlores, 2017).

Así que para lograr que la energía sea un recurso asequible, diversos países de la unión europea (Energy, 2007; Hills \& Michalena, 2017), Asia y diversos países de latinoamérica, entre los que destacan México y Brasil, están apostando por el desarrollo de energías renovables (Griffith-Jones, Spratt, Andrade \& Griffith-Jones, 2017) . 
Por ejemplo, Alemania eliminará los procesos con base en carbón para enfocarse a las energías limpias a partir del 2018 (Mayorga, 2017). De igual manera, China se encuentra realizando cambios sustanciales para modificar su economía basada en recursos de carbón por una renovable y sustentable (Guo, Wang, Li y Zhou, 2016; Mathew, 2016; Sun, Xy y Yin, 2016).

En el año 2016, China, Estados Unidos y Japón, lideraron la lista de los diez países que más invirtieron en energías renovables, seguidos de Reino Unido, Alemania, India, Sudafrica, México, Chile y Brasil (Frankfurt School y UNEP, 2016). De ellos, Sudafrica, México y Chile fueron considerados los nuevos mercados con mayor inversión en energías renovables (Montalvo, 2016).

México tiene un gran potencial en cuanto al desarrollo de la energía fotovoltaica gracias a los recursos naturales del país, por lo que hoy es un nicho para el mercado de energía solar (Mundo-Hernández, De Celis, Hernández Álvarez y Carrillo, 2014; World Energy Resources, 2016), a pesar de esto, no cuenta con técnicos especializados en energías renovables (Wiesner, 2014).

Por otro lado, Canadá y Estados Unidos han tenido un desarrollo exponencial en el sector hidrocarburos. Canadá extrae su petróleo de arenas bituminosas, lo cual implica un proceso costoso ya que requiere una tecnología altamente especializada 
que ha logrado mantener en 60 dólares el costo por barril (BBC Mundo, 2011; CEEPYS, 2015).

Por su parte, Estados Unidos lo extrae de las rocas (esquisto), proceso que también requiere de tecnología especializada para fracturar las rocas y hacer la extracción. Aunque también es un proceso costoso, ha permitido que la producción de barriles aumentara de 7 millones de barriles diarios en el 2005 a 12 millones de barriles diarios a la fecha (Egan, 2016).

México, tiene el mismo tipo de recursos naturales que los de Estados Unidos, especialmente el petroleo de esquisto o shale oil y cuenta con grandes yacimientos petrolíferos en las profundidades del golfo de México (Morales, 2016). A pesar de esto, no se cuenta con la tecnología para llevar a cabo el proceso ni con el recurso humano capacitado para ello. Por lo que poner en marcha la Reforma Energética en México era cuestión de tiempo, pues uno de los objetivos es abrir las puertas del sector energético a la inversión extranjera (Alpizar-Castro, Rodríguez-Monroy, 2016; Rincón-Flores, Ramírez-Montoya y Serra, 2017), lo que ya está implicando cambios significativos en los ámbitos político, económico, social y educativo. 


\subsection{Antecedentes del problema}

Ante la inminente reforma energética en México han surgido una serie de problemáticas a confrontar, uno de ellas es la educativa. Aunque la UNESCO (2017) declaró que se ha incrementado el número de escuelas que incluyen educación sustentable, algunos estudios han encontrado que no existe una cultura con respecto a las energías renovables en diversos países desde los niveles básicos (Kandpal y Broman, 2014; Ocetkiewicz, Tomaszewska y Mróz, 2017).

Esto podría explicar por qué la reforma energética en México ha causado tanta controversia en la sociedad mexicana (Barrientos del Monte y Añorve-Añorve, 2014 ). Por lo que el desarrollo de iniciativas en torno a la educación en temas de energía es un proceso necesario, si se quiere cumplir con las expectativas de la reforma energética, tanto a nivel regional como mundial.

Kandpal y Broman (2014, p. 302 ) proponen una serie de estrategias para que el proceso educativo se desarrolle exitosamente:

a) Desarrollar conciencia entre los estudiantes con respecto a la naturaleza y retos relacionados con la energía.

b) Que los estudiantes conozcan los diferentes tipos de energías renovables así como sus implicaciones tecnológicas, socioculturales y económicas. 
c) Que motiven a los estudiantes a desarrollar innovaciones en cuanto a los retos de energía.

d) Que desarrollen valores y actitudes positivas en cuanto al uso de energías renovables y su impacto socio-económico.

Para Mota y Oliveira (2013) la innovación, sustentabilidad y la educación están fuertemente conectados, en el que la innovación es el principio y final del proceso creativo del conocimiento. Estos investigadores brasileños proclaman por la internacionalización de estudiantes y profesores como medio para ampliar su conocimiento y detonar la innovación.

En Israel, por ejemplo, existen laboratorios físicos en los que se desarrollan proyectos sobre energías renovables (fotovoltaica, eólica e hidráulica) en donde los datos son analizados a través de simulaciones computacionales y colecciones de datos, luego, los resultados obtenidos son compartidos a través de internet (Friman, 2017), generando así comunidades de aprendizaje.

La educación sobre el manejo de energía en Eslovenia ha enfatizado en la instrucción por expertos activos en el área y demandan que este tipo de instructores sean quienes enseñen en las universidades (Sucic, Lah y Visocnik, 2016) y que la 
formación de los universitarios sea más interdisciplinaria ya que en el manejo de energía se involucran diversis disciplinas, desde las técnicas hasta las administrativas.

En otro estudio, realizado en la Universidad Aalto en Finlandia, encontraron que los estudiantes exigen una enseñanza en la que puedan poner en práctica sus conocimientos relativos a energía y sustentabilidad (Mälkki y Paatero, 2014). En México, dentro del conjunto de las leyes secundarias enmarcadas en la Reforma Energética (RE), el gobierno mexicano anunció un plan de diez acciones inmediatas.

Esas acciones se desarrollaron para la implementación de la reforma energética en las que, la acción número seis corresponde al Programa Estratégico de Formación de Recursos Humanos en Materia Energética (Secretaría de Energía, 2015). Pues a mediano plazo se espera la creación de 135 mil empleos directos y 365 mil empleos indirectos dentro del sector energético.

Así que, ante una creciente necesidad de fuerza laboral a mediano y largo plazo, se requerirá una demanda mano de obra especializada en energías renovables y no renovables, tanto en cuestiones técnicas, especializadas como administrativas (Serra, 2017b). Por lo que resultó urgente educar de manera masiva y democrática, para formar a especialistas y para educar a la sociedad mexicana en general. Ante esta necesidad de masificar la educación en temas de energía y sustentabilidad, la Secretaría de Energía (SENER), el Consejo Nacional de Ciencia y Tecnología (CONACYT) y el 
Tecnológico de Monterrey (ITESM) emprendieron el proyecto México-EUA con ID 266632 titulado "Laboratorio Binacional para la Gestión Inteligente de la Sustentabilidad Energética y la Formación Tecnológica (Agreement: S0019-2014-01).

Su objetivo es apoyar y facilitar "la implementación de la Reforma Energética para crear un sector competitivo y de clase mundial con recursos provenientes del Fondo de Sustentabilidad Energética CONACYT-SENER, lo cual generará valiosas oportunidades de empleos para una amplia gama de profesionales" (EnergiaLab, 2016, p. 1). El proyecto consta de nueve sub-proyectos, trabajando en colaboración con la Secretaría de Energía, CONACYT, el Tecnológico de Monterrey (México), la Universidad de Arizona (EUA) y la Universidad de Berkeley (EUA). El propósito es diversificar las acciones y explorar sinergias entre esas instituciones (Laboratorio Binacional, 2017). De esta manera se busca desarrollar acciones estratégicas para el desarrollo de soluciones sostenibles.

Uno de esos subproyectos corresponde al de Innovación abierta, interdisciplinaria y colaborativa para formar en sustentabilidad energética a través de Cursos Masivos, Abiertos y en Línea, mejor conocidos como MOOC (por sus siglas en inglés), cuya encomienda fue cubrir la necesidad de educar de manera masiva en temas de sustentabilidad energética. 
Este subproyecto tiene como propósito impactar a las comunidades académicas, empresariales y sociales de México, creando conciencia en cuanto a la necesidad de una reforma energética así como de las opciones energéticas sustentables (Tecnológico de Monterrey, 2016; MexicoX, 2017). Uno de los objetivos es dar a conocer el tema energético en Latinoamérica, contribuyendo así a su divulgación, reflexión y desarrollo, como parte escencial en el desarrollo económico, social y político de un país.

Además, se tuvo la consigna de aportar en el área de la tecnología educativa incluyendo elementos innovadores como laboratorios virtuales, realidad aumentada y la estrategia didáctica de gamificación (Buckley y Doyle, 2014; Seaborn y Fels, 2015) con el propósito de favorecer la motivación y el aprendizaje de los participantes.

Por otro lado, la presente investigación forma parte de dos grupos de investigación, el Grupo de investigación en InterAcción y e-Learning (GRIAL) de la Universidad de Salamanca (España) y el Grupo de Investigación e Innovación en Educación (GIEE) del Tecnológico de Monterrey (México).

En el GRIAL se desarrollan en la actualidad diversas investigaciones sobre elearning (GRIAL, 2018), en las que se incluyen estudios sobre los MOOC desde una perspectiva crítica (García-Peñalvo, Fidalgo-Blanco y Sein-Echaluce, 2017) o en las que se ofrecen propuestas innovadoras como los MOOC híbridos ó hMOOC (García- 
Peñalvo, Fidalgo-Blanco \& Sein-Echaluce, 2018) y de cómo estos curso han mejorado la tasa terminal y la percepción de los participantes (Borrás-Gené, Martínez-Nuñez y Fidalgo-Blanco, 2016).

En el GIEE se desarrollan diversas investigaciones en torno a la innovación en educación. En cuanto a los MOOC se han realizado estudios sobre competencias digitales que se desarrollan en estos ambientes (Hernández-Carranza, Romero-Corella, \& Ramírez-Montoya, 2015), sobre indicadores de calidad de los MOOC (Alemán, Sancho-Vinuesa y Gómez, 2015), sobre uso de recursos abiertos en MOOC (Guerrero, Glasserman y Ramírez-Montoya, 2017; Mercado-Varela, Fernández, Lavigne y RamírezMontoya, 2018), entre otros.

Actualmente el GIIE es el grupo que tiene a cargo el proceso de Investigaciones Educativas del subproyecto Innovación abierta, interdisciplinaria y colaborativa para formar en sustentabilidad energética a través de MOOCs, dentro del macroproyecto Laboratorio Binacional en el cual se desarrolla la presente investigación y que a continuación se detalla.

\subsection{Planteamiento del problema}

La presente investigación se enmarcó dentro del subproyecto Innovación abierta, interdisciplinaria y colaborativa (IAIC), el cual forma parte del macro proyecto Laboratorio Binacional para la Gestión Inteligente de la Sustentabilidad Energética y la 
Formación Tecnológica que está compuesto de diez subproyectos (Laboratorio Binacional, 2017; Ramírez-Montoya, 2016a).

El subproyecto IAIC tiene como objetivo desarrollar doce cursos MOOC que informen, capaciten e inviten a la reflexión de manera masiva a la población de habla hispana en temas de sustentabilidad energética, de tal forma que se promueva una democratización de la educación a partir del acceso abierto y uso de internet (Liyanagunawardena, Williams, y Adams, 2013). Particularmente CONACYT estableció que el subproyecto Innovación abierta, interdisciplinaria y colaborativa apoye la formación de talento humano especializado en materia de sustentabilidad energética, y desarrollar talento humano con las capacidades necesarias para responder a las condiciones tecnológicas existentes en la cadena de valor energética del país (sector eléctrico), a través de posgrados, de la oferta de cursos masivos en línea que estarán disponibles a nivel nacional, y validar a través de los procesos de certificación de competencias (CONACYT, 2018).

En la Figura 1 se pueden apreciar los cursos $\mathrm{MOOC}$ que se desarrollaron como parte del subproyecto IAIC, así como la secuencia sugerida. La oferta educativa se clasificó en cinco tipos de cursos, de acuerdo con el objetivo que persiguen:

1) Difusión y conocimiento general: Este tipo de $\mathrm{MOOC}$ se centra en brindar información general sobre temas de energía. 
2) Básico teórico: exponer conceptos básicos relacionados con temas de energía.

3) Básico teórico experimental: abordar principios de la energía eléctrica y explorar procesos para su aplicación.

4) Básico teórico demostrativo: verificar la aplicación de conceptos a través de demostraciones.

5) Especializado experimental: experimentar conceptos avanzados de la energía eléctrica a través de demostraciones y/o laboratorios virtuales.

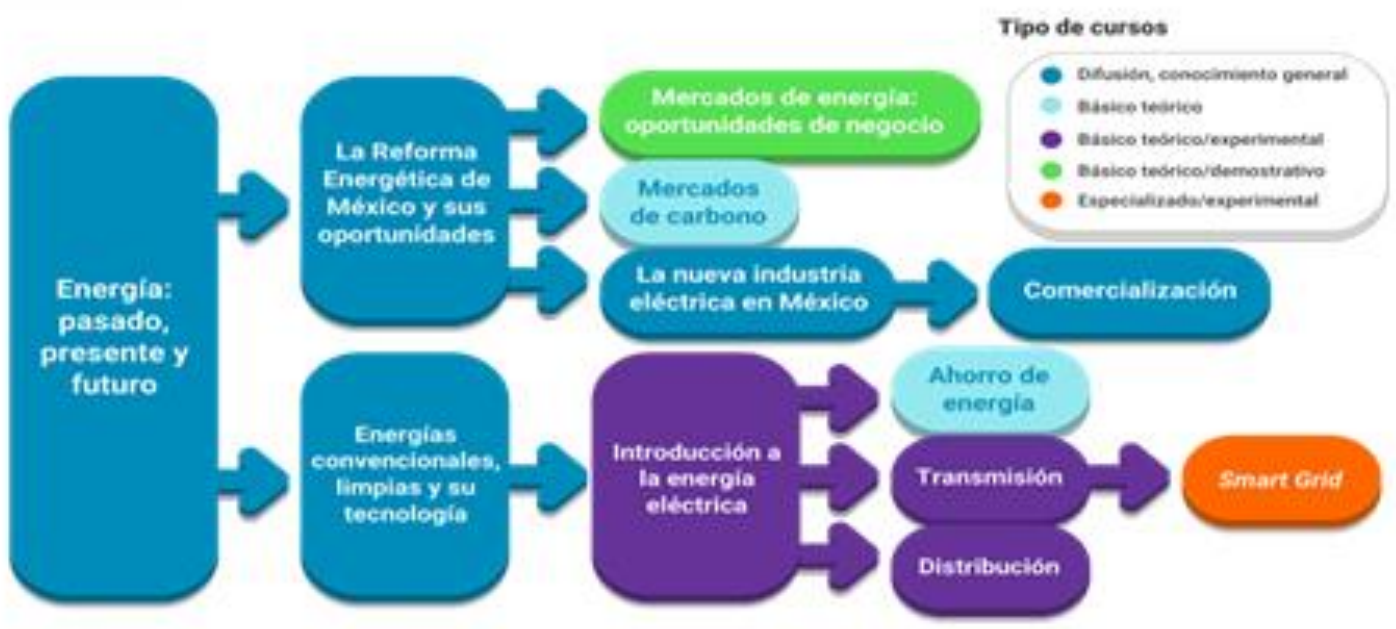

Figura 1.Secuencia sugerida para tomar los cursos MOOC (Valdivia, Villegas, Farías y Aldape, 2017, p. 20)

La construcción y desarrollo de los MOOC para el proyecto de energía, fue un trabajo interdisciplinario y complejo en el que participaron tres grupos de expertos: uno en el área de energía y sustentabilidad, otro grupo experto en el área de 
innovación educativa e investigación y el tercer grupo, expertos en producción y desarrollo de MOOC (Rincón-Flores, Ramírez-Montoya y Mena, 2016c).

Para el desarrollo de contenidos participaron expertos del Grupo de Investigación en Energía y Cambio Climático del Tecnológico de Monterrey, así como expertos de las instituciones socias del Laboratorio binacional como son Comisión Federal de Electricidad (CFE), del Instituto Nacional de Electricidad y Energías Limpias (INEEL), y del Tecnológico Nacional de México, además de otros expertos invitados en temas de energía (Valdivia Vázquez, Farías, Villegas y Aldape, 2017). El grupo de expertos en temas de energía fue asesorado por el equipo de producción, quienes son especialistas en educación en línea, formado por diseñadores instruccionales, diseñadores gráficos, productores de audioviduales y programadores web. Los equipos expertos en innovación educativa y de investigación sirvieron de soporte al grupo de expertos en contenidos y eventualmente, sus investigaciones han fortaleciendo el diseño pedagógico de estos cursos. 


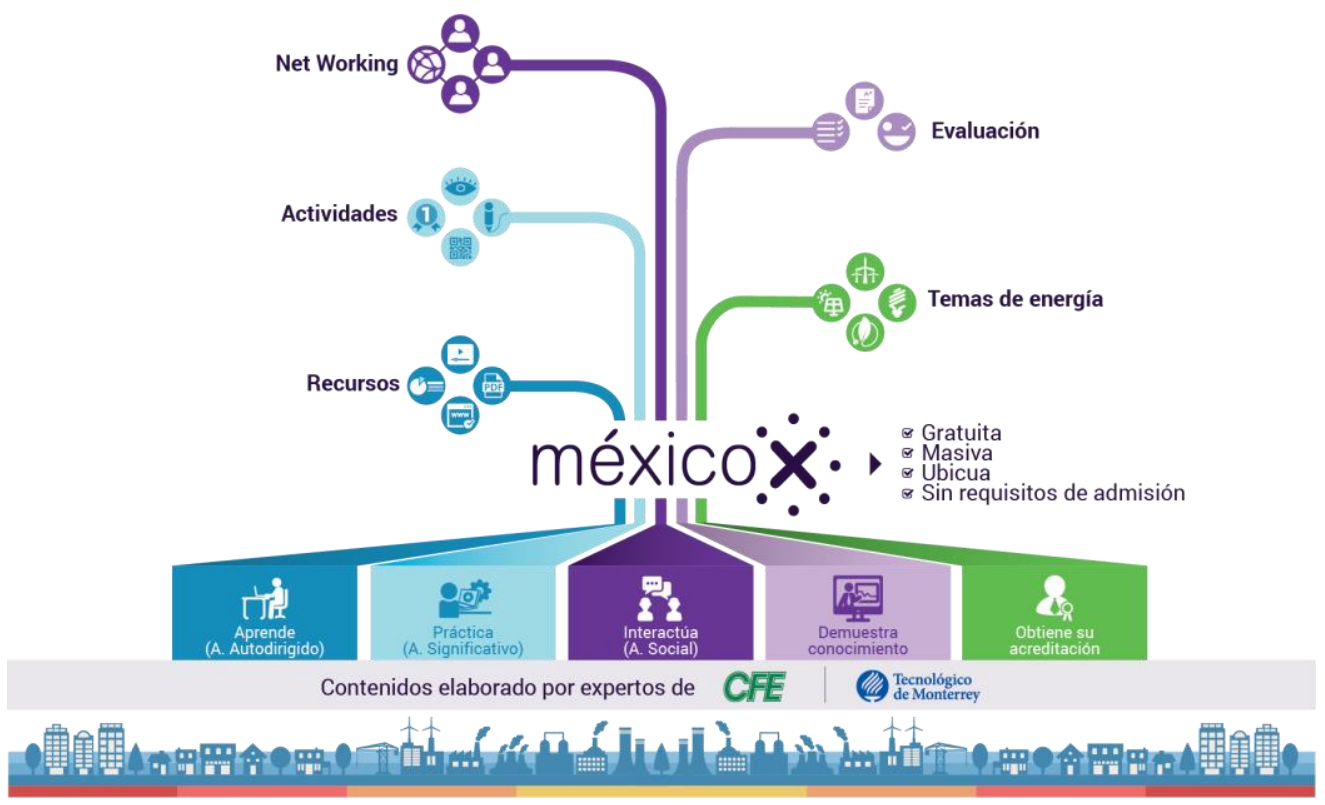

Figura 2.Modelo Instruccional del Sub-proyecto: Innovación abierta, interdisciplinaria y colaborativa para formar en sustentabilidad energética a través de MOOC. Naldivia et al., 2017, p. 22).

Como se puede observar en la Figura 2, la arquitectura pedagógica de los MOOC Energía corresponden a un $\mathrm{xMOOC}$, los cuales se caracterizan por ser autodirigidos ya que los participantes ven videos de los temas y luego desarrollan evaluaciones (Observatorio de Innovación Educativa del Tecnológico de Monterrey, 2014), es decir, en todo momento del curso el participante es responsable de autorregular su aprendizaje.

No obstante, se integraron a estos cursos estrategias didácticas innovadoras, pues una de las peticiones de CONACYT y SENER al subproyecto IAIC, fue la de integrar elementos educativos como la gamificación, realidad aumentada y laboratorios virtuales, con el propósito de enriquecer a este tipo de cursos. 
Vale la pena comentar en este momento que, en general, los $\mathrm{MOOC}$ se clasifican en dos tipos: los CMooc (conectivista) y los XMOOC (conductista). Los CMOOC se basan en la conectividad, es decir, los participantes establecen redes de comunicación con otros a partir de redes sociales o dentro de la infraestructura de la plataforma del MOOC (Aguaded-Gómez y Medina-Salguero, 2015; García-Peñalvo, Fidalgo-Blanco y Sein-Echaluce, 2017; Siemens, 2005).

En este tipo de curso se da mayor valor al proceso de las actividades que a la validación de conocimientos por medio de evaluaciones y generalmente no son masivos. No obstante, a pesar de que los $\mathrm{xMOOC}$ han beneficiado a muchas personas alrededor del mundo a través del acceso abierto de la educación (Ramírez-Montoya y García-Peñalvo, 2015), han sido objeto de diversas críticas.

Por ejemplo, que subyacen en la teoría del aprendizaje del conductismo (Ping, 2013), que el estudiante no tiene apoyo de un tutor que le indique sus fallas (Hone y El Said, 2016; Xing, Chen, Stein y Marcinkowsky, 2016), que son aburridos o monótonos (Barak, Watted y Haick, 2015; Hew, 2016) y su baja tasa terminal (Bartolomé-Pina y Steffens, 2015), entre otras. Por tal motivo fue imperativo incluir estrategias didácticas innovadoras que propiciaran un aprendizaje significativo y que motivaran al participante a continuar hasta el final, especialmente por la importancia de las 
temáticas que abordan los XMOOC-Energía y por las necesidades educativas sobre estos temas en México y Latinoamérica.

Por ello, en la presente investigación se estudió a la gamificación como estrategia educativa innovadora, específicamente, la gamificación basada en retos (Rincón-Flores, Ramírez-Montoya y Mena, 2016a, 2016b). En la Figura 3 se puede observar el modelo diseñado por los equipos de innovación educativa e investigación.

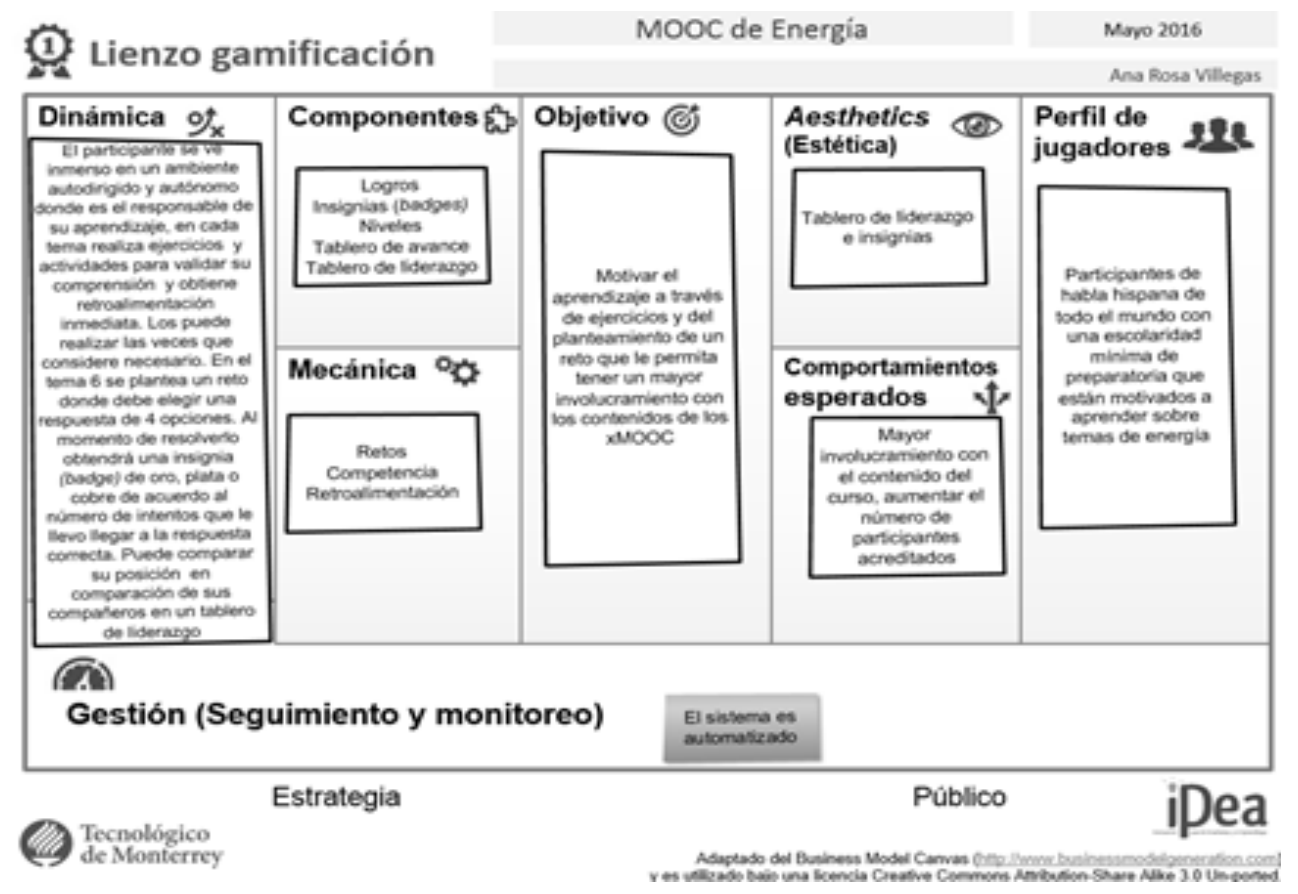

Figura 3. Lienzo de gamificación del Modelo Instruccional para los xMOOC- Energía (Villegas et al., 2016).

El lienzo de Gamificación que se muestra en la Figura 3 fue desarrollado con base en el modelo de Werbach y Hunter (2015). Así que partiendo del hecho de que una innovación lo es hasta que se verifica que se mejoró lo que ya se venía haciendo (García-Peñalvo, García de Figuerola y Merlo, 2010) era necesario valorar el impacto 
de la gamificación en los xMOOC-Energía. Por ello la presente investigación surgió con el propósito de fortelecer la didáctica del curso y para evaluar el nivel innovación alcanzado por los participantes cuando resolvieron los retos gamificados relacionados a temas de energía y sustentabilidad. Por lo que ante esta oportunidad pedagógica, tecnológica, innovadora y masiva, surgió el siguiente interrogante, la cual fungió como pregunta principal de esta investigación:

PI: ¿Cuál es la relación entre la gamificación basada en retos y el nivel de innovación alcanzado por los participantes en cuanto a temas de energía y sustentabilidad en los Cursos Masivos Abiertos del Sector Energético?

A partir de la interrogante anterior surgieron las siguientes preguntas subordinadas:

Pl1: ¿Cuál fue la influencia de la gamificación basada en retos en los participantes en cuanto a las dimensiones cognitiva, social y emotiva?

$\mathrm{Pl}_{2}$ : ¿De qué manera la gamificación basada en retos contribuyó con el aumento de la tasa terminal con respecto a la que se ha registrado "normalmente" en los estudios internacionales?

$\mathrm{Pl}_{3}$ : ¿De qué manera la gamificación basada en retos contribuyó con el desempeño de los participantes en la evaluación final? 


\subsection{1 objetivos.}

Derivado de las preguntas anteriores, el objetivo de esta investigación fue valorar el impacto de la gamificación basada en retos que giran en torno a problemáticas sobre temas de energía y sustentabilidad, a partir de uno de los cursos masivos abiertos del sector energético, con la finalidad de proponer un modelo de evaluación de la gamificación para fortalecer la innovación abierta en los MOOC.

\subsubsection{1 objetivos específicos.}

A continuación, se describen los objetivos específicos que emanaron del objetivo general.

1) Determinar el tipo de innovación educativa implicada en la gamificación del curso $\mathrm{MOOC}$ seleccionado a partir de la literatura y de otros estudios desarrollados sobre esta estrategia, en otros cursos de este tipo.

2) Determinar la relación entre la participación de los estudiantes en el reto gamificado con respecto a la tasa terminal, sus características sociodemográficas y la evaluación final.

3) Analizar la influencia de la gamificación basada en retos en los participantes en relación a las dimensiones: cognitiva, social y emotiva.

4) Diseñar un modelo que permita diseñar y evaluar, estrategias didácticas 
como la gamificación, en ambientes de innovación abierta (MOOCs).

\subsubsection{Hipótesis.}

A partir de lo anterior se establecieron las hipótesis nula y alternativa.

-Hipótesis nula

La gamificación basada en retos desarrollada en un entorno masivo abierto no potencia niveles de innovación más altos para la solución de problemáticas reales que giran en torno a las opciones energéticas autosustentables.

-Hipótesis alternativa

La gamificación basada en retos desarrollada en un entorno masivo abierto potencia niveles de innovación más altos para la solución de problemáticas reales que giran en torno a las opciones energéticas autosustentables.

\subsubsection{Supuestos de la investigación.}

El estudio presentó los siguientes supuestos de investigación los cuales tienen el propóstio de servir de avenidas para conducir el desarrollo la investigación.

1.3.3.1 Supuesto 1. La estrategia de gamificación basada en retos fortalece el diseño didáctico de los xMOOC ya que sitúa al participante en un ambiente andragógico menos conductista y más orientado al fortalecimiento y construcción de su aprendizaje. 
1.3.3.2 Supuesto 2. La estrategia de gamificación basada en retos es una estrategia didáctica innovadora ya que contribuye a mejorar la tasa terminal y a que los estudiantes tengan una participación activa durante el curso, es decir, mejora el diseño conductista de los XMOOC.

1.3.3.3 Supuesto 3. La estrategia de gamificación basada en retos contribuye a que los participantes logren un nivel medio a alto de innovación, motivados por la temática del reto gamificado y la aplicación de los conocimientos adquiridos durante el curso xMOOC energía.

\subsection{Justificación}

El estudio se enmarca dentro del proyecto Laboratorio Binacional que "apoya la implementación de la Reforma Energética para crear un sector competitivo y de clase mundial" (Coldwell, 2017, p. 1) y una de sus encomiendas fue precisamente agregar elementos innovadores dentro de los cursos con el propósito de hacerlos más atractivos a los participantes de México y del mundo de habla hispana.

Por lo que la presente investigación resulta relevante por éste y otros factores, los cuales podrían integrarse en tres: (1) el fortalecimiento de los XMOOC integrando estrategias didácticas innovadoras como la gamificación, (2) la evaluación de la gamificación incluida en estos $\mathrm{XMOOC}$ como innovación; y (3) valoración del nivel de innovación alcanzado por los participantes en un ambiente abierto. 
El crecimiento y uso de los cursos masivos online, particularmente, los xMOOC han traido consigo una serie de beneficios a nivel mundial y a la vez escepticismo en la comunidad educativa (García-Aretio, 2015). Por un lado, causa preocupación la baja tasa terminal. Según Jordan (2013) el número de personas que completan los cursos es menor de un $10 \%$ comparado con los cursos tradicionales.

En segundo lugar, las interacciones entre los profesores y estudiantes siguen siendo de baja intensidad comparado con los cursos tradicionales (Alcorn, Christensen \& Emanuel, 2014). En tercer lugar, se suele favorecer la enseñanza conductista centrada en contenidos y evaluaciones de retroalimentación inmediata (GonzálezGonzález, Collazos y García, 2016).

Por tal motivo, actualmente se están desarrollando iniciativas para integrar estrategias innovadoras en los $\mathrm{xMOOC}$ siendo los avances tecnológicos un factor esencial para ello. Algunos investigadores como Vaibhav y Gupta (2016) y FidalgoBlanco, Sein-Echaluce, Borrás-Gené y García-Peñalvo (2014) consideran que incluir recursos como la gamificación en los xMOOC podría contribuir a incrementar la motivación y la eficiencia terminal, por lo que fortalecer el diseño de los xMOOC energía con gamificación resultó viable, relevante e interesante.

Por otro lado, partiendo de la premisa que el hecho de hacer las cosas de modo diferente no es sinónimo de innovar, ha de tenerse en cuenta que los cambios tienen 
que implicar una mejora con respecto a lo que se venía haciendo por medio de una evaluación sistemática (García-Peñalvo, 2015). Por ello resulta importante evaluar a la gamificación diseñada en los $\mathrm{xMOOC}$ energía ya que permitirá detectar sus fortalezas y sus áreas de oportunidad. Al mismo tiempo que, arrojará elementos para diseñar un modelo de evaluación y mejora contínua de este tipo de estrategia tanto para los cursos $\mathrm{xMOOC}$ energía del proyecto Laborotorio Binancional como cualquier otro que esté aplicando la estrategia didáctica de la gamificación.

Finalmente, el diseño de la gamificación de los xMOOC energía subyace en la mecánica de retos (Apple, 2010). El reto gamificado se presenta en la última semana del curso, esto permite que el estudiante pueda aplicar sus conocimientos y experiencia en la solución de una problemática relacionada con los temas de energía y sustentabilidad. Aunque parte de la solución del reto gamificado es autodirigido se ofreció una parte abierta, en la que los participantes pudieron proponer una solución alternativa con la idea de promover la innovación en ambientes abiertos. Así que evaluar el nivel de innovación de las propuestas de los estudiantes, ayudará a fortalecer la didáctica del reto gamificado y a la vez, a detectar a aquellas soluciones que resulten creativas y auténticamente innovadoras.

La idea es comunicar las mejores propuestas a los expertos de la comunidad que atiende las problemáticas en torno a los temas de energía y sustentabilidad a 
través de un laboratorio ciudadano que permita el intercambio de conocimiento en estos temas, para generar soluciones y desarrollar oportunidades de negocio que fortelezcan el desarrollo de la Reforma Energética y a la solución creativa de problemas relacionados a la sustentabilidad energética en México y el mundo. Con base en lo anterior, el aporte científico de la presente investigación es el de contribuir con un modelo de innovación educativa para el diseño y desarrollo de la gamificación basada

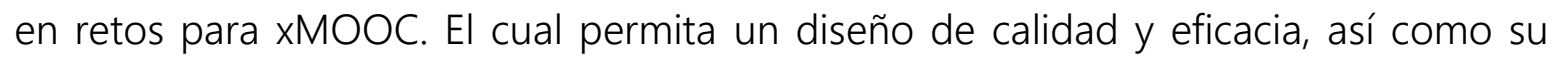
contribución en el nivel de innovación logrado por los participantes en temas de sustentabilidad energética. Así que la presente investigación resulta interesante e importante gracias a su impacto en la educación sobre temas de sustentabilidad energética, cuya reflexión y aprendizaje generan conciencia en la ciudadania mexicana y del resto del mundo de habla hispana, a la vez, sirve de plataforma para integrar a la comunidad en la solución creativa e innovadora de soluciones de problemáticas de energía y sustentabilidad.

\subsection{Delimitaciones y limitaciones}

En la siguiente sección se presenta a grandes rasgos el contexto a partir del cual se llevó a cabo el presente estudio, así como todos aquellos factores que pudieron obstaculizar el desarrollo del mismo. 
1.5.1 Delimitaciones. El presente estudio estuvo delimitado en un proyecto financiado por la Secretaría de Energía (SENER) y el Consejo Nacional de Ciencia y Tecnología (CONACYT), el cual fue otorgado al Tecnológico de Monterrey. El macro proyecto lleva el nombre de Laboratorio Binacional para le gestión inteligente de la sustentabilidad energética y la formación tecnológica, el cual tiene como objetivo "la implementación de la Reforma Energética para crear un sector competitivo y de clase mundial con recursos provenientes del Fondo de Sustentabilidad Energética CONACYT-SENER, lo cual generará valiosas oportunidades de empleos para una amplia gama de profesionales.

El macro proyecto estuvo dirigido por diez subproyectos, uno de éstos es el subproyecto Innovación abierta, interdisciplinaria y colaborativa para formar en sustentabilidad energética a través de MOOC, en el cual se desarrolló la presente investigación. El objetivo del subproyecto fue desarrollar doce cursos xMOOC desde nivel básico a niveles especializados y con duración de siete semanas, en los cuales se incluyeran innovaciones educativas como la realidad aumentada, aprendizaje basado en retos y gamificación.

Los cursos fueron desarrollados por tres grupos de expertos, los contenidos por el equipo experto en temas de energía y sustentabilidad el cual fue acompañado y asesorado por el equipo experto en diseño y producción tecnológica de los MOOCs, 
así como por el equipo experto en innovación educativa e investigación. Los cursos XMOOC energía se imparten en la plataforma EdX y MéxicoX, para este estudio se delimitó en la plataforma MéxicoX.

Los XMOOC energía en el que se llevó a cabo la investigación fue el llamado Energías convencionales, limpias y su tecnología (ECLyT). Su importancia dentro de la formación en el sector energético se enuncia como que:

Es imperativo conocer a profundidad los pros y contras de las diferentes tecnologías energéticas para minimizar el impacto negativo en el propio entorno al seleccionar, usar, racionalizar y aprovechar las energías empleadas en el diario quehacer. El participante desarrollará competencias de análisis y juicio crítico ante la selección de un recurso energético, elaborando un discurso consciente y fundamentado donde se considere el entorno y sus recursos (EnergíaLab, 2017, p.1).

En la Figura 4 se puede observar la imagen en la cual se oferta el curso dentro de la plataforma MéxicoX. 


méxico. Cursos Perfil Explorar Cursos $f y$ ín

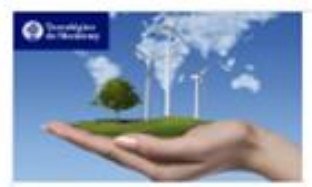

\section{Energías convencionales, limpias y} su tecnología

Tecnológico de Monterrey - ECLY17092X

Finalizado - Nov 10, 2017

\section{- $\quad$ f $\quad$ Ver curso archivado}

Figura 4. Imagen de la oferta del curso ECLyT dentro de la plataforma MéxicoX (http://www.mexicox.gob.mx).

El curso tiene una duración de seis semanas, los materiales en cada tema incluyen videos con autoevaluaciones, infográficos y materiales escritos. Las actividades consisten en evaluaciones de respuesta inmediata en cada tema, ejercicios de práctica, el establecimiento de relaciones de trabajo efectivas (networking), una práctica que se evalúa entre pares, un reto gamificado y una evaluación final. En el Capítulo 3, se aborda con más detalle el curso ECLyT así como el Reto Gamificado.

Finalmente, el enfoque metodológico utilizado fue el mixto ya que esta metodología permitió ir de lo general a lo particular para evaluar la relación de la estrategia didáctica de gamificación basada en retos con respecto a su papel innovador y su influencia en el nivel de innovación alcanzado por los participantes en la solución de problemas relacionados a las opciones de energía sustentables (Creswell, 2015). 
1.5.2 limitaciones. Una de las restricciones más significativas, fueron las limitaciones de la plataforma tecnológica, ya que uno de los instrumentos más relevantes para este estudio, solo se pudo aplicar por fuera y esto pudo provocar que no todos los participantes los respondieran. Por otro lado, la legislación de protección de datos no permitía tener acceso abierto a los correos de los participantes para realizar entrevistas personalizadas, lo que dificultó relacionar directamente a estos participantes con los que respondieron las encuestas de principio y final.

Por otro lado, la plataforma MéxicoX no cuenta con un sistema que permita la obtención de analíticas de datos que puedan ser procesadas para estudios más sofisticados. Las limitaciones tecnológicas de la plataforma MéxicoX también dificultó el desarrollo del reto gamificado, por lo que se recurrió a desarrollo externo y por consecuencia la obtención de la información también se quedó fuera del espacio de la plataforma.

\subsection{Definición de términos}

En esta sección se presentan algunos términos que se consideraron importantes para una mejor comprensión de la investigación.

Energía sustentable, es aquella que proviene de recursos naturales cuyo abastecimiento es prácticamente infinito como el sol, el viento, la lluvia y el movimiento del agua 
proveniente de ríos y mares a diferencia de la energía proveniente de fósiles como el carbón, petróleo y arenas bituminosas (Probst, 2017).

Gamificación, es una estrategia que toma elementos del juego en contextos que no son de juego (Deterding, Khaled, Nacke y Dixon, 2011).

MOOC, son cursos masivos, abiertos y en línea que se originaron en el marco de la educación a distancia y del acceso abierto (Méndez-García, 2015). Se clasifican en dos grandes grupos, los xMOOC y los cMOOC.

Reforma Energética, fue promulgada el 20 de diciembre del 2013 bajo el gobierno de Enrique Peña Nieto que modifica los artículos 25, 27 y 28 de la Constitución Mexicana. Establece 21 artículo que mandatan al congreso de la Unión a crear las leyes necesarias para alinear el marco jurídico a dichos cambios (Serra, 2016b). La reforma Energética surgió por tres razones: geológicas, problemáticas internas (PEMEX) y el desarrollo energético a nivel internacional (Morales, 2016).

Retos, según Apple (2010) es una actividad que involucra al estudiante en la solución de problemáticas de la vida real a través del trabajo colaborativo y haciendo uso de la tecnología. 
Sustentabilidad, es el desarrollo puesto en marcha para satisfacer las necesidades de los habitantes del mundo sin amenazar o comprometer los recursos del futuro (Jonker \& Harmsen, 2013).

XMOOC, estos MOOC se caracterizan por subyacer en la teoría de aprendizaje conductista y por ser autodirigidos, CMOOC, estos cursos se caracterizan por la conectividad ya que se apoyan de las redes sociales para conducir el aprendizaje (Méndez-García, 2015).

MéxicoX, es una plataforma educativa que tiene el objetivo de acercar a la gente a cursos masivos abiertos, en línea, los cuales son impartidos por las más importantes instituciones educativas del país. MéxicoX comenzó en junio del 2015, entre los cursos, se encuentran los de administración de empresas y derecho, agricultura, silvicultura, pesca y veterinaria, artes y humanidades, matemáticas y estadística, ciencias sociales, periodismo e información, educación, ingeniería y construcción, certificaciones genéricas, salud y bienestar y Tecnologías de la información y la comunicación (TIC) (Secretaría de gobernación, 2017).

En este capítulo se abordó una visión general del tema energético en el mundo para luego ubicarlo en México, contexto en el cual se desarrolló la presente investigación. El trabajo tiene como objetivo explicar la relación de la gamificación con respecto a diversos aspectos de los participantes, tales como desempeño, eficiencia 
terminal, nivel de innovación, entre otros. A continuación, se presenta la revisión de la literatura en la que se abordaron los temas que sustentaron de manera teórica a la presente investigación, tales como innovación educativa, MOOCs y gamificación. 


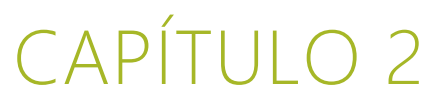

\section{REVISIÓN DE LA LITERATURA}

En el presente capítulo se presenta el estado del arte de los constructos implicados en el estudio, primero se comienza hablando sobre la innovación con el propósito de conocer los aspectos teóricos que permitan situarse en lo que es la innovación a partir de los modelos teóricos y las propuestas de evaluación. Para ello nos basaremos en la literatura específica de campo para situar y valorar la estrategia didáctica del presente estudio. En una segunda sección se aborda la temática de los MOOC, desde su origen y cómo han evolucionado a lo largo de estos últimos años.

También se ofrece al lector diversos casos de éxito, así como, algunas críticas o áreas de oportunidad que algunos investigadores han señalado con respecto a este tipo de cursos, especialmente con respecto a los xMOOC. En la tercera sección se aborda la estrategia didáctica de gamificación en la que se ofrecen definiciones conceptuales, los orígenes de la gamificación y su relación con el juego, elementos y condiciones que la conforman, así como las ventajas y terrenos no explorados sobre esta estrategia. Finalmente, el capítulo cierra abordando la temática de gamificación en MOOC a través de un mapeo sistemático de la literatura. 


\subsection{Innovación abierta, interdisciplinaria y colaborativa}

En esta sección se abordará el concepto de la innovación desde distintas perspecticas teóricas y empíricas, así como diferentes modelos innovación y de evaluación de la innovación. A continuación se detalla este concepto desde tres dimensiones: (1) apertura (2) interdisciplinariedad, (3) colaboración.

2.1.1 Innovación colaborativa e interdisciplinaria. Aunque la innovación ha ido tomando más fuerza en diversos sectores del mundo, en ocasiones se cree que basta con hacer cambios para que la innovación tenga lugar. Innovar no es sólo cambiar sino que ese cambio implique hacer las cosas de mejor manera y que esta mejora sea el resultado de un proceso de evaluación enfocado a un progreso de la calidad con respecto a lo que ya se hace (Valenzuela, 2017). Los procesos de innovación surgen a partir de una problemática o reto latente en una comunidad u organización, en la que se integran recursos humanos, materiales y creativos, a partir de los cuales se pueda llegar a una solución que genere una mejor calidad del entorno (Rubia, Anguita, Jarrín y Ruiz, 2010) ya sea educativo, social, empresarial, es decir, cualquiera en el que se presente una oportunidad de mejorar.

No obstante, a pesar de las precisiones anteriores, un proceso de innovación debe ir más allá de "cambiar para mejorar". García-Peñalvo (2015) afirma que la evaluación y evolución de la innovación debe medirse, contribuyendo así a un proceso 
de mejora contínua, y no sólo eso, sino que además debe diseminarse y difundirse, especialmente en espacios de conocimiento abierto. Por su parte, Fidalgo-Blanco (2014) resalta que la tecnología ha provocado la evolución de las organizaciones (llámense educativas, sociales, empresariales, por mencionar algunas) de manera natural o forzada, por lo que la evolución no es suficiente, también es importante innovar.

Esto se ilustra en diversas situaciones en las que las organizaciones, especialmente educativas, son proveidas de recursos tecnológicos que no son utilizados para mejorar el proceso de enseñanza-aprendizaje o, en el peor de los casos, son almacenados porque las instituciones no tienen los recursos suficiente para mantener el equipo o no se cuenta con el suficiente ancho de banda para una eficiente conectividad o los profesores no tienen acceso a una formación digital, entre otros (Díaz Barriga, 2014; Heredia, 2010). Por lo que se cuenta con escuelas evolucionadas en cuanto a recursos tecnológicos pero que no mejoran el proceso de enseñanza aprendizaje.

Albert Einstein ya lo decía, "no se puede seguir haciendo lo mismo y esperar que las cosas cambien". La innovación va más allá del lanzamiento de nuevos productos o de usar los últimos lanzamiento tecnológicos (García-Peñalvo, García de Figuerola y Merlo, 2010). Si se quiere mejorar lo que ya se hace, el camino es a través 
de la innovación, para Ramírez-Montoya (2012) la incorporación de nuevos materiales, nuevos comportamientos así como nuevas creencias y concepciones son cambios inherentes a la innovación de tal forma que hay una transformación del conocimiento cuyos beneficios pueden ser individuales o colectivos y de distinta índole.

Así, la innovación es un proceso social que enriquece a la sociedad del conocimiento y en el que "el riesgo, la confianza, la colaboración, la diferenciación, la sostenibilidad, el valor, la calidad, son parte indisociable de la innovación" (Gros y Lara, 2009, p. 227). Según la Organización para la Cooperación y Desarrollo Económico, la innovación es la piedra angular para el desarrollo económico de los países, incluso es la manera de abordar los problemas económicos que se enfrentan a raíz de la globalización y sin duda ha sido pieza clave en el surgimiento de las economías emergentes como la de China, Corea y Brasil (OECD, 2015).

De esta manera se puede apreciar que la innovación es un elemento crucial para el crecimiento y desarrollo de cualquier tipo de organización, ya sea educativa, empresarial, médica, industrial, entre otras (Marklund, Vonortas y Wessner, 2009). Dicho crecimiento y desarrollo impactará a su vez a la entidad en la que se encuentre. Así, la innovación al ser un tema correspondiente a una organización lleva implícto el trabajo colaborativo, en el entendido que es sinónimo de aunar esfuerzos teniendo 
como común denominador el logro de resultados (García y Mena, 2016; GarcíaValcárcel, Muñoz-Repiso, Hernández Martín y Recamán Payo, 2012).

Según Jhonson et al., citado por Neri, Noguez y Alanís (2017, pp. 161-162), el trabajo colaborativo debe reunir las siguientes características para que la dinámica sea exitosa:

1. Responsabilidad individual. Cuando se lleva a cabo una tarea de manera colaborativa, es necesario que haya desde un principio una asignación y distribución bien definidas de la carga de trabajo que deberá realizar cada integrante. Buscando que la repartición se asigne de acuerdo a las fortalezas de cada miembro para potencializar sus conocimientos y habilidades.

2. Interdependencia positiva. Para que se logre la interdependencia positiva es necesario que cada miembro no solo conozca y se apropie del conocimiento generado en el equipo, sino que todos los integrantes se responsabilicen de que los demás hayan aprendido los conocimiento y hayan desarrollado las habilidades necesarias para el desarrollo del proyecto en común.

3. Interacciones promotoras frente a frente. Este elemento se refiere a la comunicación constante y efectiva que se debe establecer entre los miembros de equipo cuando se realiza un trabajo colaborativo. 
4. Desarrollo de habilidades interpersonales. A lo largo de la interacción entre los diferentes miembros del equipo, es necesario que los integrantes desarrollen habilidades específicas adecuadas para tener una mejor comunicación e interacción entre los compañeros.

5. Proceso de grupo. A lo largo del desarrollo de la actividad y al final, es necesario hacer una reflexión crítica y profunda sobre cómo se llevó a cabo el proceso de interacción grupal.

Por otro lado autores como Bi y Yang (2014) proclaman que la innovación además de colaborativa debe ser interdisciplinaria para potenciar la innovación, la nanotecnología y la biotecnología ilustran claramente como convergen la innovacion colaborativa e interdisciplinaria. De esta forma, puede notarse como los progresos científicos y tecnológicos han actuado como motores de la interdisciplinariedad y que lo seguirán haciendo (Jar, 2010). Actualmente, la colaboración y la interdisciplinariedad también se da en ámbitos educativos, empresariales, sociales e industriales, quizás no de manera natural y sí, de manera más compleja.

Pues actualmente, el entorno se ha vuelto más complejo que requiere de un vasto acervo de conocimiento y habilidades, por lo que se requiere del trabajo de grupos interdisciplinarios en los que la interacción provoque una estimulación cognitiva que desarrolle nuevas asociaciones y por consecuencia, nuevo conocimiento 
(Hernández-Pozas y Neri, 2017). Hunter, Bedell y Mumford, citados por HernándezPozas y Neri (2017, p. 183) establecieron catorce factores para el éxito creativo de los equipos interdisciplinarios, los cuales se enuncian a continuación:

1. Colegas positivos

2. Relación positiva con el supervisor

3. Recursos

4. Retos

5. Claridad en la misión

6. Autonomía

7. Intercambio interpersonal positivo

8. Estimulación intelectual

9. Apoyo de la administración superior

10. Incentivos positivos

11. Flexibilidad y toma de riesgo

12. Éxfasis en el producto

13. Participación

14. Integración organizacional

Por su parte, ante este mundo globalizado, los Hernández-Pozas y Neri (2017) agregan que los retos a los que se enfrentan los grupos interdisciplinarios son la diversidad cultural así como las estructuras políticas de las instituciones.

2.1.2 Modelos de innovación. Al ser la innovación tan importante y compleja, existen diversos modelos de innovación tanto en el ámbito educativo como 
empresarial, los cuales tienen muchos aspectos en común, lo que tiene senido ya que la meta final es cambiar para mejorar.

2.7.2.1 Modelo analítico e interpretativo. Después de un largo recorrido entre el sector empresarial y educativo, Lester y Piore (2004) encontraron dos modelos de innovación, uno analítico y otro interpretativo. El modelo analítico está orientado a la solución de problemas, es un proyecto orientado a una tarea específica que cuenta con principio y fin. Por lo general es intrínseco a una organización, planificado y resultado de un proceso de investigación $(I+D+i$, investigación+desarrollo+innovación).

Por otro lado, el enfoque interpretativo se enfoca más en el proceso que en el producto o solución de una problemática. Gracias a su dinamismo el principio y final no son reelevantes, lo que importa son las interacciones que desarrollan durante el proceso, por lo que este tipo de innovación se desarrolla a través de redes de comunicación que conectan a la organización con el entorno.

El enfoque interpretativo está relacionado con el concepto de innovación abierta, ya que la organización coloca a disposición de la comunidad un determinado producto o servicio para que sea reutilizado, modificado o mejorado. Contribuyendo de esta manera a la mejora contínua dentro de un colectivo. En la Tabla 1 se muestran diferencias entre ambos modelos. 


\section{Tabla 1}

Cuadro comparativo ente los modelos analítico e interpretativo propuesto por Lester y Piore (2004, p. 97).

\begin{tabular}{ll}
\hline Modelo Analítico & Modelo Interpretativo \\
\hline El enfoque es el proyecto, tiene principio y fin. & El enfocque es el proceso, no hay principio ni fin. \\
$\begin{array}{ll}\text { La dirección se centra en el logro de las metas. } \\
\begin{array}{l}\text { Se negocia a través de reuniones para que existan } \\
\text { confusiones. }\end{array}\end{array} \begin{array}{l}\text { Se aclaran las confusiones a través de la } \\
\text { interaccción de los participantes. }\end{array}$ \\
$\begin{array}{ll}\text { El diseño de las innovaciones se basa en liseño de las innovaciones son el resultado de } \\
\text { investigaciones previas. }\end{array}$ \\
$\begin{array}{l}\text { Los objetivos y los medios están claramente } \\
\text { definidos y diferenciados. }\end{array}$
\end{tabular}

Aunque los modelos interpretativos y analíticos tienen un enfoque generalizado,

resulta útil ubicar el tipo de innovación que se está desarrollando pues de esta forma habrá mayor claridad entre los personas o grupos participantes y será más eficiente la evaluación de los resultados de las innovaciones.

2.1.2.2 Modelo comprensivo. En la India se ha encontrado que la separación entre el arte y la ciencia ha minimizado la capacidad de innovación por parte de los estudiantes y que esto a la larga, trae consigo serias consecuencias, pues cuando los estudiantes terminan la carrera profesional existen muy pocos que se adentran al área de investigación, especialmente porque no están a la altura de los centros investigativos (Dande, Ashutosh, Ajgaonkar, Parkhi, Tyagi, Tanay y Parekh, 2013). Por otro lado, los nuevos profesionistas deben generar innovaciones a lo largo de su trayectoria profesional aportando nuevo conocimiento o adaptando y utilizando el conocimiento creado por otros. 
Por tal motivo, surgió la necesidad de proponer un modelo de innovación para los niveles educativos estructurales en el desarrollo educativo de los estudiantes indios. Son tres niveles los que proponen, elemental, secundario y superior. Los investigadores proponen que en nivel elemental la educación debe ser mínimamente invasiva, además de la educación formal de los profesores, a los niños se les debe permitir aprender por sí mismos, ya sea mediante la exploración o a través de la colaboración, lo que ayudará al desarrollo de la curiosidad de tal forma que esto abonará al espíritu investigativo en los últimos años de su educación.

En el nivel secundario se debe proporcionar el conocimiento adecuado al estudiante a la vez se le debe proveer un entorno adecuado para que descubra sus fortalezas y debilidades. Este nivel es muy importante ya que es la antesala de la educación superior, un momento crucial para todo estudiante que aspira a una vida profesional, pues es el momento en el que tomará decisiones con respecto a su futuro. Un estudiante de educación superior asume la responsabilidad de su vida en el futuro. La falta de una adecuada formación en la universidad, ya sea teórica o práctica, aumentaría la ya existente brecha entre la oferta y la demanda de graduandos. Para disminuir esa brecha, se propone lo siguiente:

a) Que el diseño del currículo esté diseñado con base en las necesidades del entorno laboral. Lo que tiene sentido, pues si la innovación es mejorar lo que se 
hace, ¿Cómo se podría mejorar algo que no se conoce o de lo que se tiene poca preparación?

b) Que las autoridades impongan que las universidades sean parte del programa Junta de estudios (Board of Studies, BoS por sus siglas en inglés) en el cual, 40 o $50 \%$ de los miembros forman parte de la industria. Esta práctica ayuda a las instituciones para mantenerse actualizado sobre las últimas demandas de la industria.

c) La falta de experiencia adecuada en la formación del cuerpo docente es un obstáculo importante en el proceso de aprendizaje. Así que el establecimiento de institutos de formación de docentes, de programas de intercambio y el fomento de investigación aumentaría la cantidad como la calidad de los maestros.

Para este modelo también es importante que el enfoque de la enseñanza universitaria tenga múltiples enfoques disciplinario e interdisciplinarios. Por lo que los métodos de enseñanza deberán diseñarse para favorecer el progreso de los estudiantes en cuanto al desarrollo de las competencias relacionadas con el proceso de innovación.

2.1.2.3 Modelos de innovación educativa. En cuanto al campo educativo, Zabalza y Zabalza (2016) distinguen algunos modelos de innovación, los cuales están enfocados 
al área educativa (ver Tabla 2). Estos modelos tienen que ver con el desarrollo innovador de los profesores y con la capacidad de las intituciones educativas para promover la innovación. Al mismo tiempo, la dinámica desarrollada dentro de las instituciones educativas en torno al proceso de innovación, debe promover que las propuestas innovadoras generadas por los docentes sean implementadas y periódicamente evaluadas. Por lo que el seguimiento juega un papel fundamental en este proceso de innovación educativa.

En el modelo de innovación educativa centralizado, las autoridades dirigen y gestionan los procesos de innovación mientras que los periféricos o mixtos apuestan por un enfoque más democrático en el que los miembros de las organizaciones como empleados o maestros tienen la oportunidad de proponer iniciativas de innovación. 


\section{Tabla 2}

Modelos de innovación educativa según Zabalza y Zabalza (2016).

\begin{tabular}{|c|c|c|c|}
\hline Criterios & & Tipos de Modelos & \\
\hline \multirow[b]{2}{*}{$\begin{array}{l}\text { Modelos de } \\
\text { elaboración según } \\
\text { la instancia que } \\
\text { tome la iniciativa }\end{array}$} & Modelos centro-periferia & $\begin{array}{c}\text { Modelos periferia- } \\
\text { periferia }\end{array}$ & $\begin{array}{c}\text { Modelos periferia- } \\
\text { centro-periferia }\end{array}$ \\
\hline & $\begin{array}{l}\text { En este tipo de modelo el } \\
\text { liderazgo proviene de las } \\
\text { autoridades, ellos son } \\
\text { quienes gestionan y } \\
\text { facultan la iniciativa de } \\
\text { innovación. Por ejemplo } \\
\text { los directivos o } \\
\text { administradores. }\end{array}$ & \begin{tabular}{l}
\multicolumn{1}{c}{ periteria } \\
En este modelo las \\
decisiones sobre la \\
iniciativa de \\
innovación surgen \\
desde los centros \\
escolares. Por ejemplo \\
los profesores de una \\
centro escolar.
\end{tabular} & $\begin{array}{l}\quad \text { centro-periteria } \\
\text { Este modelo es } \\
\text { parecido del modelo } \\
\text { centro-periferia con la } \\
\text { variante de que } \\
\text { quienes toman la } \\
\text { iniciativa son las } \\
\text { instacnias periféricas y } \\
\text { el centro es quien } \\
\text { gestiona y autoriza. }\end{array}$ \\
\hline \multirow[b]{2}{*}{$\begin{array}{l}\text { Modelos basados } \\
\text { en el estatus } \\
\text { profesional de } \\
\text { quienes llevan a } \\
\text { cabo la propuesta } \\
\text { innovadora }\end{array}$} & Modelos técnicos & Modelos prácticos & Modelos mixtos \\
\hline & $\begin{array}{l}\text { Son aquellos en los que } \\
\text { los encargados de llevar } \\
\text { a cabo la iniciativa de } \\
\text { innovación son expertos } \\
\text { como especialistas, } \\
\text { universitarios, } \\
\text { académicos, etc. }\end{array}$ & $\begin{array}{l}\text { En este tipo de } \\
\text { modelo la elaboración } \\
\text { de la propuesta está a } \\
\text { cargo de los } \\
\text { profesionales como } \\
\text { profesores o } \\
\text { ejecutivos. }\end{array}$ & $\begin{array}{l}\text { Estos modelos } \\
\text { combinan tanto a } \\
\text { expertos como a } \\
\text { profesionales. Los } \\
\text { primeros se ocupan de } \\
\text { la parte técnica y los } \\
\text { segundos a la parte } \\
\text { práctica. }\end{array}$ \\
\hline \multirow{3}{*}{$\begin{array}{l}\text { Modelos basados } \\
\text { en el nivel de } \\
\text { fundamentación de } \\
\text { la propuesta }\end{array}$} & \multirow{2}{*}{$\begin{array}{c}\text { Modelo I+D+D } \\
\text { (Investigación-desarrollo- } \\
\text { difusión) }\end{array}$} & $\begin{array}{l}\text { Modelo generativo o } \\
\text { iterativo "democrático" }\end{array}$ & \\
\hline & & Este modelo no tiene & \\
\hline & $\begin{array}{l}\text { Este modelo se } \\
\text { caracteriza por poner en } \\
\text { marcha los resultados de } \\
\text { investigaciones. Este tipo } \\
\text { de innovaciones tiene un } \\
\text { alto nivel de desarrollo } \\
\text { interno pero su } \\
\text { desventaja es que no es } \\
\text { flexible. }\end{array}$ & $\begin{array}{l}\text { una fundamentación } \\
\text { científica ya que surge } \\
\text { de la práctica cotidiana } \\
\text { lo cual lo hace más } \\
\text { abierto y flexible. La } \\
\text { desventaja es que al } \\
\text { ser tan flexible no } \\
\text { todas las personas se } \\
\text { involucran en el } \\
\text { proceso de innovación. }\end{array}$ & \\
\hline
\end{tabular}

Existen tres elementos esenciales en el desarrollo de una innovación: la apertura,

la actualización y la mejora de la calidad. La apertura es la capacidad de adaptación, así como el desarrollo o mejora de actitudes, conocimientos, destrezas y recursos. La 
actualización consiste en estar al corriente de los últimos avances relacionados a la innovación implementada.

Por su parte, la mejora de la calidad consiste en evaluar en qué medida la innovación mejora el proceso. Este último elemento es el que determina si la innovación cumple su propósito fundamental, pues no basta con usar los últimos lanzamientos tecnológicos o tendencias educativas, sino evidenciar cómo contribuyeron en la mejora de los procesos formativos

2.1.2.4 Modelos de innovación empresarial. El origen de estos modelos descansa en la teoría de Schumpeter (García Manjón y Rodríguez, 2011) y están relacionados con el papel que juega el emprendedor dentro de la industria, la empresa y la sociedad (ver Tabla 3). Estos modelos resultan útiles para evaluar el nivel de empredimiento de un individuo y de la misma empresa. Los modelos Schumpeterianos están mayormente dirigidos hacia la innovación abierta, en las que los consumidores y las empresas interactúan constantemente, es decir, las innovaciones son más democráticas. Por ejemplo Lego, la empresa juguetera danesa, solicita a sus clientes que sugieran cuáles edificios les gustaría que sean replicados en los blocks de juego. 
Tabla 3

Resumen de los modelos basados en la teoría Schumpeter (García Manjón y Rodríguez, 2017).

\begin{tabular}{ll}
\hline Tipos de modelo de innovación & Descripción \\
\hline $\begin{array}{l}\text { 1.Modelos de Tecnología de } \\
\text { empuje (technology push) }\end{array}$ & $\begin{array}{l}\text { Este es un modelo lineal que tiene origen en la } \\
\text { investigación y en la generación de nuevos } \\
\text { conocimientos. }\end{array}$ \\
\hline 2.Modelos de tirón de la demanda & $\begin{array}{l}\text { Este modelo resalta la importancia de las necesidades } \\
\text { del consumidor siendo éstas la fuente de ideas para los } \\
\text { departamentos de I+D (investigación y desarrollo). }\end{array}$ \\
\hline 3.Modelo interactivo & $\begin{array}{l}\text { En este modelo las fuerzas tecnológicas y las de } \\
\text { mercado están interactuando constantemente en la } \\
\text { generación de nuevas ideas. }\end{array}$ \\
\hline Modelo de Marquis & $\begin{array}{l}\text { Este modelo sugiere también, que dentro de una } \\
\text { organización las ideas pueden surgir, no solo del } \\
\text { departamento de investigación sino de otros } \\
\text { generándose una sinérgia creativa gracias a la } \\
\text { interacción. }\end{array}$ \\
\hline $\begin{array}{l}\text { Es este tipo de modelos el tiempo de desarrollo es un } \\
\text { factor esencial a nivel competitivo. Las fases del } \\
\text { proceso de innovación tecnológica son gestionados } \\
\text { como una serie de procesos que interactúan entre ellos. }\end{array}$ \\
\hline Eoden cadena
\end{tabular}

Otro ejemplo es el de Walmart, esta empresa pide a sus clientes que opinen sobre cuales productos deberían verderse online (King y Lakhani, 2013). De hecho, en la Tabla 3 se puede apreciar como los seis modelos tienen una fuerte vinculación con el entorno, por ello resulta interesante que los futuros egresados de universidades o escuela técnicas, tengan vinculación con la empresa e industria aún siendo estudiantes. 
2.1.2.5 Análisis de los modelos: semejanzas y disidencias. Los modelos AnalíticoInterpretativo, así como el modelo Comprensivo, son modelos que permiten una primera ubicación del tipo de modelo que una organización o institución educativa está llevando desarrollando. El modelo Analítico-Interpretativo divide a las iniciativas de innovación en analíticas, las cuales tienen una perspectiva hacia adentro de la organización o institución educativa, mientras que las interpretativas o abiertas son las innovaciones que se desarrollan a partir de las interacciones con el entorno.

Las propuestas del tipo analítios son similares a los modelos propuestos de Innovación Educativa mientas que las propuestas del tipo Interpretativo coinciden con los modelos Schumpenterianos o Empresariales. Es decir, los modelos los Analíticos surgen del interior de la organización como los modelos de Innovación Educativa, los cuales tienen una dirección más hacia adentro de las organizaciones.

Mientras que el modelo Interpretativo surge de las necesidades del entorno tal y como sucede con los modelos Schumpenterianos o Empresariales. No obstante, en el área de Innovación Educativa se ha desatado una corriente sobre el desarrollo de competencias que perimitan egresar profesionales que den solución de manera creativa e innovadora a las problemáticas de un entorno siempre cambiante. Lo anterior, tiene una relación directa con el modelo Comprensivo el cual invita a reflexionar sobre cual debería ser el tipo de educación en los tres niveles 
fundamentales; primario, secundario y superior, durante la trayectoria académica del estudiante. De tal manera que, su formación le permita desarrollar innovaciones e investigación. En otras palabras, se apuesta por una formación académica que desarrolle competencias relacionadas con la innovación (Pérez y Vila, 2013).

2.1.3 Competencias para desarrollar Innovación. En la literatura se encuentran diversas definiciones sobre lo que es una competencia, algunas se fundamentan en los cuatro pilares de la educación propuestos por la UNESCO (saber conocer, saber hacer, saber ser y saber convivir (Lozano y Gallardo, 2017). Para otros, es el desempeño ejemplar, dentro de una situación determinada, que combina conocimiento, actitudes y valores (Lozano Rodríguez y Herrera Bernal, 2013).

Los métodos de enseñanza que más influencia ejercen en el desarrollo de competencias para la innovación, según un estudio realizado por Vila, Dávila y Mora (2010) con 10,000 graduados latinoamericanos, son: la participación en proyectos de investigación, el aprendizaje basado en problemas, presentaciones orales, así como hechos y conocimientos prácticos. En la Tabla 4 se muestran algunas actividades que favorecen el desarrolla de las competencias para la innovación. 


\section{Tabla 4}

\section{Actividades y competencias en el proceso de innovación (Vila, Dávila y Mora, 2010, p. 12).}

Actividades

Percepción de problemas

Propuesta de nuevas ideas

Evaluación de nuevas ideas

Adopción y aplicación
Competencias

Detección de oportunidades

Encontrar nuevas ideas y soluciones

Predisposición a cuestionar nuevas ideas

Movilización de las capacidades ajenas

En el mismo estudio, Vila, Dávila y Mora (2010) encontraron que los métodos tradicionales como la asistencia a clases, trabajos escritos y el profesor como principal actor en el proceso de aprendizaje no contribuyen en el desarrollo de las competencias de innovación mostradas en la Tabla 4. Incluso Vila y Pérez (2013) en un estudio similar desarrollado con 5,500 graduandos españoles encontraron resultados similares.

Todo lo anterior muestra el papel que juega la educación en el desarrollo de competencias para la innovación en la formación de egresados que sean capaces de cubrir las normas de competencia establecidas por las empresas o por las instituciones educativas. No obstante, desarrollar competencia para la innovación, es importante que las Instituciones educativas se encuentren en una dinámica de innovación en la que alumnos y profesores participen.

2.1.4 Tipos de innovación. En este apartado se describirán los tipos de innovación que se han establecido en los últimos diez años y que han servido como 
marco de referencia para ubicar su naturaleza. Se abordarán los conceptos de las siguientes: innovación disruptiva o revolucionaria, innovación incremental o evolutiva y la innovación abierta.

2.1.4.1 Innovación disruptiva. La innovación disruptiva es un concepto que fue acuñado por Clayton Christensen de la Univesidad de Harvad en 1997 en su libro "The innovator's dilemma". Surgió en el ámbito empresarial aunque gracias al desarrollo tecnológico se ha extendido al ámbito educativo. Christensen (2012) define a la innovación disruptiva como el proceso en el que se utilizan tecnologías sofisticadas para transformar en algo simple y económico lo que anteriormente era complejo y costoso.

Por su parte, Christensen, Raynor y McDonald (2015) establecieron que la innovación disruptiva se enfoca a nuevos mercados y a nuevos productos. La imprenta es quizás una de las innovaciones disruptivas más importantes en la historia pues anteriormente el conocimiento solo era accesible a un grupo de élite (Christensen, Johnson y Horn, 2016). Ahora mismo, el conocimiento está al alcance a través de la masificación de publicaciones escritas y digitales, antigüamente elaborados por escribanos y escritos sobre pieles.

Para CONACYT (2018) la innovación disruptiva se produce cuando 
"...se incorpora al mercado un producto o servicio que en sí mismo es capaz de generar una categoría que no se conocía antes, provocando cambios revolucionarios en la tecnología. Representa un punto de inflexión para las prácticas existentes, ya que se enfoca en la base de un concepto absolutamente nuevo, provocan la aparición de nuevas industrias" (p. 7).

De manera similar, en el sector educativo, el desarrollo de la tecnología ha permitido democratizar la educación, incialmente con la educación a distancia y actualmente con los cursos masivos abiertos y en línea (MOOC por sus siglas en inglés). Expertos en educación como Acaso y Manzanera (2015) y Christensen, Johnson y Horn (2016) entre otros, afirman que la educación está pasando por un proceso disruptivos por dos razones, una es el creciente desarrollo tecnológico y la otra es la naturaleza ubícua del aprendizaje.

Así mismo, mucho se ha cuestionado sobre los resultados de aprendizaje que se dan en el aula. Acaso (2014) habla de una "bulimia de conocimientos" refiriéndose al hecho de que los estudiantes absorben una vasta cantidad de información y luego la "vomitan" en el examen. Entonces, ¿podemos asegurar que el estudiante realmente aprendió? Jhonson (2011) no lo tiene claro y se expresa a favor de una aprendizaje obícuo en el que el estudiante pueda aprender a su ritmo usando los recursos 
didácticos que mejor le convengan, de ahí que la educación en línea pueda ser un medio ideal para ello.

2.1.4.2 Innovación incremental o evolutiva. La innovación incremental o evolutiva, se refiere a la introducción paulatina de mejoras en los procesos o productos ya establecidos (García-Manjón y Rodríguez-Escobar, 2011), es decir, se mejora a partir de los mismos productos y de los mismos clientes, o bien, ofreciendo nuevos productos o servicios a los mismos clientes (Christensen, 2012). En la industria automotriz un ejemplo puede ser la incorporación de coches eléctricos, o cuando se introdujo en la industria de las comunicaciones el teléfono inalámbrico.

Para De Miguel (2016) la innovación evolutiva o incremental es aquella que no requiere cambiar las reglas establecidas para desarrollar cambios importantes en la manera de hacer las cosas dentro de la empresa. Tal es el caso con la empresa Apple, la cual continua creciendo tan solo con ofrecer mejoras a los productos que ya tiene establecidos en el mercado, de tal forma que este tipo de innovación ha generado un alto nivel de fidelidad por parte de sus clientes.

Para el Consejo Nacional de Ciencia y Tecnología (CONACYT, 2018) la innovación incremental

"...supone la creación de valor sobre un producto o servicio que ya existe, añadiéndole nuevas mejoras. Este tipo de innovación 
parte de una base conceptual ya existente, e introduce ciertos cambios, por norma general se trata de pequeñas modificaciones, que mejoran el producto en algún aspecto: puede ser una mejora de su imagen o apariencia, un incremento de sus funcionalidades o prestaciones que ofrece, o la modificación de algún aspecto a fin de mejorar su eficiencia ( $p$. 7)."

Si transponemos el concepto de innovación evolutiva o incremental en el ámbito educativo, equivale a mejorar lo que ya se hace en las aulas, en los ambientes de aprendizajes no presenciales o en mejorar el modelo educativo existente (FidalgoBlanco, 2014; Ramírez-Montoya, 2012). Tal es el caso de la incorporación de estrategias didácticas innovadoras en el proceso de enseñanza con el propósito de mejorar el aprendizaje, por ejemplo, la gamificación, el aprendizaje basado en retos o la incorporación del uso de algún software en una clase de Matemáticas.

2.1.4.3 Innovación abierta. La innovación abierta descansa en un proceso de networking a partir del cual se generan nuevas ideas o proyectos. Es el uso deliberado de entradas y salidas de conocimiento para acelerar la innovación interna (Chesbrough, Vanhaverke y West, 2008). Esta idea asume que las ideas de innovación provienen de agentes internos y externos (González, Glasserman, Ramírez-Montoya y García- 
Peñalvo, 2017). En este sentido, la conectividad juega un papel de gran importancia, esto se debe a su alcance y a la gran diversidad de recursos digitales, los cuales impulsan la democratización del conocimiento a través de la ciencia abierta y con ello la innovación (Ramírez-Montoya y García-Peñalvo, 2018) . Por ejemplo, General Electric (GE) y la National Aeronautics and Space Administration (NASA) han creado un sistema online de concurso en el que cualquier persona y de cualquier lugar del mundo puede enviar proyectos innovadores (Gustetic, Crusan, Rader y Ortega, 2015; King y Lakhani, 2013).

En el área educativa, los $\mathrm{MOOC}$, los repositorios abiertos, los laboratorios ciudadanos y las redes digitales, ilustran claramente a la innovación abierta. Los MOOC son ambientes de aprendizaje masivos, abiertos y en línea, los cuales permiten que la educación esté al alcance de un gran número de personas alrededor del mundo y con ello, que el intercambio de conocimiento y experiencias sea más enriquecedor (Aguaded-Gómez, 2013; Vázquez-Cano y López-Meneses, 2015).

Los repositorios abiertos se definen como un conjunto de servicios web que son centralizados y cuyo propósito es organizar, gestionar, preservar y divulgar materiales digitales, especialmente producción científica y académica (González et al., 2017). Así, cada vez que una institución educativa coloca en repositorios con licenciamiento 
abierto los contenidos de sus productos de investigación o buenas prácticas, se suma al movimiento educativo en abierto y a la innovación en abierto.

Los laboratorios ciudadanos son un espacio abierto para que los individuos se integren en equipos de trabajo para llevar a cabo una idea y prototipar algún producto, servicio, modelo, entre otros, como respuesta a una problemática (Yañez-Figueroa, Ramírez-Montoya y García-Peñalvo, 2017) . Dicha problemática toma más bien el sentido de un reto, en el que los miembros del equipo suman ideas y conocimiento para llegar a una solución.

Por otro lado, los grandes avances tecnológicos en cuanto a conectividad han provocado que herramientas sociales como Facebook, Twitter, WhatsApp, YouTube, entre otros, estén más al alcance de los ciudadanos y no solo con un sentido recreativo sino que se han expandido al ámbito profesional y educativo (Valerio, 2017). Así, el acceso a los contenidos abiertos ha crecido exponencialmente en los último años gracias a las redes digitales, las cuales se suman en favor a la dinámica de la innovación abierta.

2.1.5 ¿Cómo se puede evaluar a la innovación? Antes de mostrar algunas propuestas sobre cómo evaluar la innovación es importante considerar los elementos que forman parte de la dinámica de innovación. La innovación no debería considerarse como una moda sino, como el producto de una reflexión de las necesidades que una 
organización demanda, por lo que requiere de planificación, constancia y paciencia en el proceso (García- Fanjón y Rodríguez, 2012) ya que la resistencia o miedo al cambio pueden ser obstáculos dentro del proceso.

Por otro lado, la apertura, la actualización y la mejora de la calidad son tres condiciones importantes en el desarrollo de la innovación (Zabalza y Zabalza, 2016). La apertura es la capacidad de adaptación, la flexibilidad así como el desarrollo o mejora de actitudes, conocimientos, destrezas y recursos. La actualización consiste en estar al corriente de los últimos avances relacionados o en torno a la innovación implementada. La mejora de la calidad es el propósito fundamental de la innovación, como ya se ha comenado antes, se trata de mejorar lo que ya se hace.

2.1.4.1 Evaluación de la innovación con base en la profundidad y extensión. El modelo fue propuesto por Eckel y Kezar (2011) y se compone de dos dimensiones: la profundidad y la extensión de las innovaciones. La profundidad se refiere a una mejora no superficial mientras que la extensión tiene que ver con la cantidad de adoptantes de la innovación (Ver Tabla 5). 


\section{Tabla 5}

\section{Resumen del modelo de Eckerl y Kezar (2017)}

\section{Extensión}

Estas innovaciones son llamadas epitelial, son cambios de poca intensidad pero que afectan a un número considerable de profesores o personas de una organización o de otra índole.

Las innovaciones colocadas en esta posición (baja profundidad y baja extensión) dan lugar a cambios parciales de bajo impacto.
Estas innovaciones dan lugar a cambios transformacionales y de gran impacto.

Estas innovaciones generan cambios aislados, es decir, solo pocos miembros de la organización desarrollan cambios profundos.

Profundidad

Este modelo resulta muy útil ya que permite situar el nivel de innovación logrado por las instituciones educativas, lo que facilita el seguimiento y la mejora contínua. Además puede proveer de información para determinar los pasos a seguir para que dicha innovación se traslade al siguiente nivel.

2.1.4.2 Evaluación de la innovación con base en la eficiencia y nivel de innovación.

Schwartz, Bransford y Sears (2005) proponen un modelo clásico dentro del campo de la Innovación, el cual tiene como propósito evaluar la eficiencia de la misma, ver Figura 5. 


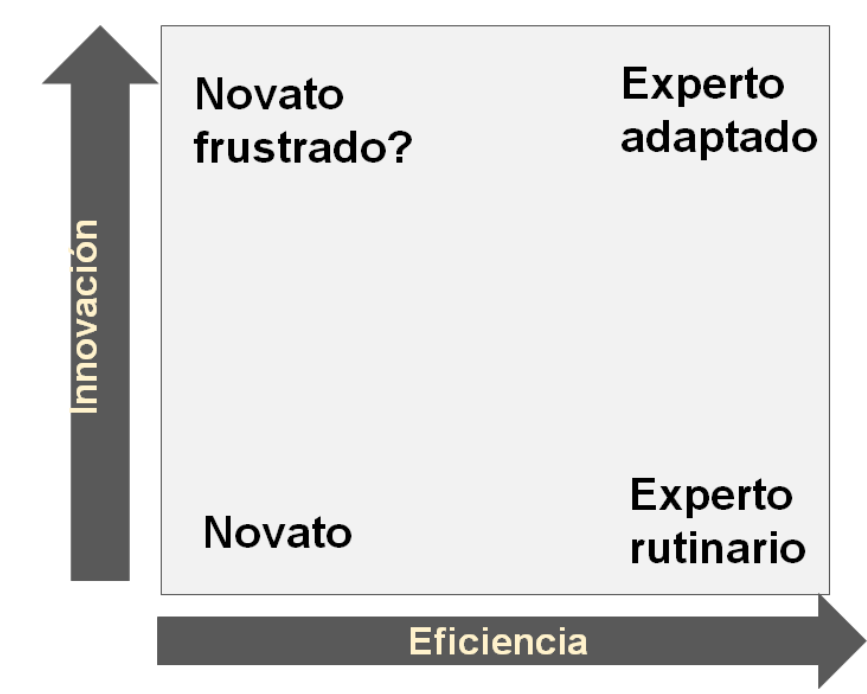

Figura 5. Modelo de innovación y eficiencia propuesto

por Schwartz, Bransford y Sears (2005, p. 40).

Tal y como se desprende de la Figura 5, el modelo considera dos dimensiones que idealmente deberían complementarse: la eficiencia y la innovación. La eficiencia, situada en el eje horizontal, alude al conocimiento que se tiene sobre un área en particular mientras que la innovación es la habilidad de responder ante una nueva situación.

En el primer cuadrante se pueden observar cuatro posiciones, el nivel novato que ocurre cuando se tiene baja eficiencia y baja capacidad de innovación, es decir se cuenta con poca experiencia y habilidades para desarrollarse en una nueva situación. Por otro lado, un nivel bajo de eficiencia y un alto nivel de innovación puede colocar a los individuos en una situación de frustración ya que puede darse una copiosa lluvia de ideas fundamentadas en un conocimiento o experiencia deficiente, lo que podría generar más tiempo y esfuerzos en la generación de una propuesta. 
Ahora bien, las personas que tienen una eficiencia alta pueden responder rápidamente aplicando su conocimiento y habilidades para resolver un problema o comprender una explicación. Por ejemplo, los médicos a diario toman decisiones rápidas en cuanto a diagnósticos para curar o salvar vidas, por lo que la eficiencia también incluye un alto nivel de consistencia, así que la práctica se convierte en el medio ideal para que una persona se convierta en experto rutinario.

Por el contrario, cuando los expertos tienen un nivel bajo de innovación sucede que se vuelven expertos rutinarios y en ocasiones, puede ocurrir que no se interesen en seguir aprendiendo y se quedan estancados en sus viejas rutinas. Esto es un obstáculo para reconceptualizar el conocimiento por lo que un nivel alto de innovación sería lo ideal. Por lo que la enseñanza académica debería enfocarse en un aprendizaje basado en retos de tal manera que se desarrolle el nivel experto así como el nivel innovador en un nivel alto, dando lugar al experto adaptativo.

\subsubsection{Evaluación de la innovación con base en el nivel de involucramiento en el}

proceso de innovación. En una investigación desarrollada por Lozano Rodríguez y Gallardo (2017) a través de un estudio de casos. En dicho estudio se aplicaron entrevistas, observaciones y estudio de las respectivas trayectorias laborales de profesores quienes contaban con un trabajo reconocido en los procesos de innovación 
educativa. Una vez concluido el estudio, definieron tres niveles de innovación (Lozano y Gallardo, 2017, pp. 92-93):

a) Innovador novato: es el que trabaja en procesos de innovación y está motivado en realizar cambios, pero no se encuentra actualmente inmerso totalmente en procesos de experimentación y divulgación de manera formal.

b) Innovador en progreso: es el que trabaja en procesos de innovación y está motivado en realizar cambios, y que está inmerso totalmente en los procesos de experimentación y divulgación de manera formal desde hace 10 años o menos.

b) Innovador experto: ha dedicado parte de su tiempo a concebir, operar y evaluar procesos de innovación educativa como parte de sus funciones, analizando el impacto de los proyectos, tanto en el alumno como en el formador involucrado.

Así que el desarrollo de competencias para la innovación también es un atributo que debe incluirse en el proceso educativo de las diversas instituciones educativas, al mismo tiempo establecer un entorno en el que los profesores se puedan sumar a la dinámica del proceso de innovación.

2.1.4.4 Evaluación de la innovación con base en el impacto. El modelo está fundamentado en el modelo OSAR (Echeverría, 2011) y considera cuatro niveles. Aunque el enfoque es empresarial puede extenderse a otros tipos de organizaciones. 
Mejora: Es la innovación de primer nivel. Supone el cambio sobre lo que ya estamos haciendo y no supone un impacto muy alto ni en la organización ni en el entorno. El principal objetivo es la mejora de le eficiencia de la organización y tiene un carácter incremental. Los paradigmas de la organización se mantienen intactos y los cambios se dan en mejoras incrementales en sus productos, procesos o formas organizativas.

Cambio: Es la innovación de segundo nivel. Supone una modificación de los paradigmas en la organización y afecta a la estructura, a la estrategia y a la cultura corporativa. Hay mucho aprendizaje corporativo modificando las formas de creación de valor. La empresa introduce nuevos productos y procesos, puede haber cambios en su modelo de negocio y aparte de las innovaciones incrementales introduce cambios mucho más profundos.

Transformación: Es la innovación de tercer nivel. Afecta a la propia identidad de la organización y supone un cambio en sus estructuras, cultura y modelos, desarrollando un aprendizaje abierto y continuo. La empresa lanza nuevos productos y procesos para la empresa o para el mercado, abre nuevos canales y entra en nuevos mercados, a la vez transforma su modelo de negocio. En este nivel la organización deja de ser lo que era para crear algo nuevo, donde existe mucho aprendizaje de carácter sistémico y meta-aprendizaje. 
Impacto: Es la innovación de cuarto nivel. Implica que las innovaciones de la empresa afectan al entorno, al mercado y a su cadena de valor o a la sociedad. Normalmente estas empresas generan un spill-over de valor en todo lo que las rodea. Suele darse en innovaciones sociales o disruptivas y se generan nuevos modelos de negocio y de creación de valor que suelen romper con lo establecido. El aprendizaje es muy alto y es compartido con el entorno.

En función de todo lo expuesto anteriormente, creemos que resultaría interesante sintetizar la información a partir de una rúbrica de evaluación de la innovación, (ver Apéndice VII) y que se utilizó como parte de los instrumentos de esta investigación.

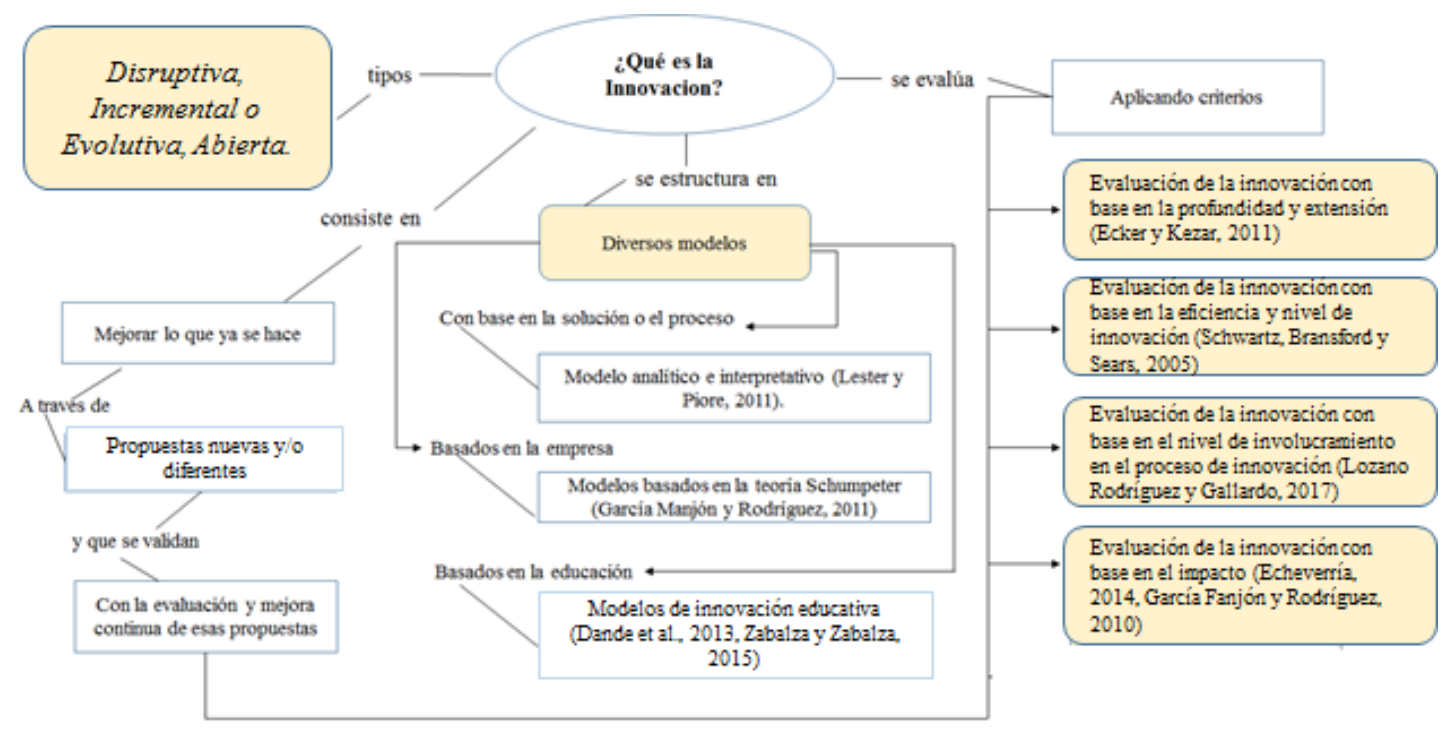

Figura 6. Esquema gráfico del constructo de Innovación (Elaboración propia). 
Para finalizar esta sección, se muestra en la Figura 6 un esquema gráfico en el que se resumen los conceptos presentados sobre el tema de la Innovación.

\subsection{Los MOOCs como Ambientes de Innovación Abierta}

En esta sección se relatan los inicios de los $\mathrm{MOOC}$, es decir como surgieron a partir del movimiento abierto y como han ido evolucionando desde que surgieron. También se describirán los tipo de MOOC que existen, sus características así, como las historias de éxito y áreas de oportunidad que giran en torno a este innovador y cada vez más creciente ambiente educativo.

\subsubsection{De la innovación abierta a los MOOCs. Es indudable que la conectividad} cada vez más al alcance del ser humano y la gran diversidad de recursos digitales impulsan fuertemente a la innovación abierta y aunque algunos empresarios tienen una actitud reservada en cuanto al tema, empresas como Netflix y General Electric han invertido grandes cantidades de dinero para desarrollar ideas creativas a través de la innovación abierta colaborativa. Netflix concursó el mejor algoritmo para recomendar películas a sus clientes ofreciendo 1 millón de dólares al ganador. Por su parte, GE ha creado un sistema online a través de académicos, empresarios y cualquier persona que desee enviar sus ideas.

En un lapso de seis meses atrajo 60.000 participantes y recibió más de 5.000 ideas de 85 países, la compañía y sus socios han invertido más de 134 millones de 
dólares en las ideas recibidas (King y Lakhani, 2013). De manera similar, la National Aeronautics and Space Administration (NASA) ha motivado la creatividad e innovación entre sus seguidores proponiendo al público una serie de retos como el "Reto del guante astronauta" (Astronaut glove challenge) que consiste en concursar innovaciones en cuanto a funcionalidad de los guantes utilizados por los astronautas en el espacio (Gustetic, Crusan, Rader y Ortega, 2015), así, el gobierno de Estados Unidos ha encontrado en este programa una manera de dar solución a problemáticas complejas a través de la innovación.

Esto hace evidente que la innovación abierta es una fuente de propuestas que se diseminan para desarrollar conocimiento (García-Peñalvo, García de Figuerola y Merlo, 2010; Ramírez-Montoya, 2015) gracias a su acceso libre y a la participación colaborativa e interdisciplinaria de diversas comunidades (UNESCO, 2015) contribuyendo así a la competitividad internacional de un país, de tal suerte que la innovación podría convertirse en la constante que determine el nivel de desarrollo de las naciones, tal y como ya lo han proclamado en la sección anterior Marklund, Vonortas y Wessner (2009) y la OCDE (2015) entre otros.

De forma similar, en el área educativa, los $\mathrm{MOOC}$ se han convertido en espacios de aprendizaje para la innovación abierta y que ha venido tomando una importancia vertiginosa en los últimos años. En el año 2011 la Universidad de Stanford lanzó el 
primer curso MOOC de la historia con el título de Introducción a la Inteligencia Artificial, en este curso se matricularon más de 160,000 personas (Dennis, 2012), desde entonces el crecimiento ha sido exponencial en diversas universidades alrededor del mundo (Del Moral y Villalustre, 2015), de hecho el año 2012 fue llamado el año de los MOOC (Chauhan, 2014). En la Figura 7 se puede observar el crecimiento de agosto del 2016 a febrero del 2017.

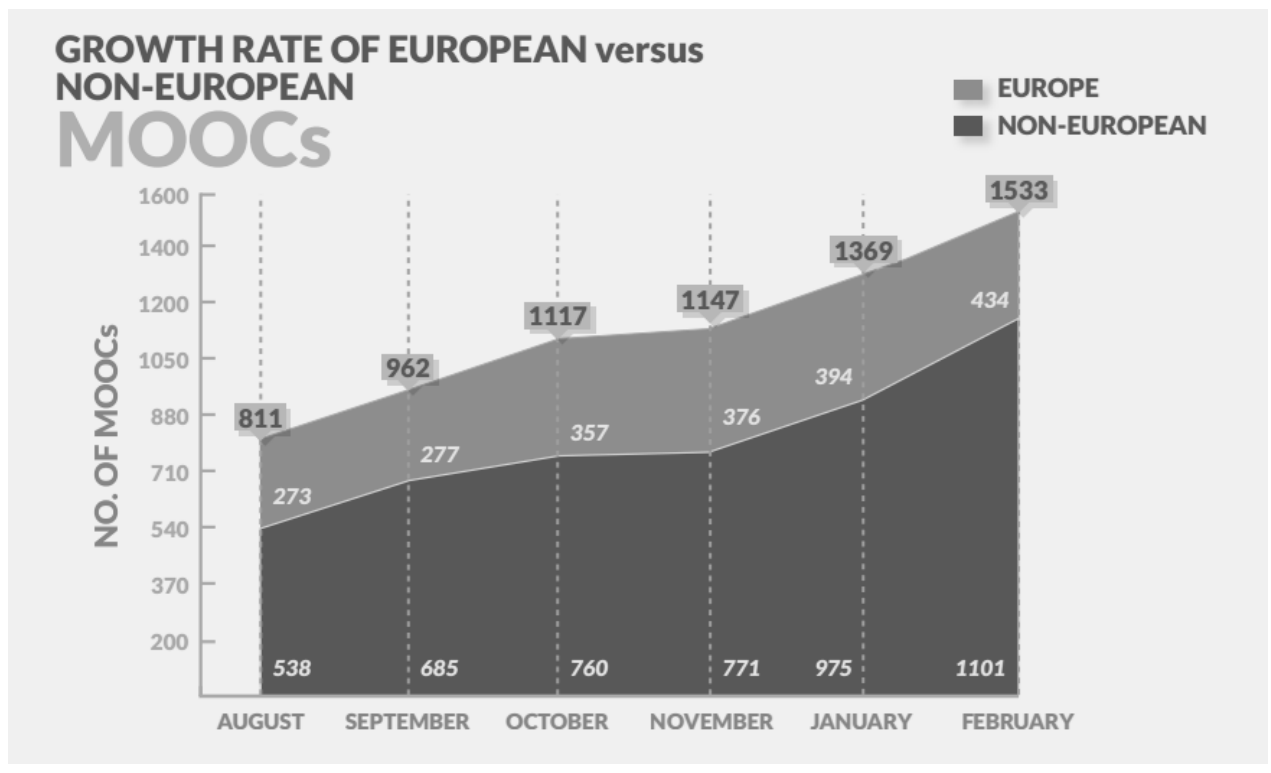

Figura 7. Crecimiento de los MOOC tomado de https://www.openeducationeuropa.eu.

Como se aprecia en la Figura 7, los MOOC representan un fenómeno educativo creciente. Están enmarcados dentro de la educación a distancia y fueron impulsados por el movimiento abierto que comenzó en el 2002 cuando la UNESCO adoptó el término Open Educational Resources (OER por sus siglas en inglés) en el que se disponen al dominio público una serie de recursos educativos compartidos por otros 
(Benlamri y Klett, 2015). Así, ante este escenario y unos años más tarde surgen los MOOC como una oportunidad para mejorar la transferencia de conocimiento a cualquiera que desee adquirirlo (Ramírez-Montoya, 2015).

El movimiento masivo abierto ha ido cobrando popularidad año tras año pues representa una oportunidad para democratizar la educación (Vázquez-Cano, LópezMeneses y Sarasola 2013). Los MOOC son un ambiente de aprendizaje que se caracteriza por ser un medio accesible para la educación ya que permite el acceso gratuito a una variedad de recursos educativos, además de que promueve interrelaciones entre personas de todas partes del mundo (Aguaded-Gómez, 2013). En este sentido, los MOOC constituyen una innovación disruptiva en la educación a distancia y abierta (Ramírez-Montoya,García-Peñalvo, \& McGreal, 2018).

Además, los MOOC pueden contribuir a la capacitación del personal en el mundo empresarial, gracias al formato en línea pues hace posible que el alumno pueda seguir el curso desde cualquier lugar y momento (Olsson, 2016). Pues los participantes pueden iniciar y completar los estudios en función de sus necesidades, es decir, deben ser flexibles. Castaño y Cabero (2013, p. 89) propusieron las siguientes características generales de los MOOC:

Es un recurso educativo que tiene cierta semejanza con una clase, con un aula. 
触 Con fechas de comienzo y finalización.

Cuenta con mecanismos de evaluación.

S. Es online.

De uso gratuito.

5s abierto a través de la web, y no tiene criterios de admisión.

Sermite la participación interactiva a gran escala de cientos de estudiantes.

A estos criterios se puede agregar que los mecanismos de evaluación son automáticos, actualmente participan miles de estudiantes y no siempre es gratuito.

Por su parte Baturay (2015, p. 428) propone tres características:

Abierto (Open): la participación en un MOOC es libre y abierta a cualquiera quien tenga acceso a internet. El trabajo generado que es generado por estudiantes y facilitadores, es compartido y accesible al público.

19articipativo (participatory): El aprendizaje en un MOOC es mejorado tanto en la creación como en el compartir de las contribuciones personales así como en las aportaciones de otros, pero las participaciones son voluntarias. 
Distribuido (distributed): Los MOOC tienen un enfoque conectivista, por lo tanto, cualquier conocimientos puede ser distribuido a través de las redes de los participantes."

Por otro lado, en un estudio reciente de Fundación Telefónica realizado en el 2015 se destacan los siguientes hallazgos (Vázquez-Cano y López-Meneses, 2015, p. 28):

Sxiste un mayor número de estudiantes varones

Sas plataformas norteamericanas albergan a más de un tercio de todos los estudiantes MOOC.

Wa mitad de los estudiantes mundiales de cursos MOOC se concentran en países de habla inglesa (Estados Unidos, Reino Unido, India y Canadá).

España de sitúa como segundo país europeo, después del Reino Unidos, con mayor número de alumnos.

1. Entre el $60 \%$ y el $80 \%$ de los estudiantes de cursos MOOC poseen estudio superiores.

Desde un punto de vista didáctico y tecnológico, los $\mathrm{MOOC}$ contribuyen al desarrollo tanto de la arquitectura tecnológica como de los modelos pedagógicos (Hernández-Carranza, Romero-Corella y Ramírez-Montoya, 2015) gracias a su carácter masivo y autodirigido. Por su parte, Del Moral y Villalustre (2015) afirman que un MOOC 
de calidad forma parte de un ecosistema versátil que satisface las demandas de los usuarios de tal manera que puedan organizar sus propios aprendizajes y que puedan contar con un eficaz sistema de comunicación. Lo que implica tanto un buen diseño pedagógico como una adecuada y funcional plataforma tecnológica.

Johnson y Liber (2008) consideran cinco dimensiones importantes para el desarrollo de un $\mathrm{MOOC}$ para gestionar un entorno personal de aprendizaje, estos son: acceso y organización de contenidos, mecanismos para propiciar el aprendizaje, comunicación social y formativa, creación y publicación de elaboraciones personales y colaboración en tareas de producción colectiva. Por lo que se puede deducir que cada vez cobra más importancia el trabajo interdisciplinario en el diseño y desarrollo de los MOOC, tanto por los avances tecnológicos como, por las demandas y necesidades de los participantes.

Por otro lado, Méndez-García (2015) propone una serie de recomendaciones prácticas a la hora de diseñar e implementar un MOOC, particularmente un XMOOC, de las cuales se destacan las siguientes:

1. Los MOOC deben causar una buena primera impresión, pues cualquier falla de contenido o tecnológica puede ser irreversible gracias a la comunicación exponencial que se da en las redes sociales. 
2. Tanto, las tareas como, los requisitos para concluir exitosamente el MOOC debe quedarle claro al participante desde el principio.

3. Se sugiere incluir videos o documentos que sirvan de guía para la utilización de la plataforma elegida.

4. Los videos deben ser claros, cortos ( 7 a 10 minutos máximo) y en los que se evite en la medida de lo posible exponer al profesor durante todo el recurso.

5. Ofrecer distintos materiales, de tal manera que puedan atenderse a la mayoría de los estilos de aprendizaje.

6. Incluir actividades colaborativas fomentando el uso de redes sociales y/o de contenidos agregados.

7. Mantener el interés y motivación del alumnado a partir de actividades variadas e nnovadoras y de distinto nivel.

8. Que la institución educativa sea responsable en todo momento a pesar de la gratuitidad del curso.

Si bien es cierto que los $\mathrm{MOOC}$ han sido criticados severamente y que ciertamente no resuelven la totalidad del problema educativo (Chiappe-Laverde, Hine \& Martínez-Silva, 2015) no cabe duda que detrás del diseño, desarrollo y seguimiento, existe un gran cantidad de trabajo interdisciplinario cuyo mérito no debe tomarse con 
ligereza sino, como una oportunidad de crear, innovar y transformar. Más adelante se abordarán las innovaciones pedagógicas en los MOOC, particularmente la Gamificación.

\subsubsection{Plataformas tecnológicas y tipos de MOOC. Actualmente existe una} variedad de MOOCs y diversas plataformas. En general, se puede decir que existes dos tipos, los xMOOCs y los cMOOCs (Bartolomé-Pina y Steffens, 2015). Los xMOOCs surgieron en el 2011, son autodirigidos basados en multimedia interactiva como videos y textos, se caracterizan por ser : conductistas, formación formal centrada en contenidos, la evaluación consiste en: test, evaluación por pares, evaluaciones parciales y finales de retroalimentación inmediata.

A raíz de los xMOOCs han surgido grandes compañías de plataforma tecnológica como Audacity, EdX y Coursera, las cuales asisten a prestigiosas universidades como Harvard y Stanford (Conole, 2016). Por otro lado, los CMOOC se caracterizan por ser conectivista su es aprovechar el poder de los medios sociales de tal forma que los participantes puedan comunicarse y colaborar a través de una variedad de canales como twitter, blogs, wikis, facebook, entre otros (Siemens, 2005, 2012a). También se distinguen por un enfoque en la formación informal, centrada en tareas en donde la evaluación consiste en conocimiento aportado y/o creado en entornos personales de aprendizaje. 
Esto es que, mientras un $\mathrm{xMOOC}$ se centra en contenidos y es autodirigido, un cMOOC se enfoca en la colaboración, cooperación entre los estudiantes a través de diversas redes sociales. Kaplan y Haenlein (2016, p. 448) proponen una tabla de comparativa entre los $\mathrm{xMOOC}$ y $\mathrm{cMOOC}$ a través de las cinco Ps: Profesor, Participantes, Pedagogía, Patrón y Plataforma, ver Tabla 6.

\section{Tabla 6}

Comparativo entre XMOOC y CMOOC a través de las cinco Ps (Kaplan y Hanlein, 2016, p. 448)

\begin{tabular}{|c|c|c|}
\hline & $\mathrm{XMOOC}$ & $\mathrm{CMOOC}$ \\
\hline Profesor & $\begin{array}{l}\text { Es el instructor que diseña un curso } \\
\text { estandarizado para todos. }\end{array}$ & $\begin{array}{l}\text { Es el facilitador que anima el } \\
\text { proceso individual de } \\
\text { aprendizaje. }\end{array}$ \\
\hline Participantes & Aprendices pasivos & Aprendices activos \\
\hline Pedagogía & $\begin{array}{l}\text { Contenidos predeterminado, basado en } \\
\text { un currículum formal que usa un estilo } \\
\text { tradicional y evalución por pares. }\end{array}$ & $\begin{array}{l}\text { El contenido se desarrolla } \\
\text { colaborativamente sin un } \\
\text { currículum formal, estilo } \\
\text { seminario sin evaluaciones. }\end{array}$ \\
\hline Patrones & $\begin{array}{l}\text { Es estructurado con sesiones regulares } \\
\text { en un periodo fijo y determinado. }\end{array}$ & $\begin{array}{l}\text { No es estructurado y se basa en } \\
\text { un aprendizaje continuo. }\end{array}$ \\
\hline Plataforma & $\begin{array}{l}\text { Centra el contenido en la plataforma } \\
\text { tecnológica. }\end{array}$ & $\begin{array}{l}\text { Descentralizado de la } \\
\text { plataforma tecnológica, el } \\
\text { desarrollo es a través de la } \\
\text { colaboración. }\end{array}$ \\
\hline
\end{tabular}

Con respecto al aporte pedagógico de los xMOOCs y cMOOCs, autores como Borrás-Gené, Martínez-Nuñez y Fidalgo-Blanco (2014) y González-González, Collazos y García (2016) consideran que los cMOOCs tienen un aporte mayor en cuanto al desarrollo cognitivo de los participantes gracias a la red de colaboración y al seguimiento de quienes administran los cursos. Incluso Fidalgo-Blanco, Sein-Echaluce 
y García-Peñalvo $(2013,2016)$ apuestan por una combinación de xMOOCs y cMOOCs

pues consideran que cada tipo de curso tiene unas ventajas e inconvenientes, debido

a la estrategia formativa tanto para el enfoque del aprendizaje como, en la evaluación

del mismo. Ahora bien, recientemente los MOOCs se han diversificado aún más gracias

a las necesidades del educativas, Coughlan (2014) citado por González-González,

Collazos y García (2016) los ha clasificado en diferentes tipos, ver Tabla 7.

\section{Tabla 7}

Clasificaciones de los MOOCs según Coughlan (2014 resumido por González-González et al., 2016, p. 8)

Big Open Online Course (BOOC) Sigue un formato híbrido ya que combina el aprendizaje distribuido (cmooc) con retroalimentación personalizada (xmooc) y se basa en la teoría de la cognición situada centrándose en el aprendizaje contextual (hickey, 2013).

\begin{tabular}{|c|c|}
\hline $\begin{array}{l}\text { Distributed Open Collaborative } \\
\text { Course (DOCC) }\end{array}$ & $\begin{array}{l}\text { Sigue la pedagogía híbrida que } \\
\text { incluye vídeosconferencias a cargo } \\
\text { de expertos (xMOOC) y reconoce } \\
\text { que el conocimiento se distribuye } \\
\text { en red (cMOOC). Los materiales de } \\
\text { aprendizaje, lecturas y tareas se } \\
\text { distribuyen y se basa en el plan de } \\
\text { estudios, la rúbrica de clasificación y } \\
\text { la personalización. }\end{array}$ \\
\hline $\begin{array}{l}\text { Little Open Online Course } \\
\text { (LOOC) }\end{array}$ & $\begin{array}{l}\text { El modelo sigue el formato } \mathrm{xMOOC} \\
\text { basado en vídeos elaborados por } \\
\text { un profesor, podcasts y la } \\
\text { participación a través de } \\
\text { discusiones. }\end{array}$ \\
\hline $\begin{array}{l}\text { Massive Open Online Research } \\
\text { (MOOR): }\end{array}$ & $\begin{array}{l}\text { Sigue el modelo xMOOC que } \\
\text { incluye videos por parte de la } \\
\text { instructores. Los materiales del } \\
\text { curso incluyen un e-book escrito } \\
\text { por los instructores del curso que } \\
\text { incorpora ejercicios y la resolución }\end{array}$ \\
\hline
\end{tabular}




\begin{tabular}{|c|c|}
\hline & $\begin{array}{l}\text { de problemas. Este modelo } \\
\text { incorpora la Zona de Desarrollo } \\
\text { Próximo (ZDP) de Vygotsky. Así, } \\
\text { cada capítulo del texto se basa en } \\
\text { los conceptos e ideas básicas para } \\
\text { introducir temas complejos y evalúa } \\
\text { el dominio de conceptos de } \\
\text { aprendizaje a través de desafíos y } \\
\text { las tareas. El curso incluye un apoyo } \\
24 \times 7 \text { por parte de los instructores. }\end{array}$ \\
\hline $\begin{array}{l}\text { Small Private Online Course } \\
\text { (SPOC) }\end{array}$ & $\begin{array}{l}\text { Se inspira en los xMOOC e incluye } \\
\text { vídeos del instructor, tareas } \\
\text { interactivas y discusión en grupos. } \\
\text { Sigue el modelo de "aula invertida } \\
\text { o flipped classroom" (Coughlan, } \\
\text { 2013). Los estudiantes online se } \\
\text { matriculan como estudiantes } \\
\text { presenciales tradicionales, que a su } \\
\text { vez ejercen de mentores. }\end{array}$ \\
\hline $\begin{array}{l}\text { Synchronous Massive Open } \\
\text { Online Courses (SMOC) }\end{array}$ & $\begin{array}{l}\text { Sigue el modelo xMOOC, en } \\
\text { donde los materiales de } \\
\text { aprendizaje incluyen recursos web } \\
\text { gratuitos y lecturas en ñínea. Las } \\
\text { conferencias en directo se utilizan } \\
\text { para involucrar a los estudiantes y } \\
\text { la participación de los alumnos se } \\
\text { fomenta a través de la } \\
\text { participación en foros de discusión. } \\
\text { Las clases se dividen en grupos } \\
\text { pequeños y controlados por los } \\
\text { tutores que son los ex alumnos del } \\
\text { curso. Tener los mismos } \\
\text { estudiantes en el mismo grupo a lo } \\
\text { largo del semestre ayudar a crear } \\
\text { un sentido de comunidad y } \\
\text { promueve la interacción constante } \\
\text { entre los estudiantes. }\end{array}$ \\
\hline
\end{tabular}

Sin duda, esta diversificación sugiere que la velocidad a la cual crece el fenómeno de los MOOCs es cada vez más rápida gracias a las oportunidades y necesidades académicas o de capacitación que se presentan en todo el mundo, a pesar 
de las limitaciones de conectividad y de soporte tecnológico que se presentan en algunos países, particularmente aquellos que están en vías de desarrollo (VázquezCano y López-Meneses, 2015).

Existe una diversidad de plataformas en las que descansan los MOOCs por ejemplo, las plataformas enfocadas en contenidos son: (1) $E d X$, la cual se caracteriza por no ser lucrativa y fue desarrollada en MIT, (2) la plataforma Coursera, la cual ofrece la opción de evaluación por pares, desarrollada por Harvard y (3) Udacity, que se enfoca a la informática y desarrollada por la Universidad de Stanford (Bartolomé y Steffens, 2015). Por otro lado, DesirelLearn, MiridiaX y FutureLearn ofrece más opciones de conectivismo (Sánchez-Vera, León-Urrutia y Davis 2015). En una publicación, VazquezCano y López-Meneses (2015), encontraron que Coursera estaba a la cabeza con 7.2 millones de usuarios seguido de Edx con 4 millones y Udemy con 2 millones. En ese entonces Udacity estaba por debajo de los 300,000 usuarios.

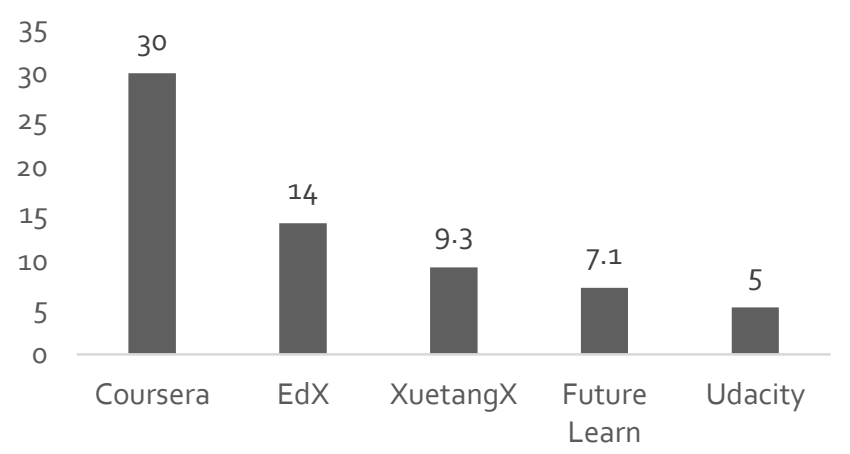

Figura 8. Número de usuarios (en miles) de diversas plataformas. (Vásquez-Cano y LópezMeneses, 2015) 
En la Figura 8 se muestran los resultados actualizados sobre el número de usuarios (Guijosa, 2018) y se puede apreciar el aumento exponencial de cada plataforma. Además aparece en este ranking una plataforma China con 9.3 millones de usuarios, una cifra que sobrepasa el número de usuarios que Coursera registró en el año 2015.

\subsubsection{Impacto de los MOOCs en la educación alrededor del mundo y sus áreas}

de oportunidad. Como se ha expuesto anteriormente, los MOOCs surgen como un medio para democratizar la educación a distancia. La UNESCO (2013) considera que son una oportunidad para llevar la educación a diferentes contextos garantizando su formación a lo largo de la vida y es a la vez una esperanza para aquellas naciones en condiciones vulnerables para garantizar el acceso a la educación de todos sus habitantes (Vázquez-Cano y López-Meneses, 2015). Y aunque existen opiniones encontradas con respecto a los $\mathrm{MOOC}$, es importante resaltar que no resolverán todo el problema educativo (García-Aretio, 2015) pero sí son una alternativa para quienes deseen aprender.

En un estudio desarrollado por Hew y Cheung (2014) encontraron cuatro razones frecuentes que motivan a los participantes a matricularse en un MOOC. Unos se enrolan por curiosidad y vivir nuevas experiencias de formación con personas de otras partes del mundo (Breslow, Pritchard, DeBoer, Stump, Ho y Staton, 2013), y otros 
se inscriben por un reto personal, especialmente si es un curso ofrecido por universidades reconocidas como el Massachussets Institute of Technology (MIT, EUA) o la Universidad de Harvard (EUA), e incluso hay quienes se enrolan en ellos como simple pasatiempo (Young, 2013).

El tipo de participante más común es el que desea saber sobre un tema en especial con la idea de aumentar o refrescar sus conocimientos o para aprender sobre algo que necesitan en ese momento para aplicar en su trabajo. Por ejemplo, AT\&T, Microsoft y Bank of America han desarrollado sus propios MOOC (Meister, 2015) tanto para capacitar a sus empleados como para educar a sus clientes (Olsson, 2015) así los ambientes en linea, abiertos y masivos no solo puede contribuir a la educación sino a elevar la productividad.

Cabe destacar que los MOOC tienen una mejor aceptación en los participantes que no están inscritos en la universidad, en el estudio desarrollado por Castaño, Maíz y Garay (2015) además encontraron que las mujeres consideran que se aprende bien en el MOOC y que son fáciles de usar. Otro hallazgo interesante fue que los participantes no inscritos en la universidad consideran el uso de videos y e-actividades facilita la comprensión de ciertos temas y que esta es una manera interesante de aprender. En la misma línea Hood, Littlejohn y Milligan (2015) encontraron que los participantes no universitarios presentaron mejor aprendizaje autorregulado que los 
participantes que se inscribieron por interés general. Esto puede dar la idea que los MOOC resultan más interesantes y significativos por aquellos participantes que tienen un interés más allá que el de solo cumplir con un crédito universitario.

Por otra parte, el curso MOOC The Ancient Greek Hero, lanzado por la Universidad de Harvard y el Centro de Estudios Helénicos desarrollado en la plataforma EdX ha permitido colocar a disposición del mundo, y a través de la licencia de Creative Commons, diversas fotografías en alta resolución de manuscritos antigüos (Muellner, 2015). Además ha permitido utilizar herramientas tecnológicas para promover la comprensión de textos antiguos así como una retroalimentación inmediata en los análisis de los mismos. Sin duda esto hace evidente que los MOOC, como parte del movimiento abierto (Ramírez-Montoya, 2015), favorecen la educación global en temas muy diversos.

En India, los MOOC han favorecido la actualización de la profesión contable, tanto a los estudiantes como a los profesionales en ejercicio. Ambadkar (2015) encontró que el sistema educativo contable de la India puede disponer de los MOOC para democratizar el acceso de cursos contables de calidad. Por otro lado en Taiwan, específicamente, en la Universidad Yaun Ze, en un estudio desarrollado por Tseng, Tsao, Yu, Chan y Lai (2016) encontraron que un MOOC sobre programación de más de 400 estudiantes reportó una buena retención gracias al diseño pedagógico. 
En la universidad de Macau en China, existen apenas una docena de MOOC, en un estudio desarrollado por Zou (2015) encontró que la determinación y la disciplina juegan un rol importante para concluir exitosamente un MOOC y que a pesar de que cada vez la aceptación por este tipo de cursos está creciendo, los estudiantes necesitan apoyo y guía que sirvan de aliento y motivación.

Aunque la producción científica en el movimiento de los MOOCs todavía no se ha desarrollado a plenitud (López-Meneses, Vázquez-Cano y Román, 2015; ChiappeLaverde, Hine y Martínez-Silva, 2015), pues la masificación no es una indicador de éxito (Caballo, Caride, Gradaílle y Pose, 2014), especialmente cuando la tasa terminal es de alrededor del 4\% (Armstrong, 2014). Por lo que se espera que estos entornos de aprendizaje sean una fuente de proyectos de investigación, si se quiere que este movimiento educativo, como cualquier otro, se fortalezca sobre terreno firme (García Aretio, 2015).

Al mismo tiempo, se desea que los MOOCs se conviertan en una oportunidad para aprovechar los beneficios de la tecnología, por ejemplo, que genere aprendizaje ubicuo y emergente de calidad (Aguaded-Gómez, 2013). También se espera que las investigaciones se centren en tres áreas: arquitectura tecnológica, evaluación de los modelos pedagógicos (evaluaciones, acreditaciones, costos) y el diseño del modelo educativo en la educación superior (López-Meneses, Vázquez-Cano y Román, 2015). 
En la misma línea, investigadores como Xing, Chen, Stein y Marcinkowsky (2016)

sugieren que las investigaciones exploren las características de los estudiantes como conocimiento previo en el uso del aprendizaje en línea, que los investigadores colaboren con el instructor para examinar en conjunto la eficiencia de los MOOCs y cuál sería un modelo generalizado que sea efectivo para todos los estudiantes de MOOCs.

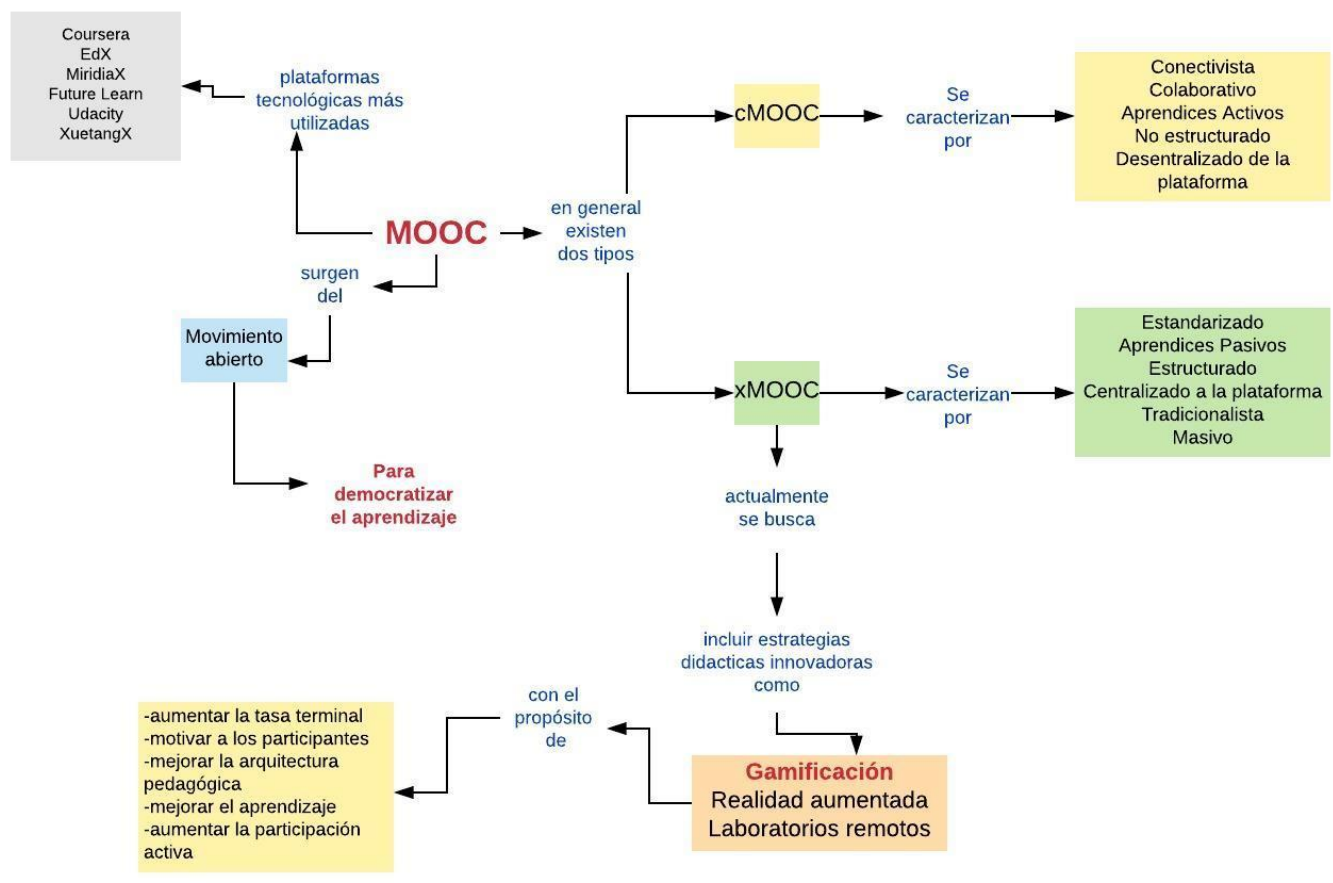

Figura 9. Esquema gráfico del constructo MOOC (Elaboración propia).

En la Figura 9 se muestra el esquema gráfico que resume los temas abordados en esta sección. En el siguiente apartado daremos una revisión profunda sobre la gamificación y su impacto en la educación para finalizar en un tercer apartado con el tema Gamificación en MOOC. 


\subsection{El papel de la Gamificación en la Educación.}

Diversas críticas a los $\mathrm{MOOC}$, como la baja tasa terminal no mayor del 4\% (Armstrong, 2014) y la falta de seguimiento por parte de los instructores (Xing, Chen, Stein y Marcinkowsky, 2016; Hone y El Said, 2016), han motivado a que se integren estrategias innovadoras, especialmente en los xMOOC cuyo paradigma pedagógico ha descansado en el conductismo (Ping, 2013). Por lo que actualmente, se han desarrollado propuestas pedagógica que disponen la integración de estrategias didácticas innovadoras. Por ejemplo, las investigaciones de González-González, Collazos y García (2016), Borrás-Gené, Martínez-Nuñez y Fidalgo-Blanco (2016) , entre otros, proponen que innovaciones didácticas como la gamificación sean incluidas en los MOOC, con la finalidad de enriquecerlos, de favorecer la motivación y aumentar la eficiencia terminal.

Para fines de la presente investigación se ha estudiado la gamificación basada en mecánica de retos en los $\mathrm{xMOOC}$, por tal motivo se presenta una revisión de la literatura sobre el aprendizaje lúdico y a partir de ahí, cómo se derivó la gamificación.

\subsubsection{Del aprendizaje lúdico a la gamificación. El juego es una actividad universal} y que ha estado presente a lo largo de la historia de la humanidad en diversas áreas y disciplinas. Huizinga (2012), filósofo e historiador holandés que fue el primero en estudiar el fenómeno de la lúdica en la vida del hombre en los años cincuenta, sostuvo 
que el juego es más antiguo que la cultura misma pues el ser humano, al igual que los animales, ha jugado desde siempre y se percibe como una actividad útil que no sólo ofrece diversión, relajación o entretenimiento sino aprendizajes valiosos. Además, al ser una actividad voluntaria provee de un escenario equitativo ya que el participante sólo puede ser derrotado por alguien más ingenioso (Gökcen, 2014). Es evidente que el juego ha tenido un papel importante en el desarrollo cultural y social del ser humano, incluso en el plano intelectual.

Por ejemplo, el fenómeno lúdico ha estado presente en el arte, el lenguaje, los deportes o los negocios y también en el desarrollo de disciplinas complejas como las matemáticas. Además, el aspecto lúdico aporta diversión y deleite, que permite que los individuos se alejen de las complicaciones de la realidad. Chamoso, Durán, García, Martín y Rodríguez (2004) establecen un conjunto de características fundamentales del juego de las cuales se destacan: el carácter lúdico, reglas propias y el carácter competitivo. El carácter lúdico proporciona entretenimiento, las reglas propias deberán ser aceptadas libremente por los participantes y cumplirse cabalmente.

El carácter competitivo es el que aporta un desafío personal para ganar al resto de los competidores. Por ejemplo, en la Italia del siglo XVI, Cardano, del Ferro, Ferrari y Tartaglia organizaban frecuentemente torneos en los que se trataba de resolver lo más rápidamente posible los problemas (retos) propuestos por su adversario 
(Deulofeu, 2001). De esta manera se puede observar que un componente del juego es el reto que en sí mismo implica, que atrae la atención y concentración de quien lo practica.

Una de las razones por las que haya poca producción investigativa en torno al aprendizaje lúdico y su impacto en la educación, es que se ha considerado al juego en el proceso enseñanza-aprendizaje como antitético (Corbalán, 2000). No obstante, poco a poco va cobrando más relevancia e incluso se puede vislumbrar una evolución. Pues se ha encontrado que los juegos ayudan a experimentar, a explorar opciones, consecuencias y a probar los propios límites, lo que permite crear situaciones de gran valor educativo ya que aumenta la motivación e interés de los estudiantes (MuñizRodriguez, Alonso y Rodriguez-Muñiz, 2014). Así mismo, Pulos y Sneider (1994) afirman que el juego educativo es una oportunidad única para integrar en el aprendizaje los aspectos cognitivos, afectivos y sociales.

Así, el aprendizaje lúdico se ha convertido en una herramienta poderosa para mejorar los ambientes áulicos. Vale la pena resaltar que el juego es una actividad que es practicada por personas de todas las edades y de todas partes del mundo. En la niñez, jugar es una necesidad, aunque en la vida adulta no solo es una cuestión de liberar energías sino de desarrollar distintas facultades humanas (García-Aretio, 2016). 
Por lo que el juego puede aplicarse en cualquier nivel educativo, así como en cualquier espacio de aprendizaje.

En un estudio desarrollado por Stefani, Andrés y Oanes (2014) sobre tipos de juegos y espacios lúdicos, encontraron que es una actividad realizada desde la infancia hasta la vida adulta y que a través del tiempo se ha ido adaptando, mezclando con distintas culturas y respondiendo al momento histórico que se está viviendo. Dentro de los resultados se destaca que los juegos motores, en los que las habilidades motoras se destacan, predominaron en todas las generaciones a lo que los investigadores concluyen que este tipo de juego es transmitido de generación en generación, aunque, en los juegos electrónicos predominan las generaciones más jóvenes.

En un estudio elaborado por la Pew Internet y el American Life Project reportó que el $99 \%$ de los hombres adolescentes y el $94 \%$ de las mujeres juegan juegos electrónicos (Lenhart, Kahne, Middaugh, Macgill, Evans y Vitak, 2008). Esto lleva a pensar que los medios interactivos están llamados a ocupar un lugar preferencial en la nueva educación, en los que, sin duda, cada vez más se implican los juegos (Galvis, 2013).

Los juegos pueden ser usados con distintos objetivos de aprendizaje. Corbalán (1996) define tres tipos: juegos de conocimiento, juegos de estrategia y juegos de azar. Los primeros tienen que ver con abordar algún tópico de manera más activa, creativa 
y participativa (Chamoso et al., 2004). Los segundos implican un desafío (reto) por lo tanto el proceso metacognitivo del participante es de un nivel mayor, por lo que didácticamente pueden ser más atractivos gracias al impacto que puede implicar en el aprendizaje de los estudiantes, así como en el desarrollo de otras habilidades tales como la creatividad, toma de decisiones y resolución de problemas (Galvis, Mariño, Trech y Recamán, 2013).

Finalmente, los juegos de azar se distinguen por su proceso aleatorio y pueden ser utilizados en temas de probabilidad, aunque con un poco de ingenio podrían utilizarse en cualquier otro tópico y combinándolo con un juego de conocimiento o estrategia. Cuando el juego ha sido diseñado adecuadamente puede ayudar a determinar el nivel de desempeño de un sujeto, a medir la velocidad y agilidad o bien, para repasar o integrar contenidos e incluso para construirlos.

También servirá de motor para propiciar incrementos en la complejidad de los retos y en las demandas cognitivas requeridas durante la actividad lúdica, convirtiendo al juego en una forma de evaluación (De la Cruz, Chung y Baker, 2010). Así que la respuesta inmediata que también caracteriza a los juegos resulta ser un elemento favorable para la autorregulación del aprendizaje por parte de los estudiantes (Tay, 2015). Por lo que el juego además de ayudar a hacer más atractivas las clases también puede ser un instrumento útil para la evaluación. 
Aunque el juego puede ser una estrategia de aprendizaje poderosa es importante considerar sus limitaciones en el proceso educativo. Al igual que con cualquier programa educativo o actividad, es necesario reflexionar al momento del diseño de la actividad lúdica, el contexto, el contenido didáctico, los estilos de aprendizaje, entre otros (Contreras-Espinosa, 2016), así como la periodicidad en la que se aplican.

Mayer (2015) por su parte señala que la mayoría de las publicaciones sobre el uso de los juegos en la educación son descriptivas y más enfocadas a resultados motivacionales que cognitivos, considera que es necesario evaluar la eficacia de los juegos comparando con un grupo control. Por otro lado, Mora, Riera, GonzálezGonzález y Arnedo-Moreno (2017) desarrollaron una revisión sistemática sobre gamificación, en donde encontraron que hay una diversidad de concepciones de la gamificación, lo que muestra que todavía hay camino que recorrer en cuando a investigación se refiere.

Esto no debería desalentar al lector sino más bien motivarlo a desarrollar un diseño basado en el análisis y la reflexión que le permita valorar objetivamente y a profundidad los resultados del aprendizaje lúdico o basado en juegos. Por lo que vale la pena resaltar que, a pesar de las controversias, el juego persiste en el aprendizaje, no solo en los niveles básicos sino en niveles superiores (Hanus y Fox, 2015) tanto por los beneficios o ventajas ya comentadas como, por la inevitable presencia de la tecnología 
en la vida del ser humano. Así, la gamificación surge como un derivado del aprendizaje lúdico. La definición más generalizada sobre la gamificación es que usa los elementos del juego en contextos que no son de juego (Pedreira, García, Brisaboa y Piattini, 2014).

El término fue acuñado por Nick Pelling en el 2002 aunque tomó popularidad hasta el 2010 gracias a los sistemas de recompensa en entornos digitales que ha ofrecido el sector empresarial y comercial (Rodríguez y Santiago, 2015). Años más tarde, la gamificación comenzó a incorporarse en el entorno educativo alrededor del mundo, lo que ha generado interés y escepticismo por las comunidades académicas, quizás como parte de lo heredado por el aprendizaje lúdico.

\subsubsection{Construyendo un ambiente Gamificado. De forma similar al juego, la} gamificación es una tendencia que surgió años atrás. Por ejemplo, las insignias (badges) y rangos (ranks) tienen su base de utilización en el ejército, incluso, líderes de la antigüa Unión Soviética usaban elementos del juego para incentivar el buen desempeño de sus militantes (Dicheva, Dichev, Agre y Angelova, 2015). Años más tarde, la gamificación se extendió a los negocios, marketing, salud y recientemente a la educación. Empresas como Starbucks, Amazon, eBay, Heineken y Nike, entre otras, han incursionado en la gamificación para aumentar la fidelización de sus clientes. Por ejemplo, en el 2013 la campañana M\&M’s eye-spy pretzel tuvo gran impacto y se volvió viral rápidamente. 
A través de la cuenta de Facebook de la marca, colocó una imagen repleta de M\&M's en donde el cliente debía encontrar un pequeño pretzel escondido dentro del dulce, esto generó 25,000 likes, se compartió 6000 veces y hubieron 11,000 comentarios (Williams, 2015). Otro ejemplo exitoso es el de Starbucks, con su campaña Starbucks My Reward, que consiste en un sistema de recompensas. Al acumular cierto número de estrellas (badgets) los clientes reciben algún tipo de recompensa (Petersen, 2013).

En el 2012 los usuarios de My Reward totalizaron cerca de 4.5 millones de dólares, en la actualidad solamente las tarjetas generan 3 millones de dólares al año (Chou, 2013). Brian Burke (2012), analista de Gartner Inc. predice que para el 2020 la gamificación se aliará con la innovación abierta para desarrollar ideas que generen mecanismos exitosos de marketing. En un estudio realizado a ejecutivos de marketing por Lucassen y Jansen (2014) encontraron que nueve de los 10 entrevistados consideran que la gamificación tiene un futuro prometedor, lo que refuerza las predicciones de Burke.

También vale la pena decir que aunque cada vez son más las empresas que usan la gamificación son pocas las investigaciones que se han desarrollado al respecto (Houtari y Hamari, 2011), por lo que se visulumbra un área de oportunidad investigativa en este campo. Así como en los negocios, la gamificación ha ido ganando terreno en la educación, en gran parte por que toma los elementos y mecánicas de los juegos, a 
la era digital en la que vivimos y a los beneficios que el juego en sí mismo posee (Maican, Lixandroiu y Constantin, 2016).

La gamificación usa elementos que favorecen la motivación intrínseca y extrínseca, por ejemplo, el ofrecimiento de premios (rewards) favorece a lo extrínseco mientras que subir de un nivel a otro es un reto que favorece lo intrínseco (Surendeleg, Murwa, Yun y Kim, 2014). También ofrece la oportunidad de experimentar con reglas, emociones y roles sociales (Lee y Hammer, 2011). Por lo que esta estrategia puede motivar a los estudiantes a aprender mejor. La gamificación, por tanto, se refiere a introducir elementos y experiencias de juego en el diseño de procesos de aprendizaje de cualquier área de estudio dirigidos no solo al aprendizaje sino a desarrollar ciertas habilidades y actitudes transversales como la colaboración, autorregulación del aprendizaje y creatividad (Caponetto, Earp y Ott, 2014; Dichev y Dicheva, 2017). También provee la oportunidad de explorar y de aprender de sus errores gracias a la retroalimentación inmediata y al número de intentos previamente permitidos (Koivisto, Multisilta, Niemi, Katajisto y Erickson, 2016). Así, la gamificación puede ser una herramienta valiosa para el proceso de enseñanza-aprendizaje.

\subsubsection{Enganche y flujo (engagement y flow) como elementos inherentes a la}

gamificación. El enganche (engagement) ha sido definido por Hamari, Shernoff, Rowe, Coller, Asbell-Clarke y Edwards (2016) como la capacidad de inmersión o el nivel de 
flujo (flow) alcanzado en el desarrollo de una actividad mientras que para Gruman, Holmes-Rovner, French, Jeffres, Sofaer, Shaller y Prager (2010) y Russell, Ainley, y Frydenberg (2005) es la cantidad de energía aplicada en acciones y logro de tareas.

El enganche es la pasión por participar y completar las actividades de aprendizaje asignadas (Skinner y Belmont, 1993). Dicho en otras palabras, se trata de dar un impulso positivo para la consecución de una meta. Fredricks, Blumenfeld y Paris (2004) proponen tres tipos de enganche, el conductual, el cognitivo y el emocional. El primero se refiere a la actitud positiva del estudiante para participar y poner atención en clases, el segundo a la disposición para pensar y comprender un tema o concepto, en cuyo proceso interviene la autorregulación (Deci y Ryan, 2008). El emocional se relaciona con las reacciones o sentimientos de los estudiantes dentro del salón de clase, como felicidad, apatía, ansiedad, interés o aburrimiento.

Por otro lado, Csikszentmihalyi $(1990,1997)$ desarrolló una teoría sobre el flujo (flow), el cual consiste en un estado de absorción en una actividad que se disfruta de manera intrínseca, los individuos que se encuentran en este estado se muestran gozosos y exitosos (Admiraal, Huizenga, Akkerman y Damm, 2011). Recientemente, se han desarrollado diversos estudios en los que se pretende inducir en un estado de flujo a los estudiantes o usuarios a partir de la solución de retos o desafíos (Hou y Li, 2014; Tsai, Huang, Hou Hsu y Chiou, 2016; Koivisto y Hamari, 2014; Chang y Wei, 2016). Por 
lo que un adecuado enganche puede generar un estado favorable de flujo (Hamari et al., 2016).

Al mismo tiempo, en la teoría de la autorregulación se muestra que la motivación intrínseca se relaciona con tres factores: la autonomía, la competencia y la socialización (Decy y Ryan, 2000; Sailer, Hense, Mayr y Mandl, 2017) mientras que la motivación extrínseca se rige por la regulación externa, introyección, identificación e integración (Topîrceanu, 2017). En este sentido, tanto el enganche como el flujo pueden impactar en la motivación tanto intrínseca como extrínseca del estudiante o usuario, ya que se provocan cambios en la conducta de la persona al aplicar diversos mecanismos o estrategias didácticas con el propósito de generar compromiso (Alsawaier, 2018).

\subsubsection{Juego educativo (serious game) versus Gamificación. Antes de explicar los}

elementos de la gamificación es necesario hacer lagunas precisiones. Si bien es cierto que la definición generalizada de gamificación es que usa los elementos de juego en contextos que no son de juego, resulta pertinente establecer la diferencia entre gamificación y un serious game. Un serious game es un juego que no tiene como primer propósito el entretenimiento o la diversión (Suttie, Louchart, Macuean, Westera, Brown y Djaouti, 2012), es una aplicación computacional que combina el aprendizaje con el entrenamiento (Mouahe, Fahli, Moussetad y Eljamali, 2012) para el aprendizaje de un tema en particular que generalmente resulta complejo a los estudiantes. 
También son utilizados en otras áreas, por ejemplo Torres-Carrion y GonzálezGonzález (2016) desarrollaron un juego serio para la mejora fonológica de los niños con dislexia, que consistió en una interfaz donde los infantes completaban partes faltantes de una palabra al mismo tiempo que la escuchaban. A pesar de las ventajas que puede tener un juego educativo o serious game resulta ser costoso debido al desarrollo computacional que implica además que por lo general se desarrolla para un tema en particular (Faiella y Ricciardi, 2015).

La gamificación aunque puede implicar el uso de recursos tecnológicos, económicamente puede ser más viable dado que la estrategia se relaciona más con el diseño de un sistema para motivar el aprendizaje aunque puede ser complejo. Werbach y Hunter (2012) establece tres elementos de un ambiente gamificado: las dinámicas, las mecánicas y los componentes (ver Figura 10).

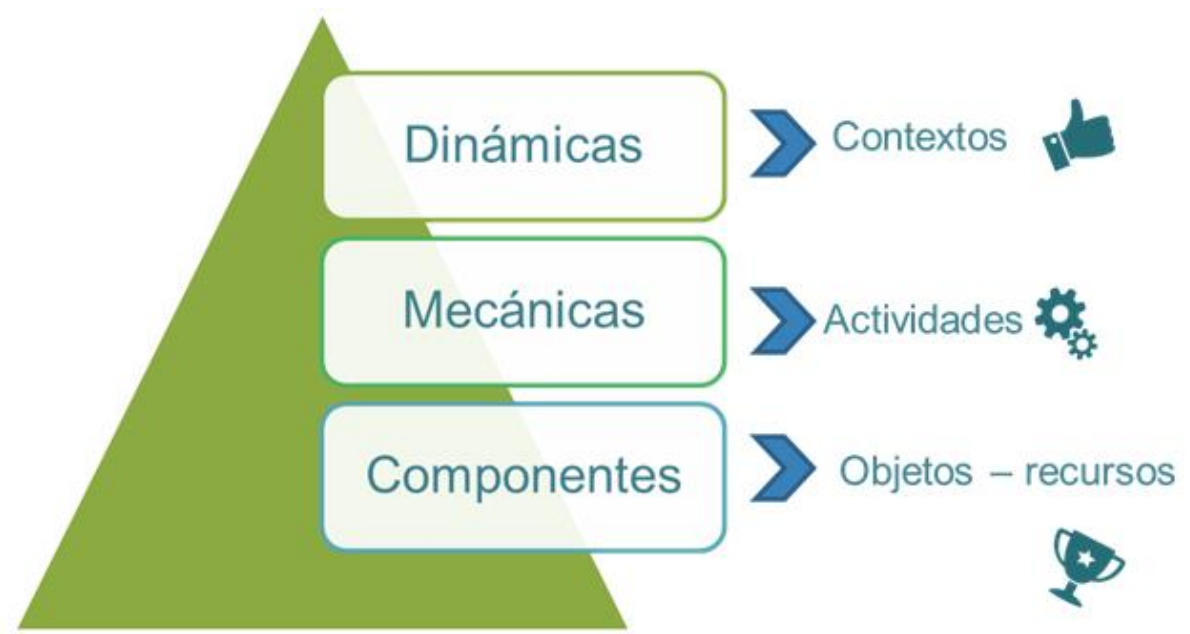

Figura 10. Elementos de la Gamificación según Werbach y Hunter (2012, p. 154). 
Los tres elementos deben estar presentes para que un ambiente pueda llamarse gamificado y preferentemente debería utilizar tecnología digital (Rodríguez y Santiago, 2015). Los componentes son los objetos físicos o virtuales utilizados para reconocer el desempeño de los participantes, como badgets, trofeos o puntos. Las mecánicas son las actividades que se desarrollan dentro del entorno gamificado, como las competencias, las oportunidades o los retos, entre otros. La dinámica se refiere al ambiente que se quiere generar en el entorno gamificado, por ejemplo, un ambiente social generado por la participación colaborativa.

Para ilustrar los tres elementos de la gamificación según el modelo de Werbach y Hunter usemos el juego del Monópoly. En este juego la dinámica consiste en una narrativa de ganar el mayor número de bienes; las mecánicas son las reglas para avanzar o retroceder en el tablero (turnos, transacciones, oportunidades y premios) así como la competencia, mientras que los componentes son los avatares que representan a los jugadores, los datos, los turnos y los tableros.

\subsubsection{Dinámicas, mecánicas y componentes.}

En esta sección se abordarán definiciones y ejemplos de diversos tipos de dinámicas, mecánicas y componentes, los cuales han sido extraídos de diferentes autores. 
2.3.5.1 Tipos de dinámicas en un ambiente gamificado. Las dinámicas son los aspectos generales a considerarse en un sistema gamificado (Kocadere y Caglar, 2015), los cuales juegan un papel importante en el diseño de estrategias y estímulos para motivar y promover comportamientos positivos para el aprendizaje (Tu, Yen, SujoMontes y Roberts, 2015). Werbach y Hunter (2012) proponen cinco tipos de dinámicas: restricciones, emociones, narrativas, progresiones y relaciones.

A continuación, se definen los tipos de dinámicas, según Werbach y Hunter (2012), Rodriguez y Santiago (2015) y Kapp (2012) Las dinámicas de restricciones (constraints) son aquellas que involucran obstáculos o desafíos y se relacionan con las mecánicas de retos. Werbach y Hunter (2015) sugieren que en este tipo de dinámica el participante tenga libertad de opciones y que se cuide la cantidad de obstáculos y el nivel de dificultad de los retos para que, el participante no pierda el interés por ser muy fácil o caiga en desánimo por ser tan complejo. Las dinámicas emocionales (emotions) tienen el propósito de entusiasmar al participante en contextos serios tales como el trabajo o la educación, los jugadores pueden experimentar curiosidad, exaltación, desánimo o felicidad no obstante, se espera que en los diseños de ambiente gamificado prevalezca un sentimiento de disfrute previniendo la ansiedad (Kocadere y Caglar, 2015).

Un aspecto importante de este tipo de dinámicas es su implicación en la motivación intrínseca y extrínseca (Woolfolk, 2008). La motivación intrínseca, en un 
sistema gamificado, se puede propiciar por la calidad del desafío o el interés por ganar, mientras que la motivación extrínseca se relaciona por los mecanismos de recompensa. Rodriguez y Santiago (2015) proponen una dosificación adecuada en los mecanismos de recompensa, ya que su exceso o defecto podría disminuir la motivación intrínseca.

Las dinámicas narrativas (narrative) son las que le dan congruencia al sistema gamificado, como la interfase y diseño de sus elementos (Werbach y Hunter, 2015). Por ejemplo, la narrativa utilizada por My rewards de Starbucks es diferente a la de Heineken. La primera tiene una interface animada con estrellas como insignias, las cuales tienen relación directa con su logotipo de marca, mientras que Heineken en su campaña por Instangram maneja un ambiente de fiesta en donde se muestra el consumo del producto a través de fotografías subidas por los seguidores de la marca. En un estudio desarrollado por Koivisto et al. (2016) se creó un simulador para estudiantes de enfermería, en la interfase se ve claramente como la narrativa está diseñada en torno a pacientes ingresados a hospitales y al tipo de lenguaje y ambientación propia del lugar, lo que sin duda colocó al estudiante en un escenario muy similar al que viviría en la vida real.

Las dinámicas de progresiones (progession) invitan al usuario a avanzar y que cada trayectoria recorrida sea una experiencia, en el área educativa, una experiencia de aprendizaje. Para Kocadere y Caglar (2015) este tipo de dinámica es el indicador del 
progreso de los jugadores. Este sistema de gamificación ha sido utilizado por Hanus y Fox (2015) quienes usaron tableros para mostrar los avances y progresos de los estudiantes y por Maican, Lixandroui y Constantin (2016) que utilizaron una aplicación gratuita llamada "The zero-cost" que se aplicó a estudiantes de ciencias económicas y negocios de la Universidad de Transilvania en Rumania, quienes afirman que a pesar de que la plataforma fue limitada para propiciar en mejor ambiente gamificado logró tres aspectos: mantener a los estudiantes en la aplicación, que regresaran a la aplicación y que compartieran sus resultados.

Finalmente, las dinámicas sociales (relacionships), promueven la interacción entre los participantes. Bogers y Sproedt (2016) desarrollaron un ambiente gamificado en un programa de postgrado dentro de un programa de innovación abierta interdisciplinario, a través de fronteras de la Universidad de Southern, Dinamarca. Ellos encontraron que este tipo de dinámica ayuda a desarrollar competencias sociales que son requeridas en el ambiente laboral.

En la Tabla 8 se muestra un ejemplo que ilustra un sistema gamificado con base en el modelo de Werbach y Hunter. 


\section{Tabla 8}

Ejemplo sobre diseño de un ambiente gamificado basado en la propuesta de Werbach y Hunter (2015)

\begin{tabular}{|c|c|c|}
\hline Dinámicas & Mecánicas & Componentes \\
\hline Restricciones & $\begin{array}{l}\text { Retos } \\
\text { Oportunidades } \\
\text { Turnos }\end{array}$ & $\begin{array}{l}\text { Avatares } \\
\text { Insignias } \\
\text { Niveles } \\
\text { Contenido abierto } \\
\text { Tablero }\end{array}$ \\
\hline Emociones & $\begin{array}{l}\text { Competiciones } \\
\text { Retroalimentación } \\
\text { Premios } \\
\text { Oportunidades } \\
\text { Turnos } \\
\text { Transacciones }\end{array}$ & $\begin{array}{l}\text { Avatares } \\
\text { Insignias } \\
\text { Combates } \\
\text { Tableros } \\
\text { Niveles } \\
\text { Puntos } \\
\text { Regalos }\end{array}$ \\
\hline Narrativas & $\begin{array}{l}\text { Retos } \\
\text { Competiciones } \\
\text { Premios } \\
\text { Oportunidades } \\
\text { Turnos } \\
\text { Transacciones }\end{array}$ & $\begin{array}{l}\text { Avatares } \\
\text { Insignias } \\
\text { Tableros } \\
\text { Niveles }\end{array}$ \\
\hline Progresiones & $\begin{array}{l}\text { Retos } \\
\text { Competiciones } \\
\text { Premios } \\
\text { Oportunidades } \\
\text { Turnos } \\
\text { Transacciones }\end{array}$ & $\begin{array}{l}\text { Avatares } \\
\text { Insignias } \\
\text { Tableros } \\
\text { Niveles } \\
\text { Puntos }\end{array}$ \\
\hline Sociales & $\begin{array}{l}\text { Competiciones } \\
\text { Retroalimentación } \\
\text { Premios } \\
\text { Oportunidades } \\
\text { Turnos }\end{array}$ & $\begin{array}{l}\text { Avatares } \\
\text { Insignias } \\
\text { Tableros } \\
\text { Niveles } \\
\text { Puntos }\end{array}$ \\
\hline
\end{tabular}

En la Tabla 8 se puede ver como se pueden generar combinaciones de componentes, mecánicas y dinámicas, la creatividad de cada diseñador pone los límites (Rodríguez y Santiago, 2015). Por su parte, Tu et al. (2016), definieron cinco tipos de dinámicas estas son: compromiso (engaging), sociales, comportamiento, exploración y motivacionales. Las sociales y motivacionales son similares a las propuestas por 
Werbach y Hunter (2012), las dinámicas de compromiso tienen el propósito de mantener activos e interactivos a los participantes, las de comportamiento son las que provocan que los participantes sigan el comportamiento esperado y las de exploración motivan el compromiso de la inspección activa y el sondeo.

Por otro lado, Bunchball (2012) define seis dinámicas: de Recompensa, de Estatus, de Logro, de Autoexpresión, de Competición y de Altruismo. En la Tabla 9 se muestran el principal motivador de cada dinámica de acuerdo a Bunchball.

\section{Tabla 9}

Resumen de los tipos de dinámicas de acuerdo con Bunchball Inc. (2012)

\begin{tabular}{ll}
\hline Tipo de dinámica & Principal motivador \\
\hline Recompensa & Ganar premios en especie o virtuales \\
Estatus & Reconocimiento de los demás \\
Logro & Vencer obstáculos o llegar a la meta sin importar los intentos realizados \\
Autoexpresión & Expresar propias ideas o pensamientos u opiniones. \\
Competición & Ser el mejor \\
Altruismo & Ayudar a los demás \\
\hline
\end{tabular}

Finalmente, a partir de lo comentado anteriormente se puede inferir que en un sistema gamificado se puede incluir más de una dinámica, todo dependerá el contexto y del diseño del sistema gamificado. Ahora veamos los tipos de mecánicas.

\subsubsection{Las mecánicas dentro de ambientes gamificados. Mientras que las} dinámicas son el para qué, las mecánicas son el cómo para el diseño de un ambiente gamificado. Rodríguez y Santiago (2015) las definen como los procesos que motivan al jugador a la acción, son los que comprometen (engagement) a los participantes 
(Werbach y Hunter, 2012). Al igual que en las dinámicas, Werbach y Hunter (2015) han definido diversos tipos de mecánicas, las cuales son: Retos (challenges), Oportunidades (chance), Competencias (competition), Cooperación (cooperation), Retroalimentación (feedback), Recursos adquiridos (resource acquisition), Recompensas (rewards), Transacciones (transactions), Turnos (turns) y Estado ganador (win state).

Las mecánicas de Retos (challenges) son aquellas tareas que requiere de un esfuerzo para resolverlas y que a la vez involucran límite de tiempo, habilidades o creatividad. Kocadere y Caglar (2015) usaron este tipo de mecánica para activar las dinámicas de restricciones (constraints) y las emocionales (emotions). Awwal, Monjurul y Care (2015), en un estudio desarrollado en la Universidad de Melbourne, Australia, encontraron que las mecánicas de retos colaborativas, bien diseñadas, pueden desarrollar o fortalecer habilidades a través de la exploración activa y el intercambio de conocimientos y habilidades de otros. Más adelante se profundizará más en esta mecánica.

Las mecánicas de Oportunidades (chance) tienen como propósito otorgar varias oportunidades a los jugadores, si esta mecánica está bien diseñada puede tener efectos positivos en los participantes ya que disminuye la frustración por no acertar a la primera. Esta mecánica puede ayudar a activar las dinámicas de restricciones y emocionales. 
Las mecánicas de Competencia (competition) tiene como estructura que un competidor gana y otro pierde, motiva las dinámicas de emoción y los componentes comúnmente utilizados son las insignias (badges) y tableros (ledearboards). Un ejemplo evidente son los partidos de cualquier deporte, como futbol, béisbol, ajedrez, etc.

Las mecánicas de Cooperación (cooperation) tienen como propósito que a través del trabajo colaborativo se pueda lograr un objetivo. Werbach y Hunter (2015) afirman que el mejor juego es aquel que involucra la competición y la cooperación. Esta mecánica es adecuada para las dinámicas sociales, de restricciones y emocionales.

Las mecánicas de Retroalimentación (feedback) son aquellas que dan respuesta al participante, generalmente su aplicación es digital. Su ventaja es que, al dar retroalimentación inmediata, el participante experimenta un sentimiento de logro y si esta mecánica se combina con una de Oportunidades (chance) se puede propiciar un proceso metacognitivo, gracias al proceso reflexivo que se motiva con el deseo de acertar y de las chances que se dan. Estas mecánicas activan las dinámicas de Emociones y de Progresiones y se pueden utilizar componentes como insignias (badges), puntuaciones (score) y niveles (levels), entre otros. (Kocadere y Caglar, 2015).

Las mecánicas de Recursos Adquiridos (resources acquisition) son aquellos recursos tangibles o intangibles que el jugador puede obtener para usarlos dentro del juego. Por ejemplo, el juego Settler of Catan consiste en acumular recursos para 
construir casas, aldeas o pueblos (Catan, 2016). Estas mecánicas activan las dinámicas de Emociones y Sociales y utilizan componentes como insignias (badges), avatares (avatars), turnos (turns), entre otros.

Las mecánicas de Recompensas (rewards) está basada en reconocer el éxito de los participantes a través de bienes materiales o virtuales. Esta mecánica motiva a las dinámicas de progreso y emocionales. Los componentes relacionados a estas pueden ser las insignias (badges) o avatares. Un ejemplo de esta mecánica son los premios en especie que son ganados por medio de la acumulación de estrellas en la gamificación My Rewards de la marca Starbucks (Bunchball, 2012).

Las mecánicas de Transacciones (transactions) tienen como objetivo que los jugadores puedan comprar y vender objetos materiales o digitales, lo cual incrementa la sofisticación del juego según Werbach y Hunter (2015). Por ejemplo, en el juego Settlers of Catan, los jugadores pueden intercambiar recursos para que de manera más rápida puedan construir sus aldeas o pueblos. Estas mecánicas dinamizan las dinámicas Emocionales, Sociales y de Competición. Se pueden utilizar componentes como Insignias (Badges), Niveles (Levels), Avatars (avatares), entre otros.

Las mecánicas de Turnos (turns) como su nombre lo indica, son aquellas en las que cada participante debe esperar su turno para hacer su jugada. El juego Monópoli puede ilustrar este tipo de mecánica, la cual puede motivar las dinámicas Sociales 
(relationship), Emocionales (emotions), Competición (competition) entre otros. Los componentes asociados pueden ser avatares (avatars), insignias (bagdes), niveles (levels), entre otros.

Finalmente, las mecánicas de Ganadores (win state) son aquellas en las que solo existe un único ganador de entre todos los competidores, la mayoría de los juegos toman este tipo de mecánica. Por ejemplo, los juegos on line multijugador o los clásicos como Mario Kart, Assasins Creed, entre otros. Estos juegos activan las dinámicas de Competencia (competition), Emocionales (emotions) y de Restricciones (constrains). Los componentes pueden ser, Avatares (avatars), Insignias (badges), Puntos (points), entre otros.

Se puede deducir a través de la literatura que un ambiente gamificado puede adoptar una combinación de dinámicas y mecánicas, eso dependerá del entorno que se desea gamificar y de los recursos con los que se cuenta. Por otro lado, los componentes son el qué de la Gamificación, en palabras Werbach y Hunter (2012) son las tácticas en movimiento. Aunque a manera de ejemplo ya se describieron algunos componentes, a continuación, se muestra una lista de ellos basado en la literatura de Werbach y Hunter (2015), Kocadere y Caglar (2015) y Bunchball (2015), ver Tabla 10. 


\section{Tabla 10}

Descripción y ejemplos de los componentes propuestos en un sistema gamificado, con base en los modelos de Werbach y Hunter (2015), Kocadere y Caglar (2015) y Bunchball (2015).

\begin{tabular}{|c|c|}
\hline Componentes & Descripción \\
\hline $\begin{array}{l}\text { 1. Logros } \\
\text { (Achievements) }\end{array}$ & $\begin{array}{l}\text { Representa el objetivo logrado por el jugador o equipo jugador, por ejemplo cuando el } \\
\text { jugador gana una insignia, por ejemplo cuando se elimina a un Cerdo en el juego Angry } \\
\text { Birds. }\end{array}$ \\
\hline
\end{tabular}

$\begin{array}{ll}\begin{array}{l}\text { 2. Avatares } \\ \text { (Avatars) }\end{array} & \text { Es la representación visual del jugador o equipo jugador. Por ejemplo el personaje que } \\ \text { 3. Insignia } & \text { se elige en Mario Kart 64. } \\ \text { (Badges) } & \text { Las insignias son las representaciones visuales de los logros, por ejemplo las estrellas de } \\ & \text { My Rewards de Starbucks. }\end{array}$

4. Reto final (Boss Por lo general antes de pasar al siguiente nivel se ofrece un reto final al jugador que figths) tiene un nivel de dificultad mayor, por ejemplo, en Mario Bross antes de pasar al siguiente nivel se debía pelear con un gran Bowser.

5. Colecciones Son una serie de objetos personales que el jugador colecciona a lo largo del juego. Por (Collections) ejemplo en Settlers of Catan los jugadores pueden coleccionar madera, tierra, roca, animales, entre otros para construir sus casas o colonias.

\begin{tabular}{|c|c|}
\hline $\begin{array}{l}\text { 6. Combates } \\
\text { (Combat) }\end{array}$ & $\begin{array}{l}\text { Son batallas cortas en las que hay un ganador en la lucha. Un ejemplo puede ser el juego } \\
\text { Street Fighter. }\end{array}$ \\
\hline $\begin{array}{l}\text { 7. Contenidos } \\
\text { cerrrados (Contect } \\
\text { unlocking) }\end{array}$ & $\begin{array}{l}\text { Es una forma de recompensa en la que el jugador tiene acceso a información adicional o } \\
\text { pistas para lograr su objetivo en un tiempo más corto, por ejemplo se puede observar } \\
\text { en el juego Plants vs Zombies. }\end{array}$ \\
\hline $\begin{array}{l}\text { 8. Otorgo de } \\
\text { regalos (Gifting) }\end{array}$ & $\begin{array}{l}\text { Son los regalos (insignias o colecciones) que el jugador puede dar a otro de forma } \\
\text { altruista. }\end{array}$ \\
\hline $\begin{array}{l}\text { 9. Tableros } \\
\text { (Leaderboards) }\end{array}$ & $\begin{array}{l}\text { Es la visualización de los logros obtenidos por todos los jugadores. Por ejemplo el juego } \\
\text { Legue of Legends. }\end{array}$ \\
\hline 10. Niveles (Levels) & $\begin{array}{l}\text { Muestran el estado de los logros del jugador o grupo de jugadores. Por ejemplo el juego } \\
\text { Candy Crush tiene más de } 500 \text { niveles y es para un solo jugador. }\end{array}$ \\
\hline 11. Puntos (Points) & $\begin{array}{l}\text { Los puntos es una manera numérica de representar el progreso de los participantes. Por } \\
\text { ejemplo el clásico Pac Man registra y muestra los puntos que se han obtenido. }\end{array}$ \\
\hline $\begin{array}{l}\text { 12. Misiones } \\
\text { (Quests) }\end{array}$ & $\begin{array}{l}\text { Las misiones es una narrativa de un reto, por ejemplo, en el juego Zelda la misión es } \\
\text { rescatar a una princesa. }\end{array}$ \\
\hline $\begin{array}{l}\text { 13. Gráficas } \\
\text { sociales (Social } \\
\text { Graph) }\end{array}$ & $\begin{array}{l}\text { Este componente parecido al tablero pero se enfoca a jugadores en línea y tiene su } \\
\text { información sirve para que los jugadores hagan alianzas futuras de juego. Por ejemplo } \\
\text { Farm Ville. }\end{array}$ \\
\hline $\begin{array}{l}\text { 14. Equipos } \\
\text { (Teams) }\end{array}$ & Es un grupo de jugadores unidos con el mismo propósito: ganar. Por ejemplo Pictoniary. \\
\hline $\begin{array}{l}\text { 15. Bienes virtuales } \\
\text { (Virtual godos) }\end{array}$ & $\begin{array}{l}\text { Son bienes virtuales que luego se convierten en objetos materiales como los puntos de } \\
\text { Payback que luego se intercambian por aquellos que se ofrezcan en los negocios } \\
\text { participantes. }\end{array}$ \\
\hline
\end{tabular}


Como se puede observar, la gamificación ofrece una variedad de elementos para el diseño de ambientes educativos gamificados, la creatividad pone los límites. No obstante, es importante sumergirse en un proceso reflexivo que considere el contexto y los objetivos que se quieren lograr, ya sean motivacionales, sociales o de aprendizaje.

\subsubsection{Fortalezas y debilidades de la gamificación. Actualmente existen diversas}

publicaciones alrededor del mundo con respecto a la aplicación de la gamificación en el ámbito educativo, sin embargo, se perciben impactos negativos con respecto al aprendizaje, posiblemente por las preconcepciones equivocadas o porque su aplicación se limita solamente al uso componentes sin que estos formen parte de un sistema gamificado que considere dinámicas y mecánicas adecuadas al contexto en el que se aplicaron (Tu et al., 2016). De hecho, hay diversos profesionales aplicando la gamificación pero, pocos investigadores (Hanus y Fox, 2015; Lee y Hammer, 2011; Mayer 2016). Esto sugiere que, todavía hay mucho por investigar en torno a la gamificación y su efecto en la educación.

En la literatura existe una diversidad de estudios empíricos sobre ambientes educativos gamificados, hay resultados positivos como negativos. Por ejemplo, retomando el estudio de Hanus y Fox (2015), ellos aplicaron la gamificación durante un semestre comparando dos grupos, uno control y uno experimental, con el propósito 
de medir los efectos de la gamificación en la motivación. La dinámica de su sistema gamificado, aunque no lo hace explícito en su artículo, fue una de progresión (progression) ya que utilizó a lo largo de 16 semanas los componentes: tablero (leaderboard) y diversas insignias (badges) correspondiente a una tarea o actividad.

Aunque inicialmente los alumnos del grupo gamificado se mostraron motivados, el enganche (engagement) fue disminuyendo a lo largo del semestre. De la misma manera, la motivación, satisfacción, esfuerzo y empoderamiento fue más bajo en el grupo experimental que en el grupo sin sistema gamificado. En este estudio, las actividades o tareas a realizar por ambos grupos fueron las mismas, lo que sugiere que un sistema gamificado basado solamente en dinámicas de progresión debe diseñarse con mayor profundidad. Tal vez considerar el tiempo, las tareas o actividades implicadas, combinar distintas dinámicas y mecánicas.

Hanus y Fox (2015) también resaltan el hecho de que su investigación solo se enfocó en algunos mecanismos de la gamificación y que sus conclusiones no deberían extenderse a todos los sistemas gamificados sino, que su investigación marca un precedente para desarrollar tecnología digital que facilite la incorporación de mecanismos y componentes de la gamificación. De hecho, estudios como los de Koivisto y Hamari (2014) o Cheng, She y Annetta (2015) han tenido resultados positivos, mas adelante se relatarán. 
Otro estudio interesante es el de Attali y Arieli-Attali (2015) de la Educational Testing Service, quienes decidieron comparar dos muestras para evaluar si un sistema de ganar puntos tenía impacto en la velocidad o en la exactitud con las que se respondían una serie de exámenes. El estudio se aplicó a dos muestras, una de adultos ( $N=1218)$ y otra de adolescentes ( $N=693$ ). Se aplicaron cuatro exámenes de 400 reactivos y 25 minutos para responder. Los resultados fueron similares en ambas muestras, no hubo efecto en la exactitud de las respuestas pero sí se incrementó la velocidad. Ellos consideran que aunque la respuesta inmediata puede ayudar en la motivación y desempeño, no siempre se tienen los resultados esperados.

De manera similar, en el estudio de Domínguez et al. (2013) se obtuvieron resultados parecidos. Su proyecto consistió en la gamificación un curso en una institución madrileña por medio de una plataforma on line, el sistema fue diseñado con dinámicas emocionales (emotion) y de progreso (progression), mecánicas de retos (challenges) y competición (competition) así como componentes del tipo insignias (badges) y tablero (leaderboard). Para el estudio utilizaron un grupo control $(n=62)$ y uno experimental $(n=11)$, el tiempo del estudio fue durante un semeste. Como resultado del estudio se encontró que las expectativas esperadas no se alcanzaron pues en el aspecto motivacional los alumnos del grupo experimental estuvieron por debajo que el grupo control. Los investigadores lo atribuyen a que al exponer los 
progresos de los estudiantes en un tablero o competir con sus compañeros resultó con un efecto contrario a lo que se supone debería lograrse con esos componentes (Rodriguez y Santiago, 2015 ).

Los investigadores consideran que quizás la falta de una retroalimentación rápida pudo haber causado esos resultados así como las fallas en la plataforma. Aunque llama la atención que en otro estudio desarrollado por Mekler, Bruhlmann, Opwis, y Tuch (2013, 2015), en el que se dieron a la tarea de evaluar el impacto del uso de puntos, niveles y tableros en la motivación, sí encontraron resultados positivos. Y aunque no hubo evidencia que los componentes utilizados favorecieron la motivación intrínseca, éstos actuaron como indicadores de progreso, lo cual dirigió y mejoró el desempeño de los estudiantes.

En este mismo orden de ideas, en un estudio desarrollado por Abramovich (2016) encontraron que el uso de insignias (badges) favoreció tanto a la evaluación formativa como sumativa. La investigación consistió en evaluar el efecto de esos componentes (badges) en un grupo presencial y en un grupo en linea (MOOC: Massive On line Open Course). En ambos casos resaltan que una evaluación basada en badges puede mejorar la motivación ya que el estudiante es expuesto a un sistema de evaluación más atractivo que el tradicional. Al mismo tiempo, subraya que es necesaria más investigación en torno a este tema. 
Los estudios anteriores refuerzan la idea de que la gamificación aunque ha resultado muy exitosa en el ámbito comercial no debe tomarse a la ligera, especialmente, en el ámbito educativo; además, aún falta consolidarla en el ámbito investigativo (Mayer, 2016; Domínguez et al., 2013). No obstante, la gamificación también ha dado resultados positivos; en un estudio desarrollado por Kebritch, Hirumi y Bai (2010) encontraron que de 16 investigaciones relacionadas con el aprendizaje gamificado y desarrolladas del 2003 al 2007, 11 tuvieron resultados positivos y 5 tuvieron tanto resultados positivos como negativos.

En otra investigación, desarrollada por Tsai et al. (2016) de la Universidad de Hong Kong, estudiaron el impacto de las mecánicas de juegos para evaluar su impacto en el enganche cognitivo (cognitive engagement) y en el enganche motivacional (engagement behavioral). Encontraron que la gamificación impacta en ambos. Por otro lado, Jhonson y Mayer (2010) desarrollaron un estudio en el que evaluaron dos experimentos. El objetivo general fue determinar si el uso de un juego de circuitos podría mejorar el desempeño de los estudiantes en un test relativo al tema de circuitos.

El primer experimento consistió en comparar un grupo control versus uno experimental. El grupo experimental jugaba en hacer movimientos con el circuito y justificaba cada movimiento a partir de una serie de opciones que se le proporcionaron. En el segundo experimento, participaron tres grupos, dos experimentales y uno de 
control. Uno experimental tuvo las mismas condiciones que en el experimento 1 y el otro debía escribir su propia explicación en lugar de seleccionar una del listado de opciones.

En ambos estudios, los grupos experimentales en los que los estudiantes podían elegir su auto explicación resultaron con mejor evaluación en el test. Sin embargo, llama la atención que en el segundo experimento el grupo control tuvo una mejor calificación que el grupo experimental que escribía su propia explicación. Esto da lugar a que los autores concluyan que estos estudiantes necesitan un apoyo mayor por parte de los profesores. También encuentran que el éxito del juego educativo Circuit Game se debió a que se combinó con una estrategia didáctica, en este caso, la autoexplicación.

En otro estudio desarrollado por Dzeng, Lin y Wang (2014) con estudiantes de la Universidad de Taiwán del curso de Negociación de Adquisiciones en la Administración de la Construcción, también se encontraron resultados positivos. De forma similar al estudio de Jhonson y Mayer (2010) se trabajó con tres grupos, un grupo control cuya clase se impartió de forma tradicional, un grupo experimental en el que utilizaron un juego de simulación de negocio en el que usaron cartas y formatos para escribir los registros de las negociaciones y el tercer grupo también utilizó el juego de simulación de negocio solo que montado en la web. 
A los tres grupos se les aplicó un pre y post test. Los grupos experimentales tuvieron un mejor desempeño en los post test con respecto a su respectivo pre test. Los resultados de los post test de los grupos experimentales fueron mayores que los del grupo control. Otro hallazgo interesante es que los participantes de los grupos experimentales opinaron que una clase tradicional debe acompañarse del juego y viceversa ya que esto le da mayor significado al tema y el aprendizaje se motiva más.

Recientemente, en el estudio de Hew, Huang, Chu y Chiu (2016) en el que, a partir de dos momentos, uno en el 2015 y otro en el 2015, evaluaron el impacto de un ambiente gamificado en el compromiso (engagement) cognitivo y conductual, así como en la percepción que los estudiantes ante un entorno gamificado. El estudio se llevó a cabo en la universidad de Hong Kong en donde participaron grupo control y experimental en ambos estudios. Tanto los grupos control como experimental tuvieron acceso a las mismas actividades de aprendizaje y al mismo tutor sin embargo el grupo experimental utilizó, según los autores, como mecánicas de juego: puntos, insignias y tableros. Hew et al. (2016) definen tres categorías a evaluar para ambos tipos de grupos: la autonomía, la competencia y el aspecto relacional. Para llevar a cabo el análisis comparativo utilizaron un diseño de investigación pre-post test, el nivel de dificultad y calidad de las actividades completadas, las vistas de los materiales, las aportaciones en los foros y un cuestionario para conocer las percepciones de los estudiantes. Aunque 
estadísticamente no hubo diferencia significativa en el pre-post test, se encontró que la calidad de las actividades desarrolladas por el grupo experimental fue superior a la del grupo control, además los estudiantes opinaron que disfrutaron la gamificación, por lo que Hew et al. (2016) concluyen que el uso de puntos, insignias y tableros incentivan poderosamente a los contextos educativos sin afectar el conocimiento factual.

Llama la atención, a manera de paréntesis, que siendo éste, un estudio reciente, los autores llaman a los puntos, insignias y tableros como mecánicas de juego cuando, el término es componentes (Werbach, 2015; Santiago, 2015; Bunchball, 2012). Lo que sugiere que aún no se ha sistematizado o modelizado el diseño de un ambiente gamificado y que se refieren a la gamificación cuando solo se ha utilizado una parte del sistema, en este caso, el uso de componentes. Esto mismo se observa en los estudios de Domínguez et al. (2013), Tsai et al. (2016) y Hanus y Fox (2015). Sin duda esto confirma que aún falta mucho por diseñar y más aún por investigar.

\subsubsection{Mecánicas de retos como elemento cognitivo de un ambiente}

gamificado. La mayoría de las investigaciones en torno al efecto de la gamificación en entornos educativos están direccionadas al aspecto motivacional de las que puede decirse que se encontraron más resultados favorables que desfavorables. Sin embargo, existen pocas investigaciones que encontraron resultados positivos en aspectos 
cognitivos (Mayer 2016, Herzig, Ameling, Wolf y Schill, 2015; Faiella y Ricciardi, 2015). Algunos investigadores proponen incluir problemas o actividades retadoras que incentiven la motivación intrínseca, la metacognición y la autorregulación del aprendizaje para favorecer un mayor aprendizaje (Hou y Li, 2014; Tu et al., 2015; Sánchez y Olivares, 2011). Es lo que en términos de Werbach y Hunter (2015) serían mecánicas de retos.

No obstante, es importante notar que una mecánica de reto por sí misma no es suficiente, debe estar inmerso en una dinámica y ligado a componentes para que se de una gamificación auténtica. La mecánica de retos puede combinarse con una mecánica de retroalimentación, estar inmersa de una dinámica emocional y ofrecer insignias o puntos como componentes (Werbach y Hunter, 2015). Por ejemplo, a través de la retroalimentación, el estudiante genera una emoción que lo lleva a reflexionar en lo que está haciendo, activando así el proceso metacognitivo (Villagrasa, Fonseca, Romo y Redondo, 2014). Una limitación en el estudio de Domínguez et al. (2013) fue que los estudiantes no contaron con retroalimentación oportuna y que hubieron fallas tecnológicas, que evidentemente no favorecieron la metacognición y emociones positivas.

Villalustre y del Moral (2014) concluyeron en su estudio que una experienica gamificada debe contar con una simulación (Pasin y Giroux, 2011) que plante un reto 
a superar de tal manera que el entorno se vuelva atractivo tanto en el área emotiva como congitiva. Así, los retos pueden comprometer significativamente a los estudiantes aumentando el nivel de concentración (Hamari et al., 2016) incluso, se puede incrementar la motivación intrínseca cuando se les estimula a que extiendan sus capacidades (Fullagar, Knight y Sovern, 2013; Borgers y Sproedt, 2015).

De hecho, Domínguez et al. (2013), Lee y Hammer (2011), y Nisbet y Williams (2009) sostienen que la gamificación tiene impacto en tres aspectos: el cognitivo, afectivo y social. Años atrás, Pulos y Sneider (1994) ya habían encontrado que un momento idóneo en el que estos aspectos convergen es cuando se expone al estudiante ante actividades donde hay dinámicas de juego. De esta forma se pueden vislumbrar que las mecánicas de retos juegan un papel importante en el área cognitiva y que en las dinámicas y en los componentes descansan los aspectos afectivos y sociales. Por ejemplo, Nisbet y Williams (2009) aplicaron actividades con mecánicas de retos y de competencia, encontrando que estas actividades atrajeron mayor interés que en los estudiantes que estuvieron bajo un tratamiento tradicional. El aspecto afectivo estuvo enmarcado por una dinámica de emocional en la que los estudiantes tenían chances u oportunidades para obtener la solución correcta, es decir, tuvieron una retroalimentación inmediata. Como ya se comentó anteriormente, el estudiante siente una emoción cuando sabe si su respuesta es correcta o incorrecta. El 
componente que utilizaron fue un sistema de puntos, los cuales se otorgaron por cada reto logrado.

En una investigación desarrollada por Rincón-Flores, Ramírez-Montoya y Mena (2016b) encontraron que, al aplicar la gamificación basada en mecánicas de retos en un curso de Cálculo Integral a estudiantes de Ingeniería se logró que el aprendizaje se sostuviera a largo plazo. Para el análisis de datos utilizaron dos pruebas, una posterior a la gamificación y una al finalizar el curso, las cuales fueron evaluadas a través del ciclo de modelación matemáticas de Blum y Leib (2007). Además encontraron que estuvieron presentes las dimensiones cognitiva, emocional y social (Nisbet y Williams, 2009; Domínguez et al., 2013), lo cognitivo en los retos, lo emocional en la respuesta inmediata que recibieron a las soluciones de sus retos y lo social en el uso de tableros a partir del cual los estudiantes podían visualizar el logro de cada equipo.

La gamificación no es exclusiva de entornos presenciales, virtuales o híbridos, actualmente se hacen esfuerzos para gamificar Cursos Masivos Abiertos en Línea (MOOC por sus siglas en inglés). Vaibhav y Gupta (2014) estudiaron el efecto de la gamificación en el enganche (engagement) o el interés en el aprendizaje de conceptos aburridos en un curso $\mathrm{MOOC}$ de inglés. Para el estudio emplearon un grupo control y uno experimental, las actividades del primer grupo fueron las tradicionales, 
particularmente lecturas. El segundo grupo utilizó una plataforma llamada quizlet.com, la cual contiene recursos gamificados como el de arrastrar palabras.

Como ya se abordó anteriormente, la retroalimentación inmediata provoca que el participante se implique con la actividad (Bunchball, 2012; Rodriguez y Santiago, 2015 y Werbach y Hunter, 2015). Los autores concluyeron en que la combinación de aprendizaje divertido y retos es positivo para la retención del aprendizaje (Vaibhav y Gupta, 2014). Ahora bien, para efecto de esta investigación se utilizará el modelo de gamificación de Werbach y Hunter (2015) gracias a que su enfoque holístico ya que integra las dimensines afectiva, cognitiva y social (Nisbet y Williams, 2009; Pulos y Sneider, 1994; Domínguez et al., 2013) así como por la estructura que permitirá un análisis más claro y profundo en la presente investigación. Mora, Riera, GonzálezGonzález y Arnedo-Moreno (2015) desarrollaron una revisión de literatura sobre diseños de ambientes gamificados y encontraron que el mejor modelo de diseño es el de Werbach y Hunter (2012). Finalmente, de la misma manera, para efecto de la presente investigación se establecen como elementos para el diseño y evaluación de retos dentro de una mecánica de reto a los siguientes:

1) Que sea estimulante, es decir que provoque una implicación en los aprendices (engagement), ante una situación simulada que evoque una misión. En otras palabras, que haga sentir al estudiante que se encuentra en un entorno diferente al 
aula tradicional y más cercano a la realidad del fenómeno que se desea estudiar (Villalustre y Del Moral; Pasin y Giroux, 2011; Riemer y Schrader, 2015; Connolly, Boyle, MacArthur, Hainey, y Boyle, 2012; Villagrasa, Fonseca, Romo y Redondo, 2014).

2) Que el estudiante pueda mostrar sus habilidades y conocimientos, es decir, que el proceso sean tan importante como el resultado de tal manera que la actividad demande un proceso cognitivo que exija el uso de sus habilidades y conocimientos, incluso que el estudiante pueda ir más allá (Hamari et al., 2016; Martin, Stephane, Rivale y Diller, 2007; Tsai et al., 2016; Johnson y Mayer 2010).

3) Que provoque una experiencia enfocada (flow experience). Se entiende por "Flow" como un estado de profunda concentración en una actividad que es intrínsecamente disfrutable, los participantes perciben su desempeño como grato y exitoso, siendo los resultados de la experiencia su propia experiencia (Csikszentmihalyi, 1997). Sin embargo se debe tener cuidado en el diseño se la actividad pues un reto más elevado que las capacidades de los participantes provocará ansiedad, una mecánica de retos baja y una alta capacidad puede provocar aburrimiento. Un equilibrio entre el nivel de dificultad y habilidades de los estudiantes puede provocar una experiencia de flow (Chang, Wu, Weng, y Sung, 2012; Nakamura y Csikszentmihalyi, 2002). 
4) Que haya retroalimentación inmediata (feedback). Cuando los participantes conocen el resultado de su desempeño de manera oportuna pueden experimentar emociones que lo estimulen en continuar con la actividad (Werbach y Hunter, 2015; Lee y Harmer, 2011) así como la activación de su proceso metacognitivo (Johnson y Mayer, 2010; Kafai y Burke, 2015; Tay, 2015)

5) Que el desempeño pueda ser reconocido por medio de compomentes tales como puntos, badges, trofeos, tableros, entre otros. Los componentes tienen la función de moticar extrísecamente a los participantes y también como medio para socializar sus progresos (Werbach y Hunter, 2015; Rodríguez y Santiago, 2015). 


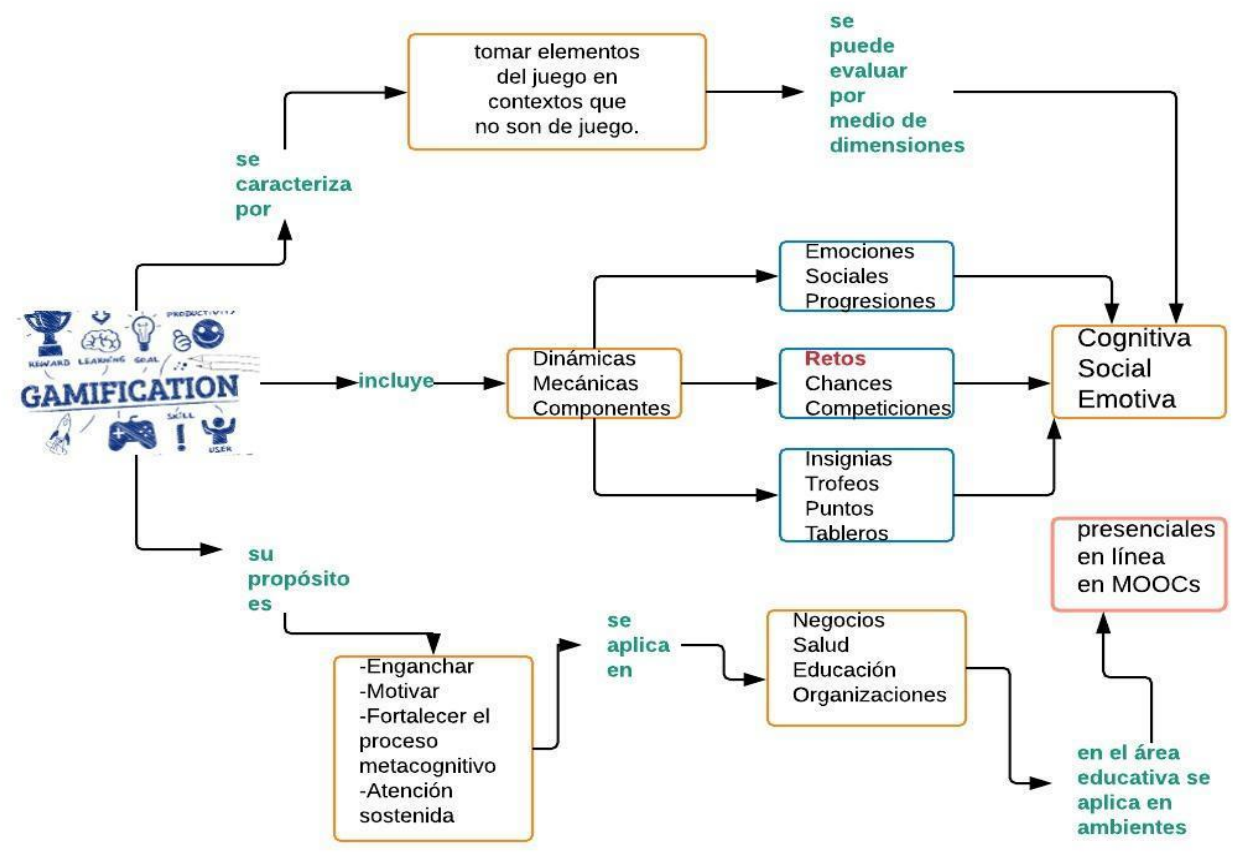

Figura 11. Esquema gráfico del constructo gamificación (Elaboración propia).

\subsection{Gamificacion en MOOC}

A pesar de que los $\mathrm{MOOC}$ han beneficiado a muchas personas alrededor del mundo a través del acceso abierto de la educación (Ramírez-Montoya, 2015), han sido objeto de diversas críticas. Por ejemplo, que subyacen en la teoría del aprendizaje del conductismo (Ping, 2013) que el estudiante no tiene apoyo de un tutor que le indique sus fallas (Xing, Chen, Stein y Marcinkowsky, 2016; Hone y El Said, 2016), que son aburridos o monótonos (Barak, Watted y Haick, 2015; Hew, 2016) y su baja tasa es terminal (Bartolomé-Pina y Steffens, 2015) entre otras.

No obstante, el crecimiento de los MOOC continua creciendo en diversas universidades alrededor del mundo (Zhou, 2016, Guijosa, 2018) y en el campo de los 
negocios (Olsson, 2016) ya que son una fuente de oportunidades. Al mismo tiempo, los MOOCs resultan idóneos para el desarrollo tecnológico de modelos pedagógicos (Hernández-Carranza, Romero-Corella y Ramírez-Montoya, 2015), en un contexto social, los MOOC permiten el acceso a diversos recursos educativos a una gran cantidad de usuarios (Aguaded-Gómez, 2013).

Por lo tanto, resulta importante incorporar estrategias didácticas innovadoras como la gamificación. Algunos investigadores como Vaibhav y Gupta (2016), BorrásGené, Martínez-Nuñez y Fidalgo-Blanco (2014), Alraimi, Zo y Ciganek (2015), Kaplan y Haenlein (2016), Hew (2016), Rincón-Flores, Ramírez-Montoya y Mena (2016a) así, como Ramírez-Donoso, Rojas-Riethmuller, Pérez-Sanagustín y Alario-Hoyos (2017) consideran que incluir recursos como la gamificación en los MOOCs podría contribuir a incrementar la motivación, la eficiencia terminal y por qué no, la mejora del aprendizaje o el nivel de desempeño.

Con el propósito de situar a la estrategia de gamificación en los MOOC se desarrolló un estudio a partir de una búsqueda en la literatura publicada en bases de datos de alto rigor científico, ver Tabla 12. Para llevar a cabo el estudio se siguieron las recomendaciones propuestas en los trabajos previos de Kitchenham, Pretorious, Budgen, Brereton, Turner, Niazi y Linkman (2010), Peterson, Feldt y Mujtaba (2008) y el de Pedreira, García, Brisaboa y Piattini (2014). 


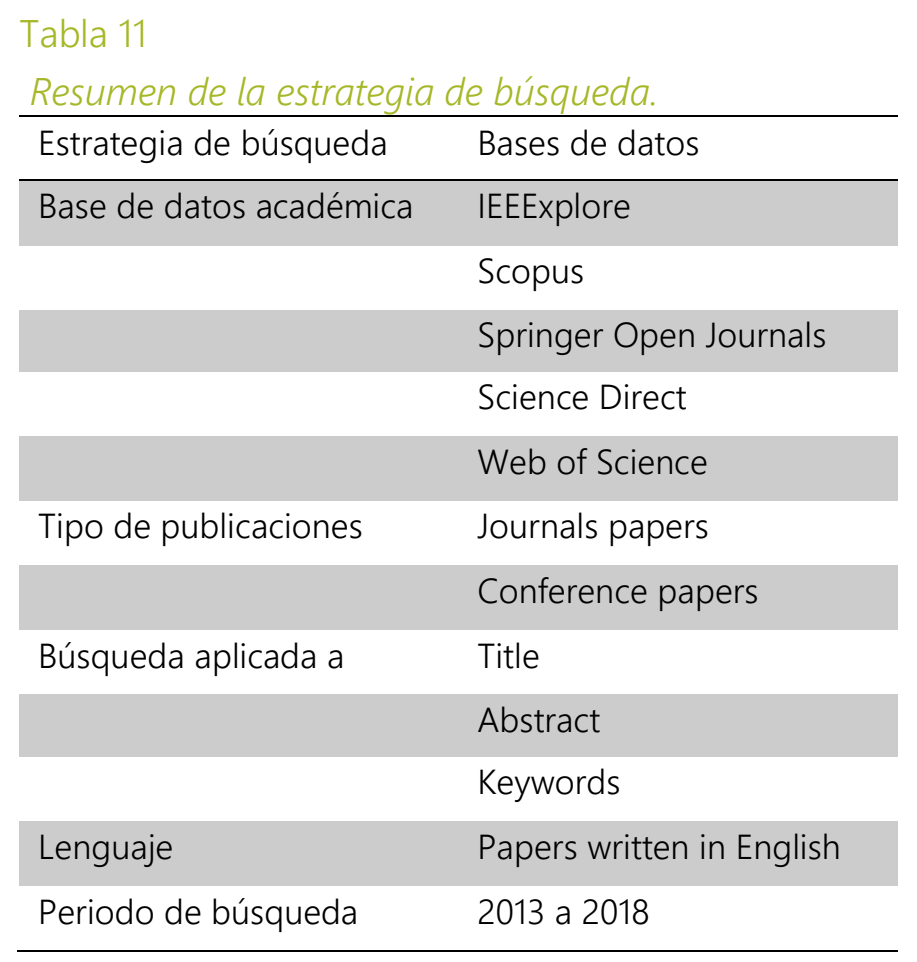

En la Figura 12 se resumen los resultados obtenidos de la primera búsqueda. En total se encontraron 495 trabajos de investigación de los cuales se eliminaron los duplicados y los que no servían al propósito de este estudio, por lo que la primera muestra se redujo a 40 artículos, luego se eliminaron los de carácter crítico o que hacían referencia a serious game, por lo tanto, la muestra finalmente quedó en 30 estudios. 


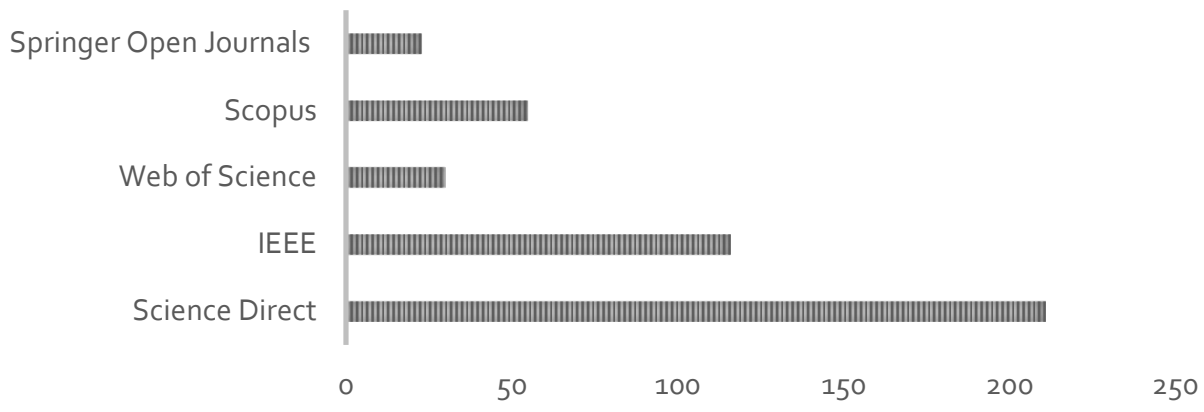

Figura 12. Resumen de los resultados de búsqueda en diversas bases de datos

Los criterios de exclusion fueron: a) publicaciones sobre serious games, b) publicaciones de antes del 2013 y c) publicaciones no arbitradas. Se establecieron ocho preguntas subordinadas con el propósito de profundizar en la investigación y conocer cómo se está aplicando la gamificación en los MOOC alrededor del mundo. Por otro lado, también se determinó cómo se ha estudiado esta temática (teóricamente, empíricamente) y en cuál tipo de foro se publicó. Así mismo, las preguntas subordinadas se agruparon en tres dimensiones: dimensión disciplinar, dimensión de investigación y dimensión de transferencia. Las preguntas de investigación se encuentran descritas en la Tabla 12. 
Tabla 12

Preguntas subordinadas de investigación del estudio.

\begin{tabular}{|c|c|c|}
\hline Dimensión & $\begin{array}{l}\text { Número de } \\
\text { Pregunta }\end{array}$ & Pregunta subordinada \\
\hline \multirow[t]{4}{*}{ Disciplinar } & RQ1 & $\begin{array}{l}\text { ¿Cómo se aplicó la gamificación en MOOC, sistema gamificado, } \\
\text { elemento de la gamificación? }\end{array}$ \\
\hline & RQ2 & ¿Qué elementos de la gamificación se aplicaron en los MOOC? \\
\hline & RQ3 & ¿Cómo se evaluó el efecto de la gamificación en MOOCs? \\
\hline & RQ4 & ¿A quién van dirigidos los MOOC gamificados? \\
\hline \multirow[t]{2}{*}{ Investigación } & RQ5 & $\begin{array}{l}\text { ¿Qué metodología de investigación se utilizó en los trabajos de } \\
\text { investigación (teórica, empírica)? }\end{array}$ \\
\hline & RQ6 & $\begin{array}{l}\text { ¿En qué tipo de publicaciones se encuentran los trabajos de } \\
\text { investigación publicados acerca de la gamificación con MOOCs? }\end{array}$ \\
\hline \multirow[t]{2}{*}{ Transferencia } & RQ7 & $\begin{array}{l}\text { ¿Cómo se evidenciaron los resultados obtenidos al incluir gamificación } \\
\text { en los } \mathrm{MOOC?}\end{array}$ \\
\hline & RQ8 & $\begin{array}{l}\text { ¿En qué medida la gamificación presentada en los estudios puede ser } \\
\text { replicada en otros MOOC? }\end{array}$ \\
\hline
\end{tabular}

Las preguntas se establecieron con la intención de guiar la investigación de una manera más ordenada para dar respuesta a cada dimensión. La dimensión disciplinar se refiere a aspectos directamente relacionados con la gamificación que proporcionen información sobre cómo se aplicó y a quién fue dirigida. La dimensión de investigación, se relaciona con los aspectos del tipo de investigación y publicación utilizada; y la dimensión de transferencia indagó sobre los resultados obtenidos y cómo la gamificación utilizada en cada estudio se podría replicar en otros contextos.

A continuación, se presentan algunos de los resultados más relevantes del estudio. 
2.4.1 Dimensión disciplinar. Esta dimensión está compuesta de cuatro preguntas subordinadas: ¿Cómo se aplicó la gamificación en MOOC (sistema gamificado, elemento de la gamificación)? „QQué elementos de la gamificación se aplicaron en los MOOC?, ¿Cómo se evaluó el efecto de la gamificación en MOOCs? y ¿A quién van dirigidos los MOOC gamificados? Los ítems están en el Apéndice I.

A partir de los estudios se encontró que la mayoría aplicaron elementos de la gamificación y solo dos de estos hicieron consciente en su investigación el diseño de su sistema gamificado. [A3], [A6] y [A7] ofrecen un sistema gamificado con dinámicas sociales pues los participantes pueden socializar sus resultados, las mecánicas dentro de esta dinámica son competiciones y recompensas. Los componentes dentro de esas mecánicas son puntos, badges, leaderboard o ledearboard team. En la figura 4 se muestra la distribución de las dinámicas y mecánicas que se determinaron a partir del modelo de Werbach y Hunter (2015). Los componentes fueron explícitos en cada estudio. 

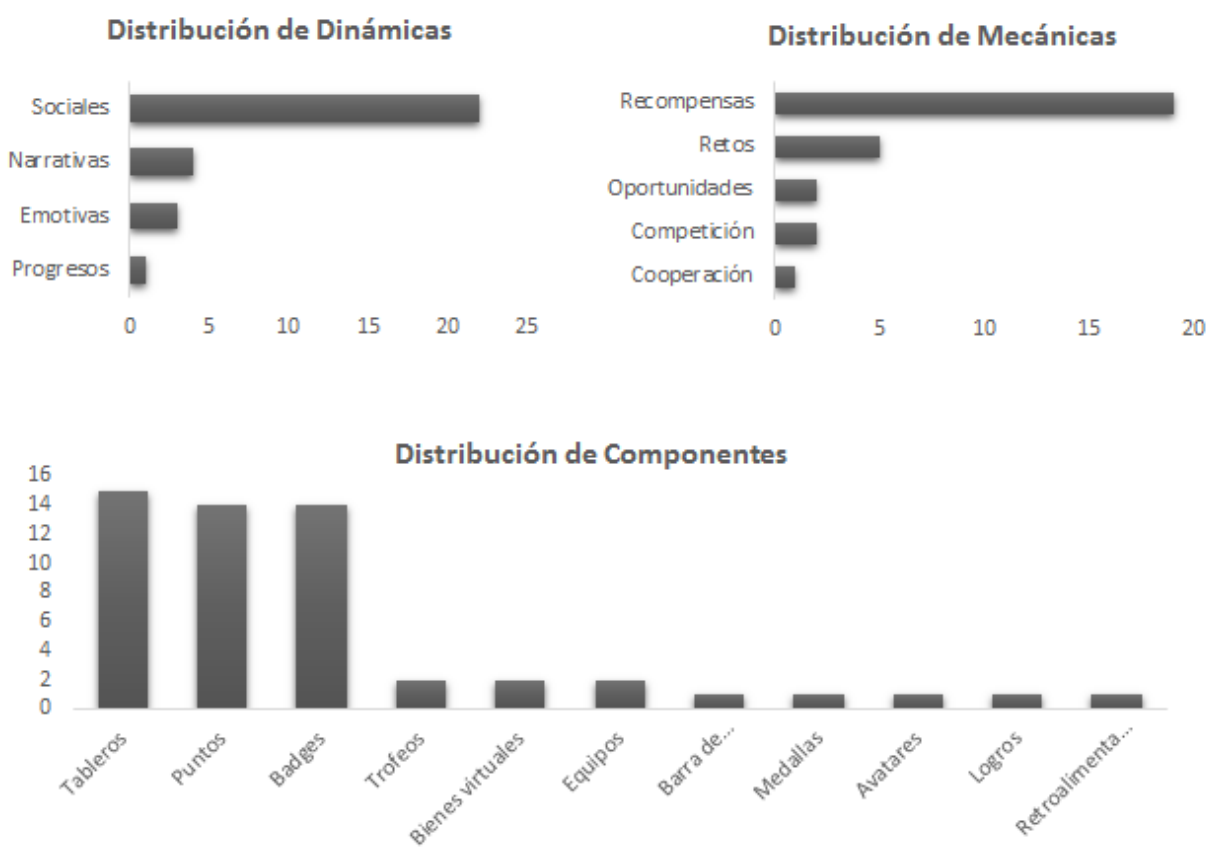

Figura 13. Distribución de las dinámicas, mecánicas y componentes.

En la Figura 13 se puede apreciar como la dinámica más popular es la social, la cuales promueven la interacción entre los participantes. Bogers y Sproedt (2016) desarrollaron un ambiente gamificado en un programa de postgrado dentro de un programa de innovación abierta interdisciplinario. Ellos encontraron que este tipo de dinámica ayuda a desarrollar competencias sociales que son requeridas en el ambiente laboral. La mecánica con mayor frecuencia es la recompensa seguida por la de retos y los componentes más utilizados son los puntos, badges y tableros. Las mecánicas de recompensa consisten en reconocer el éxito de los participantes a través de bienes materiales o virtuales mientras que los retos son aquellas tareas que requiere de un esfuerzo para resolverlas y que a la vez involucran límite de tiempo, habilidades o creatividad (Kocadere y Caglar, 2015). Los componentes relacionados a estas mecánicas 
pueden ser los badges, puntos y tableros. Para Hunter y Werbach (2015), los badges son las representaciones visuales de los logros, los puntos es la representación numérica de los logros y el tablero es la visualización socializada de los logros de los participantes. En la Tabla 13 se puede observar la distribución de los elementos de la gamificación por estudio según los modelos de Werbach y Hunter (2015) y Bunchball (2012).

\section{Tabla 13}

\begin{tabular}{|c|c|c|c|}
\hline Dinámicas & Ítems (publicaciones) & Componentes & Ítems (publicaciones) \\
\hline Emotivas & $\mathrm{A} 2, \mathrm{~A} 10, \mathrm{~A} 27$ & Logros & A29 \\
\hline Sociales & $\begin{array}{l}A 1, A 3, A 5, A 6, A 7, A 9, \\
A 12, A 13, A 15, A 16, A 17, \\
A 18, A 19, A 20, A 21, A 22, \\
A 23, A 24, A 25, A 26, A 27, \\
A 28, A 30\end{array}$ & Tableros & $\begin{array}{l}\text { A1, A7, A9, A10, A11, } \\
\text { A12, A13, A16, A17, } \\
\text { A18, A20, A23, A25, } \\
\text { A26 }\end{array}$ \\
\hline Narrativas & $\mathrm{A} 4, \mathrm{~A} 11, \mathrm{~A} 14, \mathrm{~A} 29$ & Barra de progreso & A8 \\
\hline Progresiones & A8 & Medallas & A5 \\
\hline Mecánicas & & Bienes virtuales & A6, A15 \\
\hline Reconocimientos & $\begin{array}{l}\text { A1, A2, A3, A5, A6, A7, A8, } \\
\text { A9, A12, A13, A15, A17, } \\
\text { A18, A20, A22, A24, A25, } \\
\text { A26, A30 }\end{array}$ & Puntos & $\begin{array}{l}\text { A4, A6, A10, A14, A16, } \\
\text { A18, A19, A22, A26, } \\
\text { A27, A28, A30 }\end{array}$ \\
\hline Oportunidades & $\mathrm{A} 10, \mathrm{~A} 27$ & $\begin{array}{l}\text { Tablero por } \\
\text { equipo }\end{array}$ & A6 \\
\hline Competiciones & A16, A23 & Trofeo & A6, A15 \\
\hline Cooperación & A21 & Avatares & A18 \\
\hline \multirow[t]{3}{*}{ Retos } & A4, A11, A14, A19, A28, & Insignias & $\begin{array}{l}A 1, A 2, A 3, A 5, A 6, A 7, \\
A 13, A 15, A 18, A 21, \\
A 22, A 24, A 30\end{array}$ \\
\hline & & Batallas & A3 \\
\hline & & Retroalimentación & A15 \\
\hline
\end{tabular}

Por otra parte, en la Tabla 14 se puede ver la distribución en cuanto a cómo se evaluó la gamificación en los estudios de la presente investigación. A partir de la 
muestra se encontraron seis categorías: calificaciones, a través de la literatura (otros estudios sobre gamificación), cuestionarios y entrevistas, analíticas del MOOC, tasa terminal y por medio de grupo control y experimental.

\section{Tabla 14}

\section{Evaluación de la gamificación en MOOC.}

\begin{tabular}{ll}
\hline \multicolumn{1}{c}{ Categorías } & \multicolumn{1}{c}{ Estudios } \\
\hline Calificaciones & A19, A30 \\
A través de la literatura & $\mathrm{A} 1, \mathrm{~A} 4, \mathrm{~A} 7, \mathrm{~A} 8, \mathrm{~A} 12, \mathrm{~A} 13, \mathrm{~A} 14, \mathrm{~A} 15, \mathrm{~A} 17, \mathrm{~A} 21, \mathrm{~A} 22, \mathrm{~A} 25, \mathrm{~A} 28$ \\
Cuestionarios y/o entrevistas & $\mathrm{A} 2, \mathrm{~A} 6, \mathrm{~A} 11, \mathrm{~A} 16, \mathrm{~A} 19, \mathrm{~A} 23, \mathrm{~A} 24$ \\
Analíticas & $\mathrm{A} 3, \mathrm{~A} 5, \mathrm{~A} 9, \mathrm{~A} 10, \mathrm{~A} 18, \mathrm{~A} 24, \mathrm{~A} 26, \mathrm{~A} 29$ \\
Tasa terminal & $\mathrm{A} 20$ \\
Grupo control vs experimental & $\mathrm{A} 27$ \\
\hline
\end{tabular}

Se puede observar que 13 estudios se apoyaron de la literatura previa sobre gamificación para justificar las ventajas de la estrategia mientras que el $56.7 \%$ de los estudios mostraron evidencias empíricas sobre la gamificación en MOOC.

Finalmente, el tipo de público al cual van dirigidos los $\mathrm{MOOC}$ de los estudios puede apreciarse en la Figura 14. 


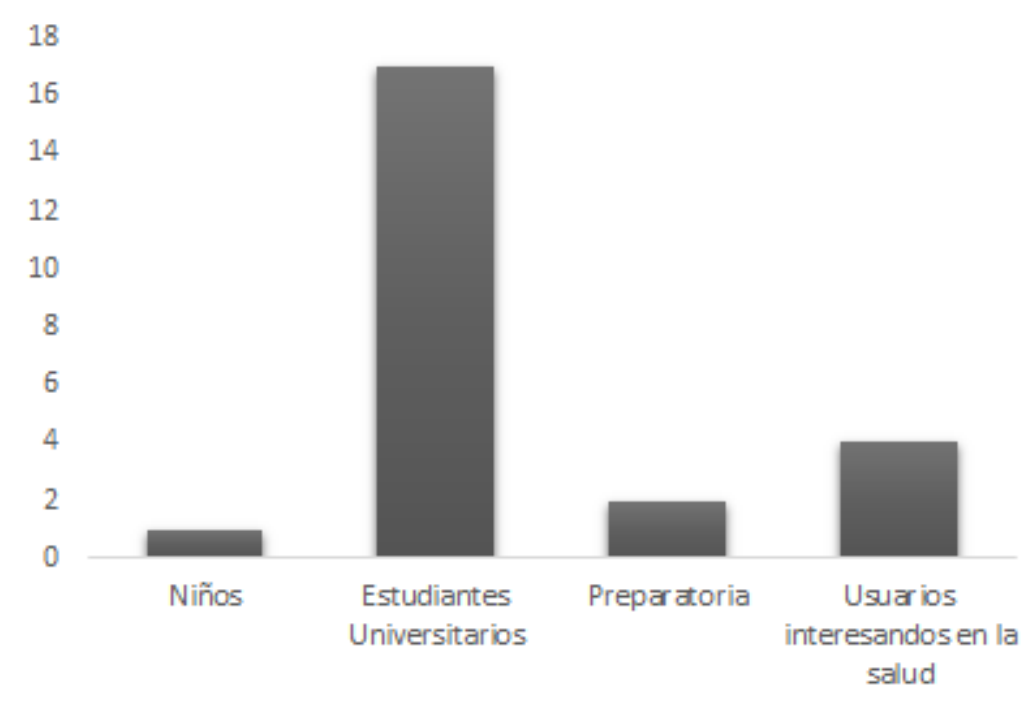

Figura 14. Distribución sobre el tipo de participantes en MOOCs con gamificación.

La mayoría de los MOOC van dirigidos a estudiantes universitarios, aunque llama la atención los estudios desarrollados en torno a usuarios interesados en el cuidado de la salud, quizás porque en la mayoría de estos interviene la industria farmacéutica.

2.4.3 Dimensión investigación. Los resultados obtenidos de la dimensión investigación estuvieron dirigidos por las preguntas alternativas: ¿Qué metodología de investigación se utilizó en los trabajos de investigación (teórica, empírica)? y en ¿qué tipo de publicaciones se encuentran los trabajos de investigación publicados acerca de la gamificación con MOOCs? Cabe señalar que de los 30 estudios revisados [A13] y [A27] tuvieron como propósito mejorar el aprendizaje, [A18], [A24] y [A30] aumentar la tasa terminal en MOOC, [A15] y [A25] incrementar la participación a través de la comunicación entre participantes y el resto se enfocó al engagement y motivation. 
Los estudios considerados como teóricos son aquellos que solo mostraron un modelo de gamification en $\mathrm{MOOC}$ o bien, que a partir de ciertos hechos investigados en su campo hacían recomendaciones sobre la gamificación en MOOC. (e.g. A4). Por otro lado, se consideraron como empíricas aquellas en las que se ejecutó, al menos un elemento gamificado, en el MOOC. Se puede observar en la figura 6, de manera casi esperanzadora, como las investigaciones empíricas tienen un porcentaje mayor a las teóricas, sin lugar a dudas gracias a los avances tecnológicos se podrá ver un avance acelerado de la inclusión de más y variados elementos gamificados en los MOOC.

Por otro lado, se observa que el porcentaje de investigaciones sobre este tema en revistas es menor que el de las conferencias, esto puede evidenciar que la línea de investigación sobre gamificación en MOOC está en una etapa emergente y que todavía queda mucho por construir. Por un lado, la tecnología seguirá facilitando la incorporación de la gamificación digitalizada en MOOC (Theisen, 2013; Amo, Sasán y Alier, 2013) sin embargo es necesario desarrollar investigaciones sobre el impacto de esas innovaciones en diversos aspectos educativos (Spector, 2014) de tal manera que la gamificación pueda llegar a una madurez investigativa.

2.4.4 Dimensión sobre transferencia. Los resultados de esta dimensión estuvieron dirigidos por las preguntas subordinadas: ¿Cómo se evidenciaron los resultados obtenidos al incluir gamificación en los MOOC? y en qué medida la 
gamificación presentada en los estudios puede ser replicada en otros MOOC? A partir de los resultados se pretende conocer hasta qué punto los modelos presentados en las investigaciones de la muestra permitirán transferirlos a otros contextos educativos. Se encontró que el 57\% de las investigaciones mostraron resultados empíricos mientras que el $43 \%$ solo muestran la experiencia didáctica o tienen un carácter dogmático. Esto confirma el hecho de que la línea de investigación sobre gamificación en MOOC está en desarrollo y que a pesar de la velocidad de los avances tecnológicos tomará varios años en consolidarse pues, aunque sea posible replicar los modelos de gamificación en MOOC en otros contextos, mucho de dependerá de los recursos con los que cuente el organismo que pretende educar o capacitar a través de cursos masivos, abiertos y en línea.

A excepción de las investigaciones A23, A24, A28 y A27 que competen a un área especializada como es la salud, todos los demás modelos podrían ser replicados en otros contextos, pero insistimos, al menos por ahora, esto dependerá del tipo de plataforma donde se pueda montar el MOOC y de los recursos con los que se cuente.

2.4.5 Conclusiones. Dentro de los resultados positivos se destacan los esfuerzos por mejorar el diseño didáctico de los MOOC, lo cual se hace evidente con la incorporación de estrategias didácticas innovadoras tales como la gamificación. También resulta interesante visualizar que el público, a quien van dirigidos los MOOC 
que incluyen la estrategia de gamificación, es heterogéneo, así mismo lo son las temáticas de los cursos, lo que ratifica la democratización de la educación a través de los MOOC.

Por otro lado, se encontró que la línea de investigación Gamificación en MOOC es emergente y que falta fortalecer la investigación científica, pues de la muestra utilizada para la presente investigación, el $67 \%$ de los estudios corresponden a conferencias, el 17\% de los estudios empíricos obtuvieron sus resultados a partir de analíticas o grupos control-experimental y se observó que de los 450 estudios encontrados en la primera búsqueda con cierta dificultad se logró obtener una muestra de 30 ítems.

En resumen, este capítulo ha abordado los temas de innovación, MOOCs, Gamificación y Gamificación en MOOC. La idea fue sentar las bases para comprender de que va la innovación y cómo se relaciona con los MOOC y con las estrategias didácticas como la Gamificación. Así, de esta manera se pudo evaluar el papel de la Gamificación en ambientes de innovación abierta, como los MOOC, paticularmente, los XMOOC.

A continuación se presenta el diseño metodológico que se llevó a cabo en este estudio, se describe la situación educativa en la que se hizo la recolección de información y se presentan los aspectos éticos que se consideraron en el transcurso de la investigación, como el manejo de los datos personales. 


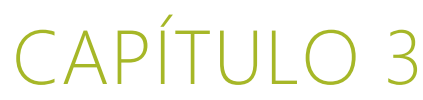

\section{METODOLOGÍA}

Considerando que el objetivo de esta investigación pretende valorar el impacto de la gamificación basada en retos que giran en torno a problemáticas sobre temas de energía y sustentabilidad, a partir de un xMOOC del sector energético, se optó por una metodología de tipo mixto, que permitiera ir de lo general a lo particular y así responder a las preguntas de investigación.

En este capítulo se aborda el diseño metodológico utilizado así como las fases que lo componen, no obstante en un primer momento se presenta el $\mathrm{xMOOC}$ en el cual se hizo la recolección de datos, explicando en qué consiste el curso, el temario y se muestra el reto gamificado. Esto con el propósito de situar al lector en el contexto didáctico en el cual se hizo la recolección de los datos y el estudio.

En un segundo momento se presentan las categorías de estudio y sus indicadores, las fuentes de información y el pilotaje de los instrumentos. En un tercer momento, se relata el diseño de cada fase de la investigación y dentro de cada una, se presenta la muestra así como la técnica de recolección de datos utilizada.

En un cuarto momento, se muestra el proceso para el análisis de los datos, así como los criterios de validez y confiabilidad. Al final del capítulo, se presentan los aspectos éticos, los cuales también tienen un papel relevante tanto en el diseño de la 
investigación como en la recolección y procesamiento de los datos, ya que delimitan el campo de acción.

\subsection{Situación educativa del marco de la investigación}

Para el desarrollo de los xMOOC-Energía se diseñó un modelo instruccional específico para el proyecto de Laboratorio Binacional, cuyo objetivo es la formación de talento adulto y a la reconversión de profesionistas en nuestro país en temas de sustentabilidad energética (Villegas et al., 2016). Dichos cursos se ofrecen a través de la plataforma MéxicoX. Cabe decir que MéxicoX es una plataforma abierta, de acceso libre, sin requisitos de admisión y gratuita. Cualquier persona desde cualquier parte del mundo que cuente con Internet y un correo electrónico puede inscribirse y obtener una constancia de participación si aprueba el curso (Valdivia et al., 2017).

Cada curso tiene una duración de seis temas en donde cada tema es abordado semanalmente. Durante cada tema y con el propósito de mantener activo al estudiante durante el curso, se ofrecen diversas actividades como videos, infográficos, networking, actividades gamificadas de repaso, evaluaciones y un reto gamificado, entre otras, ver Figura 15. 


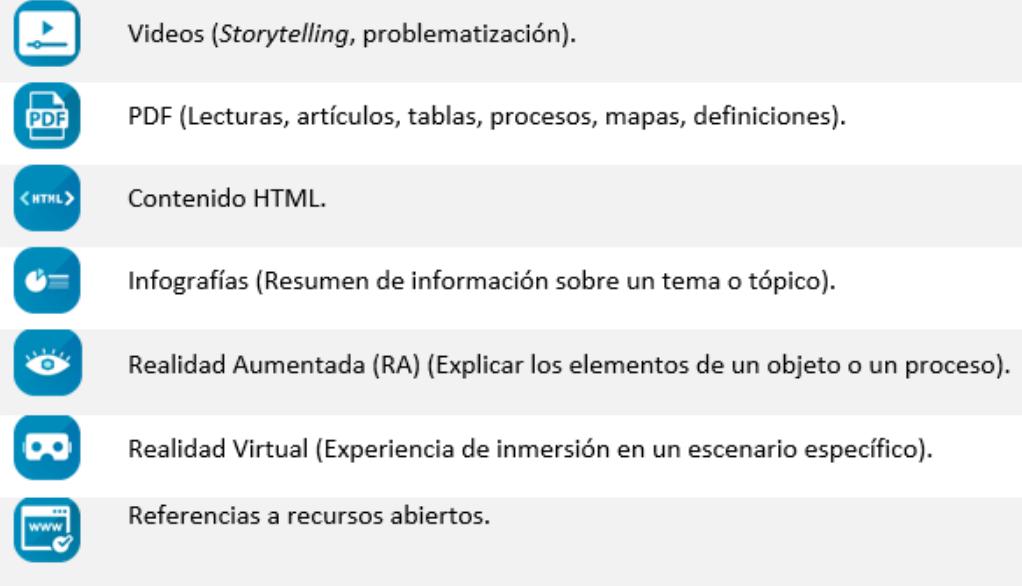

Figura 15. Algunas actividades de los xMOOC-Energía, (Villegas et al., 2016).

Cabe mencionar que algunos cursos tienen acceso a Laboratorios Remotos, a partir de los cuales, los estudiantes pueden desarrollar prácticas de laboratorio desde el lugar donde se encuentre. Así mismo, todos los cursos xMOOC-energía del proyecto Laboratorio Binacional, cuentan con la estrategia de gamificación basada en Retos.

Para el presente estudio se escogió el curso de Energías Convencionales, Limpias y su Tecnología (ECLyT), el curso es ofertado dos veces al año a partir de su lanzamiento en febrero del 2017 dentro de la plataforma MéxicoX (2018). El curso ECLyT fue seleccionado por las siguientes razones:

Se participó en las sesiones diseño en la que asistían los cuatro equipos de expertos, lo que permitió ver de cerca tanto el desarrollo instruccional como los contenidos de los cursos.

5n el curso se pilotearon los instrumentos $y$, 
Por qué es un curso que aborda los temas de las energías convencionales versus las energías limpias, problemática de gran importancia en la actualidad.

El objetivo el curso consiste en analizar las formas en las que se manifiesta la energía en diferentes situaciones de la vida diaria y del quehacer industrial, tomando una postura a favor de la diversificación en la producción de la energía; y, además hacer un análisis crítico de las energías limpias y convencionales para utilizar, racionalizar y aprovechar las energías dentro de la comunidad (López-Salinas, citado por Riofrío-Calderón, López-Salinas y Ramírez-Hernández, 2017, p. 98).

El curso Enegías Convencionales, Limpias y su Tecnología, al igual que los otros xMOOC del proyecto Laboratorio Binacional, consta de seis temas y cada uno, de cuatro subtemas, los cuales pueden ser accedidos desde la plataforma MéxicoX, si se está inscrito, o desde el portal de recursos educativos abiertos del Tecnológico de Monterrey (RITEC, 2018, http://temoa.info/es/node/768401).

Asimismo, tanto los temas como el desarrollo de los contenidos fueron definidos y desarrollados por un equipo experto en las temáticas de energías convencionales y limpias. Los temas seleccionados fueron los siguientes, lo cuales fueron explicados y resumidos por Riofrío-Calderón, López-Salinas y Ramírez-Hernández (2017, p. 112)

5ema 1. Energía, sus formas y su clasificación. Conocer dónde, cómo y cuándo se manifiesta la energía a través de la identificación de todas las variables y 
fenómenos que se relacionan con ella para reconocer el contenido energético y su calidad.

3. Tema 2. Energías convencionales. Identificar cuáles son las energías convencionales a través del estudio de diferentes recursos energéticos (carbón, petróleo, gas natural y uranio) y, las tecnologías principales utilizadas en procesos de generación de energía para comparar las ventajas y desventajas de cada proceso.

- Tema 3. Almacenamiento de energía. Comprender la importancia del almacenamiento de energía, así como los retos actuales en su implementación en la red eléctrica e identificar el papel que juega el tema del almacenamiento para lograr una sustentabilidad energética en el futuro.

Tema 4. Energía eólica e hídrica. Identificar el estado de desarrollo de las tecnologías eólicas e hidroeléctrica y la importancia de estos recursos en México y en el mundo a través del análisis de los diferentes ejes temáticos que rigen la utilización del recurso energético. Esto es para determinar el papel que tienen y tener estas tecnologías en el marco de un sector energético convertido en sustentable.

Tema 5. Energía solar y fotovoltaica. Identificar los principales tipos de tecnologías para la conversión de energía solar en térmica y eléctrica; $y$, conocer su aplicación y ventajas en el sector residencial, comercial e industrial.

19 Tema 6. Obtención de energía a partir de biomasa. Distinguir diversas formas de transformar biomasa en energía, a través de la identificación de los principales factores que intervienen en dicho proceso, además de reflexionar sobre la transformación de biomasa en energía así como de las oportunidades y posibilidades relacionadas con el mejor aprovechamiento de los recursos renovables.

El desarrollo de cada tema está acompañado de una serie de estrategias,

actividades y recursos que motivan al participante a permanecer activo durante el curso, pues a diferencia de la tasa terminal promedio a nivel mundial, la cual ronda el 5\% (Armstrong, 2014), el curso ECLyT impartido en Febrero del 2017 tuvo una tasa del $17 \%$ y del $13 \%$ en septiembre de ese mismo año. 
Los temas fueron desarrollados y abordados en los siguientes recursos: videos con texto, en donde se encuentra incorporada una autoevaluación, textos en HTML y PDF descargable, que consisten en la explicación a mayor detalle de los temas, infografías que los resumen manera gráfica y la bibliografía correspondiente a cada tema, así como un conjuntos de referencias complementarias para saber más, estos materiales también se encuentran dentro del repositorio RITEC.

Las actividades y sus ponderaciones, así como las estrategias de aprendizaje para el curso ECLyT se muestran a continuación:

5. Cada video cuenta con una autoevaluación al final del mismo.

19l final de cada tema se aplica una autoevaluación, las cuales tienen una ponderación de 5\% cada una en la calificación final.

Se cuenta con espacio de Networking o foros de discusió en los que los participantes responden a una de las preguntas relacionadas a las energías eólica e hídrica en México.

Práctica, es una actividad en la que através de un documento en línea, que el participante pone a disposición para que sea evaluada por pares, se da respuesta a todas las preguntas relacionadas a las energías eólica 
e hídrica en México presentadas en el Networking. Esta actividad tiene una ponderación del 20\% de la calificación final.

Al finalizar el tercer tema, se ofrece un ejercicio de práctica que cuenta con el componente gamificado de intentos (chances) a partir del cual el alumno puede reflexionar en su respuesta, en caso de equivocarse, para volver a intentar. Este ejericicio tiene una ponderación del 2\%.

Al final del curso se aplica una autoevaluación final, en la que se integran todos los temas del curso, el cual tiene una ponderación del 28\%.

En el ultimo tema se aplica la estrategia de Gamificación basada en retos, la cual tiene una ponderación del 20\% y que se explica a continuación.

El presente estudio se enfocó en la estrategia de gamificación basada en retos, la cual se aplica al final del curso, concretamente, en el Tema 6. El reto es un desafío en el cual, el participante debe aplicar algunos temas del curso en una situación real. Para el curso ECLyT, el reto consiste en seleccionar un combustible que provea calor e iluminación duradera contaminando lo menos posible. En la Figura 16 se muestran imágenes de la actividad. 
Tema 1. Energla, sus formas y su clasificación

Tema 2. Energlas convencionales

Tema 3. Almacenamiento de energla

Tema 4. Energia eolica e hidrica

Tema 5, Energ/a solary fotovoltaica

- Tema 6. Obtención de energia a partir de biomasa

\subsection{Transtormación} bacteriolidgica de biomasa (biogás)

6.2 Conversión tèrmica de biomasa (combustión)

6.3 Otros Biocombustibles a partir de biomasa

Reto

Reto

Tablero de liderazgo

6.4 Panorama actual en Mexico Evaluación de temg

Cierte
Combustibles para lluminación en casos de emergencia.

Fecha de entrega: para conocer la fecha de entrega del reto, revisa el botón agenda del menù superio

Objetivo: Prcponer cuà combustible seria ta mejor opción en caso de que requerir liuminación de emergencia que no provenga de la electricidad

Tema general o idea: Combustibles de uso cornin.

Pregunta esencia:

Durante arios, antes de la maskicación del servicio de electricidad, la humanidad usó combustibles para la iluminación incluso en ciertos lugares y en ocasiones especiale: todavia se sigue quemando combustible para este proposito. Combustibles como gasolina dissel o alcohol entre otros, se transforman en una fuente de energia representada en calce e îuminación al pasar por un proceso simple de combusticn que incluye la presencia de oxigeno y una chispa inicial. cubles son las caracteristicas de estos combustbles de uso común?

Reto:

Con el proceso de combustión en mente, imsgina que te encuentras en un campamento en el bosque y que débes resguardarte durante la noche en una cueva a causa de una posible tormenta. Antes de que oscurezca por completo, vas a buscar las lamparas que empacaste para alumbrar el terreno, pero te das cuenta que desafortunadamente olvidaste llevar baterias.

Entre las herramientas y materiales que tienes disponäles encuentras etanol, gasolina y diésel. Tú sabes que cualquiera de estos trea combustibles, en conjunto con un vaso de vidrio con tapa y las cirtas de tus zapatos, podria servir para elaborar una limpara que ayude a alumbras el terreno del campamento

A continuación te presentamos un video que muestra el proceso de combustión con los elementos antes mencionados. Observa con atención lo que ocurre con cada combustible y los tipos de llamas y el hollin que producen

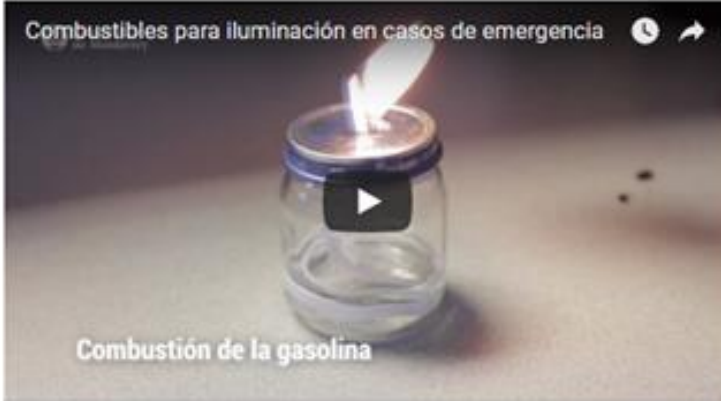

Figura 16. Mirada parcial del Reto Gamificado del curso ECLyT en la que se muestra la narrativa del reto y el acceso al video explicativo (López, 2017)

La actividad está acompañada de un video que provee información sobre

algunos combustibles (https://www.youtube.com/watch?time continue=6\&v=zHm3Uyy $4 z \mathrm{AE}$ ).

Una vez que el estudiante vió el video procede a responder el reto, para el cual tiene tres intentos. Si responde correctamente a la primera obtiene una copa de oro, a la segunda una copa de plata y a la tercera una copa de bronce. Luego, los resultados 
son publicados en un Tablero, al cual, todos los participantes tienen acceso (Ver Figura

17).

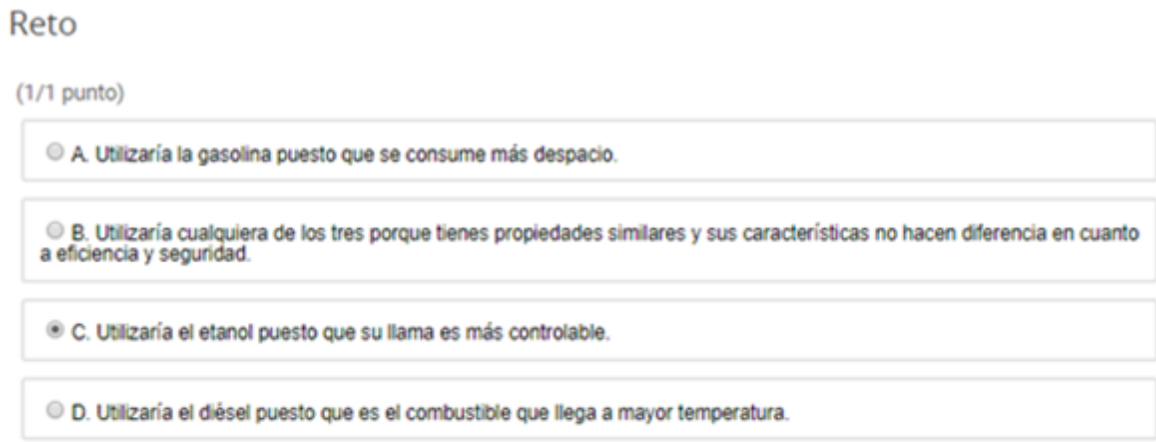

RESULTADOS DEL RETO 1

\begin{tabular}{|c|c|c|}
\hline Usuario & Tiempo en contestar & Número de intento \\
\hline juliansantinomtz & $00: 00: 03$ & 2 \\
\hline mercedtalamanteshiguera & $00: 02: 10$ & 1 \\
\hline gvbracamontes & $00: 00: 28$ & 2 \\
\hline AlexisFletes & $00: 00: 49$ & 1 \\
\hline Marvelta & $00: 00: 03$ & 4 \\
\hline miralburquerque & $00: 00: 03$ & 2 \\
\hline
\end{tabular}

Figura 17. Mirada parcial del Reto Gamificado y del Tablero del curso ECLyT, en el cual se muestra el nombre el usuario, el tiempo utilizado, el número de intentos y la insignia obtenida (López, 2017)

Como se puede ver, el curso Energías Convencionales, limpias y su Tecnología tiene una gran relevancia en la formación de temas de energía, pues como se abordó en el capítulo 1, uno de los retos más importantes a nivel mundial es producir energía 
limpia, no sin antes tener conocimiento sobre la energía convencional y cómo ha ido deteriorando el medio ambiente.

\subsection{Enfoque metodológico}

Para el desarrollo de la investigación se utilizó el método de investigación mixto (Creswell, 2015). Esta metodología se le considera el tercer paradigma y se caracteriza por el procesamiento de datos cuantitativos y cualitativos que, al ser combinados permiten una mejor comprensión del problema de estudio. Esta metodología permite observar un panorama general posibilitando ir a lo particular con respecto a: la relación entre la gamificación basada en retos y el diseño didáctico del xMOOC-Energía, el desempeño de los participantes, así como el nivel de innovación alcanzado a partir de sus propuestas en la solución de problemáticas relacionadas a las opciones energéticas autosustentables.

En otras palabras, la parte cuantitativa de la investigación fue la que marcó la pauta para el manejo y análisis de la gran cantidad de datos que nos proveyeron los xMOOC-Energía, mientras que la parte cualitativa permitió la focalización hacia casos puntuales con el propósito de profundizar en el desempeño y el nivel de innovación logrado. De esta manera no solo se pudieron analizar los datos desde lo general a lo particular, como lo sugiere una metodología mixta (Johnson y Onwuegbuzie, 2004), sino que también de manera contraria permitiendo hacer inferencias válidas y confiables. 
Así, el diseño metodológico en esta investigación fue de tipo explicativa secuencial: CUAN $\rightarrow$ CUAL (Tashakkori y Teddlie, 1998; Creswell, 2007), ya que el análisis de la etapa cualitativa explicó los resultados de la etapa cuantitativa (Castañer, Camerino y Anguera, 2012). Es decir, primero se hizo un análisis cuantitativo de la información obtenida a partir de las analíticas de los xMOOC-Energía, la minería de datos e instrumentos diseñados para esta investigación y luego se profundizó por medio del análisis cualitativo.

De la información cuantitativa, se seleccionaron ciertos participantes a fin de obtener información puntualizada sobre el desempeño, las dimensiones cognitivas, sociales y emotivas, que son relativas a la gamificación (Domínguez et al., 2013, Hannus y Fox, 2015; Williams y Nisbet, 2008) y el nivel de innovación alcanzado por los participantes (Schwartz et al., 2005; Jamiesan y Clark,2002; Eckerl y Kezer, 2003 y García-Fanjón y Rodríguez, 2003).

La información cualitativa se obtuvo a través de cuestionarios aplicados a los participantes, entrevistas aplicadas a miembros de los equipos de expertos $y$, a partir del análisis de las soluciones alternativas del Reto Gamificado, propuestas voluntariamente por los participantes del curso ECLyT. En la Figura 17 se muestra el diseño metodológico. 


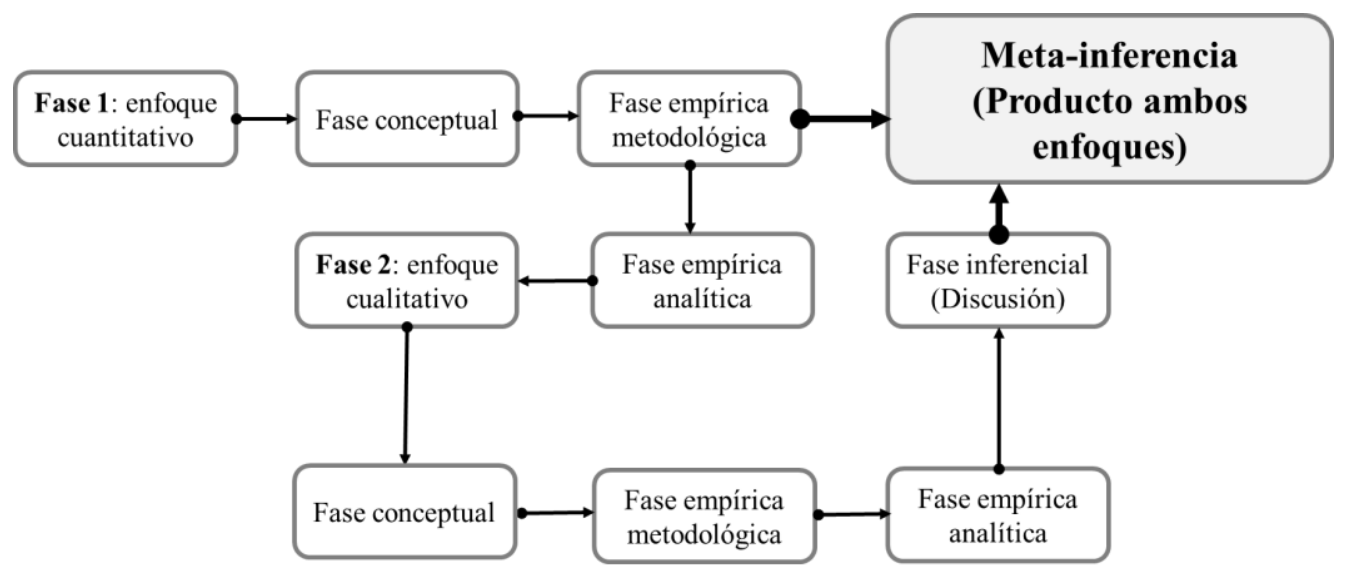

Figura 18. Diseño de investigación mixta tipo explicativa secuencial en dos fases de nuestro estudio (adaptado de Creswell y Plano-Clark, 2007).

Tal y como se muestra en la Figura 18, en la parte cuantitativa el estudio fue de tipo correlacional (Onwuegbuzie y Teddlie, 2003) mientras que en la parte cualitativa, fue un estudio de tipo fenomenológico (Pereira, 2011). En otras palabras, los resultados cuantitativos permitieron establecer correlaciones entre la gamifación basada en retos y los aspectos sociodemográficos, de desempeño y tipo de curso, para establecer relaciones y si es posible, determinar clusters. Mientras que la parte cualitativa profundizó en el nivel de innovación de cada cluster y las dimensiones cognitiva, social y emotiva.

En otras palabras, en la Fase 1, se hizo una revisión de la literatura en torno a los constructos de este estudio (Innovación, MOOC y gamificación), luego se recogieron los datos a partir de los siguientes instrumentos: (1) un cuestionario de inicio y final, (2) un cuestionario sobre las dimensiones de la gamificación y (3) las analíticas del curso. 
Esta información fue triangulada y se hicieron inferiencias a priori. En la Fase 2 se aplicaron entrevistas a cada uno de los actores de la investigación para comparar, complementar y profundizar, los hallazgos encontrados en la Fase 1. De esta manera general se obtuvieron y procesaron los datos para luego ser analizados.

\subsection{Categorías e indicadores de estudio}

Para identificar las categorías e indicadores de estudio se elaboró un cuadro de triple entrada (Ramírez-Montoya, 2016b), el cual puede encontrarse en el Apéndice II. La identificación de las categorías e indicadores surgieron a partir de la problemática de estudio, de la literatura revisada así como de los objetivos que condujeron la presente investigación.

Las categorías que se definieron fueron: 1) Innovación abierta, interdisciplinaria y colaborativa, 2) Los MOOCs como ambientes de Innovación Abierta 3) El papel de la Gamificación en la educación. Para fines de este estudio, se consideró a la Innovación como aquella que permite mejorar lo que ya se hace (García-Peñalvo, García de Figuerola y Merlo, 2010; Ramírez-Montoya, 2012; Fidalgo-Blanco, 2014), vista desde diferentes tipos como: disruptiva, incremental o evolutiva y abierta (Christensen, Johnson y Horn, 2011; García-Manjón y Rodríguez-Escobar, 2011; King y Lakhani, 2013;

Gustetic, Crusan, Rader y Ortega, 2015) . 
El concepto de innovación en relación con la gamificación se analizó desde dos perspectivas:

1) La relación entre la gamificación basada en retos y la innovación educativa en un xMOOC, en otras palabras, de qué manera la gamificación basada en retos mejoró el desempeño general y la tasa terminal en los XMOOC-energía.

2) La relación de la gamificación basada en retos y el nivel de innovación logrado por los estudiantes del xMOOC-Energía, esto es, cuál fue el nivel de innovación alcanzado por los participantes al desarrollar el reto gamificado.

Para la categoría, los MOOCs como ambientes de Innovación Abierta, se consideró el concepto de los $\mathrm{MOOC}$, los cuales son cursos masivos, abiertos y en línea y que se caracterizan por llegar a una gran cantidad de personas en cualquier lugar del mundo ( Vázquez-Cano, López-Meneses y Sarasola 2013), siempre y cuando se cuente con internet y una computadora. Los MOOC resultan un espacio en el que se pueden establecer redes entre personas de diferentes ciudades o países (Aguaded, 2015). Permitiendo así el intercambio de conocimiento y la creación de soluciones ante problemáticas reales a través del trabajo colabortativo e interdisciplinario (Kaplan y Haenlein, 2016), abonando al movimiento en abierto (Ramírez-Montoya, 2015). 
En cuanto a la tercera categoría, el papel de la gamificación en la educación se ha abordado el concepto de la gamificación como una estrategia educativa que toma elementos del juego en contextos que no son del juego (Deterding et al., 2011). La cual tiene el propósito de implicar y motivar al estudiante (Borrás-Gené, Martínez-Nuñez y Fidalgo-Blanco, 2016; Hamari, 2016; Gruman et al., 2010, Rosas-Magallanes, 2016). Para el diseño y desarrollo de la gamificación en el xMOOC-energía se consideró el modelo de Werbach y Hunter (2015) a partir del cual, y de las limitaciones tecnológicas, se estableció un modelo con dinámica social y emocional, con mecánicas de retos y reconocimientos, en las que el tablero y las copas de oro, plata y bronce, se establecieron como componentes.

Las variables anteriores se establecieron con el propósito de explicar la relación entre la gamificación basada en retos y el desempeño de los participantes, particularmente en los ambientes de innovación abierta sobre temas de sustentabilidad energética: XMOOC-Energía. Para ello se determinó a la Gamificación Basada en Retos como la variable independiente y a la innovación como la variable dependiente.

\subsubsection{Indicadores de la Categoría 1: Innovación abierta, interdisciplinaria y}

colaborativa. Los indicadores definidos para esta categoría son: tipo de innovación (disruptiva o revolucionaria, incremental o evolutiva y abierta), niveles de innovación 
(impacto, claridad, conocimiento, tipo de innovación y tipo de innovador), trabajo colaborativo y trabajo interdisciplinario.

3.3.1.1 Innovación disruptiva o revolucionaria. Es el proceso en el que se utilizan tecnologías sofisticadas para transformar en algo simple y económico lo que anteriormente era complejo y costoso (Christensen, Raynor y McDonald, 2015). Lo que provoca cambios revolucionarios y representa un punto de inflexión para las prácticas existentes (CONACYT, 2018).

3.3.1.2 Innovación incremental o evolutiva. Se refiere a la introducción paulatina de mejoras en los proceso o productos ya establecidos (García-Manjón y RodríguezEscobar, 2011), se mejora a partir de los mismos productos y servicio sin necesidad de desarrollar cambios importantes en la manera de hacer las cosas dentro de una empresa o institución (De Miguel, 2016; Fidalgo-Blanco, 2014, Ramírez-Montoya, 2014). Es decir, se mejora a partir de una base conceptual ya existente (CONACYT, 2018).

3.3.1.3 Innovación abierta. Descansa en un proceso de networking a partir del cual se generan nuevas ideas o proyectos a partir del uso deliberado de entradas y salidas de conocimiento, para acelerar la innovación interna (Chesbrough, Vanhaverke y West, 2008; Gustetic, Crusan, Rader y Ortega, 2015; King y Lakhani, 2013). Esta idea asume que las ideas de innovación provienen de agentes internos y externos (González et al., 2017). 
Por otro lado, los niveles de innovación son indicadores basados en la potencialidad de las organizaciones o individuos para idear, planear y realizar innovaciones a partir de los recursos con los que se dispone (Romero, Rébori y Camio, 2010; Wonglimpiyarat, 2010), redituando en mejores prácticas educativas (Rubia, Anguita, Jarrín y Ruiz, 2010). A continuación se describen los indicadores.

3.3.1.4 Nivel de impacto. Es el alcance de la innovación en cuanto a su profundidad y extensión (Eckel y Kezar, 2011), es decir cuáles son sus raíces y a qué cantidad de personas beneficia (Zabalza y Zabalza, 2012).

3.3.1.5 Nivel en cuanto a la claridad. Se refiere a la facilidad de comprender en que consiste la innovación así como al nivel de viabilidad (Romero, Rébori y Camio, 2010, Zabalza y Zabalza, 2012).

3.3.1.6 Nivel en cuanto al conocimiento. Este indicador se refiere al sustento teórico que está implicado en la innovación y al mismo tiempo, a que atienda a las necesidades del entorno en el cual se suscribe la propuesta (García Manjón y Rodriguez, 2011; Valenzuela, 2017 y López-Islas, 2017).

3.3.1.7 Nivel en cuanto al tipo de innovación. El tipo de innovación tiene que ver con el nivel de disruptividad de la innovación, es decir en cuál tipo se ubica, innovación incremental (García-Manjón y Rodríguez-Escobar, 2011; De Miguel, 2016 y CONACYT, 
2018) abierta (Chesbrough, Vanhaverke y West, 2008; González et al., 2017; Gustetic, Crusan, Rader y Ortega, 2015; King y Lakhani, 2013; Ramírez-Montoya, 2015) o disruptiva (Christensen, 2012; Christensen, Raynos y McDonald, 2015; CONACYT, 2018).

3.3.1.8 Nivel en cuanto al tipo de innovador. Es un nivel taxonómico desarrollado por Lozano-Rodríguez y Gallardo (2017) en el que se definieron tres niveles de acuerdo con el involucramiento, considerando los niveles de experimentación y divulgación.

\subsubsection{Trabajo colaborativo en la dinámica de la Innovación. Es una dinámica en} la cual se unen esfuerzos de diferentes individuos con la finalidad de lograr resultados (García-Valcárcel et al., 2012), el cual se da en un contexto en el que haya responsabilidad individual, interdependencia positiva, interacciones frente a frente, desarrollo de habilidades interpersonales y proceso de grupo (Neri, Noguez y Alanís, 2017)

3.3.1.10 Trabajo interdisciplinario en la dinámica de la Innovación. Son los grupos conformados con miembros de distintas disciplinas, provocando una mayor estimulación cognitiva que desarrolle nuevas asociaciones y, como consecuencia de ello, se creen ideas originales (Bi y Yang, 2014; Jar, 2010; Hernández-Pozas y Neri, 2017).

\subsubsection{Indicadores de la Categoría 2: El papel de la gamificación en la educación.}

Para esta categoría se establecieron cuatro indicadores: dimensión cognitiva, 
dimensión social, dimensión emotiva y enganche en la gamificación basada en retos (engagement).

\subsubsection{Dimensión cognitiva en la gamificación basada en retos. Se relaciona con} el proceso metacognitivo y de autorregulación que se genera dentro de una actividad gamificada (Hamari et al., 2016; Koivisto et al., 2016; Sailer, Hense, Mayr y Mandl, 2017) generando un proceso de inmersión y de enganche (Alsawaier, 2018).

\subsubsection{Dimensión social en la gamificación basada en Retos l. Se refiere al nivel de} interactividad entre los participantes así como a los efectos de la socialización de los

resultados y reconocimientos, tales como la generación de enganche o competitividad (Hanus \& Fox, 2015; Rincón-Flores, Ramírez-Montoya y Mena, 2016b; Domínguez et al," 2013, Lee \& Hammer, 2011; Khalil, Ebner y Admiraal, 2017).

3.3.2.3 Dimensión emotiva en la gamificación basada en Retos. Está relacionada con el sentimiento que se genera cuando el participante recibe retroalimentación inmediata de sus respuestas y con qué emoción se enfrenta cuando recibe un reconocimiento como insignia o badges (Hamari 2015, Faiella y Ricciardi, 2015; Mekler et al., 2013 y 2015; Yildirim, 2017; Kyewski y Krämer, 2018; Rojas-López y Rincón-Flores, 2018). 
3.3.2.4 Enganche (engagement) de la gamificación basada en retos. Se refiere a la capacidad de inmersión o el nivel de flujo alcanzado en el desarrollo de una actividad (Hamari y Koivisto, 2015; Hamari et al., 2016), es decir, es la cantidad de energía aplicada en acciones y logro de tareas (Gruman, Holmes-Rovner, French, Jeffres, Sofaer, Shaller \& Prager, 2010; Freudmann \& Bakamitsos, 2014; Kyewski y Krämer, 2018) en donde los individuos se muestran gozosos y exitosos (Admiraal, Huizenga, Akkerman y Damm, 2011).

\subsubsection{Indicadores de la Categoría 3: Alcance disruptivo del xMOOC-Energía. Los}

indicadores de esta categoría fueron: democratización del aprendizaje, calidad del diseño didáctico y modelo de innovación abierta.

3.3.3.1 Democratización del aprendizaje. Es uno de los atributos de los MOOCs que los caracteriza por ser un medio accesible para la educación ya que permite que los estudiantes tengan acceso a una variedad de recursos educativos, mayormente de forma gratuita (Vázquez-Cano, López-Meneses y Sarasola 2013; Olsson, 2016). Además, la democratización promueve interrelaciones entre personas de todas partes del mundo (Aguaded-Gómez, 2013).

3.3.3.2 Calidad del diseño didáctico. Se refiere a que un MOOC de calidad forma parte de un ecosistema versátil que satisface las demandas de los usuarios de tal manera que puedan organizar sus propios aprendizajes y que puedan contar con un eficaz sistema 
de comunicación (Del Moral y Villalustre, 2015; Villegas et al., 2016; Fernández-Díaz, Rodríguez-Hoyos y Calvo, 2017). Lo que implica dar buena impresión, claridad en las instrucciones, videos cortos y claros, diversidad de recursos de calidad, estrategias didácticas innovadoras, espacios para la colaboración y presencia de la institución educativa responsable (Castaño y Cabero, 2013; Méndez-García, 2015).

3.3.3.3 Modelo de innovación abierta. Se refiere a que si la dinámica del diseño del MOOC descansa en un proceso de networking, en donde las ideas de innovación provienen de agentes internos y externos (González et al., 2017) entre diversos grupos interdisciplinarios (Hernández-Pozas, 2017) y colaborativos (Neri, Noguez y Alanís, 2017). Generando y diseminando nuevo conocimiento (García-Peñalvo, García de Figuerola y Merlo, 2010; Ramírez Montoya, 2015; UNESCO, 2012; Valerio, 2017; Yañez et al., 2017).

\subsection{Fuentes de información}

Para el estudio se consideraron las siguientes fuentes de información para la recopilación de datos.

2. Participantes. Los estudiantes del curso Energías, convencionales, limpias y su tecnología, pertenecientes al sector energía proporcionaron información sobre su desempeño, la participación en el reto gamificado y la información sobre las dimensiones de la gamificación. Esta fuente de información dio respuesta a las tres categorías, a la primera con respecto a los indicadores 
de tipo de innovación (disruptiva, incremental y/o abierta), nivel de impacto, de claridad, de conocimiento, tipo de innovador. Con respecto a la segunda categoría, con respecto a los indicadores dimensión cognitiva, social, emotiva y el enganche. Finalmente, con respecto a la tercer categoría se relaciona con la calidad del diseño didáctico.

Artefactos. Cuatro cursos $\mathrm{xMOOC}$ desarrollados para el sector energético los cuales, fueron el escenario para el trabajo de campo ya que sirvió de marco contextual para la aplicación de los instrumentos cuantitativos y cualitativos. Esta información se relacionó con las tres categorías, con la primera con respecto a los indicadores: tipo de innovación (disruptiva, incremental y/o abierta), trabajo colaborativo y trabajo interdisciplinario. En la segunda categoría se relacionó con los indicadores: enganche, las dimensiones cognitiva, social y emotiva. Con respecto a la tercera, con los indicadores: democratización, calidad del diseño y modelo de innovación abierta.

Productos de los participantes. Los cuales fueron las propuestas alternativas al reto gamificado Combustibles para iluminación en casos de emergencia del curso ECLyT. Ésta fuente de información dio respuesta a la primera 
categoría con los indicadores: nivel de impacto, nivel de claridad, nivel de conocimiento, tipo de innovación y tipo de innovador.

Diseñadores y profesores expertos en MOOC. Los cuales proveyeron información para evaluar la calidad del diseño de la actividad gamificada y su impacto en el xMOOC cono estrategia innovadora. Esta fuente se relacionó con las categorías 1 y 3 , con la primera con respecto a los indicadores: tipo de innovación (disruptiva, incremental y/o abierta), nivel de impacto, nivel de claridad, nivel de conocimiento, tipo de innovador, trabajo colaborativo y trabajo interdisciplinario. Con respecto a la tercera categoría se relacionó con los indicadores: democratización, calidad del diseño y modelo de innovación abierta.

Material digital. Artículos de Scopus, WOS, libros, videos y revistas que permitieron conocer el estado del arte de las variables involucradas en el estudio, así como para comparar y validar los resultados obtenidos. Esta fuente de información se relacionó con las tres categorías y sus respectivos indicadores.

En la Tabla 15 se indican los datos que proporcionó cada fuente de información para el estudio, las categorías e indicadores asociados a cada fuente y qué tipo de técnica de recolección de datos se utilizó para este propósito. 
Tabla 15

Fuentes y técnicas de recolección de datos.

\begin{tabular}{|c|c|c|c|}
\hline Fuente & Datos que proporcionó & Categorías e indicadores & $\begin{array}{l}\text { Técnica de } \\
\text { recolección de datos }\end{array}$ \\
\hline Participantes & $\begin{array}{l}\text { Información cuantitativa } \\
\text { y cualitativa sobre el } \\
\text { desempeño y las } \\
\text { dimensiones cognitiva, } \\
\text { social y emotiva. }\end{array}$ & $\begin{array}{l}\text { Categoría 1, indicadores: tipo de } \\
\text { innovación (disruptiva, incremental } \\
\text { y/o abierta), nivel de impacto, de } \\
\text { claridad, de conocimiento, tipo de } \\
\text { innovador. } \\
\text { Categoría 2, indicadores: dimensión } \\
\text { cognitiva, social, emotiva y el } \\
\text { enganche. } \\
\text { Categoría 3, indicadores: calidad del } \\
\text { diseño didáctico. }\end{array}$ & $\begin{array}{l}\text { Cuantitativos: } \\
\text { cuestionarios de } \\
\text { inicio y final e } \\
\text { instrumento sobre } \\
\text { dimensiones. } \\
\text { Cualitativo: } \\
\text { entrevistas }\end{array}$ \\
\hline $\begin{array}{l}\text { Artefactos. Curso } \\
\text { xMOO-ECLyT }\end{array}$ & $\begin{array}{l}\text { Información cuantitativa } \\
\text { sobre el desempeño en } \\
\text { los cursos. }\end{array}$ & $\begin{array}{l}\text { Categoría 1, indicadores: tipo de } \\
\text { innovación (disruptiva, incremental } \\
\text { y/o abierta), trabajo colaborativo y } \\
\text { trabajo interdisciplinario. } \\
\text { Categoría 2, indicadores: enganche, } \\
\text { las dimensiones cognitiva, social y } \\
\text { emotiva Categoría 3, indicadores: } \\
\text { democratización, calidad del diseño y } \\
\text { modelo de innovación abierta }\end{array}$ & $\begin{array}{l}\text { Cuantitativos: } \\
\text { analíticas del curso. }\end{array}$ \\
\hline $\begin{array}{l}\text { Productos de los } \\
\text { participantes }\end{array}$ & $\begin{array}{l}\text { Información cualitativa } \\
\text { sobre el nivel de } \\
\text { innovación potencial } \\
\text { alcanzado en las } \\
\text { propuestas de los } \\
\text { participantes. }\end{array}$ & $\begin{array}{l}\text { Categoría 1, indicadores: nivel de } \\
\text { impacto, nivel de claridad, nivel de } \\
\text { conocimiento, tipo de innovación y } \\
\text { tipo de innovador. }\end{array}$ & $\begin{array}{l}\text { Cualitativo: Rúbrica } \\
\text { de análisis } \\
\text { significativo (ver } \\
\text { Apéndice VII) }\end{array}$ \\
\hline $\begin{array}{l}\text { Diseñadores y } \\
\text { profesores } \\
\text { expertos en } \\
\text { xMOOC }\end{array}$ & $\begin{array}{l}\text { Información cualitativa } \\
\text { sobre el diseño y calidad } \\
\text { del reto gamificado. }\end{array}$ & $\begin{array}{l}\text { Categoría 1, indicadores: tipo de } \\
\text { innovación (disruptiva, incremental } \\
\text { y/o abierta), nivel de impacto, nivel } \\
\text { de claridad, nivel de conocimiento, } \\
\text { tipo de innovador, trabajo } \\
\text { colaborativo y trabajo } \\
\text { interdisciplinario. } \\
\text { Categoría 3, indicadores: } \\
\text { democratización, calidad del diseño y } \\
\text { modelo de innovación abierta. }\end{array}$ & $\begin{array}{l}\text { Cualitativos: } \\
\text { entrevista a los } \\
\text { participantes, } \\
\text { diseñadores y } \\
\text { profesores expertos } \\
\text { en xMOOC. }\end{array}$ \\
\hline Material digital & $\begin{array}{l}\text { Información sobre } \\
\text { investigaciones } \\
\text { científicas de los temas } \\
\text { que forman parte de la } \\
\text { investigación y que } \\
\text { permitieron el diseño de } \\
\text { la rúbrica de análisis } \\
\text { significativo y del } \\
\text { instrumento sobre } \\
\text { dimensiones de la } \\
\text { gamificación. }\end{array}$ & $\begin{array}{l}\text { Esta fuente de información se } \\
\text { relacionó con las tres categorías y sus } \\
\text { respectivos indicadores. }\end{array}$ & $\begin{array}{l}\text { Análisis significativo } \\
\text { de lectura. }\end{array}$ \\
\hline
\end{tabular}




\subsection{Instrumentos y estrategias de recolección de datos}

Debido a que este estudio se aplicó una metodología mixta, del tipo

CUAN $\rightarrow$ CUAL, involucra tanto instrumentos cuantitativos como cualitativos (Tashakkori y Teddlie, 1998; Creswell, 2007). A continuación, se describen los instrumentos aplicados en la presente investigación. Los cuales se aplicaron de manera correspondiente en dos fases, las cuales se explican más adelante.

3.5.1 Cuestionarios. El cuestionario es un sistema de interrogantes, las cuales han sido ordenadas con coherencia, expresado con lenguaje sencillo y claro, que, al tener un modelo uniforme, facilita el conteo y la comprobación (García, 2002). El objetivo del cuestionario es traducir las variables de la investigación en preguntas concretas que proporcionen información viable y susceptible de ser cuantificada (Casas Anguita, Repullo Labrador y Donado Campos, 2003).

Johnson y Turner (2003) proponen tres tipos de cuestionarios que se aplican en metodologías mixtas, estos son: cualitativos puros, mixtos y cuantitativos puros. Para este estudio se utilizaron cuestionarios mixtos, los cuales se caracterizar por tener una sección de preguntas cerradas y otra de preguntas abiertas. Estos fueron: los cuestionarios de inicio y final, así como el cuestionario sobre las dimensiones de la gamificación. 
Sos cuestionarios de inicio y final (ver Apéndice III) se aplicaron el inicio del curso y al final, su objetivo fue obtener información sociodemográfica de los participantes, así como su autopercepción en cuanto a conocimientos previos, uso de la tecnología, capacidad para resolver retos, capacidad de innovación y expectativas del curso. Este instrumento corresponde a la Fase 1 de la recolección de datos.

5. El cuestionario sobre dimensiones de gamificación (ver Apéndice IV), se aplicó a los participantes casi al finalizar el curso, este instrumento tuvo el objetivo de valorar las tres dimensiones implicadas en la gamificación y cómo estas fueron percibidas por los participantes una vez que hicieron el Reto Gamificado. Este instrumento corresponde a la Fase 1 de la recolección de datos.

En la Tabla 16 se puede apreciar la relación los cuestionarios con respecto a las fuentes de información, categorías e indicadores. 
Tabla 16

Técnica de recolección de datos cuantitativos en el presente estudio.

\begin{tabular}{|c|c|c|c|}
\hline Técnica & Fuente & Categoría e indicadores & $\begin{array}{l}\text { Periodo de } \\
\text { aplicación }\end{array}$ \\
\hline $\begin{array}{l}\text { Cuestionario } \\
\text { incial y final }\end{array}$ & $\begin{array}{l}1320 \\
\text { participantes del } \\
\text { curso ECLyT al } \\
\text { inicio y por } 430 \\
\text { al final }\end{array}$ & $\begin{array}{l}\text { Categoría 1, indicadores: nivel de impacto, de } \\
\text { conocimiento, tipo de innovador. } \\
\text { Categoría 3, indicadores: democratización y } \\
\text { calidad del diseño didáctico. }\end{array}$ & $\begin{array}{l}\text { Inicial en } \\
\text { septiembre } \\
\text { del } 2017 \\
\text { Final en } \\
\text { octubre del } \\
2017\end{array}$ \\
\hline $\begin{array}{l}\text { Cuestionario } \\
\text { sobre } \\
\text { dimensiones } \\
\text { de la } \\
\text { gamificación }\end{array}$ & $\begin{array}{l}764 \text { participantes } \\
\text { del xMOOC } \\
\text { ECLyT }\end{array}$ & $\begin{array}{l}\text { Categoría 1, indicadores: tipo de innovación } \\
\text { (disruptiva, incremental y/o abierta), nivel de } \\
\text { impacto, de claridad, de conocimiento, tipo de } \\
\text { innovador. } \\
\text { Categoría 2, indicadores: dimensión cognitiva, } \\
\text { social, emotiva y el enganche. } \\
\text { Categoría 3, indicadores: calidad del diseño } \\
\text { didáctico. }\end{array}$ & $\begin{array}{l}\text { Octubre del } \\
2017\end{array}$ \\
\hline
\end{tabular}

En la Tabla 16 se puede apreciar que, aunque se inscribieron 4819 alumnos, solo

1320 respondieron la encuesta de inicio de manera voluntaria y que la cantidad de participantes que respondieron voluntariamente el cuestionario sobre las dimensiones de la gamificación fue mayor que los del cuestionario final.

3.5.2 Entrevistas. Le entrevista es definida como una conversación que se propone para un fin determinado y que resulta de gran utilidad en la investigación cualitativa (Díaz-Bravo, Torruco-García, Martínez-Hernández y Varela Ruiz, 2013). Al igual que los cuestionarios, las entrevistas pueden ser puramente cualitativa, mixta y puramente cuantitativa. La puramente cualitativa es completamente no estructurada, es espontánea y emerge del flujo natural de la conversación (Johnson y Tuner, 2003). 
Las entrevistas mixtas, también llamadas entrevistas semiestructuradas, contienen preguntas abiertas pero que han sido planeadas, su ventaja es la posibilidad de adaptarse a los sujetos, son más flexibles (Martínez, 1998 citado por Díaz-Bravo et al., 2013). Mientras que, las entrevistas puramente cuantitativas, están formadas de preguntas cerradas en las que las respuestas están relacionadas a las categorías previamente establecidas por el investigador, también llamadas entrevistas estructuradas.

Para este estudio se optó por entrevistas semiestructuradas, debido a que los sujetos de los equipos de expertos involucrados en el proyecto contaban con una disponibilidad limitada, así que fue necesario planificar las preguntas para optimizar los tiempos. Las entrevistas se aplicaron a un experto de cada equipo involucrado en el subproyecto Innovación abierta, interdisciplinaria y colaborativa para formar en sustentabilidad energética a través de MOOCs, quienes tuvieron a cargo el diseño y desarrollo del curso ECLyT.

Es decir, un experto del equipo de innovación, un experto del área de tecnología, un experto en investigación educativa y un experto en contenidos sobre temas de energía. Las transcripciones de las entrevistas se encuentran en el Apéndice IX. Las entrevistas se relacionan con la categoría 1 y con los indicadores: Tipo de innovación, Tipo de innovador, nivel de impacto, nivel de claridad, nivel de 
conocimiento, trabajo colaborativo y trabajo interdisciplinario. Así como con la categoría 3 y los indicadores: democratización, calidad del diseño didáctico y modelos de innovación abierta.

\subsubsection{Soluciones creativas y alternativas al Reto Gamificado. Esta estrategia de} recolección de datos consistió en el proceso de revisión de las respuestas abiertas y alternativas al Reto Gamificado que se les solicitó a los alumnos dentro de uno de los cuestionarios. Estas respuestas se revisaron con base en una rúbrica diseñada para evaluar el nivel de innovación logrado por los participantes (ver Apéndice VII).

La rúbrica se diseñó con base en una exhaustiva revisión de la literatura y fue revisado por expertos en el tema de innovación. Este tipo de estrategia de recolección de datos es similar a la utilizada en los trabajos de Bravo, Amate, Simo, Enache y Fernández (2011) y Sánchez-Carmona, Robles y Pons (2017) quienes analizaron las respuestas de preguntas abiertas de sus alumnos, con el propósito de, conocer tanto las experiencias positivas como las negativas de los usuarios, en cuanto a la gamificación.

3.5.4 Analíticas del curso. Esta información fue proveída por la plataforma MéxicoX, en esta base de datos, aparece el registro de calificaciones de cada actividad del curso por usuario, así como su información sociodemográfica. Los datos se 
utilizaron para establecer una relación entre las calificaciones, el Reto Gamificado y los datos sociodemográficos.

En esta información resultó muy útil para la presente investigación por la gran cantidad de información cuantitativa y categórica. El manejo de datos de las analíticas de los MOOC para dar respuesta a investigaciones en este tipo de ambientes, se pueden encontrar en los estudios de Corpeño, Quan y Lemus (2015), Chan (2016), Krause, Mogalle, Pohl y Williams (2015), Kyewski y Krämer (2018) y Warden, Stanworth y Chang (2016), quienes analizaron las analíticas en ambientes MOOC para evaluar la gamificación como estrategia didáctica.

\subsection{Pilotaje de instrumentos}

El objetivo del estudio piloto de los instrumentos fue probarlos para determinar si presentaban alguna dificultad en su aplicación así como su validación empírica para valorar si era necesario algún tipo de ajuste. También se buscó obtener resultados previos para tener un primer acercamiento de la estrategia de gamificación basada en

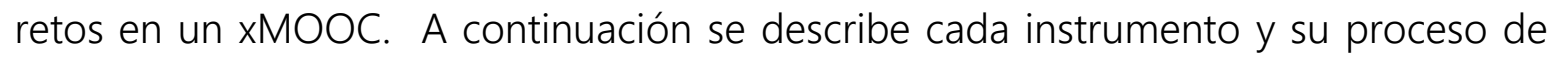
pilotaje.

3.6.1 Cuestionarios inicial y final. Los cuestionarios inicial y final fueron desarrollados por un grupo de expertos y bajo la escala de Likert (Ver Apéndice III). EI cuestionario inicial estuvo dividido por tres dimensiones: motivación e intereses, 
conocimiento general previo y conocimiento específico previo. Mientras que el cuestionario final contó con las dimensiones: satisfacción con el desarrollo profesional y satisfacción con las habilidades tecnológicas adquiridas.

Estos instrumentos fueron aplicados a los primeros cuatro cursos que fueron lanzados en enero del 2017, incluyendo el curso Energías convencionales, limpias y su tecnología. Con respecto a su confiabilidad, los resultados fueron favorables y congruentes, estos resultados aparecen en el trabajo de Valdivia, Ramírez-Montoya y Valenzuela (2018). En la Tabla 17 se muestra el alfa de Conbrach y el análisis factorial.

\section{Tabla 17}

\section{Alfa de Conbrach y Análisis factorial de los cuestionarios de inicio y final.}

\begin{tabular}{ll} 
Estructura total del instrumento 1 & $\alpha=0,898$ \\
\hline (Motivación e intereses) Factor 1 & $\alpha_{1}=0,872$ \\
\hline (Conocimiento geneneral previo) Factor 2 & $\alpha_{2}=0,879$ \\
\hline (Conocimiento específico previo) Factor 3 & $\alpha_{3}=0,728$ \\
\hline Estructura total del instrumento 2 & $\alpha=0,898$ \\
\hline (Satisfacción con el desarrollo profesional) Factor 1 & $\alpha_{1}=0,829$ \\
\hline $\begin{array}{l}\text { (Satisfacción con habilidades tecnológicas adquiridas) } \\
\text { Factor 2 }\end{array}$ & $\alpha_{2}=0,882$ \\
\hline
\end{tabular}

Según el análisis estadístico se puede ver que los instrumentos son confiables ya que las alfas de Conbrach $(\alpha)$ de cada uno fueron superiores a 0,8 y las alfas del análisis factorial indicaron que los reactivos están alineados a las dimensiones correspondientes (Kerlinger \& Lee, 2002). Sin embargo, al contrastar la información 
que emana de los reactivo se encontró la necesidad de modificar un reactivo y agregar

otros, con el propósito de obtener información más específica que se requería en este

estudio, ver Tabla 18.

Tabla 18

Cambios realizados en los cuestionarios de inicio y final.

\begin{tabular}{ll}
\hline Preguntas cuestionario inicial & Cambio realizado \\
\hline $\begin{array}{l}\text { Pregunta 28: Creo tener cierta experiencia } \\
\text { práctica en el área de energía }\end{array}$ & $\begin{array}{l}\text { Después de revisar el programa del curso, } \\
\text { considero que mis conocimientos actuales } \\
\text { superan el 50\% de los temas del programa }\end{array}$ \\
\hline
\end{tabular}

Se agregaron al cuestionario:

Pregunta 29: Después de revisar el programa del curso considero que mis conocimientos actuales me permiten resolver cualquier reto relacionado a esos temas.

Pregunta 30: Después de revisar el programa del curso considero que mis conocimientos actuales me permiten aportar soluciones innovadoras a las problemáticas relacionadas a los temas del curso.

Preguntas cuestionario final
Pregunta 16: Creo que este curso me permitió
adquirir los conocimientos básicos de los
contenidos estudiados.

\section{Cambio realizado}

Después de concluir el curso, considero que los conocimientos adquiridos sobrepasaron mis conocimientos previos sobre los temas.

Se agregaron al cuestionario:

Pregunta 18: Una vez que terminé el curso considero que los conocimientos adquiridos me permitirán resolver cualquier reto relacionado a esos temas.

Pregunta 19: Después de tomar el curso, considero que los conocimientos adquiridos me permiten aportar soluciones innovadoras a las problemáticas relacionadas a los temas del curso.

\subsubsection{Cuestionario sobre dimensiones en la gamificación. El instrumento estuvo}

compuesto por siete preguntas también con escala de Likert de 4 respuestas

(Totalmente de acuerdo, de acuerdo, en desacuerdo, totalmente en desacuerdo) y se aplicó a 608 participantes del curso Energías convencionales, limpias y su tecnología 
de la primera emisión en Febrero del 2017. El alfa de Conbrach para todo el instrumento fue de 0,8102, en la Tabla 19 se muestran los resultados.

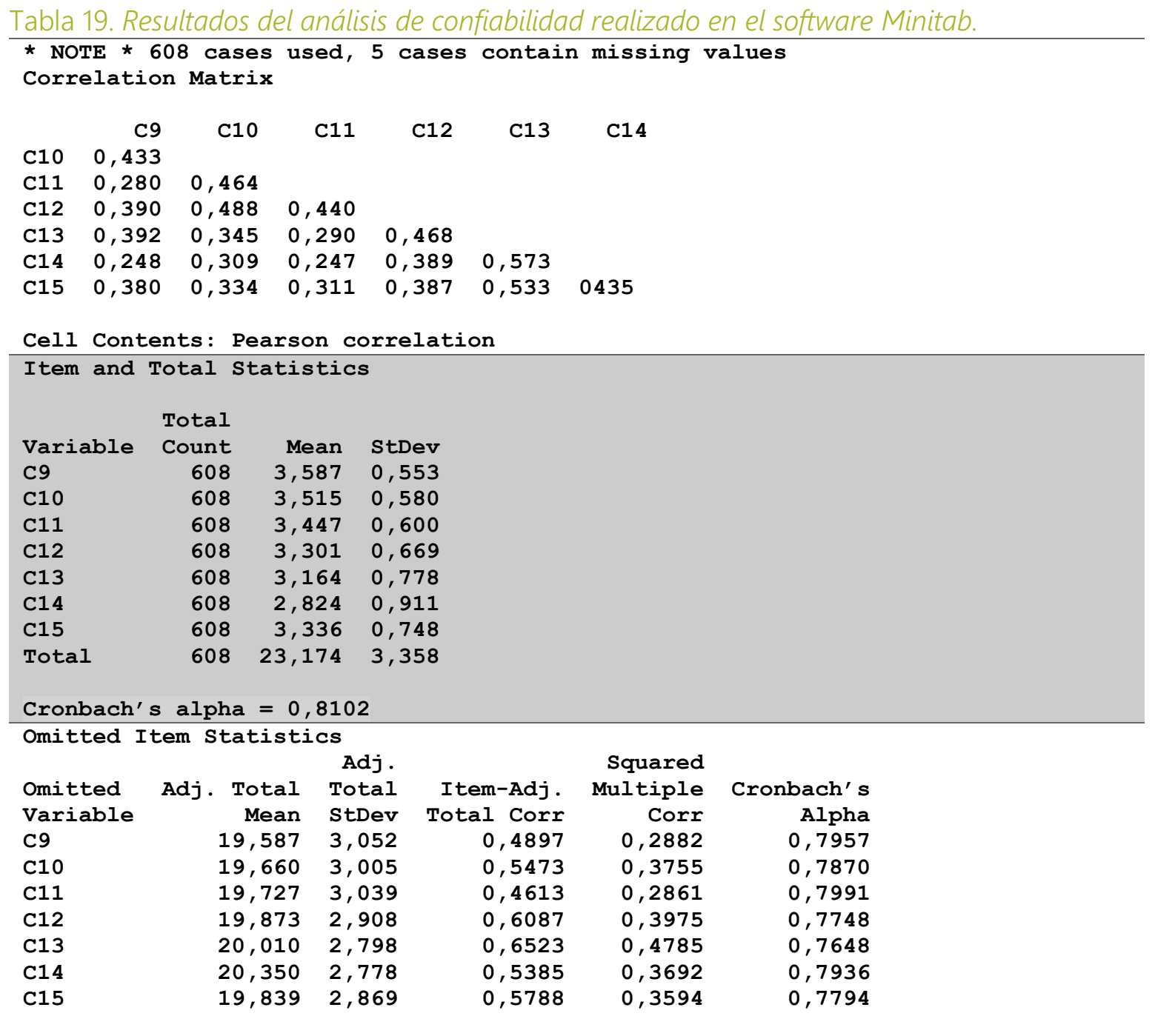

Dado que el instrumento obtuvo un alfa de Conbrach aceptable no se eliminó o modificó alguna pregunta, no obstante, se decidió agregar cuatro preguntas para equilibrar el número de preguntas por dimensiones y obtener más información sobre 
las mismas. Además se incluyeron preguntas de tipo sociodemográfico para calcular posibles correlaciones entre las variables sociodemográficas y las dimensiones cognitiva, social y emotiva de la gamificación. También se agregaron 5 preguntas abiertas a fin de profundizar en las dimensiones, en el nivel de innovación alcanzado en el reto gamificado y la calidad del reto gamificado.

En la Tabla 20 se pueden observar las modificaciones y en el Apéndice $V$ el instrumento final.

\section{Tabla 20}

\section{Preguntas agregadas en el instrumento sobre dimensiones.}

\begin{tabular}{ll}
\hline Preguntas & Dimensión social: \\
cuantitativas & 7) Me hubiera gustado resolver el reto gamificado de manera colaborativa. \\
agregadas & 8) Me hubiera gustado que mis compañeros leyeran mi propuesta alternativa \\
& al reto gamificado. \\
& Dimensión emotiva: \\
& 11) Resolver correctamente el reto gamificado me hizo sentir muy bien. \\
12) Competir para ganar un trofeo me provocó una emoción positiva.
\end{tabular}

\section{Preguntas abiertas}

Dimensión cognitiva:

13) ¿De qué manera resolver el reto gamificado contribuyó a tu aprendizaje? Dimensión social:

14) ¿De qué manera afectó tu desempeño en el reto gamificado cuando supiste que tus resultado aparecería en un tablero de liderazgo?

Dimensión emotiva:

15) ¿Qué tipo de emoción sentiste cuando recibiste un trofeo por haber respondido correctamente el reto gamificado?

Solución alternativa al reto gamificado

16) Escribe una propuesta o solución alternativa al reto gamificado "..."

Como se muestra en la Tabla 20 fueron ocho las preguntas que se agregaron en las dimensiones, 4 con escala de Likert y 4 de manera abierta. 


\subsection{Fases del estudio.}

Como ya se comentó anteriormente, el enfoque metodológico de este estudio fue mixto, correlacional y secuencial (Creswell, 2007). A continuación se describen cada una de las fases.

3.7.1 Fase 1 del estudio. En la presente investigación, la fase 1 del estudio correspondió a la parte cuantitativa, a continuación se describe el diseño de la investigación así como la población y muestra.

3.7.1.1 Diseño de investigación de la Fase 1. En un primer momento se llevaron a cabo las decisiones metodológicas emandas de los resultados de las pruebas piloto. Para ello se llevaron a cabo reuniones con los expertos que diseñaron los cuestionarios inicial y final así como para la revisión de las preguntas agregadas al cuestionario sobre dimensiones de la gamificación. En la Figura 19 se muestra el desarrollo de esta fase. 


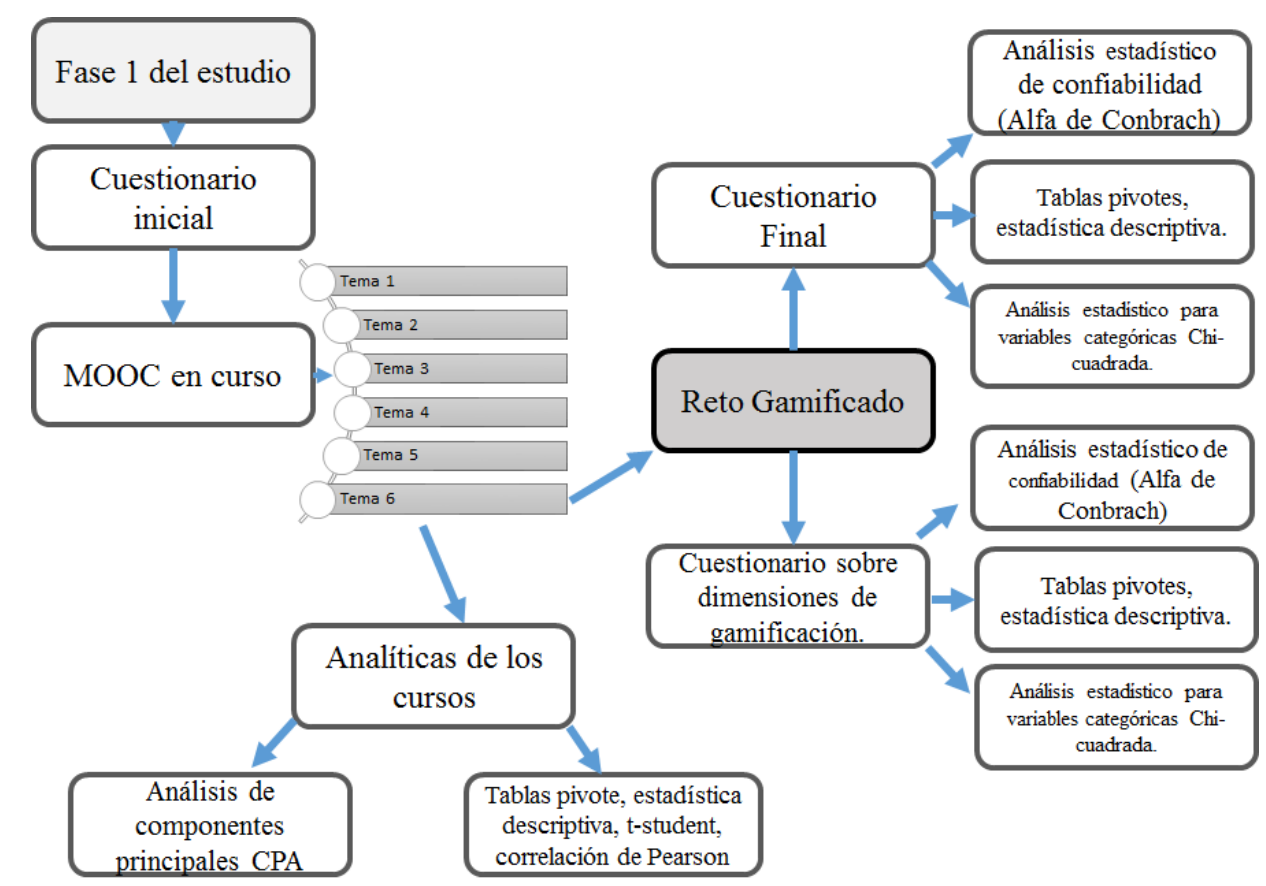

Figura 19. Esquema de Fase 1 del estudio.

En la Fase 1 se aplicó un cuestionario inicial, luego los participantes inician el curso ECLyT, en dónde cada tema se desarrolla en un periodo de una semana. En la semana 6 se aplicó el reto gamificado y también, se aplicó el cuestionario sobre dimensiones de gamificación así como el cuestionario final. Después de las semana 6 se dio una semana más de holgura para que los participantes atrasados se puedieran poner al corriente. Por ello, la información de las analíticas de datos de la plataforma MéxicoX se obtuvo hasta la semana ocho a partir de que comenzó el curso. Con la información obtenida de las analíticas, se procesó la información con el software Excel, que facilitó el cálculo de las tablas pivote, las cuales permitieron desarrollar la estadística descriptiva y las tablas de contingencia. 
Para el cálculo de la Chi-cuadrada se utilizó el software Minitab así como para la construcción de las gráficas, el cálculo de las t-students y los scatter-plots. Finalmente, para el cálculo de los componentes principales se utilizó el software XL-Stat así como para el cálculo de las correlaciones.

3.7.1.2. Población y muestra. La población del estudio estuvo conformada por 4819 participantes que se inscribieron al curso ECLyT. Para la Fase I, el muestro fue no probabilístico o intencionado, es decir, que la muestra no fue aleatoria sino dirigida (Creswell, 2015). Para el el cuestionario inicial y final, se utilizó la totalidad de participantes que los respondieron, para el inicial fueron 1320 participantes y 475 respondieron el cuestionario final.

De la misma manera, se tomó la totalidad de los participantes que respondieron el cuestionario sobre las dimensiones de la gamificación, los cuales fueron 764 usuarios que lo hicieron de modo voluntario.

Para el procesamiento de las analíticas del curso, se utilizó un muestreo no probabilístico ya que, se escogieron a los participantes que hicieron al menos una actividad durante el curso. Es decir, para fines de este estudio se consideró a un participante activo si hizo al menos una actividad, por lo que la muestra tuvo un tamaño de 1209 usuarios. 
3.7.2 Fase 2 del estudio. Esta fase se aplicaron y se analizaron los instrumentos cualitativos una vez que se aplicaron los cuantitativos, el objetivo fue profundizar en el fenómeno de estudio. A continuación se muestra el diseño de investigación de esta fase así como la muestra.

3.7.2.1 Diseño de investigación Fase 2. Al ser un diseño metodológico secuencial, fue hasta que se tuvieron los resultados cuantitativos que se procedió al análisis cualitativo, en la Figura 20 se puede observar la secuencia.

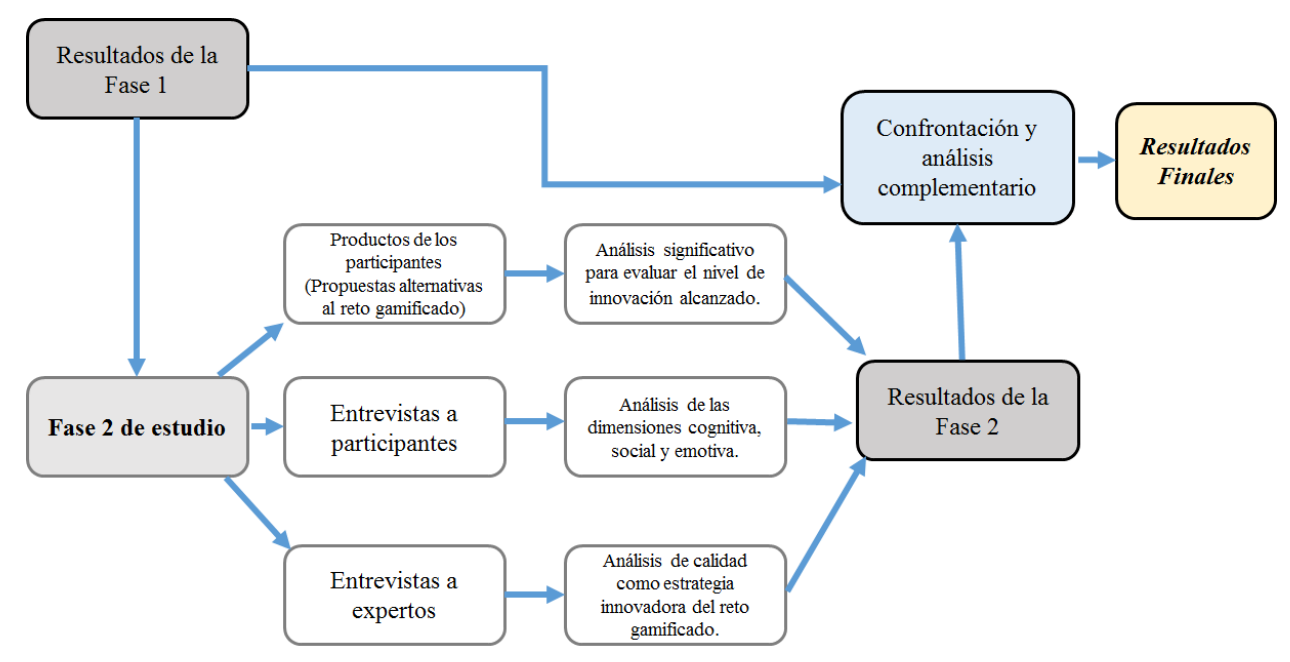

Figura 20. Esquema de Fase 2 de estudio.

En la Fase 2 se analizaron las soluciones creativas y alternativas al Reto Gamificado de los participantes, para determinar el nivel alcanzado y tipo de innovación según la rúbrica diseñada para este propósito (ver Apéndice VII). También se analizaron las preguntas abiertas con respecto a las dimensiones cognitiva, social y 
emotiva de la gamificación así como la pregunta con respecto a la calidad de la misma bajo la perspectiva de los usuarios.

Además, en esta Fase 2 se realizaron las entrevistas a los expertos involucrados en el diseño y desarrollo de los XMOOC-energía. Una vez procesada esta información se contrastó con los resultados de la Fase 1.

3.7.2.2 Muestra. Para la fase cualitativa también se utilizó un muestreo de tipo no probabilístico (Creswell, 2015). Para el análisis de los productos de los participantes, de las 764 respuestas, primero se eliminaron aquellos que no se relacionaban a la solución alternativa del reto "Combustibles para casos de emergencia", luego se eliminaron las que repetían la solución propuesta en las respuestas cerradas para finalmente trabajar con 140 respuestas que sí proponían una solución alternativa. Se aplicaron cuatro entrevistas, a un experto de cada equipo involucrado en el subproyecto Innovación abierta, interdisciplinaria y colaborativa para formar en sustentabilidad energética a través de MOOCs. Los equipos fueron el de innovación educativa, el de tecnología, el de investigación educativa y el equipo de expertos en contenido.

\subsection{Análisis de datos}

En el siguiente apartado se decribe el proceso de análisis de datos que fueron utilizados tanto para los datos cuantitativos como cualitativos. 
3.8.1 Descripción del proceso de análisis de datos. De acuerdo con Creswell, Plano Clark, Guttmann, \& Hanson (2003), para el análisis de datos, el cual, corresponde a un diseño secuencial, primero se obtuvo la información cuantitativa y con base en ésta se profundizó a través de técnicas de recolección de datos cualitativos. No obstante, los resultados de los instrumentos cuantitativos fueron triangulados entre ellos para dar respuesta a las preguntas de investigación definidas en el Capítulo 1.

Para el análisis de datos de la información cuantitativa se utilizó el programa Excel así como los softwares Minitab y XLSTAT. El software Excel facilitó el ordenamiento de los datos y el cálculo de las tablas pivote, las cuales resultaron muy útiles por la gran cantidad de datos. Con el software Minitab se calcularon las tablas de contingencia, se hicieron las pruebas Chi-cuadra, así como la estadística descriptiva. Con el software XLSTAT se calcularon las correlaciones y el Análisis de Componentes Principales (ACP).

Para la segunda fase, se hizo una lectura de las respuestas de las preguntas abiertas, primero se seleccionaron aquellas que eran congruentes a la pregunta correspondiente y luego se categorizaron, para esto, el uso de los filtros el programa Excel facilitó este proceso. Con respecto a las entrevistas, las respuestas fueron colocadas en una tabla que permitiera comparar dichas respuestas por categorías. 
Las respuestas cualitativas se utilizaron para complementar o contrastar los resultados de los instrumentos cuantitativos.

\subsubsection{Validez y confiabilidad. Tanto investigadores cualitativos como} cuantitativos están de acuerdo en que la rigurosidad es necesaria en la investigación (Onwuegbuzie, 2003). Para Maxwell (1992) citado por Onwuegbuzie y Tedlie (2003), en las investigaciones cualitativas se identifican cinco tipos de validación: validación descriptiva (precisión fáctica de lo documentado por el investigador), validación interpretativa (el grado en que la interpretación del investigador es comprendida por los miembros de comunidad científica), validación teórica (el grado en el que la explicación teórica se adapta a los datos encontrados), validación evaluativa (el grado en el que un marco de evaluación puede aplicarse a los objetos de estudio) y generalización (puede ser interna, el grado en que los resultados se pueden extender dentro del contexto de la investigación, o externa, el grado en que los resultados pueden extenderse a otros contextos).

En la investigación cuantitativa, tanto la validación interna como externa son elementos fundamentales para dar rigor al estudio. Para Gay y Airsan (2000) citado por Onwuegbuzie y Tedlie (2003) la validez interna se refiere a que si los resultados de la variable dependiente corresponden a la variable independiente definida y no a otra 
variable. Para Johnson y Christensen (2000) la validación externa es el grado en el que los resultados pueden generalizarse o extenderse a otras poblaciones.

En los métodos mixtos, el análisis de datos ofrece caminos más alcanzables y comprensibles que los que ofrecen los métodos cualitativos o cuantitativos por separado (Onwuegbuzie y Tedlie, 2003) ya que el investigador puede evaluar la información de ambos tipos de datos. Una de las prácticas más comunes es cuando los investigadores cualitativo generan más significado de sus resultados si estos son cuantificados según las frecuencias (Miles y Huberman, 1994 citado por Onwuegbuzie y Tedlie, 2003). Para esta investigación, las respuestas abiertas obtenidas de los cuestionarios aplicados a los estudiantes fueron categorizadas de acuerdo a la frecuencia.

Aunque los criterios de validez cuantitativos y cualitativos se han extendido a los métodos mixtos, diversos metodólogos no están de acuerdo en utilizar este término en los métodos cualitativos, por ello, Onwuegbuzie y Jhonson (2006) proponen que el término legitimación (legitimation) sea utilizado en lugar del término validez en los métodos mixtos. Onwuegbuzie y Jhonson (p. 57, 2006), proponen nueve tipologías de legitimación: 
Muestra integrada (Sample integration): En qué medida la realción entre los diseños de muestro cuantiativo y cualitativo producen calidad de meta-inferencias.

Legitimación dentro y fuera (Inside-outside): El grado en que el investigador precisa, presenta y utiliza apropiadamente la información cuantitativa y la cualitativa, para fines como descripción y explicación.

Legitimación de minimización de debilidades (Waekness minimizaton): Es el grago en que la debilidad de un enfoque es compensado por la fortalezas del otro enfoque.

Legitimación secuencial (Sequential): Es el grado en que se ha reducido el mínimo el potencial problema en donde las meta-inferencias podrían verse afectadas por las secuencia de fases.

Segitimación de conversión (Conversion): Se refiere al grado en que lo cualitativo o cuantitativo da calidad a la meta-inferencias.

Legitimación de la mezcla paradigmática (Paradigmatic mixing): Se refiere al grado en que las creencias epistemológicas, ontológicas, axiológicas, metodológicas y retóricas del investigador, que subyacen en los enfoques cuantitativos y cualitativos se han combinado con éxito. 
Legitimación de la conmensurabilidad (Commensurability): Se refiere al grado en que las meta inferencias se hicieron con base en una cosmovisión mixta.

Legitimación de la múltiples validaciones (Multiple validities): Es el grado en que la legitimación de los compenentes cualitativos y cuantitativos del estudio derivan del uso de validez tanto cuantitativa como cualitativa para producir calidad en las meta inferencias.

Segitimación de política (Political): Se refiere al grado en que los usuarios de la investigación de métodos mixtos valoran las meta inferencias derivadas de los resultados cualitativos y cuantitativos.

Las tipologías de legitimación aún se encuentran en estudio, por ello se sugiere que sean complementadas con los criterios de validación externa e interna que tradicionalmente se aplican a los métodos cuantitativos y cualitativos (Ihantola y Kihn, 2011). Así que para este estudio se utilizaron los criterios de validez de constructo, validez interna, validez externa, legitimación de muestra integrada, legitimación dentro y fuera, legitimación secuencial, legitimación de conversión, legitimación de la mezcla paradigmática y legitimación de la mezcla paradigmática. 
3.8.2.1 Validez del constructo. Se refiere a las amenzas relacionadas al conocimiento previo de los autores sobre el tema (García-Holgado, 2018). Para limitar esta amenaza se realizó una exhaustiva revisión de la literatura de los tres constructos implicados en el estudio, en donde un noventa y cinco porciento de las referencias son del año 2010 en adelante y provienen de bases de datos como Scopus, WoS y ESCl.

3.8.2.2 Validez interna. Con respecto a la parte cuantitativa, los cuestionarios de inicio y final fueron diseñados por un grupo de expertos y luego fueron piloteados arrojando un alfa de Conbrach de 0.898 tanto el cuestionario de inicio como el del final (Valdivia, Ramírez-Montoya y Valenzuela, 2018). Con respecto al cuestionario sobre dimensiones de gamificación, también fue elaborado por un grupo de expertos, con base en la literatura (Williams y Nisbet, 2008; Dominguez et al., 2015; Hanus y Fox; 2015; Rincón-Flores, Ramírez-Montoya y Mena, 2016), el cual tuvo un alfa de Conbrach de 0.8102 .

Con respecto a la parte cualitativa, las entrevistas semi-estructuradas fueron diseñadas por un grupo de expertos del equipo de investigación en innovación educativa, el cual estuvo presente durante dichas entrevistas. En cuanto al análisis de las soluciones creativas y alternativas al reto gamificado, fueron evaluadas de acuerdo a una rúbrica diseñada con base en la literatura respecto a innovación (ver Apéndice 
VII). El instrumento también fue revisado por algunos expertos del grupo de investigación en innovación educativa.

3.8.2.3 Validez externa. Con respecto a la validez externa, dado que los instrumentos contaron con validez interna, pueden ser replicados en otros contextos similares. Por otro lado, la validez externa fue sólida, dado que al tratarse de un curso masivo, el tamaño de las muestras fueron grandes, lo que tiene implicaciones estadísticas positivas (Corpeño, Quan y Lemus, 2015; Krause, Mogalle, Pohl y Williams, 2015, Morales, 2013; Ramírez-Montoya y Mena, 2017).

3.8.2.4 Legitimación de muestra integrada. Las muestras utilizadas en cada instrumento cuantitativo provino de la misma población y las muestras para los intrumentos cualitativos se extrajeron de las muestras de los instrumentos cuantitativos. Los expertos entrevistados fueron personas involucradas en el diseño e implementación del xMOOC ECLyT.

3.8.2.5 Legitimación dentro y fuera. El diseño de la investigación fue mixto, CUANcual, secuencial y correlacional (Creswell, 2007). Ambos enfoques, cuantitativo y cualtitativo tuvieron validez externa e interna (se explicaron en los puntos 3.8.2.2 y 3.8.2.3). 
3.8.2.6 Legitimación secuencial. El diseño de la investigación fue definido en dos fases, en la primera se recogieron y analizaron los datos cuantitativos y en la segunda los datos cualitativos, con la finalidad que los resultados cualitativos complementaran y explicaran a mayor profundidad los resultados de los cuantitativos.

3.8.2.7 Legitimación de conversión. Dado que el estudio es secuencial, los resultados cuantitativos fortalecieron a los cualitativos y viceversa.

3.8.2.8 Legitimación de la mezcla paradigmática. El análisis de los datos y las inferencias realizadas se apoyaron en ambos enfoques, dado que lo cualitativo profundizaba en los resultados cuantitativos.

3.8.2.9 Legitimación de múltiples validaciones. El estudio contó con validaciones internas, externas y de constructo ( secciones 3.8.2.1 a 3.8.2.3).

\subsection{Procesos éticos}

En todo proceso de investigación, los aspectos éticos juegan un papel importante ya que la protección de los datos de los participantes es crucial tanto por los factores morales (Howe y Moses, 1999 ) como para la información obtenida sea fiable y fluida. Smith (1990) destaca que los procesos éticos son tan importantes como los procesos epistemológicos, por lo que los valores o los derechos humanos no deberían omitirse. 
Así mismo, el investigador debe tomar en cuenta que existen diversos dilemas éticos que deben considerarse (Creswell, 2007, Lincoln y Guba, 1985), tales como la identidad de los participantes, el manejo de sus datos así como la difusión del conocimiento generado por ellos. En este sentido y para fines de la presente investigación, en cada instrumento aplicado en el proceso de la recolección de datos, se agregó un aviso de políticas de privacidad, ver Figura 21.

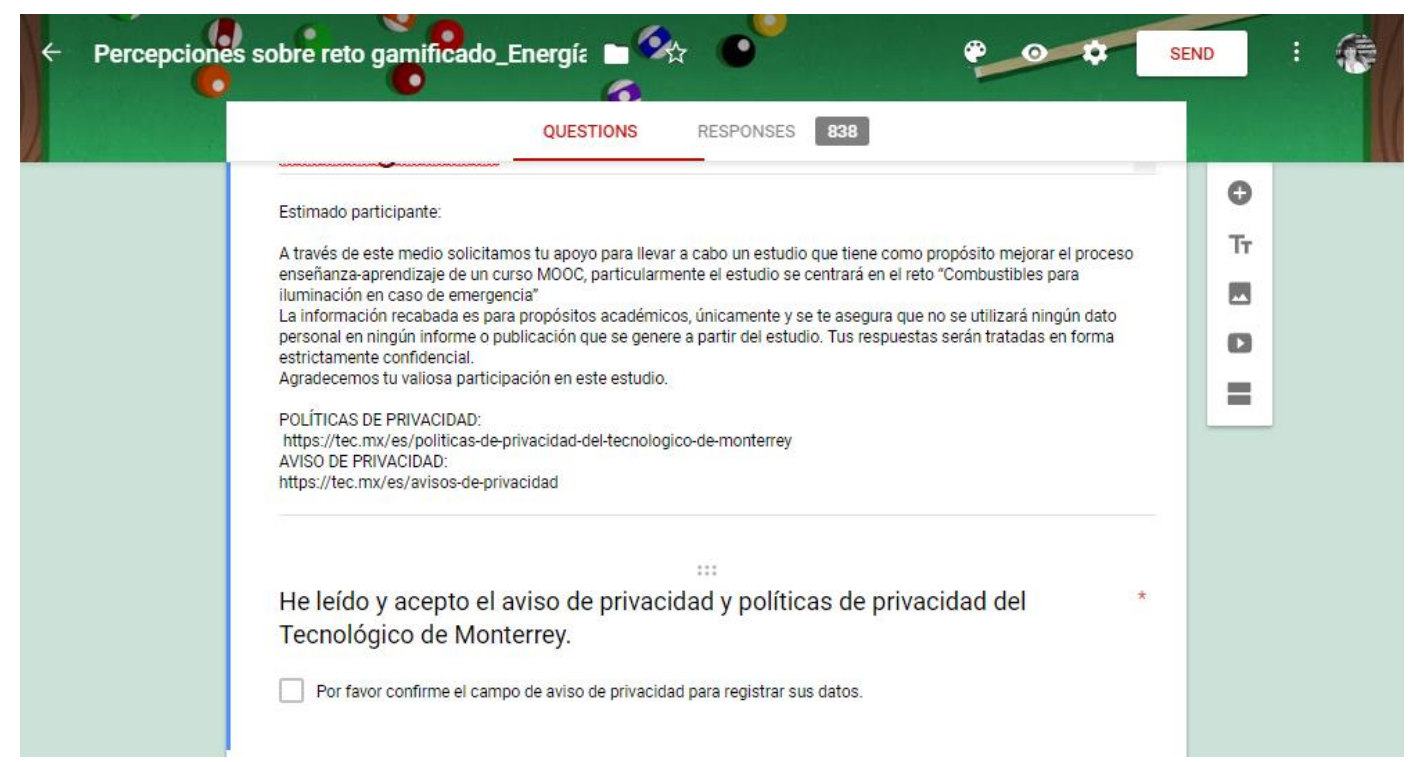

Figura 27. Aviso de políticas de privacidad.

Con respecto al acceso de la información de las analíticas del curso, se aplicó una solicitud formal a las autoridades correspondiente a partir de una carta en la que el investigador se comprometía en no difundir la información otorgada (ver Apéndice VI). Smith (1990) menciona que los aspectos metodológicos son tan valiosos e importantes como los aspectos epistemológicos, así como el cuidado ético de la 
información. Por ello, la presente investigación contó con la participación informada de los participantes, la confidencialidad y el respeto a los datos proporcionados a través de un manejo objetivo.

Por otro lado, uno de los puntos críticos en la ética de la investigación cualitativa es que la información proporcionada por los participantes a partir de las entrevistas se conserve de manera fidedigna (Noreña, Moreno, Rojas y Rebolledo-Malpica, 2012) por lo que la ética del investigador juega también un papel importante en el proceso de análisis e interpretación de la información. Por ello, el manejo de los datos fue cuidado de manera objetiva y apegados a evidencias colectadas.

Así que es recomendable manejar los procedimientos necesarios para asegurar el análisis e interpretación de la información, de manera objetiva, evitando su manipulación para tratar de ajustarlos a los supuestos de la investigación (Domínguez y Macías-Ordóñez, 2004). Por lo que al tratarse de una investigación enmarcada en un ambiente masivo, abierto y en línea, requiere del uso de técnicas de recolección de datos a través de medios electrónicos, los aspectos éticos adquieren de mayor compromiso e importancia.

A manera de cierre del Capítulo 3, se pudo constatar la complejidad y riqueza de la metodolodía mixta. En este apartado, se dio a conocer la situación educativa del marco e la investigación para colocar en contexto al lectos, se justificó la aplicación de 
la metodología mixta y se presentó el diseño de la investigación. Se mostraron los instrumentos y estrategias de recolección de datos, indicando con cuales categorías e indicadores se relacionaron.

También se dieron a conocer los criterios de legitimación que soportaron a la investigación, así como, las medidas tomadas para cuidar y respetar los aspectos éticos. Sin duda, el enfoque metodológico mixto enriquece los resultados de una investigación, no obstante su diseño, legitimación y ejecución, son más complejos que la aplicación única del método cualitativo o cuantitativo. A continuación se presentan los resultados que se obtuvieron a partir de la aplicación de los instrumentos y de las técnicas de recolección de datos; también se presenta el análisis de los mismos. 


\section{CAPÍTULO 4}

\section{RESULTADOS Y SU ANÁLISIS}

Para propósito de este estudio, se utilizaron tres fuentes de información, las analíticas del curso, los participantes, así como las personas que participaron en el diseño instruccional del curso como profesores y diseñadores. Se utilizaron cuatro instrumentos para la recolección de datos, para la fase cuantitativa: un cuestionario de inicio, un cuestionario final, un cuestionario para obtener información sobre las dimensiones cognitiva, social y emotiva. Para la fase cualitativa se utilizaron cuestionarios que se aplicaron a los participantes, diseñadores instruccionales y maestros. En un primer momento se dan los resultados de cada instrumento, luego se ofrece un análisis de estos resultados.

\subsection{Resultados de los instrumentos cuantitativos.}

Para comenzar, primero se dan a conocer los resultados sociodemográficos de quienes respondieron los cuestionarios iniciales y finales. Los cuales fueron procesados con el programa Excel para el ordenamiento de los datos y para el cálculo de las tablas pivote, las cuales, facilitaron la construcción de las tablas de contingencia, que luego se utilizaron en el software Mini-Tab para realizar las pruebas Chi-cuadrada. Este software también se utilizó para la construcción de las gráficas descriptivas. 
Para el análisis del instrumento sobre percepciones de la gamificación, se desarrolló el mismo tratamiento que en el cuestionario de inicio y final, dado que en ambos se utilizaron variables categóricas. Se establecieron relaciones entre el género, el nivel educativo y edad con respecto a cada dimensión, cognitiva, social y emotiva, las cuales se complementaron con las respuestas de cualitativas.

En la tercera sección, se presentan los resultados de las analíticas del curso, las cuales corresponden a variables continuas, lo que permitió determinar la relación entre las calificaciones, el género y la edad con respecto al reto gamificado. Para ello, se calcularon las correlaciones entre las variables, los componentes principales con ayuda del programa XL-Stat y los scatter-plots con ayuda del programa MiniTab.

4.1.1 Resultados de los instrumentos de inicio y final. De los 4819 alumnos inscritos, 1320 respondieron la encuesta de inicio, de los cuales 780 fueron hombres y 540 fueron mujeres. Llama la atención que el porcentaje mayor es el de los hombres, aunque la presencia de las mujeres tiene un número importante. En la Figura 22, también se puede visualizar la proporción del nivel de estudios de los participantes que respondieron la encuesta de inicio. Se puede apreciar que la mayoría corresponden a los niveles de preparatoria y profesional, también que la proporción de los niveles secundaria y doctorado son las más bajas. 


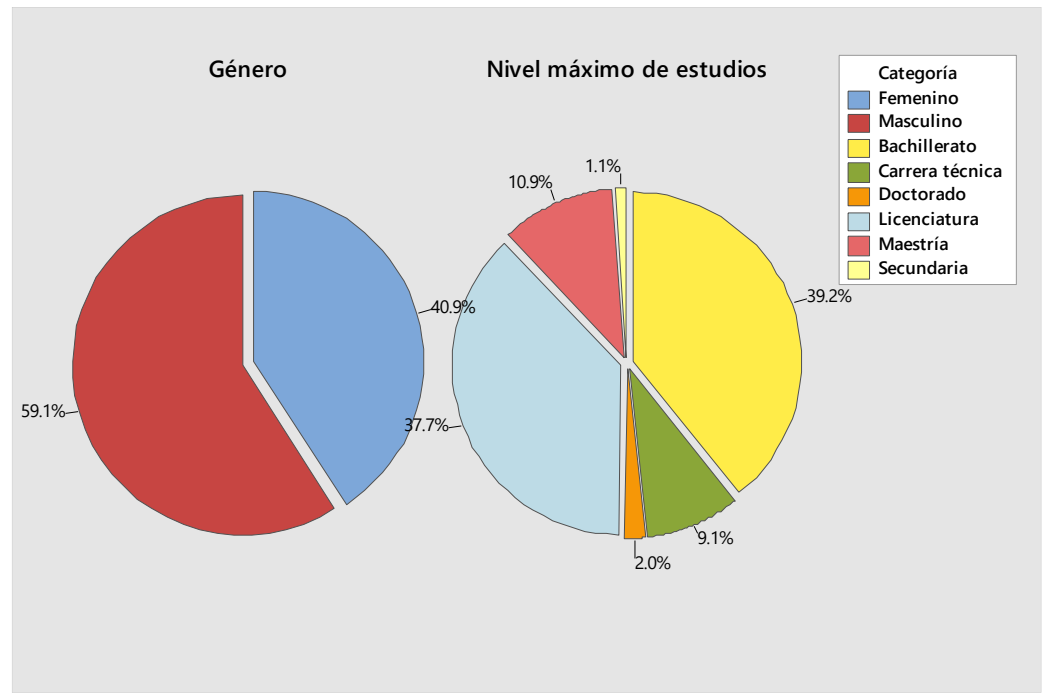

Figura 22. Proporción de hombres y mujeres que respondieron la encuesta de inicio y proporciones de nivel educativo.

Estos resultados revelan que quienes respondieron el cuestionario inicial fueron mayormente hombres y que, los niveles educativos predominantes fueron preparatoria y profesional. En la Tabla 21 se muestra que de los niveles educativos más frecuentes el $43 \%$ corresponde a mujeres y el $57 \%$ a hombres.

\section{Tabla 21}

Conteo de mujeres y hombres según el nivel educativo.

\begin{tabular}{crcr}
\hline Nivel Académico/Género & Conteo & Nivel Académico/Género & Conteo \\
\hline Preparatoria & 517 & Profesional & 497 \\
Femenino & 250 & Femenino & 186 \\
Masculino & 267 & Masculino & 311 \\
Carrera técnica & 120 & Maestría & 144 \\
Femenino & 40 & Femenino & 51 \\
Masculino & 80 & Masculino & 93 \\
Doctorado & 27 & Secundaria & 15 \\
\hline Femenino & 9 & Femenino & 4 \\
Masculino & 18 & Masculino & 11 \\
\hline
\end{tabular}


También se puede observar en la Tabla 21 que, en el nivel de preparatoria, la cantidad de mujeres y de hombres es más o menos igual, no obstante, la proporción se inclina más hacia los hombres a partir del nivel de carrera técnica. Más adelante compararemos esta información con la arrojada por las analíticas del curso con la finalidad de determinar si las proporciones son consistentes y validar la triangulación de la información.

Con respecto al resto del instrumento y para su análisis, se utilizaron las cinco preguntas que se muestran en la Tabla 22 y se compararon las respuestas de los cuestionarios tanto de inicio como del fin de curso Energías Convencionales, Limpias y su Tecnología (ECLyT). No obstante, para validar que las muestras fueran consistentes se aplicó la prueba Chi-cuadrada ya que en estos instrumentos se contienen variables categóricas.

Por otro lado, la razón por la cual se utilizaron las preguntas que se muestran en la Tabla 22 fue debido a que estos resultados serán contrastados con los resultados de la evaluación final, el reto gamificado y las calificaciones finales de los participantes, los cuales fueron proveídos por las analíticas del curso MOOC. También fueron contrastados con los resultados del cuestionario sobre el reto gamificado, el cual estuvo enfocado para analizar las dimensiones cognitivas, social y emotivas, propias de la gamificación. Una vez procesada la información cuantitativa será complementada 
con la información cualitativa, la cual se obtuvo a partir de un cuestionario que se aplicó

a los participantes del curso, a los profesores y diseñadores instruccionales que participaron en el diseño del reto gamificado.

\begin{tabular}{|c|c|c|}
\hline $\begin{array}{l}\text { Número } \\
\text { de } \\
\text { pregunta }\end{array}$ & Preguntas del cuestionario de inicio & Preguntas del cuestionario final \\
\hline 1 & $\begin{array}{l}\text { Creo que este curso mejorará mi } \\
\text { formación académica }\end{array}$ & $\begin{array}{l}\text { Creo que este curso mejoró mi } \\
\text { formación académica. }\end{array}$ \\
\hline 2 & $\begin{array}{l}\text { Creo tener cierta experiencia práctica en el } \\
\text { área de energía }\end{array}$ & $\begin{array}{l}\text { Después de haberlo tomado, estoy } \\
\text { convencido que este curso me permitirá } \\
\text { desarrollar experiencia práctica en el } \\
\text { área de energía. }\end{array}$ \\
\hline 3 & $\begin{array}{l}\text { Después de revisar el temario, considero } \\
\text { que mis conocimientos actuales superan el } \\
50 \% \text { de los temas del curso }\end{array}$ & $\begin{array}{l}\text { Después de concluir el curso, considero } \\
\text { que los conocimientos adquiridos } \\
\text { sobrepasaron mis conocimientos al } \\
\text { inicio del curso. }\end{array}$ \\
\hline 4 & $\begin{array}{l}\text { Después de revisar el temario, considero } \\
\text { que mis conocimientos actuales me } \\
\text { permitirían resolver retos relacionado con } \\
\text { al menos un tema de este curso. }\end{array}$ & $\begin{array}{l}\text { Después de concluir el curso, considero } \\
\text { que los conocimientos adquiridos me } \\
\text { permiten resolver retos relacionados } \\
\text { con al menos un tema del curso. }\end{array}$ \\
\hline 5 & $\begin{array}{l}\text { Después de revisar el temario, considero } \\
\text { que mis conocimientos actuales me } \\
\text { permitirían aportar soluciones } \\
\text { innovadoras a las problemáticas } \\
\text { relacionadas con al menos un tema de } \\
\text { este curso. }\end{array}$ & $\begin{array}{l}\text { Después de concluir el curso, considero } \\
\text { que los conocimientos adquiridos me } \\
\text { permiten aportar soluciones } \\
\text { innovadoras a las problemáticas } \\
\text { relacionadas con al menos un tema del } \\
\text { curso. }\end{array}$ \\
\hline
\end{tabular}

Dado que las preguntas del instrumento de inicio y de final corresponden a variables categóricas, se construyeron tablas de contingencia a partir de las frecuencias obtenidas, las cuales corresponden a una escala de Likert. Estas tablas se elaboraron para cada pregunta (ver Tabla 22). Para su construcción se agruparon las variables categóricas Muy de acuerdo y de acuerdo, llamándola "De acuerdo", así como Muy en 
desacuerdo y en desacuerdo, llamándola "Desacuerdo", esto se decidió para cumplir con el requisito que en la frecuencia esperada de cada celda de una tabla de contingencia debe ser al menos 5 elementos.

Una vez construidas las tablas de contingencia se calculó la Chi-cuadrada para cada una con un nivel de significancia del 5\%, en donde las hipótesis nula y alternativa, en forma general, consistieron en:

Ho: No existe una asociación significativa entre las variables.

$H_{7}$ : Existe una asociación significativa entre las variables.

En otras palabras, la prueba Chi-cuadrada nos permitió determinar si las respuestas del cuestionario de inicio y final son independientes, es decir, si el momento de contestar (inicio o final) y las respuestas del cuestionario (De acuerdo o en desacuerdo) son independientes.

En la Tabla 23 se muestra la tabla de contingencia de la pregunta 1, la cual fue respondida por 1264 participantes en la encuesta de inicio y 433 en la encuesta final. La pregunta 1: "Creo que este curso mejorará mi formación académica", se refiere a cómo el participante se percibió, antes y después de concluir el curso, con respecto a que si su nivel académico mejoró o no. 


\section{Tabla 23}

\begin{tabular}{ccccc}
\multicolumn{4}{c}{ Tabla de contingencia de la pregunta 7 de los cuestionarios de inicio y final del XMOOC ECLYT. } \\
\hline Cuestionario & Tratamiento/Escala & De acuerdo & Desacuerdo & Total \\
\hline Inicial & Frecuencia observada & 418 & 15 & 433 \\
Final & Frecuencia esperada & 426,11 & 6,89 & \\
& Frecuencia observada & 1252 & 12 & 1264 \\
& Total & 1243,89 & 20,11 & \\
& 1670 & 27 & 1697 \\
\hline
\end{tabular}

Una vez construida la tabla de contingencia, se establecieron las siguientes hipótesis:

$H_{0}=$ No existe una asociación significativa entre el momento de aplicación del cuestionario y como se percibe el participante en cuanto a su mejora académica.

$H_{7}$ : Existe una asociación significativa entre el momento de aplicación del cuestionario y como se percibe el participante en cuanto a su mejora académica.

Luego, se corrió la prueba Chi-cuadrada con un nivel de significancia del 5\%, los resultados de la prueba se muestran en la Tabla 24.

\section{Tabla 24}

Prueba de Chi-cuadrada de la pregunta 1 del cuestionario de inicio y final del MOOC ECLyT.

\begin{tabular}{llll}
\hline & Chi-cuadrada & GL & p-valor \\
\hline Pearson & 13,027 & 1 & 0,000 \\
Relación de verosimilitud & 11,159 & 1 & 0,001 \\
\hline
\end{tabular}


Dado que el p-valor resultó menor al nivel de significancia, se rechazó la hipótesis nula, por lo tanto, existe una asociación significativa entre el momento en que se aplicó el instrumento y la percepción sobre la mejora académica de los participantes, es decir, sí importa si el cuestionario se aplica al inicio o al final ya que la proporción de respuestas no fue la misma. Así que, retomando los resultados de la Pregunta 1, se observó que, al inicio del curso, el 94,8\% de los participantes estaban de acuerdo y muy de acuerdo con respecto a que el curso MOOC ECLyT mejoraría la formación académica mientras que en la encuesta final se observó una disminución, pues solamente el 88\% de ellos estuvieron de acuerdo o muy de acuerdo, ver Figura 23.

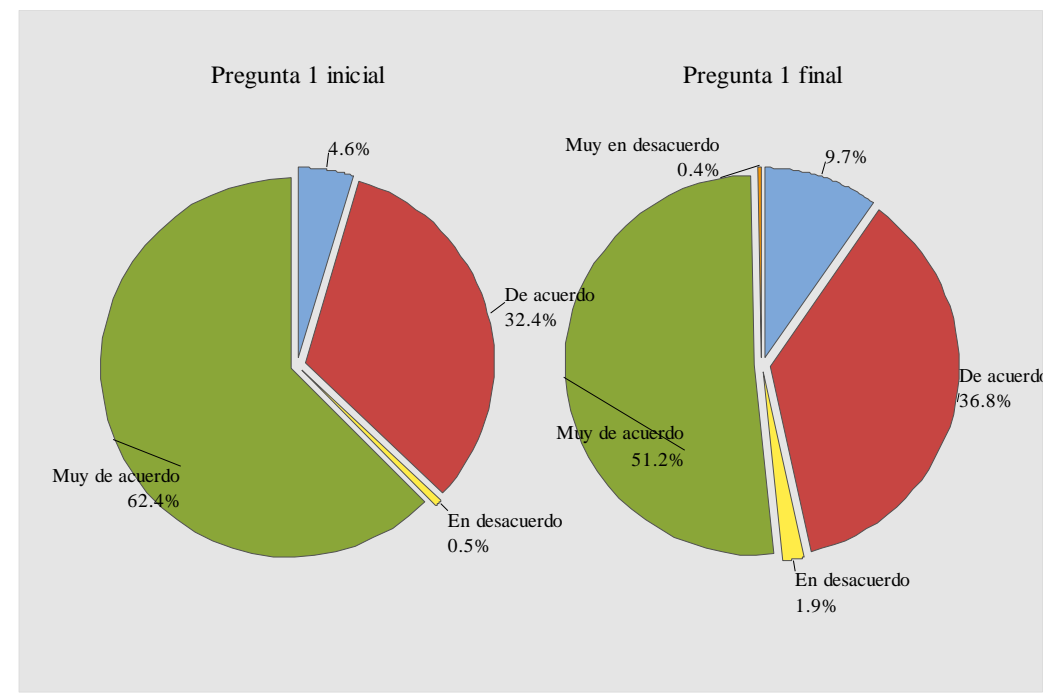

Figura 23. Resultados de la pregunta 1 tanto del cuestionario de inicio como el cuestionario final.

Esto podría significar que al inicio los participantes comenzaron con expectativas altas y al término del curso el nivel de percepción disminuyó, aunque, por 
otro lado, la tasa terminal fue de $13 \%$, este porcentaje es superior al promedio global que ronda en el 5\% según Armstrong (2014) y Bartolomé y Steffens (2015).

La pregunta 2: "Creo tener cierta experiencia práctica en el área de energía" se refiere a como se percibía el participante con respecto a que si tenía conocimientos sobre el tema de Energías limpias y convencionales al inicio y cómo se percibió al final del MOOC. En las Tablas 25 y 26 podemos ver la tabla de contingencia y el resultado de la Chi-cuadrada, respectivamente.

\section{Tabla 25}

Tabla de contingencia de la pregunta 2 de los cuestionarios de inicio y final del XMOOC ECLYT.

\begin{tabular}{lllll}
\hline Cuestionario & Tratamiento/Escala & De acuerdo & Desacuerdo & Total \\
\hline Inicial & Frecuencia observada & 403 & 16 & 419 \\
& Frecuencia esperada & 306,3 & 112,7 & \\
Final & Frecuencia observada & 804 & 428 & 1232 \\
& Frecuencia esperada & 900,7 & 331,3 & \\
& Total & 1207 & 444 & 1651 \\
\hline
\end{tabular}

Esta pregunta fue respondida por 1232 participantes en el cuestionario de inicio y por 419 en el cuestionario final. Para la prueba Chi-cuadrada se utilizó un nivel de significancia del 5\% y las hipótesis se establecieron como:

$H_{0}$ : No existe una asociación significativa entre el momento de aplicación del cuestionario y como se percibe el participante en cuanto a su experiencia práctica en el área de energía. 
$H_{1}$ : Existe una asociación significativa entre el momento de aplicación del cuestionario y como se percibe el participante en cuanto a su experiencia práctica en el área de energía.

\section{Tabla 26}

Prueba de Chi-cuadrada de la Pregunta 2 del cuestionario de inicio y final del XMOOC ECLYT.

\begin{tabular}{llll}
\hline & Chi-cuadrada & GL & p-valor \\
\hline Pearson & 152,057 & 1 & 0,000 \\
Relación de verosimilitud & 195,210 & 1 & 0,000 \\
\hline
\end{tabular}

Dado que el p-valor es menor que el nivel de significancia, se rechaza la hipótesis nula, esto es que sí existe una asociación entre las variables. En otras palabras, sí importa el momento de aplicación del cuestionario en relación a la percepción del participante con respecto a su experiencia práctica en el área de energía y obtuvo al finalizar el curso.

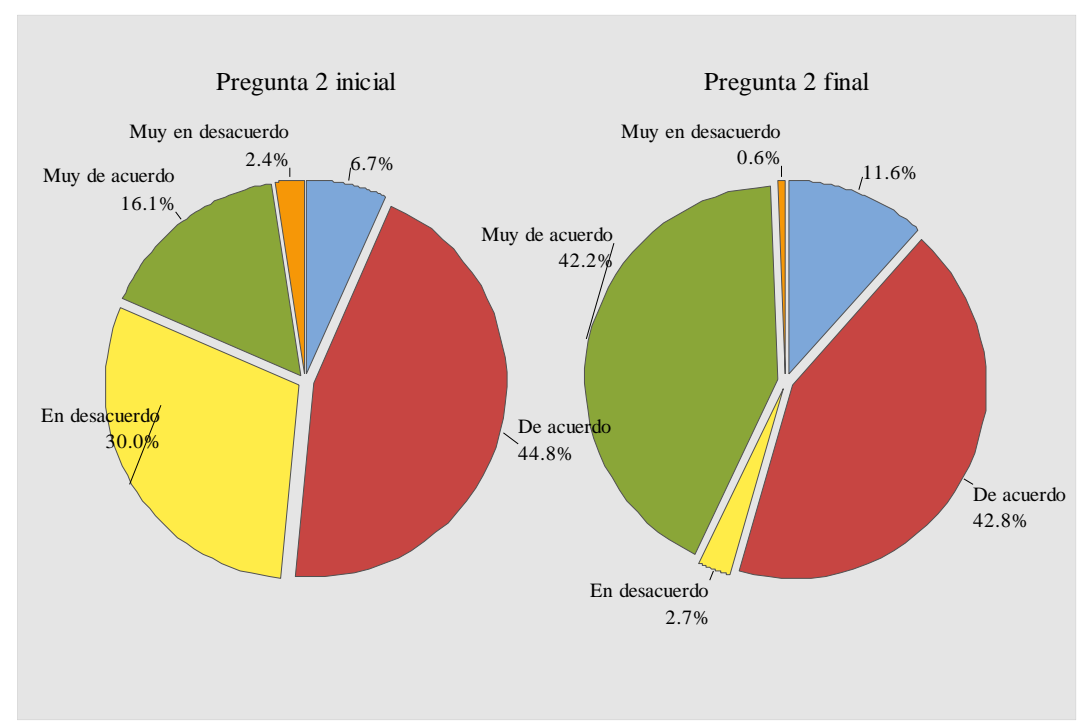

Figura 24. Resultados de la pregunta 2 tanto del cuestionario de inicio como el cuestionario final. 
En la Figura 24 se observa que al inicio el 32,4\% de los participantes se percibía que no contaba con experiencia práctica en el área de energía, mientras que en el cuestionario de salida solo el 3,3\% opinó de la misma manera. O bien, al inicio el 60\% creía tener conocimiento práctico en materia de energía y al finalizar el curso, el porcentaje incrementó al 85\%. Esto significa que al final del curso, los participantes consideraron que el curso les proveyó de conocimientos y herramientas prácticas en el área de energía.

La pregunta 3: "Después de revisar el temario, considero que mis conocimientos actuales superan el 50\% de los temas del curso" tuvo el propósito de determinar cómo se percibía con respecto a sus conocimientos respecto a los temas que se abordaron en el MOOC ECLyT. Esta pregunta fue respondida por 1232 participantes al inicio y 419 respondieron el cuestionario final, ver Tabla 27.

\section{Tabla 27}

\section{Tabla de contingencia de la pregunta 3 de los cuestionarios de inicio y final del XMOOC ECLyT.}

\begin{tabular}{lllll}
\hline Cuestionario & Tratamiento/Escala & De acuerdo & Desacuerdo & Total \\
\hline Inicial & Frecuencia observada & 398 & 19 & 417 \\
& Frecuencia esperada & 284,2 & 132,8 & \\
Final & Frecuencia observada & & & \\
& Frecuencia esperada & 723 & 505 & 1228 \\
& Total & 836,8 & 391,2 & 1645 \\
\hline
\end{tabular}

Para la prueba Chi-cuadrada se establecieron las siguientes hipótesis: 
Ho: No existe una asociación significativa entre el momento de aplicación del cuestionario y como se percibe el participante en cuanto a conocer al menos el 50\% del temario.

$H_{1}$ : Existe una asociación significativa entre el momento de aplicación del cuestionario y como se percibe el participante en cuanto a conocer al menos el 50\% del temario.

La prueba Chi-cuadrada reveló que sí hubo diferencia significativa ente como se percibieron al inicio y al final con respecto a los conocimientos en relación al temario, ya que el p-valor fue menor al 5\%. En otras palabras, se rechazó $\mathrm{H}_{0}$, ver Tabla 28.

Tabla 28. Prueba de Chi-cuadrada de la Pregunta 3 del cuestionario de inicio y final del MOOC ECLYT

\begin{tabular}{llll}
\hline & Chi-cuadrada & GL & p-valor \\
\hline Pearson & 191,757 & 1 & 0,000 \\
Relación de verosimilitud & 240,814 & 1 & 0,000 \\
\hline
\end{tabular}

Como resultado de la pregunta 3, podemos observar que al inicio el $54,8 \%$ de los participantes estuvieron de acuerdo con saber más del 50\% del temario mientras que, en el cuestionario final, el 84,9\% afirmaron que después de concluir el curso, los conocimientos adquiridos en el MOOC ECLyT sobrepasaron sus conocimientos con los que contaban al inicio del curso, ver Figura 25. 


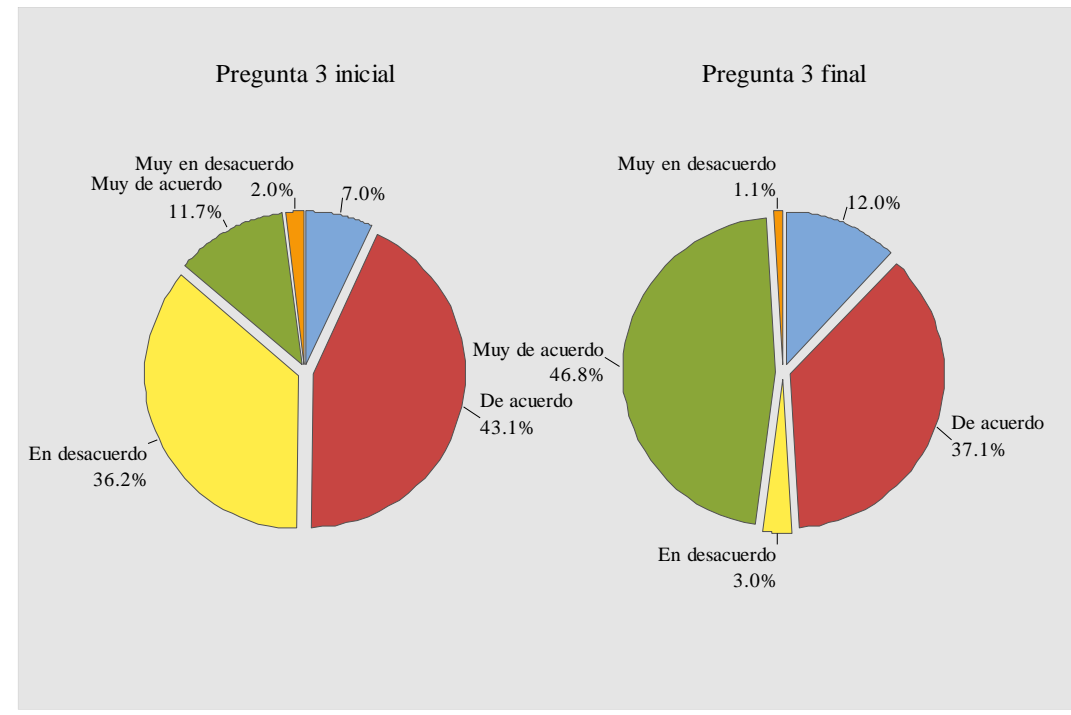

Figura 25. Resultados de la pregunta 3 tanto del cuestionario de inicio como el cuestionario final.

Esto sugiere que hubo un incremento de los participantes que se percibieron con mayor conocimiento al terminar el curso MOOC y aunque consideren que no mejoraron su formación académica, tal como lo manifestaron en la pregunta 1 y al menos hasta este momento, al finalizar el curso MOOC ECLyT los participantes consideraron adquirir conocimientos prácticos y saber más del 50\% de los contenidos del curso.

Las preguntas 4 y 5 son las que están directamente relacionadas a este estudio, no obstante, resulta importante vincularlas con los resultados de las preguntas 1, 2 y 3 así como con los resultados de los otros instrumentos. La pregunta 4: "Después de revisar el temario, considero que mis conocimientos actuales me permitirían resolver retos relacionado con al menos un tema de este curso", se refiere a que tanto el participante se considera capaz de resolver retos relacionados al área de energía de 
acuerdo a sus conocimientos antes y después de tomar el MOOC. La pregunta fue respondida por 1228 participantes al inicio y por 413 al final, ver Tabla 29.

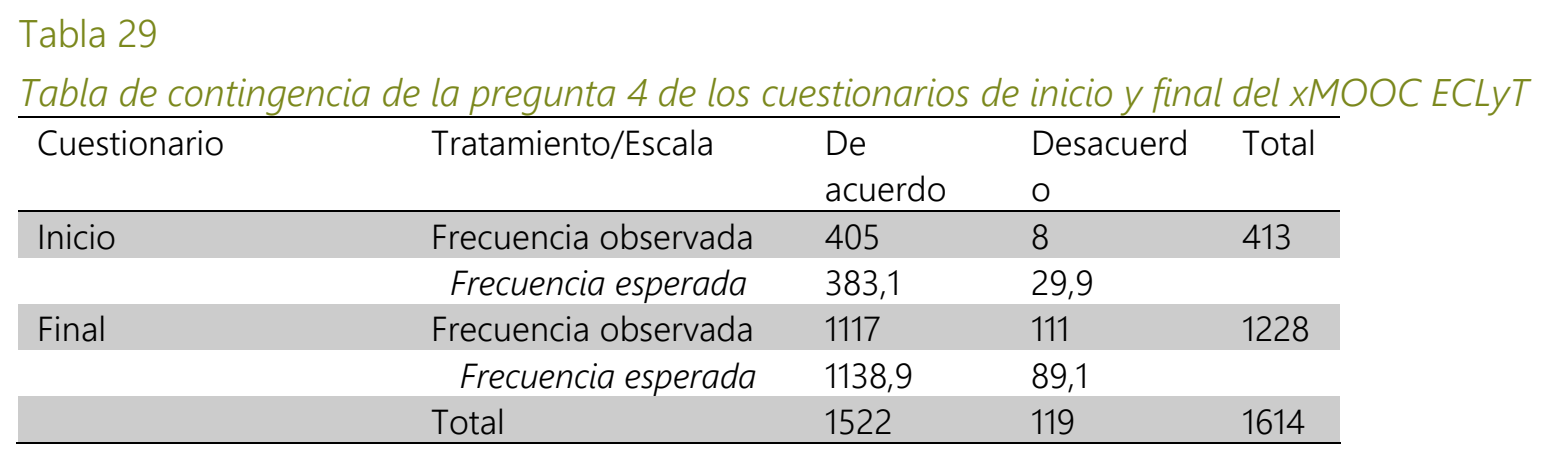

Para la prueba Chi-cuadrada se establecieron las siguientes hipótesis:

Ho: No existe una asociación significativa entre el momento de aplicación del cuestionario y como se percibe el participante en cuanto a que sus conocimientos actuales le permitirían resolver retos relacionado con al menos un tema de este curso.

$H_{7}$ : Existe una asociación significativa entre el momento de aplicación del cuestionario y como se percibe el participante en cuanto a que sus conocimientos actuales le permitirían resolver retos relacionado con al menos un tema de este curso.

Dado que el $p$-valor de la prueba Chi-cuadrada fue menor al $5 \%$ se rechaza la hipótesis nula, es decir sí existe una asociación significativa entre el momento de aplicación del cuestionario y la pregunta 4, ver Tabla 30. 
Prueba Chi-cuadrada de la pregunta 4 del cuestionario de inicio y final del XMOOC ECLYT.

\begin{tabular}{llll}
\hline & Chi-cuadrada & GL & p-valor \\
\hline Pearson & 23,177 & 1 & 0.000 \\
Relación de verosimilitud & 29,451 & 1 & 0.000 \\
\hline
\end{tabular}

En la Figura 26 se observa que en el cuestionario inicial, el $84,7 \%$ de los participantes estaba de acuerdo en que podía resolver cualquier reto relacionado con alguno de los temas de energía del MOOC y al final fue del $85,4 \%$, así que dado que la hipótesis nula fue rechazada, la diferencia entre el inicio y el final es significativa, aunque la diferencia entre ambos es relativamente pequeña. Esto significa que la porción de participantes que consideraron que después de revisar el temario sus conocimientos permitieron resolver retos relacionado con al menos un tema de este curso fue mayor al finalizar el curso.

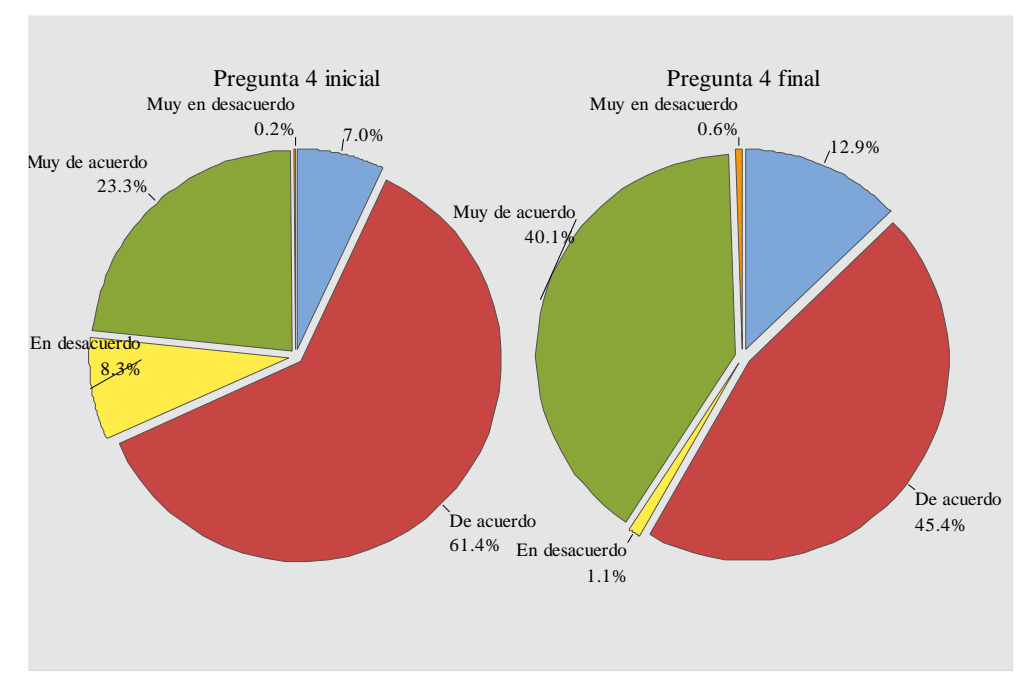

Figura 26. Resultados de la pregunta 4 tanto del cuestionario de inicio como el cuestionario final. 
Finalmente, la pregunta 5: "Después de revisar el temario, considero que mis conocimientos actuales me permitirían aportar soluciones innovadoras a las problemáticas relacionadas con al menos un tema de este curso", se refiere a que tanto se consideraba innovador antes y después de tomar el MOOC. Esta pregunta fue respondida por 1232 participantes al inicio y 418 al final, ver Tabla 31.

\begin{tabular}{|c|c|c|c|c|}
\hline Cuestionario & Tratamiento/Escala & De acuerdo & Desacuerdo & Total \\
\hline \multirow[t]{2}{*}{ Inicial } & Frecuencia observada & 404 & 14 & 418 \\
\hline & Frecuencia esperada & 380,5 & 37,5 & \\
\hline \multirow[t]{3}{*}{ Final } & Frecuencia observada & 1098 & 134 & 1232 \\
\hline & Frecuencia esperada & 1121,5 & 110,5 & \\
\hline & Total & 1502 & 148 & 1650 \\
\hline
\end{tabular}

Para la prueba Chi-cuadrada se establecieron las siguientes hipótesis:

Ho: No existe una asociación significativa entre el momento de aplicación del cuestionario y como se percibe el participante en cuanto a que sus conocimientos le permitirían aportar soluciones innovadoras a las problemáticas relacionadas con al menos un tema de este curso.

$H_{7}$ : Existe una asociación significativa entre el momento de aplicación del cuestionario y como se percibe el participante en cuanto a que sus conocimientos le permitirían aportar soluciones innovadoras a las problemáticas relacionadas con al menos un tema de este curso. 
La prueba Chi-cuadrada arrojó un p-valor menor al 5\%, por lo tanto, al igual que la pregunta 4 se vuelve a rechazar la hipótesis nula, es decir, sí existe una asociación significativa entre el momento de la aplicación del cuestionario y como se percibe el participante en cuanto a que sus conocimientos le permitirán aportar soluciones innovadoras a las problemáticas relacionadas a algún tema de energía del curso, ver Tabla 32.

\section{Tabla 32}

Prueba Chi-cuadrada de la pregunta 5 del cuestionario de inicio y final del MOOC ECLyT.

\begin{tabular}{llll}
\hline & Chi-cuadrada & $\mathrm{GL}$ & $\mathrm{p}$-valor \\
\hline Pearson & 21,658 & 1 & 0,000 \\
Relación de verosimilitud & 25,995 & 1 & 0,000 \\
\hline
\end{tabular}

En la Figura 27 se puede ver que, al inicio el $83,2 \%$ de los participantes estuvieron de acuerdo que conociendo el temario eran capaces de aportar soluciones innovadoras en alguna problemática relacionada con al menos alguno de los temas, mientras que al final fue del $85,2 \%$. 


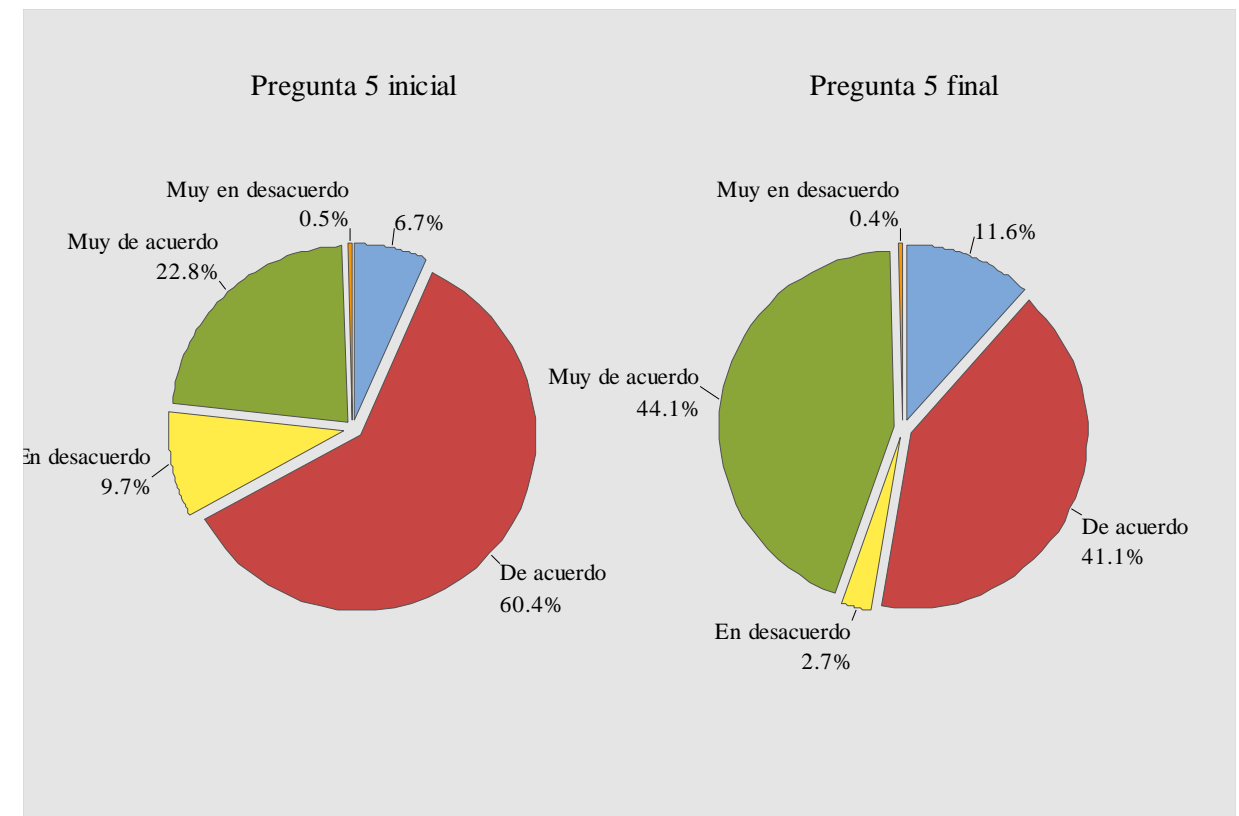

Figura 27. Resultados de la pregunta 5 tanto del cuestionario de inicio como el cuestionario final.

Así que dado el resultado de la prueba Chi-cuadrada, la diferencia entre las respuestas del cuestionario de inicio y final son significativamente diferentes, por lo que podría concluirse que sí hubo cambio en la opinión de los participantes antes y al finalizar el curso MOOC tanto en el aspecto de resolución de retos como en la aplicación de soluciones innovadoras, esto podría traducirse en que una vez que, los estudiantes tomaron el curso se consideraron capaces de resolver retos y de innovar, es decir, hay evidencia estadística de que cursar el MOOC ECLyT tuvo un impacto favorable en alguno de estos dos aspectos. Al mismo tiempo, también hubo un impacto favorable en cuanto a los conocimientos prácticos y teóricos en los temas del curso, según los resultados de las preguntas 2 y 3. 
Al menos, hasta este momento, podríamos afirmar que el MOOC ECLyT sigue conservando las características de un $\mathrm{XMOOC}$, en donde el diseño didáctico está centrado en los contenidos (Ping, 2003; Gonzalez-González et al., 2015), sin embargo, habría que profundizar en que tanto la resolución del Reto Gamificado contribuyó a que las respuestas de las preguntas 4 y 5 mejoraran en el cuestionario final, por ello, fue importante contrastar estos resultados con los de los siguientes instrumentos.

\subsubsection{Resultados del instrumento sobre las dimensiones de la gamificación:}

Cognitiva, Social y Emotiva. Este instrumento estuvo compuesto por doce preguntas con escala de Likert, las cuales estuvieron relacionadas a las dimensiones cognitiva, social y emotiva. Se establecieron cuatro preguntas por dimensiones, las cuales funcionaron como indicadores para cada dimensión, las cuales a la vez representan una parte de las categorías del estudio.

Estas dimensiones fueron abordadas en el Capítulo 2, en donde se resaltaron como elementos fundamentales para que la gamificación se desarrolle de manera exitosa (Hamari, 2015; Domínguez et al., 2013; Rincón-Flores, Ramírez-Montoya y Mena, 2016b). En este instrumento también se incluyeron preguntas sociodemográficas como género, edad, nivel de estudios y actividad. 
Tabla 33

Resultados sociodemográficos del instrumento sobre dimensiones de la gamificación.

\begin{tabular}{llllll}
\hline Nivel de estudios & Hombre & Mujer & Edad & Hombre & Mujer \\
\hline Preparatoria & 66 & 46 & Entre 16 y 20 años & 112 & 97 \\
Estudios técnicos & 17 & 9 & Entre 21 y 30 años & 217 & 122 \\
Universitario & 336 & 194 & Entre 31 y 40 años & 69 & 29 \\
Maestría & 62 & 21 & Entre 41 y 50 años & 51 & 15 \\
Doctorado & 8 & 5 & Entre 51 y 60 años & 36 & 12 \\
$\quad$ Actividad & 190 & 154 & Más de 60 años & 3 & 0 \\
Estudio & 144 & 62 & Total Hombres & 489 & \\
Estudio y trabajo & 155 & 59 & Total Mujeres & 275 & \\
Trabajo & & & & & \\
\hline
\end{tabular}

El cuestionario fue respondido por 764 participantes, de los cuales 489 fueron hombres y 275 fueron mujeres. En ambos géneros, el nivel de estudio que predominó fue el universitario, por consecuencia la mayoría se encontraba cursando sus estudios. Así mismo, la edad más frecuente fue entre 16 y 30 años (ver Tabla 33).

\subsubsection{Resultados cuantitativos de la dimensión cognitiva. A continuación, se} presentan los resultados por dimensión, de las preguntas con escala de Likert (Muy de acuerdo, de acuerdo, en desacuerdo y muy en desacuerdo). Los resultados de cada dimensión fueron procesados de manera global, por género, por nivel educativo y por edad.

Para la dimensión cognitiva, se establecieron las siguientes preguntas que aparecen en la Tabla 34. 


Tabla 34
\begin{tabular}{ll} 
Preguntas relacionadas a la dimensión cognitiva. \\
\hline Número de pregunta & Pregunta \\
\hline 1 & $\begin{array}{l}\text { La retroalimentación inmediata por parte de la platafoma en la } \\
\text { actividad del reto gamificado "Combustibles para iluminación en } \\
\text { caso de emergencia" me dieron oportunidad de analizar mejor mi } \\
\text { respuesta antes de volver a responder. }\end{array}$ \\
2 & $\begin{array}{l}\text { Resolver el reto gamificado "Combustibles para iluminación en caso } \\
\text { de emergencia" me ayudó a comprender mejor los temas } \\
\text { relacionados a esta actividad. }\end{array}$ \\
3 & $\begin{array}{l}\text { El nivel de dificultad del reto gamificado me pareció adecuado a } \\
\text { mis conocimientos sobre el tema. }\end{array}$ \\
\hline 4 & El reto gamificado favoreció mi desempeño en el examen final. \\
\hline
\end{tabular}

Los resultados de las preguntas relacionadas a la dimensión cognitiva aparecen en la Figura 30, como se puede ver, la mayoría, tanto hombres como mujeres, están de acuerdo o muy de acuerdo, con que el Reto Gamificado contribuyó de manera positiva en el aspecto cognitivo. Las preguntas 1 y 2 , fueron respondidas con mayor frecuencia para de acuerdo y muy de acuerdo, 96,7\% y 96,3\% respectivamente, mientras que la pregunta 4 fue la que tuvo menor frecuencia para de acuerdo y muy de acuerdo (88,8\%), incluso, fue el mayor porcentaje para en desacuerdo y muy en desacuerdo $(11,2 \%)$. 


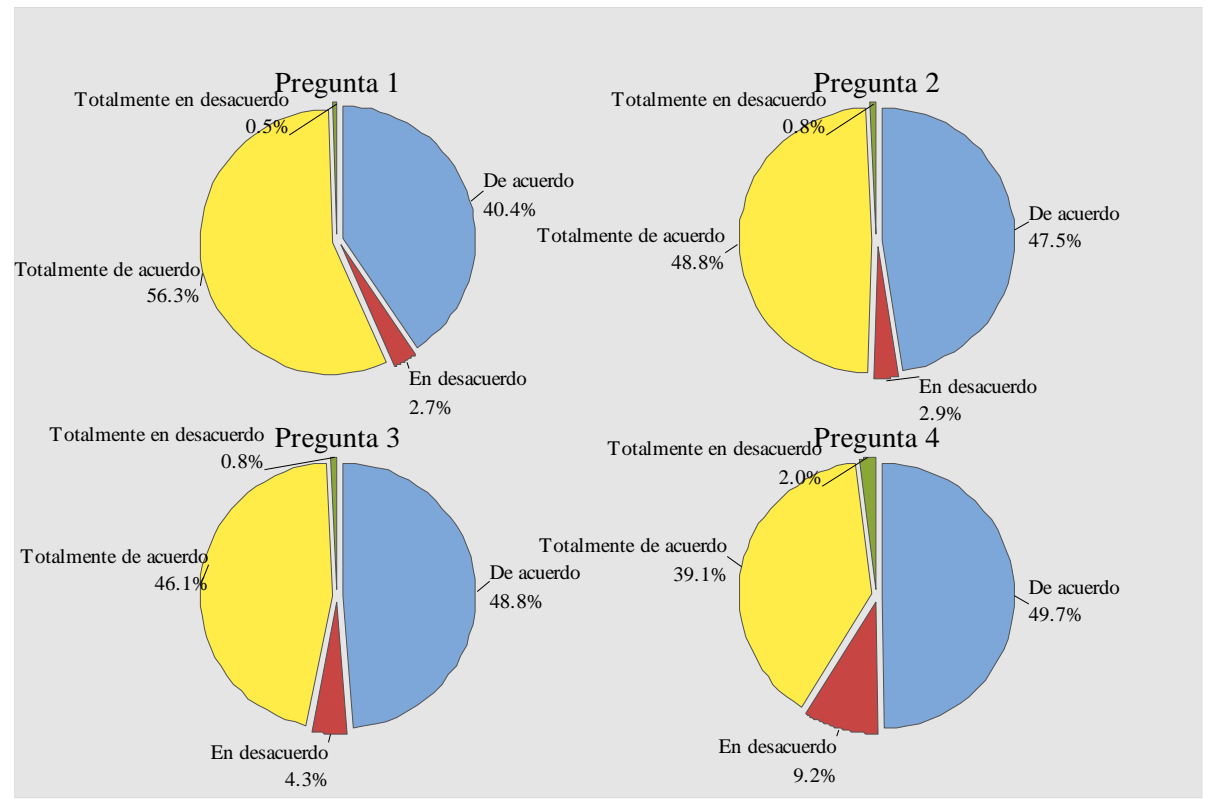

Figura 28. Resultados de la dimensión cognitiva global.

De manera más puntual, en la Tabla 35, se puede observar que tanto hombres como mujeres opinaron, en promedio, casi en la misma proporción en esta dimensión. Los hombres con un $94,7 \%$ y las mujeres con $93,3 \%$ en promedio. Aunque cuando se aplicó una prueba Chi-cuadrada, se obtuvo un p-valor menor al 5\%, por lo que se rechaza la hipótesis nula, ver Tabla 36.

Ho: No existe una asociación significativa entre el género y las respuestas de la dimensión cognitiva.

$H_{1}$ : Existe una asociación significativa entre el género y las respuestas de la dimensión cognitiva. 


\section{Tabla 35}

\begin{tabular}{llllll}
\multicolumn{6}{l}{ Frecuencias relativas y promedio de la dimensión cognitiva, por pregunta y por género. } \\
\hline Hombre & Pregunta 1 & Pregunta 2 & Pregunta 3 & Pregunta 4 & Promedio \\
\hline Totalmente de acuerdo & $58,9 \%$ & $51,7 \%$ & $48,1 \%$ & $42,3 \%$ & $50,3 \%$ \\
De acuerdo & $38,4 \%$ & $45,2 \%$ & $46,8 \%$ & $47,2 \%$ & $44,4 \%$ \\
En desacuerdo & $2,0 \%$ & $2,0 \%$ & $3,9 \%$ & $8,0 \%$ & $4,0 \%$ \\
$\begin{array}{l}\text { Totalmente en desacuerdo } \\
\text { Mujer }\end{array}$ & $0,6 \%$ & $1,0 \%$ & $1,2 \%$ & $2,5 \%$ & $1,3 \%$ \\
Totalmente de acuerdo & $51,6 \%$ & $43,6 \%$ & $42,5 \%$ & $33,5 \%$ & $42,8 \%$ \\
De acuerdo & $44,0 \%$ & $51,6 \%$ & $52,4 \%$ & $54,2 \%$ & $50,5 \%$ \\
En desacuerdo & $4,0 \%$ & $4,4 \%$ & $5,1 \%$ & $11,3 \%$ & $6,2 \%$ \\
Totalmente en desacuerdo & $0,4 \%$ & $0,4 \%$ & $0,0 \%$ & $1,1 \%$ & $0,5 \%$ \\
\hline
\end{tabular}

Esto quiere decir que, aunque la diferencia entre los hombres y mujeres es pequeña, sí es significativa, por lo que se puede concluir que los hombres estuvieron más favor con que el Reto Gamificado contribuye a la dimensión cognitiva que las mujeres. Para realizar este cálculo, se agruparon las respuestas de acuerdo y muy de acuerdo de las cuatro preguntas. De la misma manera, se agruparon las respuestas en desacuerdo y muy en desacuerdo de las cuatro preguntas. 
Tabla 36

Prueba Chi-cuadrada y tabla de contingencia para género y dimensión cognitiva.

\begin{tabular}{|c|c|c|c|c|c|}
\hline & $\begin{array}{l}\text { Muy de } \\
\text { acuerdo }\end{array}$ & $\begin{array}{l}\text { De } \\
\text { acuerdo }\end{array}$ & $\begin{array}{l}\text { En } \\
\text { desacuerdo }\end{array}$ & $\begin{array}{l}\text { Totalmente en } \\
\text { desacuerdo }\end{array}$ & Tota \\
\hline \multicolumn{6}{|l|}{ Hombre } \\
\hline Frecuencia observada & 983 & 869 & 78 & 26 & 1956 \\
\hline Frecuencia esperada & 930,64 & 912,07 & 93,45 & 19,84 & \\
\hline \multicolumn{6}{|l|}{ Mujer } \\
\hline Frecuencia observada & 471 & 556 & 68 & 5 & 1100 \\
\hline Frecuencia esperada & 523,36 & 512,93 & 52,55 & 11,16 & \\
\hline \multirow[t]{2}{*}{ Total } & 1454 & 1425 & 146 & 31 & 3056 \\
\hline & & $\begin{array}{l}\text { Chi- } \\
\text { cuadrada }\end{array}$ & $\mathrm{GL}$ & p-valor & \\
\hline Pearson & & 26,242 & 3 & 0,000 & \\
\hline $\begin{array}{l}\text { Relación } \\
\text { verosimilitud }\end{array}$ & & 26,791 & 3 & 0,000 & \\
\hline
\end{tabular}

Retomando la Tabla 35, también se puede observar, que los hombres están mayormente de acuerdo y muy de acuerdo $(96,9 \%)$ con que resolver el Reto Gamificado les ayudó a comprender mejor los temas relacionados a la actividad (Pregunta 2), mientras que las mujeres estuvieron de acuerdo y muy de acuerdo $(95,6 \%)$ con que la retroalimentación inmediata del reto les brindó oportunidad de analizar mejor su respuesta (Pregunta 1). Así mismo, tanto hombres como mujeres coinciden en estar mayormente en desacuerdo y muy en desacuerdo (10,4\% y $12,4 \%$, respectivamente) con que resolver el Reto Gamificado favoreció su desempeño en el examen final (Pregunta 4).

Con respecto al nivel educativo, se observa que el nivel universitario (licenciatura o ingeniería) están mayormente de acuerdo y muy de acuerdo $(95,5 \%)$ con que el reto 
gamificado favoreció la dimensión cognitiva, seguido del nivel preparatoria $(94,7 \%)$ y

del nivel técnico (94,3\%). Ver Tabla 37.

Tabla 37

Frecuencias relativas de la dimensión cognitiva por nivel educativo.

\begin{tabular}{llllll}
\hline Nivel Educativo & Pregunta 1 & Pregunta 2 & Pregunta 3 & Pregunta 4 & Promedio \\
\hline Preparatoria & & & & & \\
\hline Totalmente de acuerdo & $53,60 \%$ & $45,50 \%$ & $41,10 \%$ & $35,70 \%$ & $44,00 \%$ \\
\hline De acuerdo & $42,00 \%$ & $50,00 \%$ & $54,50 \%$ & $56,30 \%$ & $50,70 \%$ \\
\hline En desacuerdo & $4,50 \%$ & $3,60 \%$ & $4,50 \%$ & $7,10 \%$ & $4,90 \%$ \\
\hline Totalmente en desacuerdo & $0,00 \%$ & $0,90 \%$ & $0,00 \%$ & $0,90 \%$ & $0,40 \%$ \\
\hline Estudios técnicos & & & & & \\
Totalmente de acuerdo & $65,40 \%$ & $38,50 \%$ & $46,20 \%$ & $34,60 \%$ & $46,20 \%$ \\
\hline De acuerdo & $30,80 \%$ & $57,70 \%$ & $50,00 \%$ & $53,80 \%$ & $48,10 \%$ \\
\hline En desacuerdo & $3,80 \%$ & $3,80 \%$ & $3,80 \%$ & $7,70 \%$ & $4,80 \%$ \\
\hline Totalmente en desacuerdo & $0,00 \%$ & $0,00 \%$ & $0,00 \%$ & $3,80 \%$ & $1,00 \%$ \\
\hline Universitario & & & & & \\
\hline Totalmente de acuerdo & $55,70 \%$ & $49,20 \%$ & $47,40 \%$ & $40,90 \%$ & $48,30 \%$ \\
\hline De acuerdo & $42,30 \%$ & $47,90 \%$ & $48,90 \%$ & $49,60 \%$ & $47,20 \%$ \\
\hline En desacuerdo & $1,70 \%$ & $2,10 \%$ & $3,00 \%$ & $7,90 \%$ & $3,70 \%$ \\
\hline Totalmente en desacuerdo & $0,40 \%$ & $0,80 \%$ & $0,80 \%$ & $1.50 \%$ & $0,80 \%$ \\
\hline Maestría & & & & & \\
\hline Totalmente de acuerdo & $60,20 \%$ & $53,00 \%$ & $45,80 \%$ & $32,50 \%$ & $47,90 \%$ \\
\hline De acuerdo & $31,30 \%$ & $42,20 \%$ & $42,20 \%$ & $44,60 \%$ & $40,10 \%$ \\
\hline En desacuerdo & $7,20 \%$ & $4,80 \%$ & $10,80 \%$ & $18,10 \%$ & $10,20 \%$ \\
\hline Totalmente en desacuerdo & $1,20 \%$ & $0,00 \%$ & $1,20 \%$ & $4,80 \%$ & $1,80 \%$ \\
\hline Doctorado & & & & & \\
\hline Totalmente de acuerdo & $61,50 \%$ & $53,80 \%$ & $38,50 \%$ & $46,20 \%$ & $50,00 \%$ \\
\hline De acuerdo & $30,80 \%$ & $23,10 \%$ & $38,50 \%$ & $23,10 \%$ & $28,80 \%$ \\
\hline En desacuerdo & $0,00 \%$ & $15,40 \%$ & $15,40 \%$ & $23,10 \%$ & $13,50 \%$ \\
\hline Totalmente en desacuerdo & $7,70 \%$ & $7,70 \%$ & $7,70 \%$ & $7,70 \%$ & $7,70 \%$ \\
\hline & & & &
\end{tabular}

Según muestra la tabla 37, en todos los niveles -aunque ligeramente diferente en el nivel maestría- están mayormente de acuerdo con la pregunta uno (La retroalimentación inmediata por parte de la platafoma en la actividad del reto gamificado "Combustibles para iluminación en caso de emergencia" me dieron 
oportunidad de analizar mejor mi respuesta antes de volver a responder). Es decir, consideran que la retroalimentación inmediata favorece la dimensión cognitiva. Este mismo resultado se tuvo con la pregunta dos, que se refiere a que el Reto Gamificado favoreció la comprensión de los temas abordados en el curso.

Para validar los resultados anteriores, se aplicó la prueba Chi-cuadrada y se establecieron las siguientes hipótesis:

Ho: No existe una asociación significativa entre el nivel educativo y las respuestas de la dimensión cognitiva.

$H_{1}$ : Existe una asociación significativa entre el nivel educativo y las respuestas de la dimensión cognitiva.

Dado que el p-valor es menor que el estadístico de prueba, se rechaza la hipótesis nula, esto quiere decir que existe diferencia significativa entre el nivel educativo y las respuestas de la dimensión cognitiva, por lo tanto, el nivel universitario es el que mayormente está de acuerdo y muy de acuerdo con que el Reto Gamificado contribuye de manera positiva a la dimensión cognitiva, ver Tabla 38. 


\begin{tabular}{|c|c|c|c|}
\hline & $\begin{array}{l}\text { Muy de } \\
\text { acuerdo }\end{array}$ & $\begin{array}{l}\text { Muy en } \\
\text { desacuerdo }\end{array}$ & Total \\
\hline \multicolumn{4}{|l|}{ Doctorado } \\
\hline Frecuencia observada & 41 & 11 & 52 \\
\hline Frecuencia esperada & 48,99 & 3,01 & \\
\hline \multicolumn{4}{|l|}{ Maestría } \\
\hline Frecuencia observada & 292 & 40 & 332 \\
\hline Frecuencia esperada & 312,77 & 19,23 & \\
\hline \multicolumn{4}{|l|}{ Preparatoria } \\
\hline Frecuencia observada & 424 & 24 & 448 \\
\hline Frecuencia esperada & 422,05 & 25,95 & \\
\hline \multicolumn{4}{|l|}{ Técnica } \\
\hline Frecuencia observada & 98 & 6 & 104 \\
\hline Frecuencia esperada & 97,98 & 6,02 & \\
\hline \multicolumn{4}{|l|}{ Universidad } \\
\hline Frecuencia observada & 2024 & 96 & 2120 \\
\hline Frecuencia esperada & 1997,21 & 122,79 & \\
\hline \multirow[t]{2}{*}{ Total } & 2879 & 177 & 3056 \\
\hline & Chi-cuadrada & $\mathrm{GL}$ & p-valor \\
\hline Pearson & 52,665 & 4 & 0.000 \\
\hline Relación de verosimilitud & 39,206 & 4 & 0.000 \\
\hline
\end{tabular}

Para realizar el cálculo anterior, se agruparon las respuestas de acuerdo con la de muy de acuerdo, así como las de en descuerdo y muy en desacuerdo, sumando las respuestas de las cuatro preguntas, tal y como se hizo para el cálculo de la prueba Chicuadrada del género.

Finalmente, se presentan los resultados de acuerdo a la edad y la dimensión cognitiva. En la Tabla 39 se puede observar que los participantes entre 21 y 30 años son los que mayormente están de acuerdo o muy de acuerdo con que el reto 
gamificado favorece la dimensión cognitiva $(95,9 \%)$ seguido de los participantes de edades entre 16 y 20 años (94,9\%) y de los de 31 y 40 años (92,8\%).

Tabla 39

Frecuencias relativas de la dimensión cognitiva por edad.

\begin{tabular}{llllll}
\hline Edad & Pregunta 1 & Pregunta 2 & Pregunta 3 & Pregunta 4 & Promedio \\
\hline Entre 16 y 20 años & & & & & \\
\hline Totalmente de acuerdo & $52,4 \%$ & $44,8 \%$ & $44,8 \%$ & $36,7 \%$ & $44,6 \%$ \\
\hline De acuerdo & $44,3 \%$ & $51 \%$ & $50,5 \%$ & $55,2 \%$ & $50,2 \%$ \\
\hline En desacuerdo & $2,9 \%$ & $3,3 \%$ & $4,3 \%$ & $7,1 \%$ & $4,4 \%$ \\
\hline Totalmente en desacuerdo & $0,5 \%$ & $1,0 \%$ & $0,5 \%$ & $1,0 \%$ & $0,7 \%$ \\
\hline Entre 21 y 30 años & & & & & \\
\hline Totalmente de acuerdo & $56,3 \%$ & $49,9 \%$ & $47,5 \%$ & $41,3 \%$ & $48,7 \%$ \\
\hline De acuerdo & $41,3 \%$ & $47,5 \%$ & $49,6 \%$ & $50,4 \%$ & $47,2 \%$ \\
\hline En desacuerdo & $2,1 \%$ & $2,1 \%$ & $2,4 \%$ & $7,4 \%$ & $3,5 \%$ \\
\hline Totalmente en desacuerdo & $0,3 \%$ & $0,6 \%$ & $0,6 \%$ & $0,9 \%$ & $0,6 \%$ \\
\hline Entre 31y 40 años & & & & & \\
\hline Totalmente de acuerdo & $58,2 \%$ & $49,0 \%$ & $39,8 \%$ & $36,7 \%$ & $45,9 \%$ \\
\hline De acuerdo & $39,8 \%$ & $49,0 \%$ & $52,0 \%$ & $46,9 \%$ & $46,9 \%$ \\
\hline En desacuerdo & $2,0 \%$ & $2,0 \%$ & $7,1 \%$ & $11,2 \%$ & $5,6 \%$ \\
\hline Totalmente en desacuerdo & $0,0 \%$ & $0,0 \%$ & $1,0 \%$ & $5,1 \%$ & $1,5 \%$ \\
\hline Entre 41 y 50 años & & & & & \\
\hline Totalmente de acuerdo & $53,0 \%$ & $45,5 \%$ & $45,5 \%$ & $33,3 \%$ & $44,3 \%$ \\
\hline De acuerdo & $39,4 \%$ & $45,5 \%$ & $42,4 \%$ & $45,5 \%$ & $43,2 \%$ \\
\hline En desacuerdo & $4,5 \%$ & $6,1 \%$ & $9,1 \%$ & $15,2 \%$ & $8,7 \%$ \\
\hline Totalmente en desacuerdo & $3,0 \%$ & $3,0 \%$ & $3,0 \%$ & $6,1 \%$ & $3,8 \%$ \\
\hline Más de 51 años & & & & & \\
\hline Totalmente de acuerdo & $72,5 \%$ & $62,7 \%$ & $54,9 \%$ & $47,1 \%$ & $59,3 \%$ \\
\hline De acuerdo & $21,6 \%$ & $33,3 \%$ & $39,2 \%$ & $35,3 \%$ & $32,4 \%$ \\
\hline En desacuerdo & $5,9 \%$ & $3,9 \%$ & $5,9 \%$ & $17,6 \%$ & $8,3 \%$ \\
\hline
\end{tabular}

Nuevamente para validar lo anterior, se aplicó la prueba Chi-cuadrada y se establecieron las siguientes hipótesis:

Ho: No existe una asociación significativa entre la edad y las respuestas de la dimensión cognitiva. 
$H_{1}$ : Existe una asociación significativa entre la edad y las respuestas de la dimensión cognitiva.

Dado que la prueba arrojó un p-valor menor al 5\%, se rechaza la hipótesis nula.

Esto quiere decir que existe diferencia significativa entre la edad y las respuestas de la dimensión cognitiva, ver Tabla 40.

\begin{tabular}{|c|c|c|c|}
\hline Edad & Muy de acuerdo & Muy en desacuerdo & Total \\
\hline \multicolumn{4}{|l|}{16 a 20 años } \\
\hline Frecuencia observada & 797 & 43 & 840 \\
\hline Frecuencia esperada & 791,6 & 48,4 & \\
\hline \multicolumn{4}{|l|}{21 a 30 años } \\
\hline Frecuencia observada & 1301 & 55 & 1356 \\
\hline Frecuencia esperada & 1277,9 & 78,1 & \\
\hline \multicolumn{4}{|l|}{31 a 40 años } \\
\hline Frecuencia observada & 364 & 28 & 392 \\
\hline Frecuencia esperada & 369,4 & 22,6 & \\
\hline \multicolumn{4}{|l|}{41 a 50 años } \\
\hline Frecuencia observada & 231 & 33 & 264 \\
\hline Frecuencia esperada & 248,8 & 15,2 & \\
\hline \multicolumn{4}{|l|}{ más de 50 años } \\
\hline Frecuencia observada & 187 & 17 & 204 \\
\hline Frecuencia esperada & 192,3 & 11,7 & \\
\hline \multirow[t]{2}{*}{ Total } & 2880 & 176 & 3056 \\
\hline & Chi-cuadrada & $G L$ & $p$-valor \\
\hline Pearson & 33,857 & 4 & 0,000 \\
\hline Relación de verosimilitud & 29,049 & 4 & 0,000 \\
\hline
\end{tabular}

Esto quiere decir que los participantes entre 21 y 30 años están más de acuerdo y muy de acuerdo con que el reto favoreció la dimensión cognitiva, particularmente que contribuyó positivamente en el desempeño de la evaluación final y que tener una retroalimentación inmediata les permitió reflexionar en su respuesta. 
A partir de los resultados mostrados, se puede observar que hay cierta congruencia, pues la mayor inclinación fue con respecto a la pregunta uno por parte de los hombres, la pregunta dos por parte de las mujeres. Los participantes de entre 21 y 30 años se inclinaron más por las preguntas uno y dos, así como los universitarios.

\subsubsection{Resultados cualitativos de la dimensión cognitiva. La pregunta fue}

respondida por 753 de 764 participantes que respondieron la sección con escala de Likert, la cual correspondió a ¿De qué manera resolver el Reto Gamificado contribuyó a tu aprendizaje? Las respuestas se categorizaron en tres aspectos, los cuales fueron lo que tuvieron mayor frecuencia: 1) Contribuyó a aplicar los conocimientos vistos, 2) A analizar el problema y las respuestas, 3) A investigar o saber más sobre el tema, en las tres categorías, los participantes de nivel universitario fueron los más predominantes los cuales correspondieron a las edades de entre 16 y 30 años mayormente.

Es importante destacar que hubo 32 participantes (4.25\%) que no estuvieron de acuerdo con que el reto favoreció a su aprendizaje, algunos de estos comentaron que se debió a que les pareció muy fácil o no dieron alguna justificación. Estos participantes correspondieron mayormente al nivel universitario y maestría.

4.1.1.2 Resultados cuantitativos de la dimensión social. La dimensión social está relacionada con el hecho de que los estudiantes o participantes puedan socializar su 
conocimiento y sus resultados (Nisbet y Williams, 2009; Domínguez et al., 2013), en la

Tabla 41 se muestran las preguntas relacionadas a esta dimensión.

\section{Tabla 41}

Preguntas relacionadas a la dimensión social.

\begin{tabular}{ll}
\hline Número de pregunta & Pregunta \\
\hline 5 & $\begin{array}{l}\text { Ver tablero de liderazgo me motivó positivamente a resolver el reto } \\
\text { gamificado. }\end{array}$ \\
& $\begin{array}{l}\text { Ver los resultados de mis compañeros y el mío en el tablero de } \\
\text { liderazgo me hizo sentir motivado para resolver más ejercicios de } \\
\text { este tipo. }\end{array}$ \\
& $\begin{array}{l}\text { Me hubiera gustado resolver el reto gamificado con ayuda de otro } \\
\text { compañero del curso. } \\
7\end{array}$ \\
& $\begin{array}{l}\text { Me hubiera gustado que mis compañeros leyeran mi propuesta } \\
\text { alternativa al reto gamificado. }\end{array}$ \\
\hline
\end{tabular}

En la Figura 31 se puede ver la distribución en general para las preguntas de la cinco a la ocho, las cuales corresponden a la dimensión social. Se puede observar que la pregunta seis fue en la que estuvieron mayormente muy de acuerdo y de acuerdo, mientras que la pregunta siete fue en la que mayormente estuvieron muy en desacuerdo y en desacuerdo. 


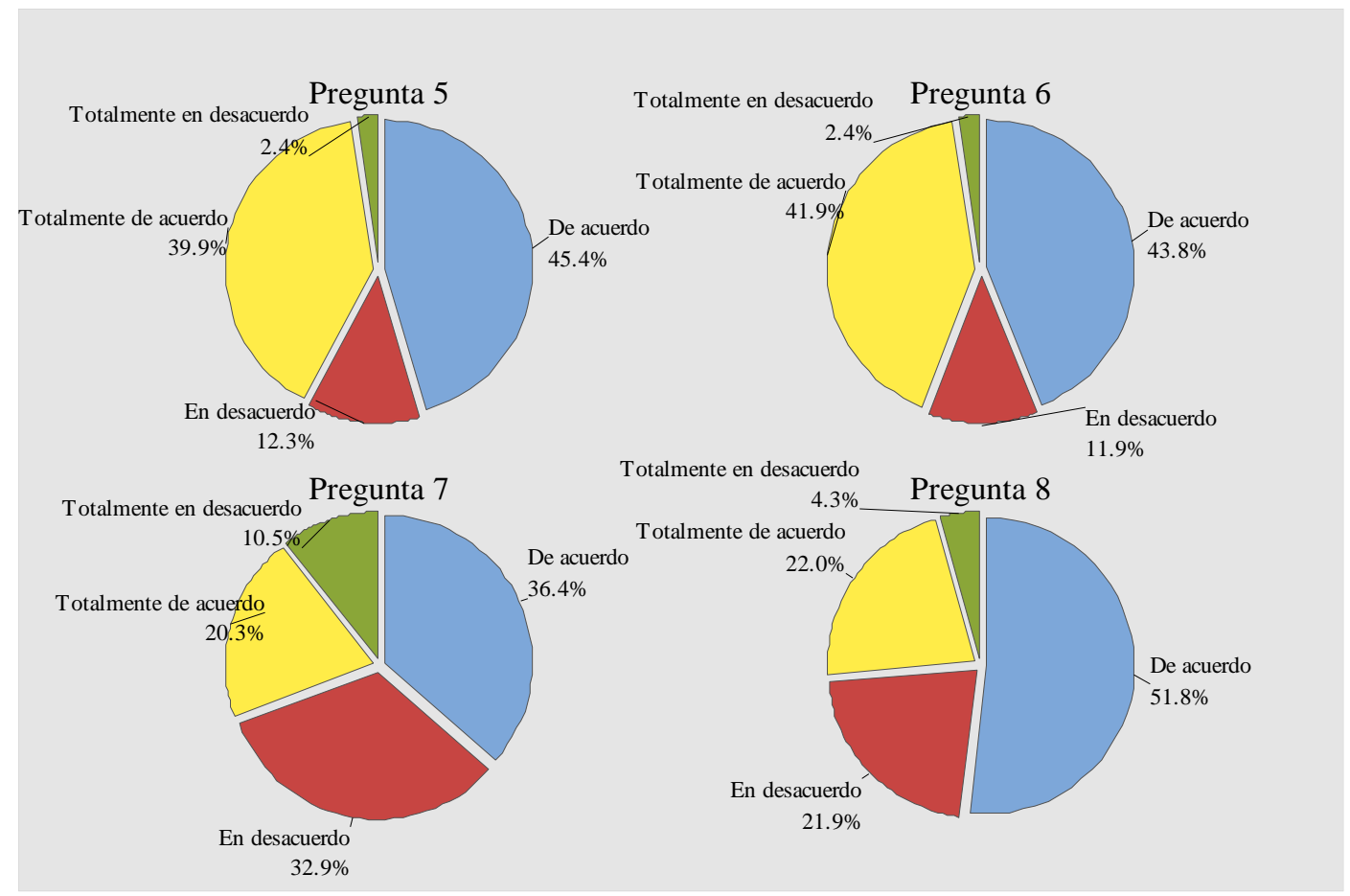

Figura 29. Distribución general de la dimensión social.

Esto quiere decir que los participantes estuvieron mayormente de acuerdo con que al ver los resultados de sus compañeros y el suyo en el tablero de liderazgo los hizo sentir motivados para resolver más ejercicios de este tipo, no obstante, mayormente estuvieron muy en desacuerdo y en desacuerdo con que "Me hubiera gustado resolver el Reto Gamificado con ayuda de otro compañero del curso", es decir, muestran mayor preferencia por resolver el Reto Gamificado de manera individual.

En la Tabla 42, se presentan los resultados por pregunta y por género, en donde se observa que los hombres están mayormente muy de acuerdo y de acuerdo con que el Reto Gamificado favoreció la dimensión social. Los hombres estuvieron mayormente muy de acuerdo y de acuerdo con que ver los resultados tanto individual como de los 
compañeros en el tablero de liderazgo los hizo sentir motivados para resolver más ejercicios de este tipo (pregunta seis), mientras que las mujeres estuvieron más de acuerdo y muy de acuerdo con que con solo ver el tablero de liderazgo se motivaron positivamente a resolver el Reto Gamificado (pregunta cinco).

Tabla 42

Respuestas de las preguntas por género y dimensión social.

\begin{tabular}{llllll}
\hline Género & Pregunta 5 & Pregunta 6 & Pregunta 7 & Pregunta 8 & Promedio \\
\hline Hombre & & & & & \\
$\quad$ Totalmente de acuerdo & $42,1 \%$ & $45,0 \%$ & $22,7 \%$ & $24,5 \%$ & $33,6 \%$ \\
\hline De acuerdo & $43,1 \%$ & $42,1 \%$ & $34,4 \%$ & $54,6 \%$ & $43,6 \%$ \\
\hline En desacuerdo & $11,9 \%$ & $10,2 \%$ & $31,3 \%$ & $16,4 \%$ & $17,4 \%$ \\
\hline Totalmente en desacuerdo & $2,9 \%$ & $2,7 \%$ & $11,7 \%$ & $4,5 \%$ & $5,4 \%$ \\
\hline Mujer & & & & & \\
$\quad$ Totalmente de acuerdo & $36,0 \%$ & $36,4 \%$ & $16,0 \%$ & $17,5 \%$ & $26,5 \%$ \\
$\quad$ De acuerdo & $49,5 \%$ & $46,9 \%$ & $40,0 \%$ & $46,9 \%$ & $45,8 \%$ \\
\hline En desacuerdo & $13,1 \%$ & $14,9 \%$ & $35,6 \%$ & $31,6 \%$ & $23,8 \%$ \\
\hline Totalmente en desacuerdo & $1,5 \%$ & $1,8 \%$ & $8,4 \%$ & $4,0 \%$ & $3,9 \%$ \\
\hline
\end{tabular}

Cabe aclarar que antes de comenzar el reto se les avisa a los participantes que verán sus resultados en un tablero y que una vez que lo resuelvan podrán ver los propios resultados y los de sus compañeros. Al mismo tiempo, se encontró que ambos géneros están muy en desacuerdo y descuerdo con la pregunta siete, es decir, hombres y mujeres prefieren resolver el reto de manera individual.

Al igual que en la dimensión cognitiva, para reforzar los resultados anteriores se establecieron las siguientes hipótesis y se corrió una prueba Chi-cuadrada. 
Ho: No existe una asociación significativa entre el género y las respuestas de la dimensión social.

$H_{1}$ : Existe una asociación significativa entre el género y las respuestas de la dimensión social.

\section{Tabla 43}

\begin{tabular}{|c|c|c|c|c|c|}
\hline & $\begin{array}{l}\text { Muy de } \\
\text { acuerdo }\end{array}$ & $\begin{array}{l}\text { De } \\
\text { acuerdo }\end{array}$ & $\begin{array}{l}\text { En } \\
\text { desacuerdo }\end{array}$ & $\begin{array}{l}\text { Totalmente } \\
\text { en desacuerdo }\end{array}$ & Todo \\
\hline \multicolumn{6}{|l|}{ Hombre } \\
\hline Frecuencia observada & 657 & 852 & 341 & 106 & 1956 \\
\hline Frecuencia esperada & 606,8 & 867,9 & 386,0 & 95,4 & \\
\hline \multicolumn{6}{|l|}{ Mujer } \\
\hline Frecuencia observada & 291 & 504 & 262 & 43 & 1100 \\
\hline Frecuencia esperada & 341,2 & 488,1 & 217,0 & 53,6 & \\
\hline \multirow[t]{2}{*}{ Total } & 948 & 1356 & 603 & 149 & 3056 \\
\hline & Chi-cuadrada & $\mathrm{GL}$ & p-valor & & \\
\hline Pearson & 30,201 & 3 & 0,000 & & \\
\hline Relación de verosimilitud & 30,225 & 3 & 0,000 & & \\
\hline
\end{tabular}

Dado que el p-valor fue menor que alfa (5\%), se rechaza la hipótesis nula, esto significa que, si hay una asociación entre el género y la dimensión social, por lo que se podría decir que las diferencias comentadas anteriormente, son significativas, ver Tabla 43.

Ahora, veamos qué sucedió con el nivel educativo. En la Tabla 44 se observan los resultados por nivel educativo y las preguntas cinco a la ocho que corresponden a la dimensión social. En esta, se puede observar que de los estudios técnicos al universitario estuvieron de acuerdo y totalmente de acuerdo con la dimensión social 
mientras que los niveles de maestría y doctorado, estuvieron menos de acuerdo y totalmente de acuerdo.

\section{Tabla 44}

Frecuencias relativas de la dimensión social por nivel educativo.

\begin{tabular}{llllll}
\hline Nivel educativo & Pregunta 5 & Pregunta 6 & Pregunta 7 & Pregunta 8 & Promedio \\
\hline Estudios técnicos & & & & & \\
\hline Totalmente de acuerdo & $50,0 \%$ & $38,5 \%$ & $26,9 \%$ & $23,1 \%$ & $34,6 \%$ \\
\hline De acuerdo & $46,2 \%$ & $57,7 \%$ & $34,6 \%$ & $42,3 \%$ & $45,2 \%$ \\
\hline En desacuerdo & $3,8 \%$ & $3,8 \%$ & $26,9 \%$ & $30,8 \%$ & $16,3 \%$ \\
\hline Totalmente en desacuerdo & $0,0 \%$ & $0,0 \%$ & $11,5 \%$ & $3,8 \%$ & $3,8 \%$ \\
\hline Preparatoria & & & & & \\
\hline Totalmente de acuerdo & $39,3 \%$ & $45,5 \%$ & $20,5 \%$ & $23,2 \%$ & $32,1 \%$ \\
\hline De acuerdo & $46,4 \%$ & $42,0 \%$ & $41,1 \%$ & $49,1 \%$ & $44,6 \%$ \\
\hline En desacuerdo & $12,5 \%$ & $10,7 \%$ & $32,1 \%$ & $25,0 \%$ & $20,1 \%$ \\
\hline Totalmente en desacuerdo & $1,8 \%$ & $1,8 \%$ & $6,3 \%$ & $2,7 \%$ & $3,1 \%$ \\
\hline Universitario & & & & & \\
\hline Totalmente de acuerdo & $40,2 \%$ & $42,5 \%$ & $20,8 \%$ & $21,9 \%$ & $31,3 \%$ \\
\hline De acuerdo & $47,5 \%$ & $44,9 \%$ & $37,2 \%$ & $52,5 \%$ & $45,5 \%$ \\
\hline En desacuerdo & $10,6 \%$ & $10,8 \%$ & $32,5 \%$ & $21,3 \%$ & $18,8 \%$ \\
\hline Totalmente en desacuerdo & $1,7 \%$ & $1,9 \%$ & $9,6 \%$ & $4,3 \%$ & $4,4 \%$ \\
\hline Maestría & & & & & \\
\hline Totalmente de acuerdo & $37,3 \%$ & $36,1 \%$ & $15,7 \%$ & $22,9 \%$ & $28,0 \%$ \\
\hline De acuerdo & $33,7 \%$ & $37,3 \%$ & $26,5 \%$ & $54,2 \%$ & $38,0 \%$ \\
\hline En desacuerdo & $21,7 \%$ & $19,3 \%$ & $39,8 \%$ & $18,1 \%$ & $24,7 \%$ \\
\hline Totalmente en desacuerdo & $7,2 \%$ & $7,2 \%$ & $18,1 \%$ & $4,8 \%$ & $9,3 \%$ \\
\hline Doctorado & & & & & \\
\hline Totalmente de acuerdo & $30,8 \%$ & $30,8 \%$ & $15,4 \%$ & $7,7 \%$ & $21,2 \%$ \\
\hline De acuerdo & $23,1 \%$ & $30,8 \%$ & $30,8 \%$ & $53,8 \%$ & $34,6 \%$ \\
\hline En desacuerdo & $38,5 \%$ & $38,5 \%$ & $23,1 \%$ & $23,1 \%$ & $30,8 \%$ \\
\hline Totalmente en desacuerdo & $7,7 \%$ & $0,0 \%$ & $30,8 \%$ & $15,4 \%$ & $13,5 \%$ \\
\hline
\end{tabular}

También se aprecia que las preguntas más favorables fueron la cinco y la seis, desde los niveles de estudios técnicos y universitarios, esto quiere decir que estuvieron más de acuerdo con que ver el tablero, así como los resultados de sus compañeros y propios, los motivó positivamente en la realización del reto. Para los niveles de maestría 
y doctorado, se mostraron más a favor con las preguntas seis y ocho, es decir, los motivó el hecho de ver sus resultados y el de sus compañeros en el tablero, aunque les hubiera gustado que sus compañeros vieran las respuestas alternativas al reto gamificado.

Ahora bien, vamos a establecer las hipótesis:

Ho: No existe una asociación significativa entre el nivel educativo y las respuestas de la dimensión social.

$H_{1}$ : Existe una asociación significativa entre el nivel educativo y las respuestas de la dimensión social.

En la Tabla 45 se puede observar la tabla de contingencia para el nivel educativo y la dimensión social, así como el resultado de la prueba Chi-cuadrada. Dado que pvalor es menor al 5\% se rechaza la hipótesis nula y se acepta la nula, es decir existe una asociación significativa entre el nivel educativo y las respuestas de la dimensión social.

\begin{tabular}{|c|c|c|c|}
\hline & $\begin{array}{l}\text { Muy de } \\
\text { acuerdo }\end{array}$ & $\begin{array}{l}\text { Muy en } \\
\text { desacuerdo }\end{array}$ & Total \\
\hline \multicolumn{4}{|l|}{ Técnica } \\
\hline Frecuencia observada & 83 & 21 & 104 \\
\hline Frecuencia esperada & 78,4 & 25,6 & \\
\hline \multicolumn{4}{|l|}{ Preparatoria } \\
\hline Frecuencia observada & 344 & 104 & 448 \\
\hline Frecuencia esperada & 337,8 & 110,2 & \\
\hline \multicolumn{4}{|l|}{ Universidad } \\
\hline Frecuencia observada & 1629 & 491 & 2120 \\
\hline
\end{tabular}




\begin{tabular}{llll}
\hline $\begin{array}{l}\text { Frecuencia esperada } \\
\text { Maestría }\end{array}$ & 1598,3 & 521,7 & \\
\hline $\begin{array}{c}\text { Frecuencia observada } \\
\text { Frecuencia esperada }\end{array}$ & 219 & 113 & 332 \\
\hline $\begin{array}{c}\text { Doctorado } \\
\text { Frecuencia observada }\end{array}$ & 290,3 & 81,7 & \\
\hline Frecuencia esperada & 39,2 & 23 & 52 \\
\hline Total & 2304 & 12,8 & \\
\hline & Chi-cuadrada & DF & p-valor \\
\hline Pearson & 30,657 & 4 & 0,000 \\
\hline Relación de verosimilitud & 28,320 & 4 & 0,000 \\
\hline
\end{tabular}

En cuanto a los resultados de las preguntas cinco, seis, siete y ocho con respecto

a la edad y la dimensión social, se tuvieron los siguientes resultados, ver Tabla 46.

\section{Tabla 46}

Respuestas por edad para la dimensión social.

\begin{tabular}{llllll}
\hline Edad & Pregunta 5 & Pregunta 6 & Pregunta 7 & Pregunta 8 & Promedio \\
\hline Entre 15 y 20 años & & & & & \\
\hline Totalmente de acuerdo & $41,4 \%$ & $44,8 \%$ & $25,2 \%$ & $21,9 \%$ & $33,3 \%$ \\
\hline De acuerdo & $48,6 \%$ & $43,8 \%$ & $43,3 \%$ & $53,3 \%$ & $47,3 \%$ \\
\hline En desacuerdo & $8,6 \%$ & $8,6 \%$ & $26,7 \%$ & $23,3 \%$ & $16,8 \%$ \\
\hline Totalmente en desacuerdo & $1,4 \%$ & $2,9 \%$ & $4,8 \%$ & $1,4 \%$ & $2,6 \%$ \\
\hline Entre 21 y 30 años & & & & & \\
\hline Totalmente de acuerdo & $40,7 \%$ & $42,5 \%$ & $22,7 \%$ & $24,5 \%$ & $32,6 \%$ \\
\hline De acuerdo & $46,0 \%$ & $44,8 \%$ & $36,9 \%$ & $51,0 \%$ & $44,7 \%$ \\
\hline En desacuerdo & $11,5 \%$ & $11,8 \%$ & $30,4 \%$ & $20,4 \%$ & $18,5 \%$ \\
\hline Totalmente en desacuerdo & $1,8 \%$ & $0,9 \%$ & $10,0 \%$ & $4,1 \%$ & $4,2 \%$ \\
\hline Entre 31 y 40 años & & & & & \\
\hline Totalmente de acuerdo & $39,8 \%$ & $39,8 \%$ & $14,3 \%$ & $20,4 \%$ & $28,6 \%$ \\
\hline De acuerdo & $39,8 \%$ & $41,8 \%$ & $25,5 \%$ & $48,0 \%$ & $38,8 \%$ \\
\hline En desacuerdo & $16,3 \%$ & $13,3 \%$ & $41,8 \%$ & $22,4 \%$ & $23,5 \%$ \\
\hline Totalmente en desacuerdo & $4,1 \%$ & $5,1 \%$ & $18,4 \%$ & $9,2 \%$ & $9,2 \%$ \\
\hline Entre 41 y 50 años & & & & & \\
\hline Totalmente de acuerdo & $34,8 \%$ & $34,8 \%$ & $4,5 \%$ & $9,1 \%$ & $20,8 \%$ \\
\hline De acuerdo & $42,4 \%$ & $42,4 \%$ & $33,3 \%$ & $60,6 \%$ & $44,7 \%$ \\
\hline En desacuerdo & $16,7 \%$ & $18,2 \%$ & $43,9 \%$ & $24,2 \%$ & $25,8 \%$ \\
\hline Totalmente en desacuerdo & $6,1 \%$ & $4,5 \%$ & $18,2 \%$ & $6,1 \%$ & $8,7 \%$ \\
\hline Más de 50 años & & & & & \\
\hline Totalmente de acuerdo & $35,3 \%$ & $39,2 \%$ & $15,7 \%$ & $25,5 \%$ & $28,9 \%$ \\
\hline De acuerdo & $43,1 \%$ & $43,1 \%$ & $31,4 \%$ & $47,1 \%$ & $41,2 \%$ \\
\hline
\end{tabular}




\begin{tabular}{llllll} 
En desacuerdo & $19,6 \%$ & $15,7 \%$ & $43,1 \%$ & $21,6 \%$ & $25,0 \%$ \\
Totalmente en desacuerdo & $2,0 \%$ & $2,0 \%$ & $9,8 \%$ & $5,9 \%$ & $4,9 \%$ \\
\hline
\end{tabular}

En cuanto a la edad, en general, los participantes entre 15 y 30 años están más de acuerdo con que el Reto Gamificado favorece la dimensión social mientras que los participantes entre 31 y 50 años están más en desacuerdo. Los participantes entre 15 y 20 años y de 41 años en adelante, estuvieron más de acuerdo con la pregunta cinco, es decir, con el hecho de que al ver el tablero se sintieron más motivados mientras que los participantes de 21 a 40 años estuvieron más motivados con el hecho de ver los resultados de sus compañeros en el tablero, en otras palabras, los motivó más competir con otros participantes (pregunta seis).

Por otro lado, llama la atención que los participantes entre 15 y 40 años estuvieron más en desacuerdo con que resolver el reto gamificado con otro compañero hubiera sido mejor (pregunta siete) mientras que los mayores de 40 años estuvieron más en desacuerdo con competir con otros compañeros (pregunta seis). Así que podemos decir que el uso del tablero motivó la resolución del reto gamificado y que, además, la mayor parte de los participantes prefieren resolverlo de manera individual.

Ahora bien, vamos a establecer las hipótesis para validar los resultados anteriores: 
Ho: No existe una asociación significativa entre la edad y las respuestas de la dimensión social.

$H_{7}$ : Existe una asociación significativa entre la edad y las respuestas de la dimensión social.

\section{Tabla 47}

Respuestas por edad para la dimensión social.

\begin{tabular}{|c|c|c|c|c|c|}
\hline & $\begin{array}{l}\text { Muy de } \\
\text { acuerdo }\end{array}$ & $\begin{array}{l}\text { De } \\
\text { acuerdo }\end{array}$ & $\begin{array}{l}\text { En } \\
\text { desacuerdo }\end{array}$ & $\begin{array}{l}\text { Muy en } \\
\text { desacuerdo }\end{array}$ & Total \\
\hline \multicolumn{6}{|l|}{16 a 20 años } \\
\hline Frecuencia observada & 280 & 397 & 141 & 22 & 840 \\
\hline Frecuencia esperada & 260,58 & 373,00 & 165,75 & 40,68 & \\
\hline \multicolumn{6}{|l|}{21 a 30 años } \\
\hline Frecuencia observada & 442 & 606 & 251 & 57 & 1356 \\
\hline Frecuencia esperada & 420,64 & 602,12 & 267,56 & 65,67 & \\
\hline \multicolumn{6}{|l|}{31 a 40 años } \\
\hline Frecuencia observada & 112 & 152 & 92 & 36 & 392 \\
\hline Frecuencia esperada & 121,60 & 174,07 & 77,35 & 18,98 & \\
\hline \multicolumn{6}{|l|}{41 a 50 años } \\
\hline Frecuencia observada & 55 & 118 & 68 & 23 & 264 \\
\hline Frecuencia esperada & 81,90 & 117,23 & 52,09 & 12,79 & \\
\hline \multicolumn{6}{|l|}{ más de 50 años } \\
\hline Frecuencia observada & 59 & 84 & 51 & 10 & 204 \\
\hline Frecuencia esperada & 63,28 & 90,59 & 40,25 & 9,88 & \\
\hline \multirow[t]{2}{*}{ Total } & 948 & 1357 & 603 & 148 & 3056 \\
\hline & & & Chi-cuadrada & $\mathrm{GL}$ & p-valor \\
\hline Pearson & & & 65,623 & 12 & 0,000 \\
\hline Relación de verosimilitud & & & 63,275 & 12 & 0,000 \\
\hline
\end{tabular}

En la Tabla 47 se muestra que el $p$-valor es menor al 5\% por lo que se rechaza la hipótesis nula, por lo tanto, existe una asociación ente la edad y las respuestas de la dimensión social, así que se puede decir que los resultados presentados muestran diferencias y coincidencias en las distintas edades. 
En resumen, en esta dimensión los hombres estuvieron mayormente de acuerdo y muy de acuerdo con la pregunta seis mientras que las mujeres con la pregunta cinco. Los participantes de nivel técnico y universitario estuvieron a favor de las mismas preguntas, no obstante, las personas de nivel maestría y doctorado se proclamaron más a favor de las preguntas siete y ocho, es decir estos prefieren trabajar colaborativamente y socializar sus resultados, mientras que los de nivel técnico y universitario prefieren competir de manera individual.

\subsubsection{Resultados cualitativos de la dimensión social. La pregunta que se relacionó} con esta dimensión fue ¿De qué manera afectó tu desempeño en el Reto Gamificado cuando supiste que tu resultado aparecería en un tablero de liderazgo? La pregunta fue respondida por 753 de 764 participantes, las respuestas se categorizaron en dos: 1) No me afectó de ninguna manera y 2) Me motivó a esforzarme. En estas respuestas predominaron los universitarios, seguidos de los niveles maestría y preparatoria.

Aunque las respuestas: "no me gustó", "me puse nervioso" tuvieron muy poca frecuencia (15) puede resultar un foco de alerta para mejorar la actividad.

4.1.2.4 Resultados de la dimensión emotiva. Finalmente, para la dimensión emotiva se aplicaron las siguientes preguntas, ver Tabla 48. Esta dimensión tiene que ver con la emoción que se provoca cuando una persona participa en una actividad gamificada (Domínguez et al., 2013; Hanus y Fox, 2015; Nisbet y Williams, 2008), por 
ejemplo, cuando recibe retroalimentación inmediata y ésta es positiva puede experimentar una sensación de logro mientras que, si la respuesta es negativa puede sentirse retado o decepcionado, por ello es importante ofrecer varios intentos.

\section{Tabla 48}

Preguntas relacionadas a la dimensión emotiva.

\begin{tabular}{|c|c|}
\hline Número de pregunta & Pregunta \\
\hline 9 & $\begin{array}{l}\text { El haber obtenido una insignia de trofeo de oro, plata o bronce en } \\
\text { el reto me hizo sentir muy bien. }\end{array}$ \\
\hline 10 & $\begin{array}{l}\text { El haber tenido varias oportunidades para resolver correctamente el } \\
\text { reto gamificado me motivó positivamente para resolverlo otra vez. }\end{array}$ \\
\hline 11 & $\begin{array}{l}\text { Resolver correctamente el reto gamificado dentro de los tres } \\
\text { primeros intentos me hizo sentir satisfecho con mi capacidad. }\end{array}$ \\
\hline 12 & Competir para ganar un trofeo me pareció emocionante. \\
\hline
\end{tabular}

En la Figura 30 se muestra una visión general de las respuestas de la dimensión emotiva, a simple vista se observa que el porcentaje de totalmente de acuerdo y de acuerdo fue menor que en las dimensiones cognitiva y social. Esto se probará al final de esta sección. 


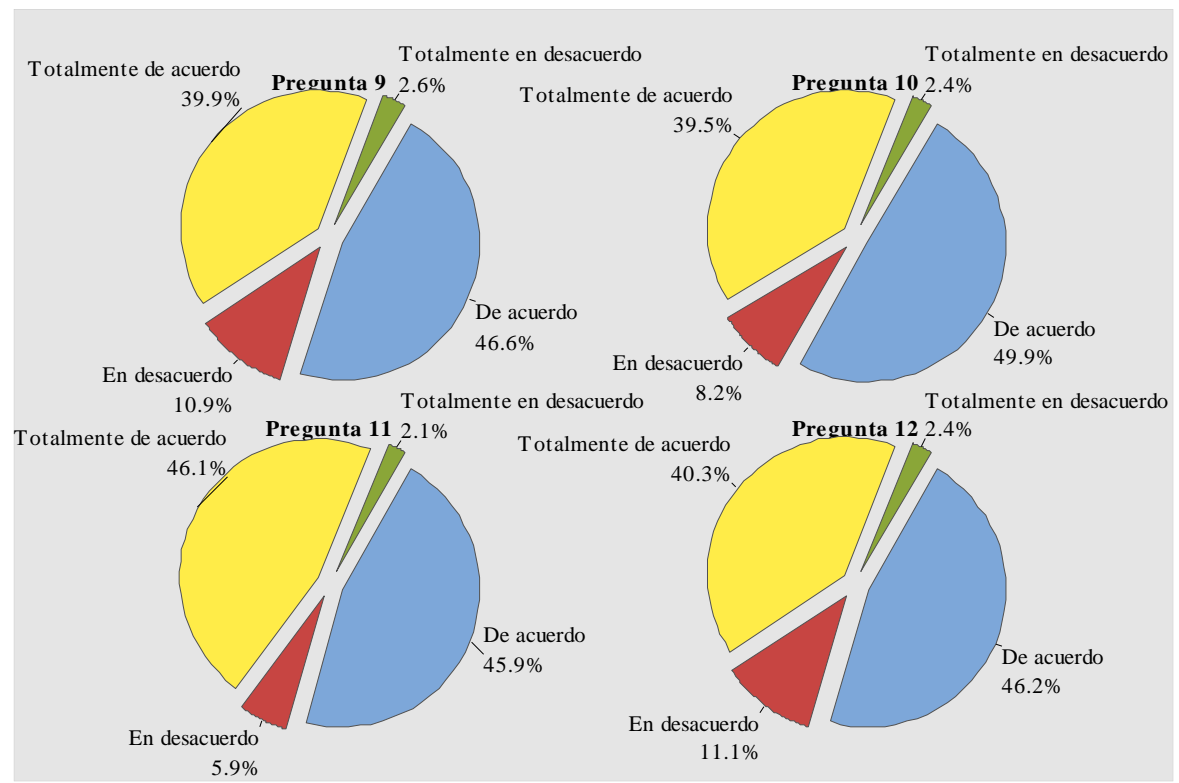

Figura 30. Resultados globales de la dimensión emotiva.

A grandes rasgos, los participantes estuvieron mayormente muy de acuerdo y de acuerdo con la pregunta once (92\%), es decir, que resolver el reto dentro de los primeros intentos los hizo sentir satisfechos con su capacidad, lo cual confirma lo dicho anteriormente y con la mecánica de chances propuesta en el modelo de Werbach y Hunter (2015).

Ahora veremos los resultados por género, nivel educativo y edad, tal y como se presentó en las dimensiones cognitiva y social. En general ambos géneros están de acuerdo con que el Reto Gamificado favorece la dimensión emotiva, aunque ligeramente los hombres estuvieron más a favor que las mujeres. Más adelante se comprobará con la prueba Chi-cuadrada. 
En la Tabla 49 se pueden apreciar los resultados de las preguntas nueve a la doce por género. Se observa como los hombres estuvieron mayormente de acuerdo y muy de acuerdo con que resolver correctamente el reto gamificado dentro de los primeros intentos los hizo sentir satisfechos con su capacidad, es decir, favoreció el sentimiento de logro (pregunta 11), mientras que las mujeres, además, estuvieron mayormente de acuerdo y muy de acuerdo con el hecho de que haber tenido varias oportunidades las motivó positivamente para intentarlo de nuevo (pregunta 10).

\section{Tabla 49}

Respuestas de las preguntas nueve a la doce por género.

\begin{tabular}{lccccc}
\hline Género & Pregunta 9 & Pregunta 10 & Pregunta 11 & Pregunta 12 & Promedios \\
\hline Hombre & & & & & \\
Totalmente de acuerdo & $43 \%$ & $42 \%$ & $50 \%$ & $44 \%$ & $44 \%$ \\
De acuerdo & $46 \%$ & $47 \%$ & $43 \%$ & $43 \%$ & $45 \%$ \\
En desacuerdo & $9 \%$ & $8 \%$ & $4 \%$ & $11 \%$ & $8 \%$ \\
Totalmente en desacuerdo & $3 \%$ & $3 \%$ & $3 \%$ & $3 \%$ & $3 \%$ \\
Mujer & & & & & \\
Totalmente de acuerdo & $35 \%$ & $35 \%$ & $40 \%$ & $35 \%$ & $36 \%$ \\
De acuerdo & $48 \%$ & $56 \%$ & $51 \%$ & $52 \%$ & $52 \%$ \\
En desacuerdo & $15 \%$ & $8 \%$ & $8 \%$ & $12 \%$ & $11 \%$ \\
\hline Totalmente en desacuerdo & $3 \%$ & $1 \%$ & $1 \%$ & $2 \%$ & $1 \%$ \\
\hline
\end{tabular}

Por otro lado, los hombres estuvieron mayormente en desacuerdo y muy en desacuerdo con la pregunta doce mientras que las mujeres con la pregunta nueve, es decir, el $14 \%$ de los hombres consideraron que competir para ganar un trofeo no les pareció interesante mientras que el 18\% de las mujeres no están de acuerdo con que haber obtenido una insignia las hizo sentir muy bien. Evidentemente, como se observa 
en la Tabla 56, tanto en las preguntas nueve como en la doce, la mayoría estuvo de acuerdo, hombres y mujeres, no obstante, es interesante comentar los porcentajes mayores en desacuerdo pues ofrecen áreas de oportunidad para indagar más a fondo y mejorar la actividad, contribuyendo a la mejora continua.

Ahora bien, vamos a establecer las hipótesis para correr la prueba Chi-cuadrada para robustecer los resultados:

Ho: No existe una asociación significativa entre el género y las respuestas de la dimensión emotiva.

$H_{1}$ : Existe una asociación significativa entre el género y las respuestas de la dimensión emotiva.

Dado que la Tabla 50 nos muestra que el p-valor es menor al 5\%, se rechaza la hipótesis nula, por lo que sí hay una asociación significativa entre el género y la dimensión emotiva, en otras palabras, se puede decir que las similitudes y diferencias mostradas en la Tabla 49 son significativas. 
Tabla 50

Prueba Chi-cuadrada y tabla de contingencia por género y dimensión emotiva.

\begin{tabular}{|c|c|c|c|c|c|}
\hline & $\begin{array}{ll}\text { Muy de } \\
\text { acuerdo }\end{array}$ & $\begin{array}{l}\text { De } \\
\text { acuerdo }\end{array}$ & $\begin{array}{l}\text { En } \\
\text { desacuerdo }\end{array}$ & $\begin{array}{l}\text { Totalmente } \\
\text { en desacuerdo }\end{array}$ & Total \\
\hline \multicolumn{6}{|l|}{ Hombre } \\
\hline Frecuencia observada & 874 & 157 & 869 & 56 & 1956 \\
\hline Frecuencia esperada & 922,3 & 176,7 & 810,9 & 46,1 & \\
\hline \multicolumn{6}{|l|}{ Mujer } \\
\hline Frecuencia observada & 567 & 119 & 398 & 16 & 1100 \\
\hline Frecuencia esperada & 518,7 & 99,3 & 456,1 & 25,9 & \\
\hline \multirow[t]{2}{*}{ Total } & 1441 & 276 & 1267 & 72 & 3056 \\
\hline & Chi-Cuadrada & $\mathrm{GL}$ & p-valor & & \\
\hline Pearson & 30,581 & 3 & 0000 & & \\
\hline Relación de verosimilitud & 31,051 & 3 & 0,000 & & \\
\hline
\end{tabular}

Con respecto al nivel educativo, los resultados se presentan en Tabla 51. Se observa que los participantes de nivel estudios técnicos se muestran mayormente de acuerdo y muy de acuerdo, con las preguntas diez y once, es decir, para ellos el haber tenido varios intentos para responder correctamente y haberlo logrado dentro de ese intervalo, los hizo sentir muy bien para responder el reto.

\section{Tabla 51}

Respuestas de las preguntas nueve a la doce por nivel educativo.

\begin{tabular}{lccccc}
\hline Nivel educativo & Pregunta 9 & Pregunta 10 & Pregunta 11 & Pregunta 12 & Promedio \\
\hline Estudios técnicos & & & & & \\
Totalmente de acuerdo & $42 \%$ & $46 \%$ & $42 \%$ & $35 \%$ & $41 \%$ \\
De acuerdo & $46 \%$ & $46 \%$ & $50 \%$ & $50 \%$ & $48 \%$ \\
\hline En desacuerdo & $12 \%$ & $8 \%$ & $8 \%$ & $15 \%$ & $11 \%$ \\
Totalmente en desacuerdo & $0 \%$ & $0 \%$ & $0 \%$ & $0 \%$ & $0 \%$ \\
\hline Preparatoria & & & & & \\
Totalmente de acuerdo & $36 \%$ & $41 \%$ & $39 \%$ & $39 \%$ & $39 \%$ \\
De acuerdo & $54 \%$ & $50 \%$ & $51 \%$ & $53 \%$ & $52 \%$ \\
En desacuerdo & $9 \%$ & $7 \%$ & $8 \%$ & $7 \%$ & $8 \%$ \\
Totalmente en desacuerdo & $2 \%$ & $2 \%$ & $2 \%$ & $1 \%$ & $2 \%$ \\
Universitario & & & & & \\
\hline Totalmente de acuerdo & $42 \%$ & $40 \%$ & $48 \%$ & $42 \%$ & $43 \%$ \\
\hline
\end{tabular}




\begin{tabular}{lccccc}
\hline De acuerdo & $47 \%$ & $51 \%$ & $46 \%$ & $46 \%$ & $47 \%$ \\
\hline En desacuerdo & $10 \%$ & $8 \%$ & $4 \%$ & $10 \%$ & $8 \%$ \\
\hline Totalmente en desacuerdo & $2 \%$ & $2 \%$ & $2 \%$ & $2 \%$ & $2 \%$ \\
Maestría & & & & & \\
Totalmente de acuerdo & $37 \%$ & $33 \%$ & $46 \%$ & $35 \%$ & $38 \%$ \\
\hline De acuerdo & $39 \%$ & $46 \%$ & $39 \%$ & $39 \%$ & $40 \%$ \\
\hline En desacuerdo & $14 \%$ & $14 \%$ & $12 \%$ & $20 \%$ & $15 \%$ \\
\hline Totalmente en desacuerdo & $10 \%$ & $7 \%$ & $4 \%$ & $6 \%$ & $7 \%$ \\
Doctorado & & & & & \\
Totalmente de acuerdo & $23 \%$ & $31 \%$ & $31 \%$ & $38 \%$ & $31 \%$ \\
\hline De acuerdo & $31 \%$ & $54 \%$ & $54 \%$ & $31 \%$ & $42 \%$ \\
\hline En desacuerdo & $46 \%$ & $8 \%$ & $15 \%$ & $31 \%$ & $25 \%$ \\
\hline Totalmente en desacuerdo & $0 \%$ & $8 \%$ & $0 \%$ & $0 \%$ & $2 \%$ \\
\hline
\end{tabular}

De manera similar, los participantes de niveles universitario, maestría y doctorado también se mostraron mayormente de acuerdo y muy de acuerdo, con la pregunta once, mientras que los participantes de preparatoria estuvieron mayormente de acuerdo y muy de acuerdo con que la competición les pareció emocionante (pregunta doce).

De nueva cuenta, vamos a establecer las hipótesis para correr la prueba Chicuadrada y robustecer los resultados:

Ho: No existe una asociación significativa entre el nivel educativo y las respuestas de la dimensión emotiva.

$H_{7}$ : Existe una asociación significativa entre el nivel educativo y las respuestas de la dimensión emotiva. 
Según la prueba Chi-cuadrada mostrada en la Tabla 52 se rechaza la hipótesis nula, por lo tanto, al igual que en el caso del género, resulta que hay una asociación significativa entre el nivel educativo y la dimensión emotiva, es decir que las diferencias y similitudes encontradas en esta característica, son significativas.

\section{Tabla 52}

Prueba Chi-Cuadrada y tabla de contingencia por nivel educativo y dimensión emotiva.

\begin{tabular}{|c|c|c|c|}
\hline & De acuerdo & En desacuerdo & Total \\
\hline \multicolumn{4}{|l|}{ Técnica } \\
\hline Frecuencia observada & 406 & 42 & 448 \\
\hline Frecuencia esperada & 396,98 & 51,02 & \\
\hline \multicolumn{4}{|l|}{ Preparatoria } \\
\hline Frecuencia observada & 93 & 11 & 104 \\
\hline Frecuencia esperada & 92,16 & 11,84 & \\
\hline \multicolumn{4}{|l|}{ Universidad } \\
\hline Frecuencia observada & 1912 & 208 & 2120 \\
\hline Frecuencia esperada & 1878,59 & 241,41 & \\
\hline \multicolumn{4}{|l|}{ Maestría } \\
\hline Frecuencia observada & 259 & 73 & 332 \\
\hline Frecuencia esperada & 294,19 & 37,81 & \\
\hline \multicolumn{4}{|l|}{ Doctorado } \\
\hline Frecuencia observada & 38 & 14 & 52 \\
\hline Frecuencia esperada & 46,08 & 5,92 & \\
\hline \multirow[t]{2}{*}{ Total } & 2708 & 348 & 3056 \\
\hline & Chi-Cuadrada & $\mathrm{GL}$ & p-valor \\
\hline Pearson & 56,494 & 4 & 0,000 \\
\hline Relación de verosimilitud & 46,924 & 4 & 0,000 \\
\hline
\end{tabular}

Finalmente, se presentan los resultados de las preguntas nueve a doce con respecto a la edad, ver Tabla 53. Se encontró que los participantes entre 15 y 20 años son los que están más de acuerdo con que el reto gamificado favorece a la dimensión emotiva, seguidos de las personas de entre 21 y 30 años. Mientras que las personas mayores de 50 años son las que presentan una menor proporción. 
Tabla 53

Respuestas de las preguntas nueve a doce por edad.

\begin{tabular}{lccccc}
\hline Edad & Pregunta 9 & Pregunta 10 & Pregunta 11 & Pregunta 12 & Promedio \\
\hline Entre 15 y 20 años & & & & & \\
\hline Totalmente de acuerdo & $37 \%$ & $42 \%$ & $45 \%$ & $34 \%$ & $40 \%$ \\
\hline De acuerdo & $53 \%$ & $51 \%$ & $50 \%$ & $58 \%$ & $53 \%$ \\
\hline En desacuerdo & $7 \%$ & $4 \%$ & $4 \%$ & $5 \%$ & $5 \%$ \\
\hline Totalmente en desacuerdo & $2 \%$ & $2 \%$ & $1 \%$ & $3 \%$ & $2 \%$ \\
\hline Entre 21 y 30 años & & & & & \\
\hline Totalmente de acuerdo & $43 \%$ & $42 \%$ & $47 \%$ & $45 \%$ & $44 \%$ \\
\hline De acuerdo & $45 \%$ & $48 \%$ & $45 \%$ & $44 \%$ & $46 \%$ \\
\hline En desacuerdo & $10 \%$ & $8 \%$ & $5 \%$ & $10 \%$ & $8 \%$ \\
\hline Totalmente en desacuerdo & $2 \%$ & $3 \%$ & $3 \%$ & $1 \%$ & $2 \%$ \\
\hline Entre 31 y 40 años & & & & & \\
\hline Totalmente de acuerdo & $38 \%$ & $34 \%$ & $46 \%$ & $41 \%$ & $40 \%$ \\
\hline De acuerdo & $47 \%$ & $52 \%$ & $45 \%$ & $40 \%$ & $46 \%$ \\
\hline En desacuerdo & $11 \%$ & $13 \%$ & $8 \%$ & $17 \%$ & $13 \%$ \\
\hline Totalmente en desacuerdo & $4 \%$ & $1 \%$ & $1 \%$ & $2 \%$ & $2 \%$ \\
\hline Entre 41 y 50 años & & & & & \\
\hline Totalmente de acuerdo & $35 \%$ & $32 \%$ & $38 \%$ & $35 \%$ & $35 \%$ \\
\hline De acuerdo & $42 \%$ & $52 \%$ & $48 \%$ & $42 \%$ & $46 \%$ \\
\hline En desacuerdo & $17 \%$ & $11 \%$ & $9 \%$ & $18 \%$ & $14 \%$ \\
\hline Totalmente en desacuerdo & $6 \%$ & $6 \%$ & $5 \%$ & $5 \%$ & $5 \%$ \\
\hline Más de 51 años & & & & & \\
\hline Totalmente de acuerdo & $43 \%$ & $35 \%$ & $53 \%$ & $39 \%$ & $43 \%$ \\
\hline De acuerdo & $33 \%$ & $49 \%$ & $35 \%$ & $35 \%$ & $38 \%$ \\
\hline En desacuerdo & $22 \%$ & $16 \%$ & $12 \%$ & $22 \%$ & $18 \%$ \\
\hline Totalmente en desacuerdo & $2 \%$ & $0 \%$ & $0 \%$ & $4 \%$ & $1 \%$ \\
\hline
\end{tabular}

Llama la atención que todas las edades se muestran mayormente a favor de la pregunta once, es decir, que se sintieron muy bien al haber respondido correctamente dentro del número de intentos. Además, los participantes entre 15 y 20 años se inclinaron también por la pregunta doce, es decir, que competir les pareció emocionante. 
Es importante resaltar que en mayor proporción los participantes de todas las edades experimentaron alguna emoción con el Reto Gamificado, esto coincide con los estudios antropológicos de Huizinga (2000) quien encontró que el juego es parte natural y necesaria en la vida de las personas. De la misma manera, estos resultados coinciden con el estudio desarrollado por Stefani, Andrés y Oanes (2014) quienes encontraron que, aunque de diferente manera, las personas de diferentes edades tienen una predisposición positiva hacia el juego.

Finalmente, vamos a establecer las hipótesis para correr la prueba Chi-cuadrada para robustecer los resultados:

$H_{0}$ : No existe una asociación significativa entre la edad y las respuestas de la dimensión emotiva.

$H_{1}$ : Existe una asociación significativa entre la edad y las respuestas de la dimensión emotiva.

De la misma manera que en las dimensiones anteriores, se rechaza la hipótesis nula, ver Tabla 54. Por lo tanto, al existir una asociación significativa se tiene que las similitudes y diferencias presentadas en la Tabla 58 son significativas. 
Tabla 54

Prueba Chi-Cuadrada y tabla de contingencia por edad y dimensión emotiva.

\begin{tabular}{|c|c|c|c|c|c|}
\hline & $\begin{array}{ll}\text { Muy } & \text { de } \\
\text { acuerdo } & \\
\end{array}$ & $\begin{array}{l}\text { De } \\
\text { acuerdo }\end{array}$ & $\begin{array}{l}\text { En } \\
\text { desacuerdo }\end{array}$ & $\begin{array}{l}\text { Muy en } \\
\text { desacuerdo }\end{array}$ & Total \\
\hline \multicolumn{6}{|l|}{16 a 20 años } \\
\hline Frecuencia observada & 332 & 445 & 44 & 19 & 840 \\
\hline Frecuencia esperada & 347,98 & 396,36 & 75.31 & 20,34 & \\
\hline \multicolumn{6}{|l|}{21 a 30 años } \\
\hline Frecuencia observada & 600 & 617 & 111 & 28 & 1356 \\
\hline Frecuencia esperada & 561,75 & 639,84 & 121.58 & 32,84 & \\
\hline \multicolumn{6}{|l|}{31 a 40 años } \\
\hline Frecuencia observada & 155 & 180 & 49 & 8 & 392 \\
\hline Frecuencia esperada & 162,39 & 184,97 & 35.15 & 9,49 & \\
\hline \multicolumn{6}{|l|}{41 a 50 años } \\
\hline Frecuencia observada & 92 & 122 & 36 & 14 & 264 \\
\hline Frecuencia esperada & 109,37 & 124,57 & 23.67 & 6,39 & \\
\hline \multicolumn{6}{|l|}{ más de 50 años } \\
\hline Frecuencia observada & 87 & 78 & 34 & 5 & 204 \\
\hline Frecuencia esperada & 84,51 & 96,26 & 18.29 & 4,94 & \\
\hline \multirow[t]{2}{*}{ Total } & 1266 & 1442 & 274 & 74 & 3056 \\
\hline & Chi-Cuadrada & $\mathrm{GL}$ & $\mathrm{p}$-valor & & \\
\hline Pearson & 66,345 & 12 & 0.000 & & \\
\hline Relación de verosimilitud & 62,312 & 12 & 0.000 & & \\
\hline
\end{tabular}

En resumen, se puede ver una uniformidad en las respuestas, los hombres se inclinan por la pregunta once y las mujeres por la diez y once. En todos los niveles educativos a excepción de preparatoria, se inclinan por la pregunta once, así como todas las edades a excepción del rango de los 15 a 20 años. Estas excepciones están a favor de la pregunta doce, es decir les parece emocionante competir, lo cual es propio de las nuevas generaciones llamadas millennials.

4.1.2.5 Resultados cualitativos de la dimensión emotiva. Esta pregunta fue respondida por 754 participantes de los 764, la cuestión fue ¿Qué tipo de emoción sentiste cuando recibiste un trofeo por haber respondido correctamente el reto 
gamificado? Los resultados se categorizaron en cuatro categorías: 1) Entusiasmo, 2) Satisfacción, 3) Ninguna emoción y 4) Emoción negativa. La primera categoría fue la que tuvo más frecuencia, las categorías satisfacción y ninguna emoción tuvieron casi la misma frecuencia y la cuarta fue la que tuvo menos frecuencia (40 de 754), no obstante, es importante saber que al no haber logrado ganar una insignia en forma de trofeo, a algunos participantes les provocó emociones de tristeza y frustración.

4.1.3 Analíticas del curso ECLyT. La analítica del curso la proveyó el mismo curso, contiene datos socio-demográficos así como las calificaciones de los participantes en cada una de las actividades. Para el procesamiento de los datos se utilizaron los datos de aquellos participantes que al menos hicieron una actividad, lo que resultó en 1209 datos. El software utilizado fue Excel para la elaboración de las tablas pivote, el Minitab para las recodificaciones y los scatter-plots. El software XL-STAT se utilizó para el cálculo de las correlaciones y el análisis de componentes principales.

El análisis de componentes principales (ACP) se utiliza cuando en un mismo fenómeno intervienen una serie de variables. Estas técnicas de análisis de datos multidimensionales, como el $\mathrm{ACP}$, se utilizan para obtener información de interés proveniente de grandes conjuntos de datos y que, debido a su magnitud, es difícil dar lectura en su formato original. Estas técnicas se conocen a menudo como herramientas de minería de datos o data science (XL-STAT, 2018). 
El ACP es un procedimiento estadístico que utiliza una transformación ortogonal para convertir un conjunto de observaciones de variables posiblemente correlacionadas en un conjunto de valores de variables sin correlación lineal denominada componentes principales (Jolliffe, 2012). La dimensión de un conjunto de datos puede reducirse cuando las cargas de diferentes variables están bastante cercanas, indicando que darán la misma información, por lo tanto, pueden eliminarse algunas de las variables. También, si las variables independientes y explicativas de interés se agrupan en la proyección, es indicativo de que puede existir relación de causalidad entre estas variables (Rincón-Flores, Ramírez, Mena y Ramírez-Montoya, 2018). Por lo tanto, se utilizó el ACP para encontrar las variables explicativas para el Reto Gamificado (RG).

\subsubsection{Resultados sociodemográficos y su relación con el reto gamificado. Los} resultados fueron procesados con Excel y Minitab. En estos resultados se relacionaron las variables sociodemográficas con el reto gamificado (RG). De los 4819 participantes inscritos, 1209 alumnos hicieron al menos una actividad, 621 aprobaron el curso y 588 no lo hicieron, lo que arrojó una tasa terminal del $12.89 \%$, muy alta de acuerdo a otros estudios encontrados en la literatura (Armstrong, 2014).

De los 1209 participantes 647 hicieron el reto, de los cuales 229 fueron mujeres y 418 fueron hombres. En la Tabla 55 se muestran los resultados de los participantes 
que hicieron el reto por género y nivel educativo, en esta se muestra que los niveles de primaria, técnica, maestría y doctorado, en ambos géneros, obtuvieron el mayor porcentaje de participación mientras que comparando ambos géneros, los hombres tuvieron mayor participación en todos los niveles a excepción del de primaria.

\section{Tabla 55}

Número de mujeres y hombres que hicieron el reto por nivel educativo.

\begin{tabular}{llllllll}
\hline $\begin{array}{l}\text { Nivel } \\
\text { educativo }\end{array}$ & Mujeres & Reto & $\%$ & Hombres & Reto & $\%$ & $\begin{array}{l}\text { Total reto } \\
\text { por nivel }\end{array}$ \\
\hline Primaria & 1 & 1 & $100 \%$ & 1 & 1 & $100 \%$ & 2 \\
Secundaria & 29 & 11 & $39,9 \%$ & 27 & 11 & $40,7 \%$ & 22 \\
Preparatoria & 250 & 123 & $49,2 \%$ & 285 & 155 & $54,3 \%$ & 278 \\
Técnica & 26 & 15 & $57,6 \%$ & 64 & 40 & $62,5 \%$ & 55 \\
Profesional & 116 & 52 & $44,8 \%$ & 266 & 147 & $55,3 \%$ & 199 \\
Maestría & 44 & 22 & $50 \%$ & 85 & 56 & $65,8 \%$ & 78 \\
Doctorado & 6 & 5 & $83,3 \%$ & 9 & 8 & $88,8 \%$ & 13 \\
Total & 472 & 229 & $48,5 \%$ & 737 & 418 & $56,7 \%$ & 647 \\
\hline
\end{tabular}

De los 1209 participantes 621 aprobaron de los cuales 221 fueron mujeres y 400 hombres. De las mujeres aprobadas, 213 hicieron el reto y 394 de los hombres. En la Tabla 56 se muestran los resultados de los participantes aprobados, que hicieron el reto por nivel educativo y género. 
Tabla 56

Número de mujeres y hombres aprobados que hicieron el reto por nivel educativo.

\begin{tabular}{llllllll}
\hline Nivel educativo & Mujeres & Reto & $\%$ & Hombres & Reto & $\%$ & $\begin{array}{l}\text { Total reto } \\
\text { por nivel }\end{array}$ \\
\hline Primaria & 1 & 1 & $100 \%$ & 1 & 1 & $100 \%$ & 2 \\
Secundaria & 10 & 10 & $100 \%$ & 10 & 10 & $100 \%$ & 22 \\
Preparatoria & 122 & 115 & $94,3 \%$ & 152 & 147 & $96,7 \%$ & 278 \\
Técnica & 14 & 14 & $100 \%$ & 37 & 37 & $100 \%$ & 55 \\
Profesional & 51 & 50 & $98 \%$ & 139 & 139 & $100 \%$ & 199 \\
Maestría & 18 & 18 & $100 \%$ & 53 & 52 & $98,1 \%$ & 78 \\
Doctorado & 5 & 5 & $100 \%$ & 8 & 8 & $100 \%$ & 13 \\
Total & 221 & 213 & $96,4 \%$ & 400 & 394 & $98,5 \%$ & 647 \\
\hline
\end{tabular}

Se puede observar que, de las mujeres aprobadas, las de nivel maestría tuvieron una mayor participación que los hombres (100\%) y que los hombres de nivel preparatoria y profesional tuvieron una participación más alta en el RG que las mujeres. Los demás niveles tuvieron la misma participación y en general, los hombres aprobados tuvieron una mayor participación que las mujeres.

En la Tabla 57 se muestra a los participantes aprobados y no aprobados, que hicieron o no, el RG y por nivel educativo. 


\section{Tabla 57.}

Resultados de los participantes aprobados y no aprobados que hicieron el reto gamificado por nivel educativo.

\begin{tabular}{lllll}
\hline Nivel educativo & $\begin{array}{l}\text { Total } \\
\text { participantes }\end{array}$ & $\begin{array}{l}\text { Aprobados } \\
\text { Hicieron } \\
\text { RG }\end{array}$ & $\begin{array}{l}\text { No } \\
\text { aprobados } \\
\text { Hicieron el } \\
\text { RG }\end{array}$ & $\begin{array}{l}\text { Aprobados } \\
\text { No hicieron } \\
\text { el RG }\end{array}$ \\
\hline Primaria & 2 & 2 & 0 & 0 \\
Secundaria & 56 & 20 & 2 & 0 \\
Preparatoria & 535 & 262 & 16 & 12 \\
Técnica & 90 & 51 & 4 & 1 \\
Profesional & 382 & 189 & 10 & 1 \\
Maestría & 129 & 70 & 8 & 0 \\
Doctorado & 15 & 13 & 0 & 0 \\
Total & 1209 & 607 & 40 & 14 \\
\hline
\end{tabular}

Como se puede ver en la Tabla 57, la mayoría de los participantes de todos los niveles hicieron el Reto Gamificado, a excepción del nivel secundaria, tanto los participantes aprobados como no aprobados, quizás porque el mercado meta del curso son aquellos participantes con nivel preparatoria como mínimo. También llama la atención que los niveles educativos con mayor participación en el RG en proporción, fueron los niveles de primaria, técnica, maestría y doctorado.

Por otro lado, de los 621 participantes aprobados 14 no hicieron el reto (2,25\%), de los cuales 12 fueron de nivel preparatoria, 1 de nivel técnico y 1 de profesional, así mismo, de los 588 participantes que no aprobaron, 40 hicieron el reto (6,8\%), los cuales se encuentran entre los niveles secundaria y maestría, ver Tabla 57. Ante estos resultados, es muy interesante ver que el 54\% de los 1209 participantes hicieron el reto, lo que implica que hubo interés por desarrollar esta actividad. 
Dentro de los participantes que hicieron al menos una actividad, 42 fueron extranjeros y 1167 fueron mexicanos. De los 42 extranjeros, 14 no aprobaron el curso y 28 lo aprobaron, de los 14 que no acreditaron 3 hicieron el reto y 28 de los que sí acreditaron. En cuanto al género, de las 14 mujeres extranjeras, 10 hicieron el RG y de los 28 hombres extranjeros, 21 lo hicieron.

En la Tabla 58 se muestran los resultados por nivel educativo y género que hicieron el RG. Se puede observar que hubo una mayor disposición de los hombres por resolver el RG y que los niveles de preparatoria y técnica fueron los que mayormente participaron en la actividad. Así mismo, se observa que el 73,8\% de los 42 estudiantes extranjeros participaron en el RG, por lo que hubo interés por parte de esta población.

Tabla 58

Estudiantes extranjeros que hicieron o que no hicieron el RG por nivel educativo.

\begin{tabular}{|c|c|c|c|c|c|c|c|c|c|}
\hline Nivel & Todos & $\begin{array}{l}\text { Muj no } \\
\text { aprob }\end{array}$ & $\begin{array}{l}\text { Muj } \\
\text { apro }\end{array}$ & $\%$ & Todos & $\begin{array}{l}\text { Homb } \\
\text { no } \\
\text { aprob }\end{array}$ & $\begin{array}{l}\text { Homb } \\
\text { aprob }\end{array}$ & $\%$ & $\begin{array}{l}\text { Total } \\
\text { reto }\end{array}$ \\
\hline Primaria & 0 & 0 & 0 & $0,0 \%$ & 0 & 0 & 0 & $0,0 \%$ & $0,0 \%$ \\
\hline Secundaria & 5 & 1 & 2 & $60,0 \%$ & 1 & 0 & 1 & $100,0 \%$ & $66,7 \%$ \\
\hline Preparatoria & 5 & 1 & 3 & $80,0 \%$ & 5 & 1 & 3 & $80,0 \%$ & $80,0 \%$ \\
\hline Técnica & 0 & 0 & 0 & $0,0 \%$ & 8 & 0 & 7 & $87,5 \%$ & $87,5 \%$ \\
\hline Profesional & 1 & 0 & 1 & $100,0 \%$ & 10 & 0 & 6 & $60,0 \%$ & $63,6 \%$ \\
\hline Maestría & 3 & 0 & 2 & $66,7 \%$ & 4 & 0 & 3 & $75,0 \%$ & $71,4 \%$ \\
\hline Doctorado & 0 & 0 & 0 & $0,0 \%$ & 0 & 0 & 0 & $0,0 \%$ & $0,0 \%$ \\
\hline Total & 14 & 2 & 8 & $71,4 \%$ & 28 & 1 & 20 & $75,0 \%$ & $73,8 \%$ \\
\hline
\end{tabular}


Por otro lado, en la Figura 31 se puede ver la distribución por países que participaron con al menos una actividad en el curso ECLyT, en ésta, se aprecia que la mayor parte de los estudiantes extranjeros provenían de Colombia, seguido de Perú, Ecuador y Argentina.

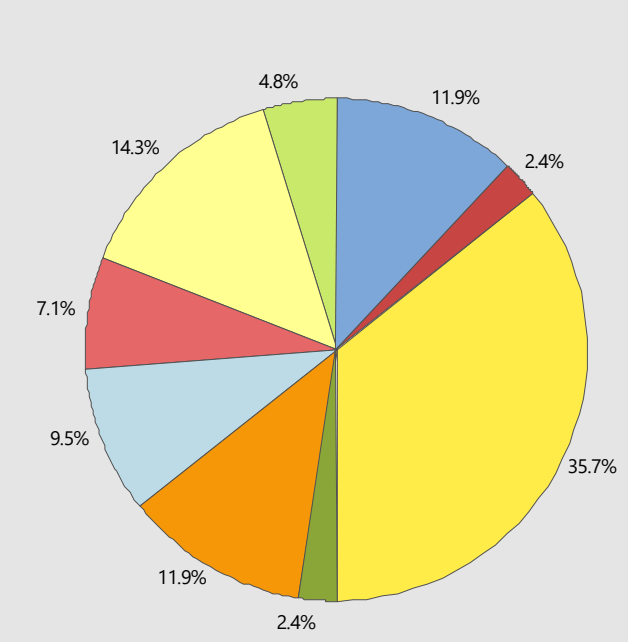

Figura 37. Distribución de los participantes extranjeros en el curso ECLyT por país.

En cuanto a los participantes mexicanos, se encontró que 1167 estudiantes, hicieron al menos una actividad, de los cuales 593 que aprobaron el curso, 579 hicieron el RG (97,6\%), de los cuales 205 fueron mujeres y 374 hombres, ver Tabla 59. 


\section{Tabla 59}

Participantes mexicanos aprobados y no aprobados que hicieron el reto.

\begin{tabular}{lccccccccc}
\hline Nivel & Todos & $\begin{array}{c}\text { Muj no } \\
\text { aprob }\end{array}$ & $\begin{array}{c}\text { Muj } \\
\text { aprob }\end{array}$ & $\%$ & Todos & $\begin{array}{c}\text { Homb no } \\
\text { aprob }\end{array}$ & $\begin{array}{c}\text { Homb } \\
\text { aprob }\end{array}$ & $\%$ & Total \\
\hline Primaria & 1 & 0 & 1 & $100,0 \%$ & 1 & 0 & 1 & $100,0 \%$ & $100,0 \%$ \\
Secundaria & 24 & 0 & 8 & $33,3 \%$ & 24 & 9 & 9 & $75,0 \%$ & $54,2 \%$ \\
Preparatoria & 244 & 7 & 112 & $48,8 \%$ & 277 & 7 & 143 & $54,2 \%$ & $51,6 \%$ \\
Técnica & 28 & 1 & 15 & $57,1 \%$ & 61 & 3 & 31 & $55,7 \%$ & $56,2 \%$ \\
Profesional & 114 & 2 & 48 & $43,9 \%$ & 256 & 8 & 133 & $55,1 \%$ & $51,6 \%$ \\
Maestría & 41 & 4 & 16 & $48,8 \%$ & 81 & 4 & 49 & $65,4 \%$ & $59,8 \%$ \\
Doctorado & 6 & 0 & 5 & $83,3 \%$ & 9 & 0 & 8 & $88,9 \%$ & $86,7 \%$ \\
Total & 458 & 14 & 205 & $47,8 \%$ & 709 & 31 & 374 & $57,1 \%$ & $53,5 \%$ \\
\hline
\end{tabular}

Al igual que en los resultados globales y como en los participantes extranjeros, las mujeres de primaria, profesional y doctorado fueron las que mayormente participaron mientras que los hombres mexicanos participaron mayormente en todos los niveles, ver Tabla 59. No obstante, el 53,4\% de los 1167 participantes hicieron el reto, esto deja entrever que hay un interés por participar en el RG por parte de los estudiantes mexicanos, al mismo tiempo, se observó en proporción, mayor interés por parte de los alumnos mexicanos que los extranjeros para participar en el RG.

En cuanto a la ubicación geográfica, en la Tabla 60 se muestra que la mayor parte de los participantes mexicanos en el curso ECLyT fueron del Estado de México seguidos de la Ciudad de México, Veracruz, Puebla, Guadalajara y Chihuahua. No obstante, Chihuahua tuvo el mayor porcentaje de aprobación y de realización del Reto Gamificado. 


\section{Tabla 60}

Distribución de porcentajes de aprobados y realización del RG por Estado.

\begin{tabular}{llllllll}
\hline Estado & Total & \%Aprobados & $\%$ RG & Estado & Total & \%Aprobados & $\%$ RG \\
\hline Aguascalientes & 10 & $30 \%$ & $100 \%$ & Durango & 6 & $50 \%$ & $100 \%$ \\
\hline Baja Cal N & 10 & $60 \%$ & $100 \%$ & Edo. Mex & 250 & $52 \%$ & $96 \%$ \\
\hline Baja Cal S & 6 & $50 \%$ & $100 \%$ & Guerrero & 40 & $45 \%$ & $100 \%$ \\
\hline Campeche & 12 & $25 \%$ & $67 \%$ & Guadalajara & 95 & $58 \%$ & $100 \%$ \\
\hline C. de México & 117 & $48 \%$ & $100 \%$ & Hidalgo & 37 & $54 \%$ & $100 \%$ \\
\hline Chihuahua & 55 & $80 \%$ & $95 \%$ & Jalisco & 38 & $61 \%$ & $100 \%$ \\
\hline Chiapas & 18 & $50 \%$ & $100 \%$ & Michoacán & 22 & $64 \%$ & $100 \%$ \\
\hline Coahuila & 31 & $39 \%$ & $100 \%$ & Morelos & 15 & $60 \%$ & $100 \%$ \\
\hline Colima & 9 & $11 \%$ & $0 \%$ & Nayarit & 3 & $100 \%$ & $100 \%$ \\
\hline Estado & Total & $\%$ Aprobados & $\%$ RG & Estado & Total & $\%$ Aprobados & $\%$ RG \\
\hline Nuevo León & 19 & $32 \%$ & $100 \%$ & Tamaulipas & 24 & $67 \%$ & $94 \%$ \\
\hline Oaxaca & 20 & $35 \%$ & $100 \%$ & Tlaxcala & 5 & $20 \%$ & $100 \%$ \\
\hline Puebla & 96 & $48 \%$ & $98 \%$ & Veracruz & 104 & $44 \%$ & $96 \%$ \\
\hline Querétaro & 7 & $71 \%$ & $100 \%$ & Yucatán & 23 & $43 \%$ & $90 \%$ \\
\hline Quintana Roo & 16 & $31 \%$ & $100 \%$ & Zacatecas & 19 & $47 \%$ & $100 \%$ \\
\hline Sinaloa & 11 & $45 \%$ & $100 \%$ & & & & \\
\hline San L Potosí & 15 & $53 \%$ & $100 \%$ & Total mexicanos & 1167 & \\
\hline Sonora & 5 & $80 \%$ & $100 \%$ & Aprobados & 593 & \\
\hline Tabasco & 29 & $45 \%$ & $100 \%$ & RG & & 579 & \\
\hline & & & & & & & \\
\hline
\end{tabular}

Al mismo tiempo, se observa que, aunque los porcentajes de aprobación del curso cayeron en la mayoría de los Estados, el porcentaje de quienes realizaron el Reto Gamificado de esa porción fue mayor al 90\%

\subsubsection{Correlaciones y Análisis de componentes principales (ACP). Para el}

ordenamiento de los datos se utilizó el software Excel y MiniTab 2018, luego para el cálculo de las correlaciones se utilizó el XL-STAT. Los datos utilizados fueron los 1209 
que corresponden a las personas que se inscribieron al curso ECLyT y que hicieron al menos una actividad.

Las actividades que fungieron como variables cuantitativas fueron: las evaluaciones de cada tema (30\%), un ejercicio de práctica (2\%), una práctica (20\%), la evaluación final (28\%)y el reto gamificado (20\%). Las cuales conformaron la evaluación del curso. La edad, el género y el nivel educativo jugaron el papel de observaciones o etiquetas, los cuales fueron re-codificados con ayuda del software MiniTab 2018.

Para el ACP se utilizó el software XL-STAT, del cual se obtuvieron las correlaciones, los valores propios de cada variable con respecto a cada componente principal, los cosenos cuadrados, los gráficos Biplot de correlación, así como los scatterplots, los cuales fueron mejorados con ayuda del software MiniTab 2018.

En la Tabla 61 se pueden observar los resultados descriptivos de las variables y etiquetas involucradas en el tratamiento. En esta se puede apreciar que, aunque el curso ECLyT va dirigido a personas entre 17 y 65 años de edad, con preparatoria terminada (Valdivia et al., 2017), se tuvieron participantes con edades y escolaridades fuera de esos rangos. 


\section{Tabla 61}

Resultados descriptivos de las variables involucradas en el estudio.

\begin{tabular}{|c|c|c|c|c|c|c|}
\hline Variable & Obs. & $\begin{array}{l}\text { Obs. sin } \\
\text { datos } \\
\text { perdidos }\end{array}$ & Mínimo & Máximo & Media & $\begin{array}{l}\text { Desv. } \\
\text { típica }\end{array}$ \\
\hline Edad & 1209 & 1209 & 15 & 74 & 28,7 & 10,7 \\
\hline Género & 1209 & 1209 & 1 & 2 & 1,61 & 0,488 \\
\hline Nivel* & 1209 & 1209 & 1 & 7 & 4,026 & 1,224 \\
\hline Ejercicio & 1209 & 1209 & 0 & 1 & 77,9 & 40,2 \\
\hline$R G$ & 1209 & 1209 & 0 & 1 & 53,5 & 49,9 \\
\hline $\begin{array}{l}\text { Examen } \\
\text { final }\end{array}$ & 1209 & 1209 & 0 & 1 & 51,2 & 44,7 \\
\hline EV7 & 1209 & 1209 & 0 & 1 & 88,1 & 19,9 \\
\hline Ev2 & 1209 & 1209 & 0 & 1 & 77,2 & 34,2 \\
\hline Ev3 & 1209 & 1209 & 0 & 1 & 66,4 & 38,8 \\
\hline Ev4 & 1209 & 1209 & 0 & 1 & 60,9 & 42,4 \\
\hline Ev5 & 1209 & 1209 & 0 & 1 & 53,9 & 42,8 \\
\hline Ev6 & 1209 & 1209 & 0 & 1 & 52,7 & 44,8 \\
\hline Práctica & 1209 & 1209 & 0 & 1 & 16,1 & 36,6 \\
\hline \multicolumn{2}{|c|}{ Promedio total } & \multicolumn{2}{|l|}{49,73} & \multicolumn{2}{|c|}{ Promedio aprobados } & 79,11 \\
\hline \multicolumn{2}{|c|}{ Desviación A. } & & 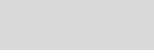 & 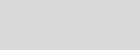 & 10,9 \\
\hline
\end{tabular}

Las correlaciones de las variables ejercicio, RG, examen final, evaluaciones 1 a 6 y práctica, 10 variables en total, se pueden ver en la Tabla 62. En la cual, se observó que el RG tiene una correlación fuerte con el examen final, así como con las evaluaciones 5 y 6. La práctica tiene muy poca relación con el resto de las variables mientras que el ejercicio y las evaluaciones 2 y 3 están correlacionadas entre sí, esto puede ser debido a que el ejercicio es una práctica preparatoria para la evaluación 3, misma que requiere conocimientos de la evaluación 2. 
Tabla 62

Correlaciones de las variables involucradas en el estudio.

\begin{tabular}{lllllllllll}
\hline Variables & Ejercicio & Reto & $\begin{array}{l}\text { Ex. } \\
\text { final }\end{array}$ & Ev1 & Ev2 & Ev3 & Ev4 & Ev5 & Ev6 & Práctica \\
\hline Ejercicio & 1 & & & & & & & & & \\
Reto & 0,476 & 1 & & & & & & & & \\
Ex. final & 0,523 & 0,797 & 1 & & & & & & & \\
Ev1 & 0,174 & 0,116 & 0,184 & 1 & & & & & & \\
Ev2 & 0,704 & 0,401 & 0,443 & 0,263 & 1 & & & & & \\
Ev3 & 0,791 & 0,548 & 0,604 & 0,237 & 0,662 & 1 & & & & \\
Ev4 & 0,647 & 0,660 & 0,725 & 0,192 & 0,550 & 0,748 & 1 & & & \\
Ev5 & 0,579 & 0,760 & 0,821 & 0,185 & 0,500 & 0,668 & 0,819 & 1 & & \\
Ev6 & 0,544 & 0,811 & 0,895 & 0,159 & 0,474 & 0,627 & 0,755 & 0,857 & 1 & \\
Práctica & 0,213 & 0,312 & 0,363 & 0,131 & 0,198 & 0,281 & 0,308 & 0,343 & 0,356 & 1 \\
\hline
\end{tabular}

En cuanto al ACP, en la Figura 32 se muestra la gráfica de sedimentación, la cual indica el peso de cada componente principal, como se puede ver los componentes F1 y F2 son los que mayor carga tienen. En el componente F1 contiene el 58.42\% de los valores propios (o varianza explicada) y el F2 contiene el $11.56 \%$, dando un total del 69.98\%. Por esta razón se utilizaron estos dos componentes.

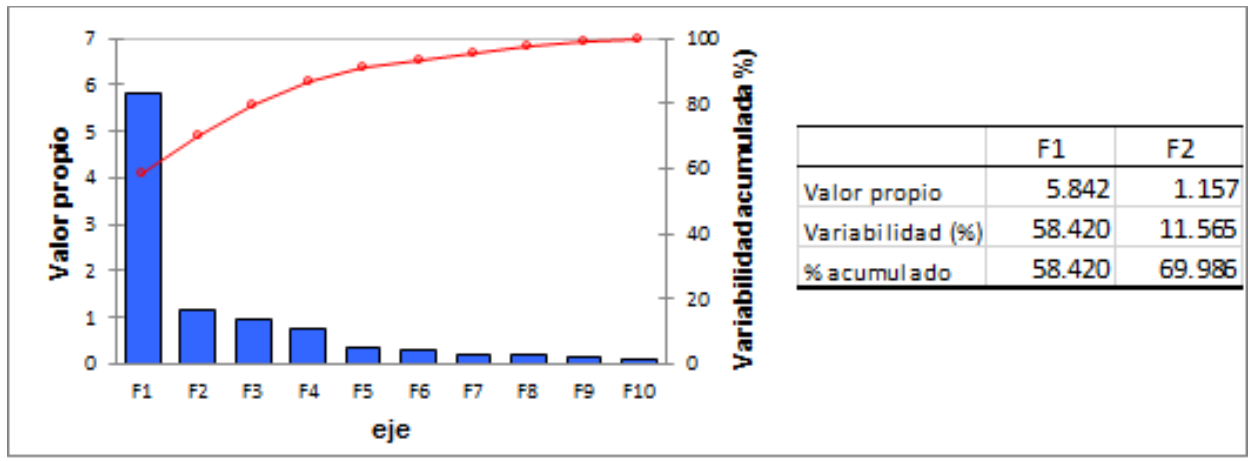

Figura 32. Gráfico de sedimentación 
Así mismo, el componente F1 es una nueva variable en la que se relacionan las variables Evaluación 2, 4 5, y 6, reto gamificado y examen final, mientras que en F2 se relacionan las evaluaciones 1 y 2, aunque solo un poco (ver Tabla 62). La variable Evaluación 1 está más relacionada con el componente F3 y la Práctica con el componente F4, ambas de manera aislada.

En la Figura 33, se muestra el gráfico Biplot de correlación, en el cual se puede apreciar como las evaluaciones 5 y 6 así como el examen final están cercanas al RG, es decir, los ángulos de los vectores son más agudos, lo mismo ocurrió con las evaluaciones 2, 3 y el ejercicio, mientras que las evaluaciones 1 y 4 están menos relacionadas. Por otro lado, la variable práctica, no se relaciona con alguna otra variable, se puede observar que el vector tiende a ser ortogonal, es decir, el hecho de que el vector esté corto significa que está de frente y el hecho de que sea ortogonal y sea el único vector en esa dirección implica que no se relaciona con alguna de las otras variables. 


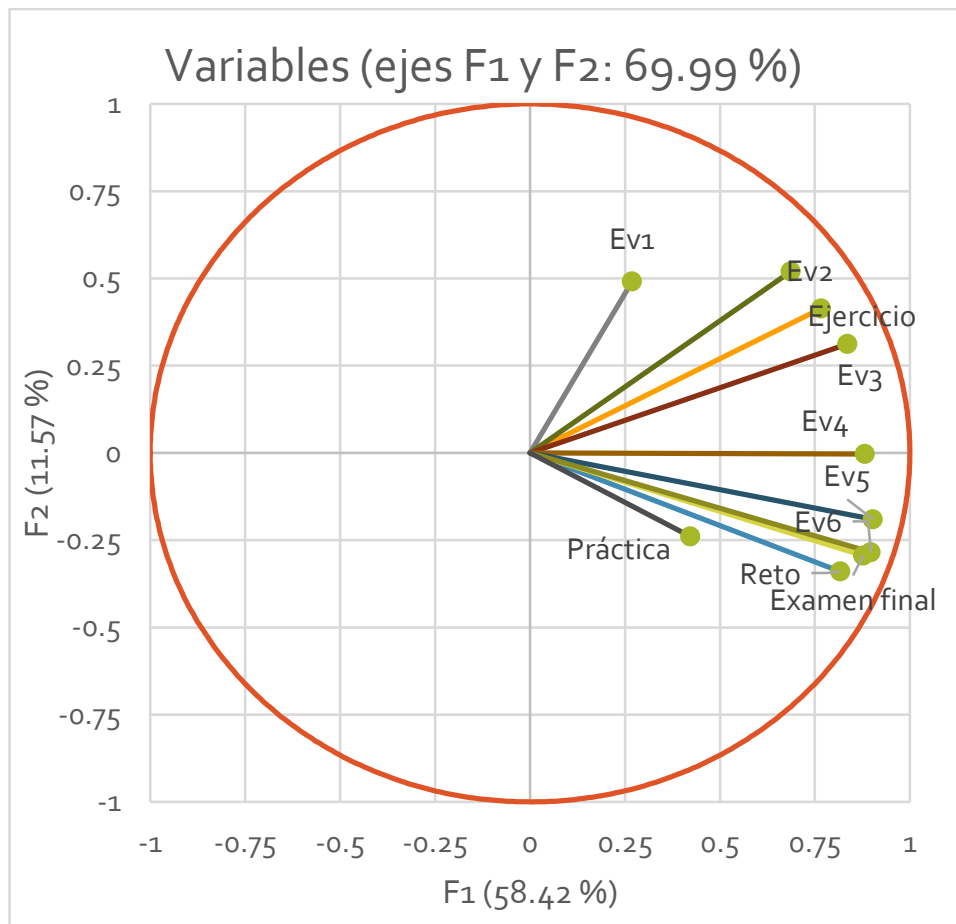

Figura 33. Gráfico Biplot de correlación con las componentes F1 y F2.

Para fortalecer lo anterior, se muestran los resultados de los cosenos cuadrados que contiene el peso de cada variable con respecto a los componentes F1 y F2, ver Tabla 68. En negrita se aprecian los valores de cada variable con respecto al componente, a mayor valor del coseno el ángulo tiende a ser más agudo y por el contrario, a menor valor del coseno el ángulo tiende a ser más ortogonal. Las variables con valores en negrita indican que están más relacionadas con el componente respectivo, por ejemplo, las variables Ejercicio, Reto, Examen final, así como las Evaluaciones de la 2 a la 6 están más relacionadas al componente F1 mientras que las evaluaciones 1 y 2 están ligeramente más relacionadas con el componente F2. De 
manera más evidente, la evaluación 1 está relacionada con la componente F3 y la práctica con F4.

\section{Tabla 63}

Cosenos cuadrados del ACP1 con respecto a los componentes F1, F2, F3 y F4.

\begin{tabular}{lllll}
\hline & $\mathrm{F} 1$ & $\mathrm{~F} 2$ & $\mathrm{~F} 3$ & $\mathrm{~F} 4$ \\
\hline Ejercicio & 0,587 & 0,171 & 0,061 & 0,035 \\
Reto & 0,667 & 0,116 & 0,000 & 0,028 \\
Examen final & 0,769 & 0,087 & 0,003 & 0,023 \\
Ev1 & 0,072 & 0,241 & 0,518 & 0,165 \\
Ev2 & 0,471 & 0,270 & 0,016 & 0,024 \\
Ev3 & 0,698 & 0,097 & 0,018 & 0,015 \\
Ev4 & 0,778 & 0,000 & 0,007 & 0,001 \\
Ev5 & 0,815 & 0,036 & 0,000 & 0,013 \\
Ev6 & 0,806 & 0,081 & 0,000 & 0,019 \\
Práctica & 0,178 & 0,057 & 0,317 & 0,447 \\
\hline
\end{tabular}

Por ello, en el Biplot mostrado en la Figura 35, tanto la evaluación 1 como la práctica tienen los vectores "cortos", esto significa que su dirección es hacia el "frente" o bien, que son ortogonales a F1 En la Figura 34, se muestra el Biplot con las componentes F1 y F3 para evidenciar esto. 


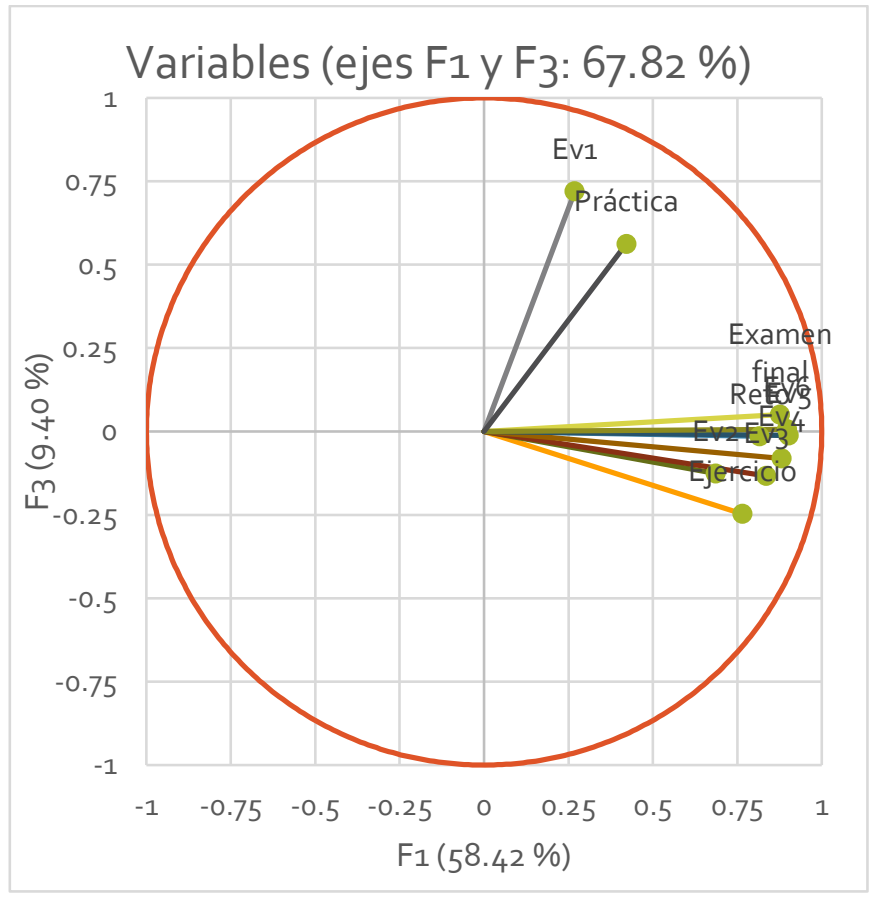

Figura 34. Gráfico Biplot de correlación con las componentes F1 y F3.

Como consecuencia del análisis de componentes principales, en las Figuras 35, 37 y 38 se pueden observar los gráficos scatter-plot con respecto a cada etiqueta, es decir género, edad y nivel educativo con respecto a las variables cuantitativas. Este gráfico nos permite observar la relación de las variables en dos dimensiones. Nótese que ambos gráficos representan lo mismo, el de la izquierda contiene los cuadrantes y los vectores de cada variable, el de la derecha representa cada etiqueta con un color diferente. 


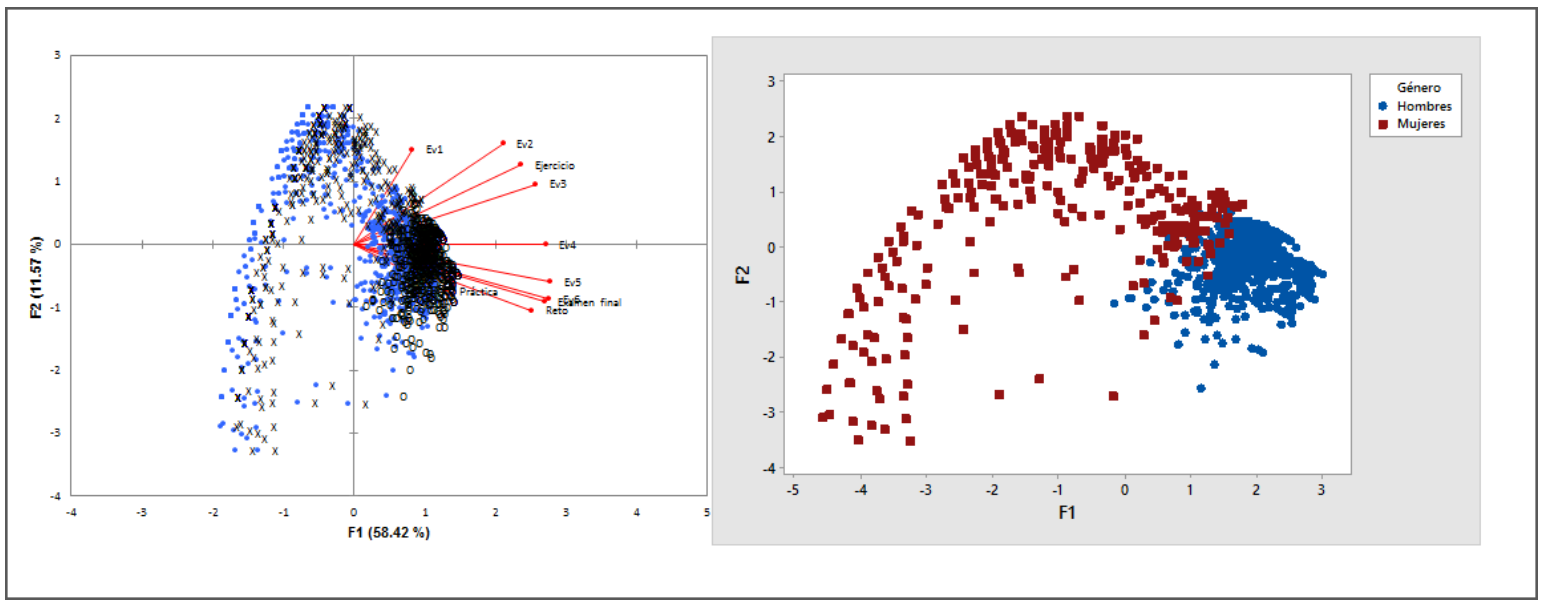

Figura 35. Scatter-plot de la etiqueta género con respecto a las variables cuantitativas.

En la Figura 35 se muestra el scatter-plot con la etiqueta de género. Se puede observar que los hombres están más relacionados con la componente F1 y que un grupo de mujeres lo están con la componente F2. De los 1209 participantes que al menos hicieron una actividad, 737 fueron hombres y 472 mujeres, de los cuales 400 hombres aprobaron (54,27\%) y 221 mujeres (46,82\%). De los hombres que pasaron el curso 418 hicieron el reto $(98,5 \%)$ y 229 de las mujeres que aprobaron $(96,38 \%)$.

En la Tabla 63 se pueden apreciar los promedios de las actividades ordenadas cronológicamente, tanto de hombres como de mujeres. Recordemos que la mínima aprobatoria es 0.6 y la máxima 1, además que se consideraron los participantes que hicieron al menos una actividad (1209 participantes). 
Tabla 64

Tasa terminal y promedio de calificaciones de hombres y mujeres del curso ECLYT.

\begin{tabular}{|c|lllll}
\hline \multirow{3}{*}{$\begin{array}{c}\text { Alumnos inscritos } \\
4819\end{array}$} & Actividades & $\begin{array}{l}\text { Promedio } \\
\text { mujeres }\end{array}$ & Desv & $\begin{array}{l}\text { Promedio } \\
\text { hombres }\end{array}$ & Desv \\
\cline { 2 - 6 } & Ev1 & 0.87 & 0.21 & 0.89 & 0.19 \\
\cline { 2 - 6 } Alumnos que realizaron al & Ev2 & 0.75 & 0.35 & 0.78 & 0.34 \\
menos una actividad & Ejercicio & 0.78 & 0.40 & 0.78 & 0.40 \\
\cline { 2 - 6 } $1209(25 \%)$ & Ev3 & 0.65 & 0.39 & 0.68 & 0.39 \\
\cline { 2 - 6 } & Ev4 & 0.60 & 0.42 & 0.62 & 0.43 \\
\cline { 2 - 6 } Alumnos que aprobaron el & Práctica & 0.16 & 0.37 & 0.16 & 0.36 \\
\cline { 2 - 6 } curso & Ev5 & 0.51 & 0.42 & 0.55 & 0.43 \\
\cline { 2 - 6 }$(12.89 \%)$ & Ev6 & 0.50 & 0.45 & 0.55 & 0.45 \\
\cline { 2 - 6 } & Reto & 0.49 & 0.50 & 0.57 & 0.50 \\
\cline { 2 - 6 } & Ex. Final & 0.48 & 0.45 & 0.53 & 0.45 \\
\cline { 2 - 6 } & Calificación & 0.47 & 0.33 & 0.51 & 0.33 \\
\hline
\end{tabular}

Se puede apreciar en la Tabla 64 que el promedio de las actividades de los hombres fue mayor que el de las mujeres, en la Figura 36 se muestran los resultados de la prueba t-student para la diferencia de medias, esto verifica que las diferencias en las calificaciones finales entre hombres y mujeres son significativas.

\section{Estadística descriptiva}

\begin{tabular}{lrrrr} 
& $\mathrm{N}$ & Media & Desv & SE Media \\
\hline Calificación hombres & 741 & 0.513 & 0.333 & 0.012 \\
Calificación mujeres & 474 & 0.473 & 0.327 & 0.015 \\
Test & & & &
\end{tabular}

$$
\begin{aligned}
& \text { Hipótesis nula } \quad H_{0}: \mu_{1}-\mu_{2}=0 \\
& \text { Hipótesis altemativa } \mathrm{H}_{1}: \mu_{1}-\mu_{2} \neq 0 \\
& \begin{array}{crr}
\text { T-Value } & \text { GL } & \text { P-Value } \\
\hline 2.04 & 1213 & 0.041
\end{array}
\end{aligned}
$$

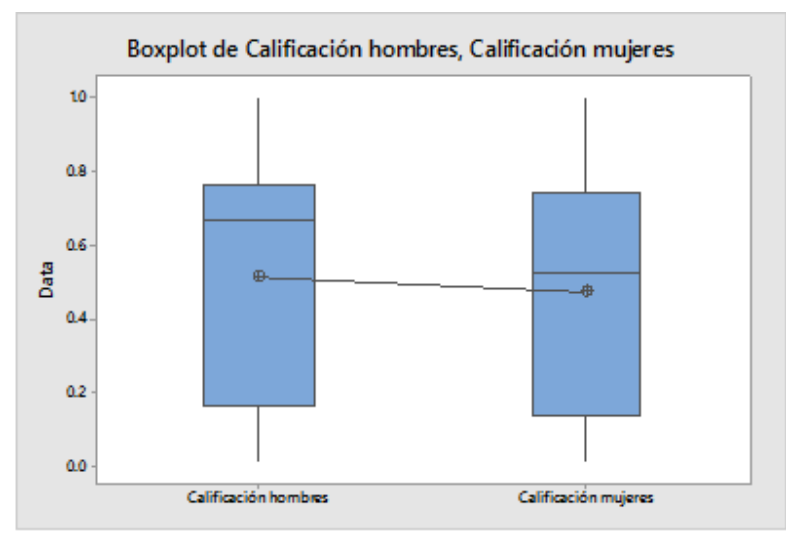

Figura 36. Prueba t-student para la diferencia de medias entre las calificaciones finales de los hombre y mujeres.

Posiblemente por ello, en la Figura 33, los hombres están más concentrados en la componente F1, la cual está relacionada con las Evaluaciones 5, 6, Reto Gamificado y Evaluación Final. También se puede apreciar que la evaluación con mayor promedio 
de las mujeres fue la Evaluación 1 y dado que el porcentaje de aprobación fue mayor en los hombres, esto pudo ser debido a que hubo más deserción a partir de la Evaluación 2, quizás por ello un grupo de mujeres están más relacionadas a la componente F2, la cual está relacionada con la Evaluación 1.

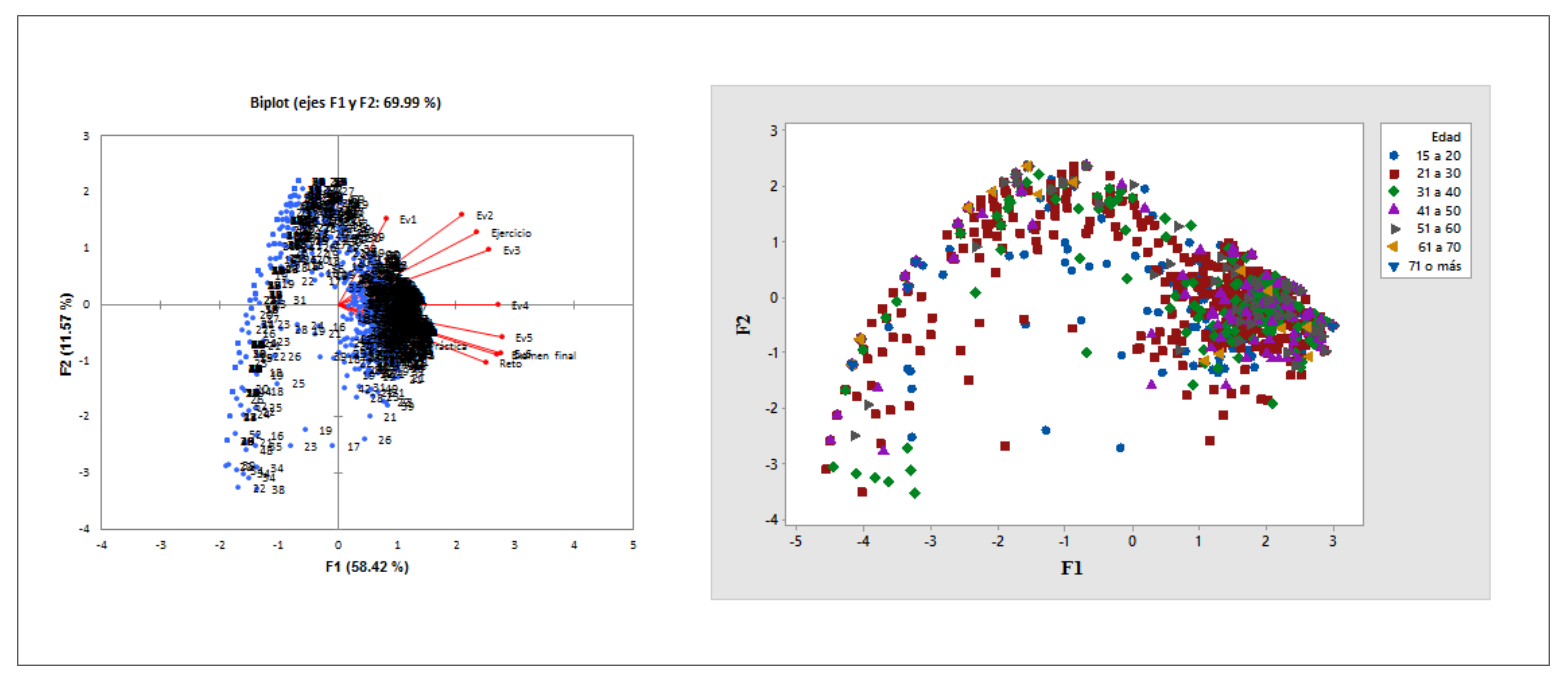

Figura 37. Scatter-plot de la etiqueta edad con respecto a las variables cuantitativas.

Con respecto a la edad, se puede apreciar en el Figura 39 que los participantes en las edades de 21 a 60 años están más relacionados con la componente F1. Al mismo tiempo se aprecia un grupo de personas de 21 a 40 años que se relacionan más con la componente F2. 


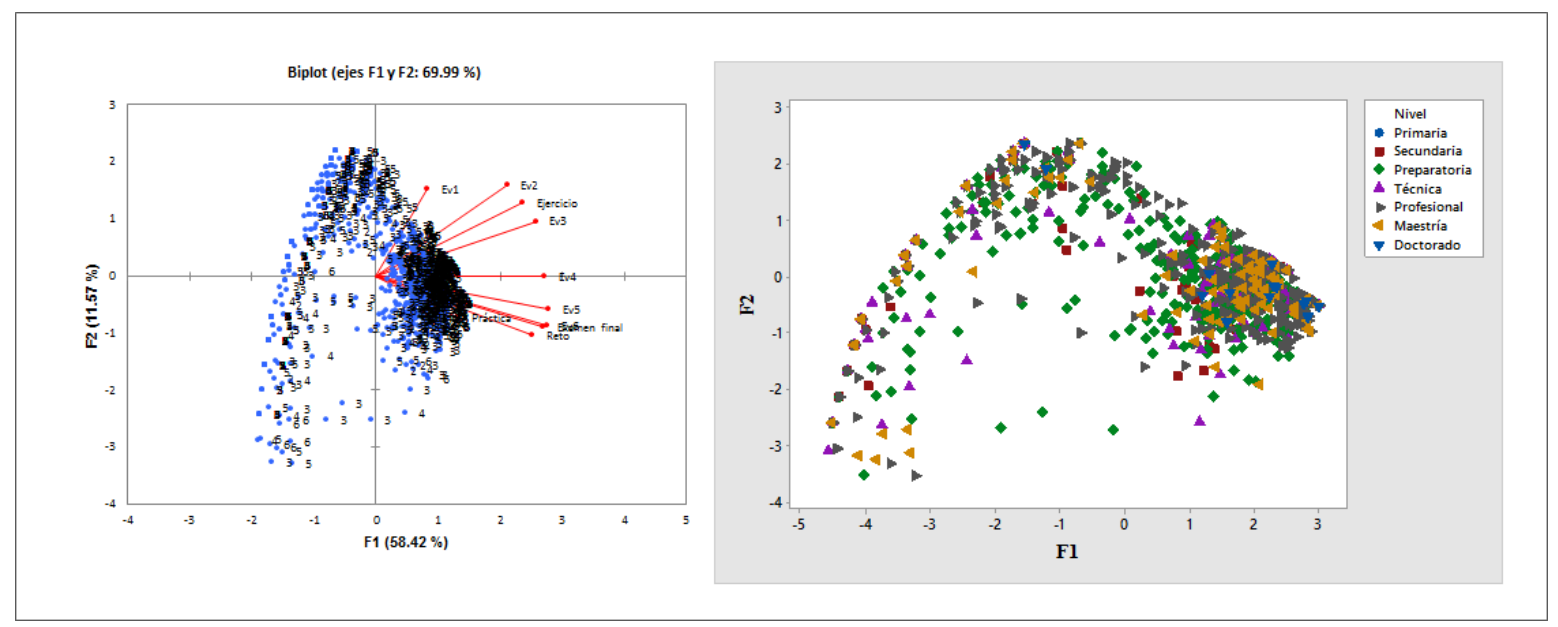

Figura 38. Scatter-plot de la etiqueta nivel educativo con respecto a las variables cuantitativas.

Con respecto al nivel educativo, ver Figura 38, vemos que los niveles, de profesional, maestría y doctorado están más relacionados a la componente F1 mientras que un grupo de preparatoria y técnica se inclinan más a la componente F2. En la Tabla 65 se puede observar que los promedios más altos correspondes a estos niveles.

Esto podría explicar porque algunos grupos de secundaria y preparatoria se relacionan con el componente F2.

Tabla 65

Promedios de cada actividad con respecto el nivel educativo.

\begin{tabular}{lllllllllll}
\hline Nivel & \multicolumn{2}{l}{ Secundaria } & \multicolumn{2}{l}{ Preparatoria } & \multicolumn{2}{l}{ Profesional } & \multicolumn{2}{l}{ Maestría } & \multicolumn{2}{c}{ Doctorado } \\
\hline & Promedio & Desv & Promedio & Desv & Promedio & Desv & Promedio & Desv & Promedio & Desv \\
Ev1 & 0,78 & 0,24 & 0,88 & 0,19 & 0,84 & 0,25 & 0,89 & 0,22 & 0,96 & 0,08 \\
Ev2 & 0,72 & 0,35 & 0,77 & 0,33 & 0,77 & 0,35 & 0,78 & 0,37 & 0,93 & 0,10 \\
Ejercicio & 0,75 & 0,44 & 0,78 & 0,40 & 0,78 & 0,41 & 0,76 & 0,42 & 0,93 & 0,16 \\
Ev3 & 0,63 & 0,39 & 0,65 & 0,38 & 0,64 & 0,38 & 0,66 & 0,40 & 0,93 & 0,12 \\
Ev4 & 0,58 & 0,42 & 0,58 & 0,42 & 0,63 & 0,42 & 0,64 & 0,44 & 0,84 & 0,26 \\
Práctica & 0,05 & 0,23 & 0,17 & 0,37 & 0,10 & 0,31 & 0,18 & 0,38 & 0,27 & 0,46 \\
Ev5 & 0,46 & 0,41 & 0,53 & 0,42 & 0,55 & 0,43 & 0,57 & 0,45 & 0,77 & 0,34 \\
Ev6 & 0,46 & 0,44 & 0,52 & 0,44 & 0,55 & 0,44 & 0,57 & 0,45 & 0,84 & 0,35 \\
Reto & 0,43 & 0,50 & 0,52 & 0,50 & 0,59 & 0,49 & 0,60 & 0,49 & 0,87 & 0,35 \\
\hline
\end{tabular}




\begin{tabular}{lllllllllll}
\hline $\begin{array}{l}\text { Examen } \\
\text { final }\end{array}$ & 0,46 & 0,42 & 0,51 & 0,44 & 0,54 & 0,43 & 0,54 & 0,46 & 0,79 & 0,33 \\
Calificación & 0,42 & 0,30 & 0,49 & 0,33 & 0,51 & 0,32 & 0,53 & 0,34 & 0,73 & 0,25 \\
\hline
\end{tabular}

De los 1209 participantes, 67 fueron de nivel secundaria de los cuales 22 aprobaron (32,6\%) y 24 hicieron el reto, 531 fueron de nivel preparatoria de los cuales 273 aprobaron $(51,41 \%)$ y 277 hicieron el reto. Del nivel técnico fueron 86 , de los cuales aprobaron $47(54,6 \%)$ y 51 hicieron el reto, 381 fueron del nivel profesional, 189 aprobaron (49,6\%) y 198 hicieron el reto. De los 129 participantes de maestría, 71 aprobaron (55,03\%) y 78 hicieron el reto y de los 15 de doctorado, 13 aprobaron $(86,7 \%)$ y 13 hicieron el reto.

En resumen, la mayoría de los hombres entre 21 y 50 años de niveles superiores se relacionan más con el componente F1, el cual está relacionada con las Evaluaciones 5, 6, Reto Gamificado y Evaluaciones Finales. También es notorio que la mayoría de los participantes que aprobaron hicieron el reto, es decir, hubo interés por parte de los usuarios para realizar esta actividad.

No obstante, la actividad práctica no se relacionó con ninguno de los componentes, esto puede sugerir que la actividad práctica no estuvo alineada al diseño educativo del MOOC ECLYT ya que la mayoría de los participantes de todos los niveles, edades y género, no la realizaron o tuvieron calificaciones bajas. 


\subsubsection{Otros resultados de los instrumentos cualitativos. En este apartado se muestran}

los resultados sobre los aspectos de mejora del Reto Gamificado, las cuales servirán para determinar si la Gamificación en un curso del tipo xMOOC es una estrategia innovadora, así como para determinar si hay aspectos a mejorar. Luego se mostrarán los resultados sobre el nivel de innovación alcanzado por los participantes.

4.1.5.1 Fortalezas y áreas de mejora. Se obtuvieron 764 respuestas de las cuales 376 se relacionaron con el reto, a partir de ahí se establecieron tres categorías: Opinión general del reto gamificado, contenido del reto y diseño de la gamificación.

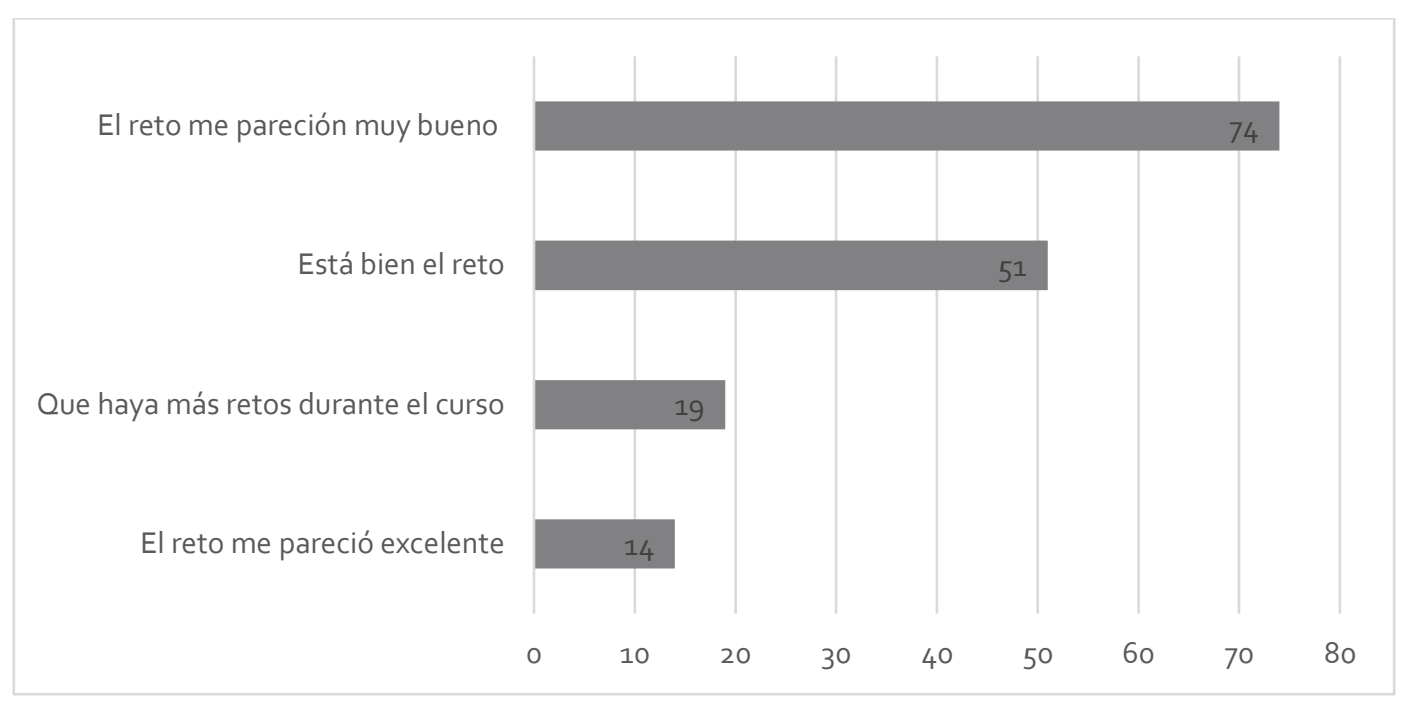

Figura 39. Resultados de la Categoría 1. Opinión general del reto gamificado

En la Figura 39 se puede ver como 158 opiniones de 376, es decir el 42,02\% tuvieron una opinión positiva del reto y que no hay nada que mejorar. Esto nos dice que hay una aceptación favorable con respecto a la estrategia didáctica. En la Tabla 65 se muestran algunas opiniones. 


\section{Tabla 66}

Algunas opiniones sobre el reto gamificado del curso Enegías Limpias y su Tecnología dentro de la categoría 1.

1. El reto me pareció un claro ejemplo de la aplicación de los combustibles que en la vida diaria puede que se llegue a llevar a cabo, puesto que es importante tener noción de sus efectos de cada compuesto. (Participante 670).

2. Me pareció un ejercicio muy apropiado para rectificar los conocimientos adquiridos y motivar la búsqueda de soluciones. (

3.Fue un reto interesante, y práctico. Sería bueno incluir algunos más a lo largo de las actividades. (Participante 27).

4. Más ejercicios de estos dentro del curso, me obligó a recordar situaciones prácticas e imaginarme cada evento, ventajas y desventajas de cada uno. (Participante 56).

5. Me pareció una actividad muy interesante y bonita. A mi me ayudó mucho el análisis de las preguntas de comprensión que venían después del video y antes de las opciones del reto. Reflexioné sobre ellas y relacioné lo visto en el video, las lecturas, el planteamiento del reto, que debía iluminar espacio cerrado durante la noche, etc.(Participante 317).

En la categoría 2, con respecto al contenido del reto se puede ver que hay

interés sobre que el reto tenga un nivel de dificultad mayor (ver Figura 40).

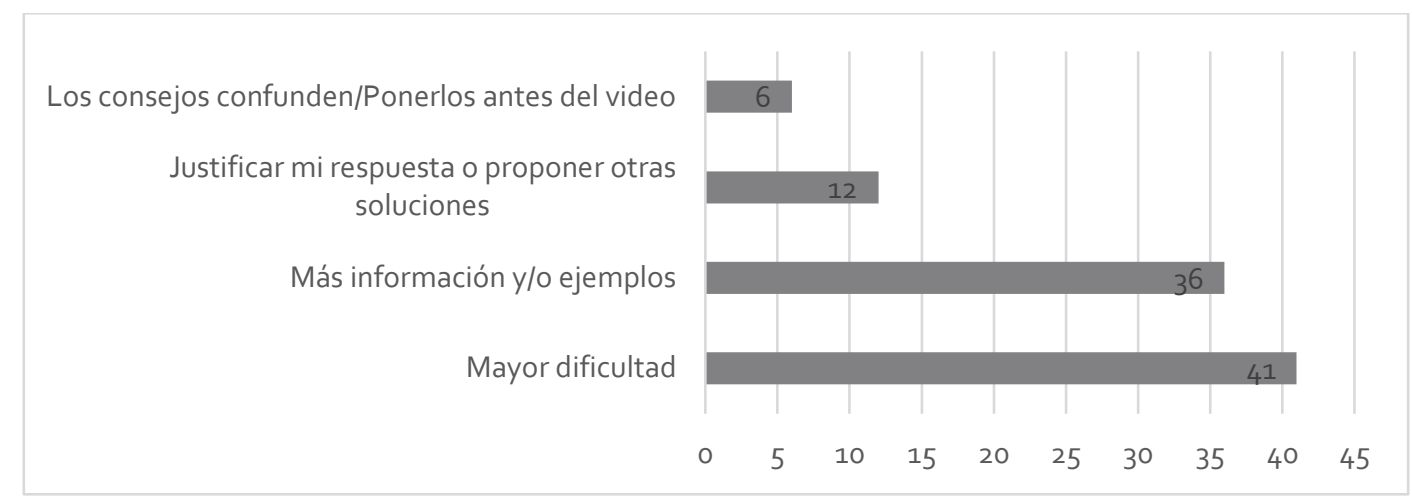

Figura 40. Resultados de la Categoría 2. Contenido del reto gamificado.

Por otro lado, llama la atención como otros participantes quieren más información que enriquezca el aprendizaje del tema y desean justificar su respuesta o proponer otras soluciones, lo que sin duda, muestra interés en el aprendizaje y su socialización. En la Tabla 67 se muestran algunas opiniones. 


\section{Tabla 67}

Algunas opiniones sobre el reto gamificado del curso Enegías Limpias y su Tecnología dentro de la categoría 2.

Un poco más de información o ligas a sitios web que contenga información respecto al tema (Participante 299).

Mayor información. ya que aunque se presentaba información relevante había información no incluida como el tema de combustión completa e incompleta, ademas de como el ollin causaría problemas a la salud (Participante 342)

Que se aumente el grado de dificultad del reto porque considero que con lo aprendido en temas anteriores ya tenemos conocimientos para un reto de este tipo. Además, que el reto se relaciones a temas de la industria. (Participantes 3).

Con el objetivo de que el discente emplee más el análisis crítico, pudiera proporcionarse mayor información, de modo tal que intervengan más factores en el escenario que se plantea. (Participante 72)

El reto está muy bien, pero sería interesante agregar un apartado en el cual se pueda obtener un combustible utilizando un método más "casero", utilizando materiales cotidianos y no equipo de laboratorio. Supongamos que no contamos con alguno y que olvidamos las baterías de las lámparas; una gran emergencia. (Participantes 101).

Introducir el análisis de sustentabilidad. De nada sirve utilizar $X$ o $Y$ compuesto si el mismo no cumple con las tres dimensiones de la sustentabilidad. Recomiendo que la toma de decisiones debe estar basada en qué tan económico es, que consecuencias/beneficios sociales contrae, y claro, su impacto en el entorno. (Participante 684).

Dentro de los comentarios de la Tabla 67 se observan comentarios recurrentes sobre que se proporcione más información sobre el tema antes y después de responder el reto, lo que sugiere agregar referencias que permitan que el estudiante tenga acceso a más información. Finalmente, en la Figura 43 se muestran los resultados de la Categoría 3 sobre el diseño del reto gamificado, en donde se puede observar que hay congruencia y pertinencia en las opiniones de los participantes ya que ciertamente las instrucciones mostradas en el MOOC no fueron claras. 


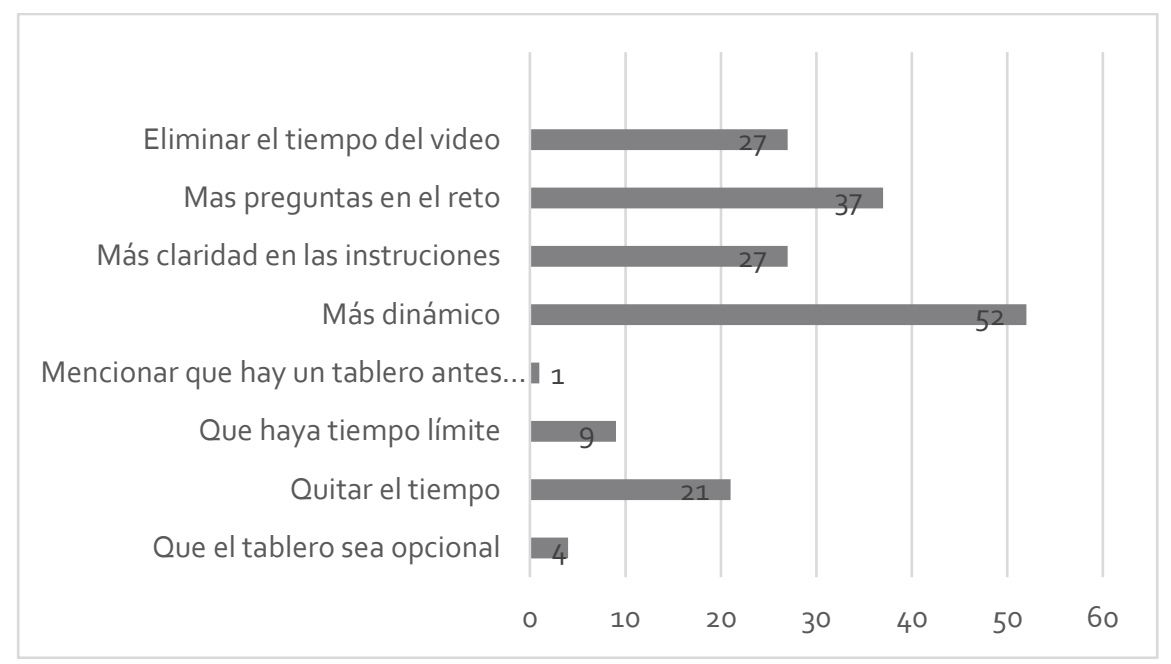

Figura 41. Resultados de la Categoría 3. Diseño del reto gamificado.

En la Tabla 67 se muestran algunos comentarios, los cuales resultaron valiosos

para mejorar esos aspectos en los retos y que se vieron reflejados en las siguientes

emisiones de los xMOOC-energía.

Tabla 68

Algunas opiniones sobre el reto gamificado del curso Enegías Limpias y su Tecnología dentro de la categoría 3.

1. Más actividades de competencia entre compañeros y reconocimientos. (Participante 10)

2. Es importantísimo el reconocimiento. Por favor seguir implementándolo. (Participante 350)

3. Debería tener un botón que diga: "Aceptas el reto" y luego de aceptar y después de leer las instrucciones, abrir la ventana con el reto a resolver junto con el cronómetro visible. Participante 79).

4. Que tenga un cronómetro, para sentir la presión, y ahí sí, sentirme motivado para contestar lo más rápido posible y sentirme retado. (Participante 145).

5. Sólo 2 intentos para que analicemos más a fondo la información que se nos brinda. (Participante 116).

Evitar poner los nombres de usuario en el tablero, solo los resultados y el numero de participante, resaltando en rojo el propio para distinguirlo del de los demás. (Participante 121)

7. que se sienta mas la competencia. (Participante 117).

8. Que no tomen el tiempo desde que inicia el vídeo o que halla un anuncio que diga " tu tiempo comienza ahora" .(Participante 154).

9. ademas de los 3 trofeos existentes, tener una opcion abierta para propuestas propias. (Participante 418). 
Los comentarios de algunos de los participantes refuerzan el interés en participar en este tipo de estrategia al mismo tiempo que proveyeron de información para mejorarlo en cada uno de los XMOOC-energía.

A partir de los resultados se puede inferir que hay una aceptación favorable con respecto a la estrategia didáctica de gamificación y prueba el hecho que dicha estrategia mejora lo que ya se hacía, lo cual la coloca de manera auténtica en una estrategia didáctica innovadora, no obstante todavía puede mejorarse.

4.1.5.2 Nivel de innovación logrado a partir de las soluciones alternativas del reto gamificado. Para procesar esta información se tomaron las respuestas de la pregunta abierta: "Escribe una propuesta o solución alternativa al Reto Gamificado: Combustibles para iluminación en caso de emergencia", que se colocó en el instrumento que se aplicó después de desarrollar el RG. De las 764 respuestas solo 140 hablaban de una propuesta diferente a las propuestas. De los participantes que dieron una propuesta, 41 fueron mujeres y 99 fueron hombres. En la Tabla 69 se muestra la distribución por edad y nivel educativo de esos 140 participantes. 


\section{Tabla 69}

Distribución de participantes por edad y nivel educativo.

\begin{tabular}{lllllll}
\hline & Preparatoria & Técnica & Profesional & Maestría & Doctorado & Total \\
\hline Entre 16 y 20 años & 11 & 1 & 23 & 0 & 0 & 35 \\
\hline Entre 21 y 30 años & 7 & 1 & 41 & 1 & 0 & 50 \\
\hline Entre 31 y 40 años & 2 & 0 & 10 & 6 & 0 & 18 \\
\hline Entre 41 y 50 años & 0 & 0 & 12 & 4 & 0 & 16 \\
Entre 51 y 60 años & 1 & 0 & 9 & 9 & 1 & 20 \\
Más de 60 años & 0 & 0 & 1 & 0 & 0 & 1 \\
Total & 21 & 2 & 96 & 20 & 1 & 140 \\
\hline
\end{tabular}

Como se puede observar, la mayoría de los participantes estuvieron entre los 16 y 30 años de los niveles preparatoria y profesional, no obstante, hubo un número considerable del nivel maestría entre 31 y 60 años. Es importante destacar que en esta pregunta participaron dos de nivel técnico y uno de doctorado.

Las 140 respuestas fueron categorizadas de acuerdo a la rúbrica de nivel de innovación que se construyó después de una profunda revisión de la literatura, ver Tabla 6. En la rúbrica se definieron cuatro atributos, los cuales serán las categorías para la clasificación de las respuestas, estas fueron: impacto, claridad, conocimiento y tipo de innovación. En la Tabla 70 se pueden revisar algunos ejemplos de respuesta: 


\section{Tabla 70}

Algunas respuestas alternativas al reto gamificado (RG).

\begin{tabular}{|c|c|c|c|}
\hline Género & $\begin{array}{l}\text { Nivel } \\
\text { estudios }\end{array}$ & $\begin{array}{l}\text { Selecciona } \\
\text { edad }\end{array}$ & $\begin{array}{l}\text { 13) Escribe una propuesta o solución alternativa al } \\
\text { reto gamificado "Combustibles para iluminación en } \\
\text { caso de emergencia". }\end{array}$ \\
\hline Hombre & Profesional & Entre 16 y 20 años & $\begin{array}{l}\text { Agregar la posibilidad de que puedan utilizarse } \\
\text { biocombustibles como métodos de iluminación, } \\
\text { asumiendo que en el planteamiento del problema } \\
\text { se den las condiciones para dicha posibilidad. }\end{array}$ \\
\hline Hombre & Profesional & Entre 21 y 30 años & $\begin{array}{l}\text { El bioetanol es un biocombustible que no es muy } \\
\text { costoso de mantener, creo es una muy buena } \\
\text { opción para iluminación en caso de un apagón. }\end{array}$ \\
\hline Mujer & Maestría & Entre 21 y 30 años & Biodisel \\
\hline Hombre & Preparatoria & Entre 21 y 30 años & $\begin{array}{l}\text { En vez de utilizar combustible inflamable para } \\
\text { iluminación de emergencia preferiría hacer uso de } \\
\text { sistemas con baterías recargables mediante dinamo. }\end{array}$ \\
\hline Hombre & Profesional & Entre 51 y 60 años & $\begin{array}{l}\text { Una alterrnativa al reto sería que, al no contar con } \\
\text { gasolina, diesel o bioetanol, qué otro combustible } \\
\text { podría usarse para iluminación y calor considerando } \\
\text { que se estaría en un lugar donde abundan } \\
\text { materiales como hojarasca, leña y otro tipo de } \\
\text { residuos vegetales combustibles que cumplirían las } \\
\text { mismas funciones, aunque con el inconveniente del } \\
\text { humo y el ollín. }\end{array}$ \\
\hline Hombre & $\begin{array}{l}\text { Estudios } \\
\text { técnicos }\end{array}$ & Entre 16 y 20 años & $\begin{array}{l}\text { Instalación de paneles solares en lugares sin acceso } \\
\text { a red eléctrica }\end{array}$ \\
\hline Hombre & Profesional & Entre 16 y 20 años & $\begin{array}{l}\text { Podríamos usar ciertas resinas en lugar de los } \\
\text { combustibles, ya que como sabemos la vecinal } \\
\text { copal tiene una buena combustión. }\end{array}$ \\
\hline Mujer & Profesional & Entre 41 y 50 años & Utilizar una lámpara solar \\
\hline Hombre & Profesional & Entre 21 y 30 años & Llevar pelets de biomasa. \\
\hline Hombre & Preparatoria & Entre 31 y 40 años & $\begin{array}{l}\text { realizar la iluminación que sea más limpia mediante } \\
\text { plantas como el nopal }\end{array}$ \\
\hline
\end{tabular}

Las respuestas fueron validadas por el líder del desarrollo del xMOOC ECLyT,

quien es un profesor investigador en los temas de energía y quien, además, forma

parte del grupo de enfoque de Energía y cambio climático. 
4.2.2.1 Nivel de innovación por género. En la Figura 42 se pueden observar los resultados del nivel de innovación logrado por género.
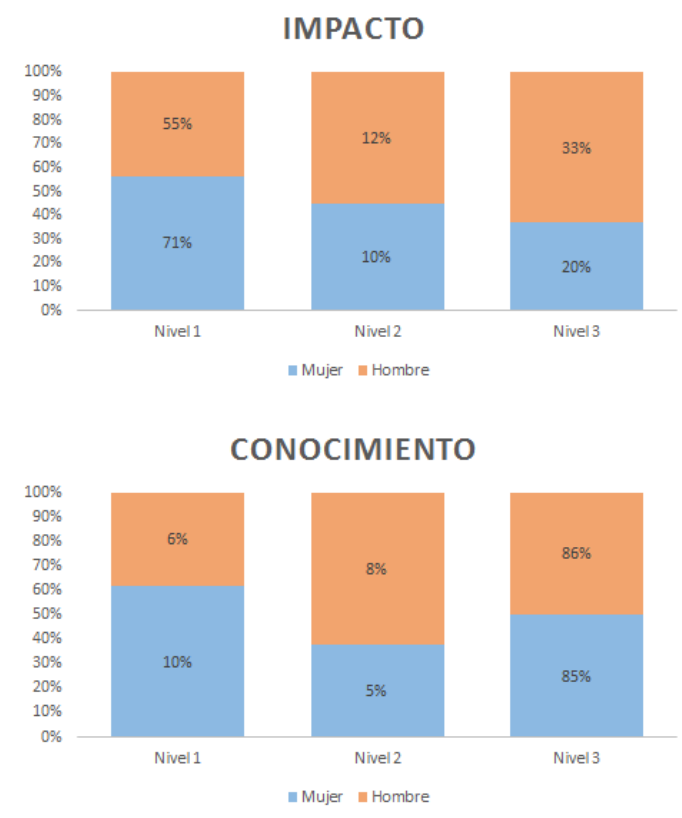

Figura 42. Nivel de innovación logrado por género.

Tanto las mujeres como hombres presentaron propuestas claras y observables y con base en los conocimientos del curso (claridad y conocimiento). En cuanto al nivel de impacto tanto hombres como mujeres se quedaron mayormente en el nivel 1, es decir que su propuesta tiene relativa ventaja con respecto a lo que ya se hace. También se encontró que en el nivel 3, la proporción de hombres fue mayor que las mujeres, es decir, que esas propuestas tienen impacto en el entorno. Con respecto al tipo de innovación, tanto hombres y mujeres se colocaron en el nivel 1, es decir, en una innovación incremental, es decir que se mejora relativamente lo que ya se hace. En el nivel 3 o innovación disruptiva, los hombres se colocaron por encima de las mujeres, 
es decir que las propuestas de los hombres pueden llegar a estar al alcance de un gran número de personas.

El nivel de innovación también se evaluó con respecto al nivel educativo, en la Figura 43 se puede ver los resultados.
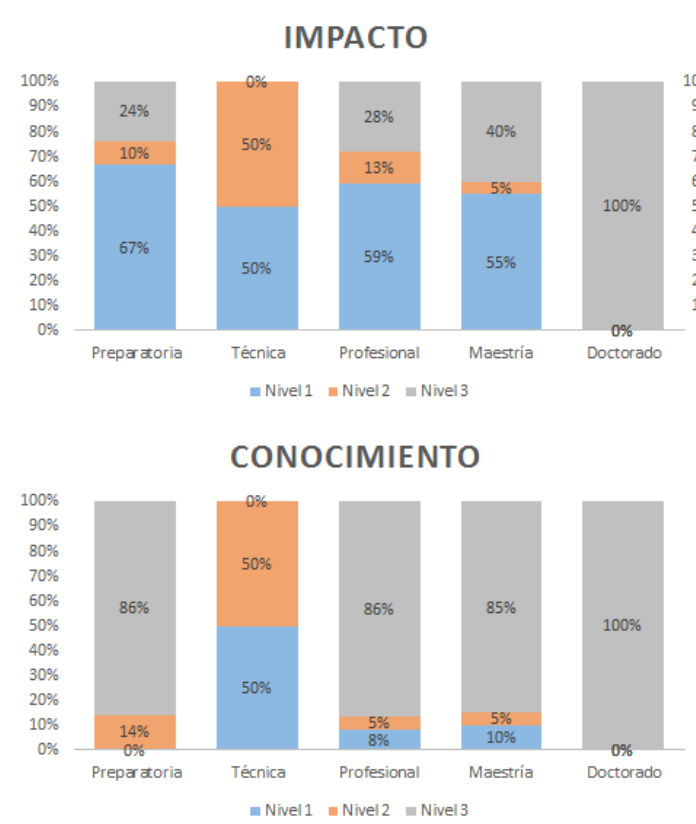

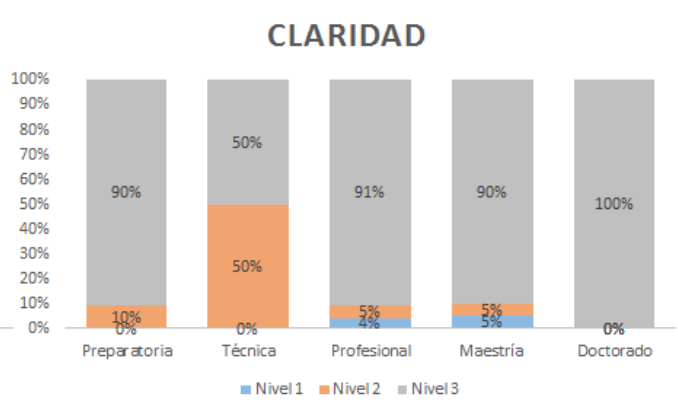

TIPO DE INNOVACIÓN

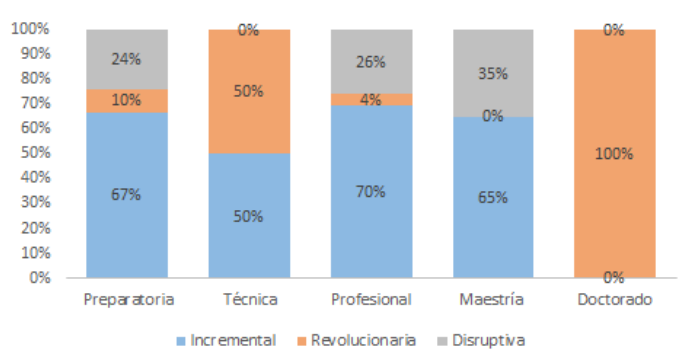

Figura 43. Nivel de innovación por nivel educativo.

En cuanto al impacto, vemos que los participantes de nivel maestría y doctorado quedaron en el nivel 3, en todos los niveles se observó que las propuestas fueron claras y con base en conocimiento del curso. Por otro lado, la mayoría de los niveles se colocaron en una innovación del tipo incremental (nivel 1), no obstante, los niveles de maestría y profesional mostraron que sus propuestas se clasificaron como innovaciones disruptivas (nivel 3). 


\subsubsection{El Reto Gamificado como recurso de innovación educativa. Para el desarrollo}

de los $\mathrm{XMOOC}$ se involucraron tres grupos interdisciplinarios: expertos en los temas de energía, expertos en desarrollo instruccional, investigadores educativos y expertos en desarrollo tecnológico. Por lo que se aplicaron cuatro entrevistas, dos al grupo de desarrolladores instruccionales, una a un investigador y una a un desarrollador tecnológico, ver Anexo IX. Con base a esas respuestas y a los resultados presentados en el presente capítulo, el RG es una estrategia con alto impacto, ya que llegó a diversos niveles educativos, es clara y fue desarrollada con base en conocimiento, pues se fundamentó en el modelo de Werbach y Hunter (2015). En cuanto al tipo de innovación, se coloca en el nivel 1 ya que mejora lo que se hace en cuanto a los xMOOC, no es todavía un cambio radical y tampoco puede multiplicarse a otros MOOC ya que se requieren recursos económicos y tecnológicos. A continuación, se presentan algunas respuestas:

"Con base en las definiciones de innovación, yo pienso que es el Reto Gamificado es una innovación incremental" (Experto en innovación educativa)

"Considero que, si es una estrategia innovadora debido a la aplicación de gamificación con un número de participantes tan alto y por la visualización de resultados a todos los participantes, logrando así la motivación entre ellos" (Experto en desarrollo tenológico) 
"Sí es innovador, aunque podría mejorarse". (Experto en contenidos)

"Considero que la gamificación sí es una innovación disruptiva, pero no la que se aplicó en el MOOC debido a las limitantes de la plataforma y la característica de los cursos" (Diseñador instruccional).

Con base en las respuestas, se puede notar que los expertos que participaron en el desarrollo de xMOOC energía, coinciden en que le gamificación basada en retos aplicada en el curso, corresponde a una innovación incremental.

\subsection{Interpretación de resultados}

A continuación, se muestra el análisis de los resultados más importantes, dichos resultados fueron desarrollados por constructo. Para este estudio se determinaron tres: gamificación, MOOC e Innovación.

\subsubsection{Análisis sobre la estrategia didáctica gamificación basada en retos en el} curso XMOOC ECLyT. Desde el inicio del curso se observó que el género masculino tuvo mayor presencia en el curso pues al término de éste, ellos tuvieron un mayor porcentaje en aprobación y realización del RG. Estos resultados se pueden observar en las Tablas 21, 55 y 63 así como en las Figuras 35 y 36, particularmente en la 35 se observó que los hombres están más agrupados en la componente F1, la cual contiene al $R G$, incluso un grupo de mujeres se agrupa en la componente F2 que no contiene al RG. Esto coincide con lo que encontraron Koivisto \& Hamari (2014) y Warden, 
Stanworth y Chang (2016), quienes encontraron que las mujeres se inclinan más por los aspectos sociales cuando estos se incluyen en la gamificación y que los hombres tienen un alto comportamiento como jugador que las mujeres. Quizá por tratarse de un xMOOC (autodirigido) las mujeres se sintieron menos atraídas por el RG.

Así mismo, enfocándonos a los participantes aprobados, se observó que en general los hombres tuvieron una mayor participación que las mujeres, no obstante, ambos géneros tuvieron una participación de al menos un 94\% en todos los niveles educativos. Estos resultados se pueden apreciar en la Tabla 56. Por otro lado, aunque la mayoría de los participantes de ambos géneros fueron de los niveles preparatoria y profesional, hubo una mayor disposición para realizar el RG por parte de los niveles técnica, maestría y doctorado, y aunque solo fueron dos participantes de nivel primaria en la muestra, ambos hicieron el reto. Los resultados se encuentran en la Tabla 57 y Figura 37. Este hallazgo puede refutar la idea generalizada de que la generación llamada millennials (26-30 años) está más predispuesta a aprender usando la tecnología que las generaciones mayores (Juárez y Carballo, 2016; Labrador, 2016).

Con el propósito de ver a profundidad la relación del género y nivel educativo con el RG, se analizaron los datos en dos grupos: participantes mexicanos y participantes extranjeros. En estos se observó un comportamiento similar que, en los resultados globales, los hombres mexicanos y extranjeros tuvieron una mayor 
propensión a participar en el RG. Esto se puede ver en las Tablas 58 y 59. Esto tiene relación con lo que comenta Lenhart et al. (2008) en su estudio sobre que los hombres tienen mayor interés en los juegos que las mujeres, así como con lo que encontró Tettegah, McCreery y Blumberg (2016) quien afirma que la efectividad de la gamificación depende de un conjunto de variables, entre estas el género. Por lo tanto, el género sí es un factor que influye en la participación de un Reto Gamificado.

Con respecto a la dimensión cognitiva, se encontró que los hombres estuvieron más a de acuerdo con que el RG favoreció a la dimensión cognitiva, en donde los hombres apoyaron el hecho de que la actividad contribuyó a comprender mejor los temas relacionados al RG mientras que las mujeres en que la retroalimentación inmediata les ayudó a analizar mejor su respuesta, ver las Tablas 36 y 37. De la misma manera, Hou y Li (2013), Hamari et al., (2016) y Keusch y Zhang (2017) encontraron que los retos gamificados, enganchan al alumno y que ofrecen oportunidades para aplicar el conocimiento mientras que Caponetto et al. (2014), Koivisto et al. (2016) y Alsawaier (2018) que entre otros factores, la gamificación, favorece la autorregulación gracias a la retroalimentación inmediata. Por lo que la gamificación basada en retos es una estrategia que favorece a lo cognitivo de manera positiva.

Esos hallazgos se vieron fortalecidos con el hecho de que el $54 \%$ de los participantes que hicieron al menos una actividad en el MOOC ECLyT hicieron el RG 
así como el 97,7\% de los que estudiantes que aprobaron, ver Tabla 57. Estos resultados coinciden con los encontrados por Morales (2013), Vaibhav et al. (2015) y Morales et al. (2016), en los que la gamificación influyó positivamente en el aprovechamiento el curso. Así que el RG favoreció el desempeño de los participantes del MOOC ECLyT.

Con respecto a la dimensión social, nuevamente los hombres estuvieron más de acuerdo con que el RG la favorece, particularmente se mostraron a favor con ver sus resultados y los de sus compañeros en el tablero, es decir con la competición, mientras que las mujeres se sintieron motivadas a resolver el RG por el hecho de saber que sus resultados se mostrarían en un tablero. Esto coincide con Lenhart et al. (2008), quienes encontraron que los hombres juegan más por su naturaleza competitiva, por otro lado, como establece Hanus y Fox (2015), la competición fue de tipo constructivo ya que todos tuvieron la misma oportunidad de ganar. Al mismo tiempo, los hallazgos encontrados se contraponen con los resultados de Domínguez et al. (2013) así como con los de Hanus y Fox (2015) en donde los resultados de los estudiantes no fueron los esperados. Por lo tanto, el desarrollo de un reto gamificado en un ambiente de competencia constructiva puede favorecer la motivación de ambos géneros.

En la dimensión emotiva, los hombres estuvieron considerablemente más de acuerdo que las mujeres en que el RG favorece esta dimensión, ver Tablas 49 y 50. Los hombres creen que haber logrado el RG dentro de los primeros tres intentos los hizo 
sentir satisfechos mientras que las mujeres sintieron que al tener varios intentos las motivó positivamente para volver a intentarlo. Magaña et al. (2016), Fernández y Arias (2017), Rojas-López y Rincón-Flores (2018), entre otros, consideran que esta dimensión contribuye al enganche y motivación extrínseca. Así que la emoción es un factor clave en el diseño de un RG ya que favorece el entusiasmo y la motivación extrínseca en el desarrollo de un reto.

Por otro lado, aunque los niveles superiores como maestría y doctorado mostraron una mayor participación en el RG (ver Tabla 57), los niveles de profesional, preparatoria y técnica, entre 16 y 30 años, manifestaron estar más de acuerdo con que el RG favoreció a las dimensiones cognitiva, social y emotiva, ver Tablas 37, 38, 39 y 40. Al respecto, Cain et al. (2014) y Noguera (2015) sostienen que la generación millennials está cambiando el modelo de enseñanza al exigir el uso de ITC en su proceso de aprendizaje. Así que, aunque hay interés por las generaciones mayores por el RG, los millennians estuvieron mayormente de acuerdo con que esta estrategia en el curso MOOC ECLyT favoreció a los aspectos cognitivo, social y emotivo.

En las respuestas cualitativas se encontró que, para la dimensión cognitiva, la mayoría de los participantes afirman que el RG, les ayudó a aplicar lo que aprendieron, a analizar el problema y a investigar o saber más. En la dimensión social, que no se 
sintieron intimidados por el hecho de que los resultados se expondrían en un tablero y que esto los motivó a esforzarse más.

En cuanto a la dimensión emotiva se encontró que, ante el RG, mayormente experimentaron, entusiasmo, satisfacción, no obstante, hubo un grupo de estudiantes que no experimentaron alguna emoción y otros que se sintieron tristes o frustrados por no haber ganado. William y Nisbet (2008), Domínguez et al. (2013), Topircenau (2017), Keush y Zhang (2017), Garett y Young (2018) entre otros investigadores, consideran que la gamificación promueve aspectos emocionales que activan el enganche y flujo (engagement y flow).

Al mismo tiempo, los aspectos cognitivos favorecen a la motivación intrínseca y los aspectos sociales promueven el intercambio de habilidades o la competencia constructiva, como lo fue el uso del tablero en el xMOOC ECLyT. Por lo tanto, el uso de estrategias como la gamificación basada en retos puede ser positiva en ambientes de aprendizaje abiertos y masivos como los xMOOC.

\subsubsection{El Reto Gamificado como buena práctica en el xMOOC ECLyT. Aunque, la} tasa terminal en el $\mathrm{xMOOC}$ ECLyT fue del $13 \%$, mayor que el $5 \%$ que es el promedio mundial (Armstrong, 2014; Cabero-Almenara, 2015), los participantes mostraron estar más de acuerdo con que el curso favorecería su formación académica al inicio del curso que al final, $94.8 \%$ al inicio, $88 \%$ al final, ver Tablas 23 y 24 y Figura 23 . Una de las 
críticas a los XMOOC es que no hay un tutor que esté guiando a los participantes o haciéndoles ver sus progresos y sus áreas de oportunidad (Hone \& El Said, 2016; Xing, Chen, Stein \& Marcinkowsky, 2016). Es posible que esto pudiera provocar que el participante percibiera que no tuvo una "formación académica", en este sentido, valdría más la pena estudiar el papel del aprendizaje autorregulado en este tipo de cursos que lo que tradicionalmente es considerado como formación académica.

Si bien los participantes consideraron que el xMOOC ECLyT no contribuyó en su formación académica al final del curso, estuvieron más de acuerdo al final del mismo que el MOOC les proveyó conocimientos y herramientas prácticas en el área de energía y que superaron sus conocimientos previos sobre el tema, $60 \%$ al inicio, $85 \%$ al final. Estos resultados se pueden apreciar en las Tablas 25 a 29, así como en las Figuras 24 y 25, estos resultados son congruentes a los mostrados en la Tabla 60, donde el promedio de los participantes aprobados fue de ,79 (79 en escala de 100) con una desviación estándar de SD=0,109. En los estudios de Sánchez-Vera, León-Urritia y Davis (2015), Castaño, Maíz y Garay (2015) y Zhou (2015), entre otros, también encontraron resultados positivos.

No obstante, esto no es evidencia de un modelo de calidad para los MOOC ya que su diseño e impartición es un proceso complejo y cambiante en donde se involucran una variedad de factores (Aguaded-Gómez y Medina-Salguero, 2015; 
Vázquez-Cano y López, 2015). En este sentido, no se debe perder de vista el propósito democrático de la educación abierta y masiva (Alemán, Sancho-Vinuesa y Gómez, 2015; Aguaded-Gómez, 2015) así como su papel en el movimiento abierto (Fidalgo-Blanco Sein-Echaluce y Borrás-Gené, 2014; Ramírez-Montoya, 2015; Ramírez-Fernández, 2015), reconociendo las innovaciones didácticas que cada vez más se incluyen con el propósito de mejorarlos y hacerlos más atractivos a los usuarios.

En este orden de ideas, los participantes se sintieron más capaces de resolver retos relacionados al tema de energías convencionales y limpias al finalizar el curso que al inicio, ver Tablas 30, 31 y Figura 25. Esto es congruente con el hecho de que el $97,7 \%$ de los participantes que aprobaron el curso hicieron el reto gamificado (ver Tabla 57). Diversos estudios en los últimos años han sugerido incluir estrategias didácticas como la gamificación para enganchar y motivar a los participantes (Amo, Casan y Alier, 2013; Hew y Cheung, 2014; Hew, 2016) al mismo tiempo, es importante evaluar este tipo de estrategias (Margaryan, Bianco y Littlejohn, 2014; Fernández-Díaz, Rodríguez-Hoyos y Calvo, 2017) con el propósito de validar su papel innovador (mejorar lo que ya se hace) y mejorar su calidad.

En este caso, se puede afirmar que el RG estuvo alineado al diseño didáctico del xMOOC ECLyT, en la Figura 33 se puede observar como esta actividad, así como la mayoría de las del curso, se relacionaron con el componente F1. González-González, 
Collazos y García (2016); Borrás-Gené, Martínez-Nuñez y Fidalgo-Blanco (2016), García-

Peñalvo, Fidalgo-Blanco y Sein-Echaluce (2017), consideran que integrar gamificación

dentro de un MOOC puede contribuir en la motivación y en mejorar la tasa terminal, no obstante, esta estrategia debe considerarse en el diseño pedagógico del curso. En otras palabras, implementar la gamificación debe ser resultado de una reflexión didáctica profunda.

No obstante, la actividad llamada práctica no estuvo relacionada a ninguno de los componentes. En la Tabla 62 se observa que está relacionada con el componente F4, el cual tiene una relación muy baja con el resto de las actividades, incluso en la Figura 33 se puede visualizar que es ortogonal a los componentes F1 y F2 y en la Figura 34 que lo es con F1 y F3. Por lo que vale la pena revisar el diseño didáctico de esta actividad.

4.2.3 Nivel de innovación. Aunque los participantes se percibieron más innovadores al final del curso que al principio, ver Tablas 31 y 32 así como Figura 27, se observó que solamente 140 de los 764 participantes que respondieron la pregunta, desarrollaron la propuesta alternativa ver Tabla 74. Quizás valdría la pena agregar espacios de discusión en donde los participantes tengan oportunidad de intercambiar ideas interdisciplinarias, así como para trabajar colaborativamente, de tal manera que puedan desarrollar competencias para la innovación (Vila, Dávila y Mora, 2010; García- 
Valcárcel et al., 2012; Bi y Yang, 2015; Trujillo, Aznar y Cáceres, 2015; Hoyle y Deschaine, 2016).

Sin duda, crear espacios para la discusión y la colaboración en este tipo de MOOC puede favorecer el desarrollo de competencias para la innovación y la creación de redes constituidas tanto de expertos como de iniciados en los temas de energía y sustentabilidad. Por otro lado, los hombres destacaron más que las mujeres en cuanto al impacto y tipo de innovación, mientras que en los rubros de claridad y conocimiento quedaron de manera similar. Esto se puede relacionar con la información de la Figura 5, en la que se muestra que según el modelo de (Schwarts, Bransford y Sears, 2005) los hombres se sitúan en experto-adaptativo (alta eficiencia, alta innovación), mientras que las mujeres en expertos-rutinarios (alta eficiencia, baja innovación), en otras palabras, la eficiencia, situada en el eje horizontal, alude al conocimiento que se tiene sobre un área en particular mientras que la innovación es la habilidad de responder ante una nueva situación (Martin, Rivadale y Diller, 2007). En el modelo de Eckel y Kezar (2003) tanto hombres como mujeres tuvieron propuestas con extensión baja, pero profundidad alta, es decir, es una innovación incremental, pero con base en conocimiento.

Los niveles de profesional y maestría, mostraron un nivel de innovación disruptiva mayor que los demás niveles, los niveles primaria y secundaria no dieron 
propuestas alternativas al reto, ver Figura 43. Diversos estudios han encontrado que el conocimiento es un factor predominante en el proceso de innovación y desarrollo de las empresas, desde Drucker (1973) hasta la actualidad (Benavides, 2005; Úbeda y Moslares, 2008; Veiga, Schumpeter y Bueno, 2012). Así que este hallazgo corrobora que, a mayor conocimiento, mayor nivel de innovación.

Según los resultados, el RG quedaría en un nivel de innovación incremental debido al costo y a las limitaciones relacionadas a la infraestructura tecnológica que cada plataforma tiene, ver Figuras 39 a 41 y Tablas 65 a 67. No obstante, la Gamificación es una estrategia potencialmente disruptiva (Baker, Bujak y DeMillo, 2012; Gross-Salvat, 2014; Marín 2015) que como toda innovación educativa debe evaluarse y estar siempre en un proceso de mejora continua (Fidalgo-Blanco, 2014; García-Peñalvo, 2015; RincónFlores, Gallardo y Fuente, 2018).

Por lo tanto, con base en los resultados, la gamificación es una estrategia innovadora ya que mejoró el diseño instruccional tradicional de los xMOOC y se coloca en un nivel de innovación incremental. Finalmente, aunque la gamificación está en proceso de convertirse en una innovación disruptiva, el xMOOC ECLyT sí se coloca en este nivel, ya que mejoró la tasa terminal promedio a nivel mundial además de que los resultados mostrados en este capítulo lo demuestran. 
Sin embargo, vale la pena cuestionarse qué se ha aprendido de esta experiencia didáctica (Zabalza y Zabalza, 2016), qué se ha ganado dentro del movimiento abierto (Ramírez-Montoya, 2016) y qué habilidades y competencias se han desarrollado tanto en los estudiantes como en el profesorado que intervino en este proyecto educativo (Ramírez-Montoya y Mena, 2017). Todo ello con la finalidad de seguir mejorando este tipo de cursos, los cuales hacen posible que la educación llegue a todos los rincones del mundo.

\subsection{Análisis de resultados}

A continuación, se presenta un análisis de los resultados con base en las categorías definidas para el estudio. Este análisis representa el aporte científico obtenido a partir del presente trabajo de investigación.

\subsubsection{Innovación abierta, interdisciplinaria y colaborativa. En este apartado se} abordan los hallazgos encontrados con respecto al tipo de innovación en el que se enmarcó el proceso de diseño, desarrollo e implementación de los xMOOC y de la estrategia didáctica Gamificación basada en retos, así como su nivel de impacto.

19 Los $x$ MOOC pueden situarse como una innovación del tipo disruptiva o revolucionaria si cuentan con un buen diseño didáctico. Los resultados de las entrevistas a los expertos (ver Apéndices VIII y IX), así como los obtenidos por parte de los participantes, en cuanto a tasa terminal, nivel de conocimiento y 
desempeño (ver Figura 25 y Tabla 63), revelaron que se cumplieron las expectativas didácticas de los participantes y que la tasa terminal fue mayor al promedio mundial. En este sentido, se está haciendo uso de la tecnología sofisticada con el propósito masificar educación de calidad (Christensen, Raynor y McDonald, 2015) lo que, al mismo tiempo, representa un punto de inflexión en la educación (CONACYT, 2018). Por lo que un buen diseño didáctico es un factor fundamental para capitalizar los beneficios de los avances tecnológicos en la educación en línea, masiva y abierta.

5or otra parte, la gamificación basada en retos en los cursos masivos, abiertos y en línea, es una innovación del tipo incremental o evolutiva si su introducción como estrategia didáctica mejora el ambiente de aprendizaje propio de los MOOC, específicamente de los xMOOC. Esto puede evidenciarse en las respuestas de los expertos (ver Apéndices VIII y IX), en la cantidad de participantes que realizaron el reto (ver Tabla 57) y en sus opiniones (ver Figura 39, Tabla 65). Esto coincide con lo establecido por García-Manjón y Rodríguez-Escobar (2011), De Miguel (2016), Fidalgo-Blanco (2014) y Ramírez-Montoya (2014), quienes afirman que una innovación incremental es una mejora paulatina de procesos o productos ya establecidos, en este caso los MOOC, es decir, se mejora a partir de una base conceptual ya existente (CONACYT, 2018). Por lo que el alcance disruptivo de la gamificación en $\mathrm{MOOC}$ dependerá de los beneficios que genere 
en términos didácticos y en qué tanto el desarrollo de la tecnología permitirá hacerla económicamente más asequible.

Sa gamificación basada en retos en MOOC puede promover innovaciones incrementales y sustentadas en conocimiento, si se ofrecen espacios abiertos para que los participantes aporten sus propias soluciones creativas y alternativas. Esto se evidenció en la cantidad de aportaciones voluntarias a pesar de que no iban a ser revisadas por sus compañeros o profesores (ver Tablas 68 y 69, ver Figuras 42 y 43). García-Peñalvo, Fidalgo-Blanco, Sein-Echaluce (2017), Borrás-Gené, Martínez-Nuñez y Fidalgo-Blanco (2016) proponen en sus investigaciones por una mezcla de las ventajas que ofrecen tanto los $\mathrm{xMOOC}$ como los $\mathrm{CMOOC}$, en la que se promueva la conectividad y la innovación abierta, como resultado de la ciencia abierta (Ramírez-Montoya y García-Peñalvo, 2018). En este sentido, abrir la posibilidad de una conectividad autodirigida podría promover redes de colaboración interdisciplinaria que den solución a diversas problemáticas en un ambiente de innovación abierta.

Así mismo, el diseño, desarrollo, implementación y evaluación de estrategias didácticas innovadoras incorporadas en un $\mathrm{MOOC}$, requiere de un auténtico trabajo colaborativo e interdisciplinario. Esto se verifica en las respuestas de los expertos (ver Apéndices VIII y IX), en la tasa terminal y desempeño de los estudiantes, así como en sus comentarios (ver Tablas 63 y 67). El trabajo 
interdisciplinario y colaborativo reúne los esfuerzos de diferentes individuos y de diversas disciplinas, para incrementar las estimulaciones cognitivas creando nuevas ideas y para lograr un mismo objetivo (García-Valcárcel et al., 2012; Neri, Noguez y Alanís, 2017; Bi y Yang, 2014; Jar, 2010; Hernández-Pozas y Neri, 2017). Por lo tanto, el éxito del diseño didáctico de los MOOC dependerá de las interacciones, el conocimiento y la creatividad que se genere en un contexto de colaboración e interdisciplinariedad.

4.3.2 El papel de la gamificación en la educación. El eje central de la investigación fue la estrategia de gamificación basada en retos aplicada en el xMOOC energía con el propósito de innovar en el diseño didáctico de un ambiente MOOC. En esta sección veremos la relación encontrada entre la gamificación basada en retos en un $\mathrm{XMOOC}$ con respecto a lo cognitivo, social, emocional y enganche.

- Ofrecer a los estudiantes varios intentos para responder correctamente una misma pregunta o reto en un ambiente $\mathrm{xMOOC}$, favorece su proceso metacognitivo, gracias a la reflexión que él mismo desarrolla para intentar de nueva cuenta responder correctamente. Esto se hace evidente en las opiniones de los participantes (ver Tablas 35, 37 y 39) así como en las correlaciones mostradas en la Tabla 61. Investigadores como Hamari et al. (2016), Koivisto et al. (2016), Sailer et al. (2017), Rincón-Flores, Ramírez-Montoya y Mena (2016b) y Tu et al. (2015) 
han encontrado que la gamificación favorece los procesos cognitivos cuando se utilizan mecánicas de retos como actividad de aprendizaje. Así que en un ambiente gamificado, las mecánicas de retos y de chances, favorecen el aspecto cognitivo y por consecuencia, el aprendizaje.

s. La retroalimentación inmediata y el uso de chances como mecánicas en un ambiente gamificado genera emociones positivas de satisfacción personal en un ambiente $\mathrm{xMOOC}$. Esto se puede ver en la Figura 32 donde se muestran los resultados globales, así como en las Tablas 49, 51 y 53 en las que se observan los resultados por género, nivel educativo y edad. Las emociones positivas juegan un papel importante en el aprendizaje, ya que son la base para que los estudiantes se inspiren y deseen obtener un buen desempeño (Garett y Young, 2018; Granic, Lobel y Engels, 2014; Hew et al., 2015; Rojas-López y Rincón-Flores, 2018; Yildirim, 2017). Por lo tanto, la gamificación como estrategia de aprendizaje es un recurso favorable para crear un ambiente donde predominen las emociones positivas.

El uso de tableros e insignias en un ambiente $\mathrm{xMOOC}$ motiva positivamente la participación de los estudiantes para resolver retos gamificados. Esto se aprecia en la Figura 29 así como en las Tablas 42, 44 y 46. Diversos investigadores como Domínguez et al. (2013), Rojas-López, Rincón-Flores, Ramírez-Montoya, Mena y García-Peñalvo (In Press). Engagement in the course of Programming in Higher Education through the use of Gamification. Universal Access in the Information 
Society (UAIS). (2018), Sailer et al. (2017) y Topirceanu (2017), encontraron que la competencia a través de componentes como tableros e insignias favorece el sentido de pertenencia y enganche, así como la interacción favorece el intercambio y construcción de conocimiento. Así que, aunque los xMOOC se caractericen por ser autodirigidos, el uso de tableros e insignias puede complementarse con la apertura de espacios sociales en los que los individuos puedan interactuar para desarrollar redes de construcción de conocimiento.

2. La Gamificación como estrategia didáctica en un ambiente xMOOC es un factor positivo que impulsa al estudiante a completar el reto. Esto se puede observar en las Tablas 54, 55 y 57, en donde la gran mayoría de los participantes que aprobaron completaron el reto. El enganche o implicación (engagement) es la pasión por realizar algo que coloca al individuo en un proceso de inmersión (flow), en donde los retos y las habilidades para resolverlos tienen una relación simbiótica (Admiraal et al., 2011; Hammedi, Leclerq y Van Riel, 2017; Heusch y Zhang, 2017). Por lo tanto, la estrategia de gamificación basada en retos en un xMOOC favorece el enganche y el proceso de inmersión (flow) de los estudiantes, permitiendo que la autorregulación del aprendizaje, propia de este tipo de cursos, sea más atractiva y afable. 
4.3.3 Alcance disruptivo de los XMOOC. Finalmente, se presentan los aportes al saber científico con respecto a los $\mathrm{MOOC}$, particularmente los $\mathrm{XMOOC}$, en donde se aborda su papel en la democratización del aprendizaje, la calidad del diseño didáctico, así como, su potencial como generador de espacios para la innovación abierta.

S. Incluir estrategias didácticas innovadoras como la gamificación en un XMOOC puede favorecer el incremento de la tasa terminal. En la Tabla 63 se aprecia la tasa terminal y en las Figuras 35, 37 y 38 se hace evidente la relación del reto gamificado con las actividades del curso, particularmente, con las aplicadas al final del curso. Armstrong (2014) y Cabero-Almenara (2015) han encontrado que la tasa terminal a nivel mundial es del 5\% mientras que Vazquez-Cano, LópezMeneses y Sarasola (2013); Olsson (2016) y Aguaded, 2015) afirman que los MOOC favorecen la democratización del aprendizaje y las interrelaciones entre participantes de diversos lugares, gracias al bajo costo (o nulo). Por lo que basta con que cualquier persona y de cualquier parte del mundo cuente con acceso a internet para obtener una educación de calidad y que ahora mismo, gracias a la tecnología, se puede contar con estrategias de aprendizaje innovadoras tales como la gamificación.

Si bien es cierto que la masividad no es un indicador de calidad de los MOOC, el trabajo colaborativo e interdisciplinario para el diseño, desarrollo, 
implementación y evaluación, son factores que la pueden asegurar. En las Figuras 25 y 26 se evidencia el grado de satisfacción de los participantes en cuanto a conocimiento. Del Moral y Villalustre (2015), Villegas et al. (2016) y FernándezDíaz, Rodríguez-Hoyos y Calvo (2017) afirman que un MOOC de calidad satisface las demandas de los usuarios, de tal manera que pueda organizar sus propios aprendizajes, a través de instrucciones claras, videos cortos, estrategias didácticas innovadoras, entre otros (Cataño y Cabero, 2013; Méndez-García, 2015). En este sentido, el trabajo interdisciplinario y colaborativo vinculado con la arquitectura pedagógica en un MOOC, juega un papel fundamental, especialmente cuando se van a incluir estrategias didácticas innovadoras.

6. Los MOOC son espacios de aprendizaje en el que se ofrece la oportunidad de potencializar la innovación abierta, tanto en los equipos desarrolladores como entre los usuarios. Esto se hace evidente en las entrevistas a los equipos de trabajo (ver Apéndice IX) así como en la cantidad y calidad de las respuestas alternativas al reto gamificado realizadas por los participantes de manera voluntaria (ver Tabla 72). Para González et al. (2017) la innovación abierta descansa en un proceso de networking en donde las ideas innovación provienen de agentes externos e internos, entre diversos grupos interdisciplinarios (Hernánes-Pozas, 2017) y colaborativos (Ner, Noguez y Alanís, 2017) con el propósito de generar y diseminar nuevo conocimiento (García-Peñalvo y 
Ramírez-Montoya, 2018; UNESCO, 2012; Valerio; 2017 y Yañez, Ramírez-Montoya y García-Peñalvo, 2017). Así, los MOOC, en particular los xMOOC, pueden abrir posibilidades de diseminación del conocimiento al proveer espacios en los que se desarrolle la innovación abierta.

En conclusión, en el presente capítulo se mostraron los resultados obtenidos a partir de los datos emanados de los instrumentos, así como de las estrategias de recolección de datos. En general, los resultados revelaron que el proceso que gira en torno a la arquitectura pedagógica de un $\mathrm{MOOC}$ crea un escenario en el que se desarrolla un auténtico trabajo colaborativo e interdisciplinario. Evidenció el papel democrático de los MOOC y cómo pueden potencializar la innovación abierta y la diseminación del conocimiento. Finalmente, la estrategia didáctica de gamificación basada en retos favorece las dimensiones cognitiva, social y emotiva, generando un ambiente de competencia constructiva, el cual abonó en el desempeño de los participantes en las evaluaciones de los últimos temas y la evaluación final.

En el siguiente capítulo se presenta un modelo para el diseño de estrategias didáctica innovadoras como la gamificación en ambientes de innovación abierta, como los MOOCs. El modelo surge a partir de los resultados obtenidos en la presente investigación. 


\section{MODELO DE INNOVACIÓN EDUCATIVA INCREMENTAL PARA EL DISEÑO DE}

GAMIFICACIÓN BASADA EN RETOS EN XMOOCS.

A partir de los resultados obtenidos se presenta el siguiente capítulo, el cual, tiene el propósito de mostrar un modelo de innovación para el diseño de la estrategia didáctica de Gamificación basada en retos, aplicadas en ambientes xMOOC. Este modelo incluye a los componentes y factores involucrados en el proceso de diseño, desarrollo, implementación y evaluación de esta estrategia didáctica innovadora. El objetivo es proponer directivas en el campo de la arquitectura pedagógica que faciliten el proceso creativo de la Gamificación basada en retos en ambientes masivos, abiertos y en línea, particularmente los del tipo xMOOC. Ya que este tipo de curso se ha caracterizado por ser conductista (Ping, 2013; Sánchez-Vera y Prendes-Espinosa, 2015; Barak et al., 2016), por lo que este modelo pretende innovarlos haciéndolos más atractivos y retadores.

Por otro lado, se pretende que este modelo permita establecer líneas de investigación educativa no solo en el campo de estudio sobre estrategias didácticas en los MOOC sino de la educación a distancia en general. Así mismo, esta propuesta puede contribuir en el diseño, desarrollo, implementación y evaluación de otras estrategias didácticas en ambientes masivos, abiertos y en línea. 
Al mismo tiempo, recordemos que la presente investigación se enmarcó en el macro-proyecto Laboratorio Binacional para la gestión inteligente de la sustentabilidad energética y la formación tecnológica (http://energialab.com/) en el cual, se suscribieron doce sub-proyectos. Uno de los cuales fue el de innovación abierta, interdisciplinaria y colaborativa para formar en sustentabilidad energética a través de xMOOCs, en el cual se suscribió esta investigación. Uno de los objetivos de este subproyecto fue introducir innovaciones didácticas en el diseño de los xMOOC energía. En este sentido, la gamificación basada en retos (Rincón-Flores, Ramírez-Montoya y Mena, 2016a, Rojas-López y Rincón-Flores, 2018) se integró como estrategia didáctica innovadora para mejorar significativamente el proceso de enseñanza-aprendizaje en un ambiente xMOOC. A continuación, se detallan los componentes del modelo.

\subsection{Trabajo colaborativo, interdisciplinario y vinculación.}

Para el desarrollo del diseño de una estrategia innovadora como la Gamificación basada en retos en un $\mathrm{XMOOC}$ se requirió de la intervención de diversos grupos interdisciplinarios trabajando en colaboración (García-Valcárcel et al., 2012; García y Mena, 2016: Neri, Noguez y Alanís, 2017), pues la generación de innovaciones lleva implícito unir esfuerzos para el logro de metas y objetivos en común.

Por otro lado, así como los progresos científicos y tecnológicos han actuado como motores de la interdisciplinariedad (Jar, 2010), de igual manera está sucediendo 
en el ámbito educativo. Así que, el trabajo colaborativo e interdisciplinario son componentes que potencian a la innovación (Bi y Yang, 2014; Hernández-Pozas y Neri, 2017), por ello es tan importante que estos componentes se conjunten. Otro elemento importante dentro de la dinámica de la innovación educativa es la vinculación de la tarea educativa con las necesidades del entorno, pues la sociedad del conocimiento se reconoce por estar a la vanguardia en el desarrollo de diversas esferas (Yañez-Figueroa, Ramírez-Montoya y García-Peñalvo, 2017) tales como la educativa, cultural, económica y política.

Esta vinculación pretende la creación de redes entre esas esferas, con la finalidad de contribuir a un mejor futuro a partir de la educación (García-Peñalvo y RamírezMontoya, 2018). Lo que ha motivado a las universidades, industria y Gobierno a transformar las políticas en favor del crecimiento y del desarrollo social, en las que la equidad y la inclusión deben jugar un papel fundamental (UNESCO, 2016). En el caso de este estudio, la industria energética, la universidad y el gobierno, fueron los componentes de la vinculación. El Laboratorio Binacional para la gestión inteligente de la sustentabilidad energética y la formación tecnológica, fue el resultado de las iniciativas generadas por la Secretaría de Energía (SENER) y el Consejo Nacional de Ciencia y Tecnología (CONACYT) así como por el Tecnológico de Monterrey, institución educativa que ha fungido como líder y desarrollador del proyecto. 
En la Figura 44 se puede observar de manera gráfica la interrelación entre los elementos de trabajo colaborativo, interdisciplinario y vinculación. A continuación, se describe la sección interna, la cual tiene que ver con el trabajo colaborativo e interdisciplinario que de desarrolló dentro del sub-proyecto Innovación abierta, interdisciplinaria y colaborativa para formar en sustentabilidad energética a través de MOOCs (xMOOC-energía).

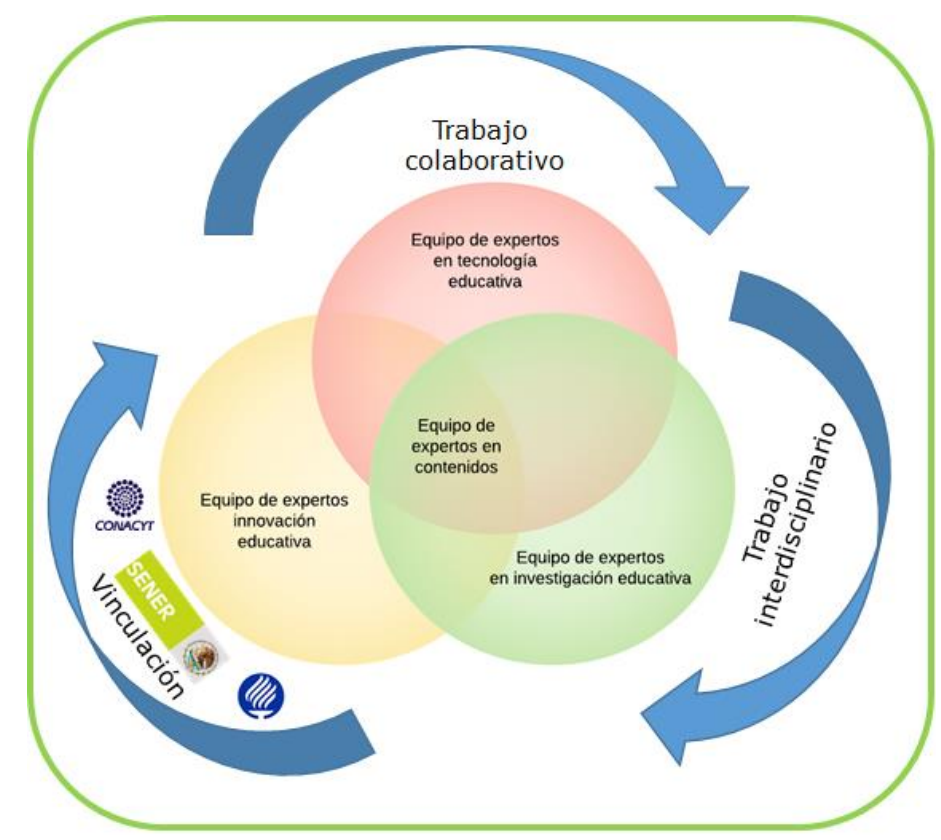

Figura 44. Trabajo colaborativo, interdisciplinario y vinculación en el sub-proyecto xMOOC-energía (Elaboración propia).

La Secretaría de Energía y el Consejo Nacional de Ciencia y Tecnología, comunicaron que una de las necesidades dentro de la Reforma Energética de México era la de ofrecer educación masiva y accesible, sobre los temas de energía y sustentabilidad que actualmente preocupan al país. Para ello se recurrió al diseño, 
desarrollo e implementación de doce cursos xMOOC que abarcaron un amplio espectro de las temáticas de sustentabilidad energética.

Por esta razón se hizo necesario formar cuatro grupos de expertos: 1) Equipo de expertos en innovación educativa, 2) en tecnología educativa, 3) en contenidos sobre temas de energía y 4) un equipo de investigadores educativos. El equipo de tecnología educativa estableció las delimitaciones de los recursos con los que se contaba, tanto por parte de la plataforma MéxicoX así como por los recursos económicos para el desarrollo tecnológico externo a la plataforma.

Así, luego de diversas reuniones entre los equipos de innovación educativa, tecnología educativa e investigación, se determinó que la gamificación partiera del modelo de Werbach y Hunter (2012) y se optó por la gamificación basada en retos, la cual se enmarcó en dinámicas de carácter social y emotivo. Se emplearon mecánicas de retos, oportunidades y reconocimientos, en las que se otorgaron trofeos que se mostraron en un tablero de liderazgo, estos dos últimos elementos fueron los componentes utilizados. Para este propósito, el equipo de tecnología realizó el desarrollo de la aplicación del tablero y ya una vez teniendo el modelo didáctico de la gamificación basada en retos, los equipos de innovación educativa e investigación trabajaron en conjunto con cada equipo de expertos en contenido de cada curso. De 
esta manera se desarrollaron diálogos para adaptar los contenidos en el modelo didáctico previamente definido.

Como resultado de este trabajo colaborativo e interdisciplinario, se desarrollaron doce retos gamificados, uno por curso y aplicado al final como el propósito de integrar varios temas del $\mathrm{xMOOC}$. Cada reto tuvo su propio diseño particular, es decir su propio sello, dentro de un modelo general de diseño, debido a la diversidad de temáticas y al estilo de cada equipo de expertos en contenido.

Esto nos deja ver la importancia del trabajo colaborativo e interdisciplinario, ya que enriquece y potencia la creatividad e innovación, esto se hace evidente en los resultados de las entrevistas a expertos, ver Apéndice IX. A continuación, se presentan algunas respuestas:

"Hay ocasiones en las que es mejor trabajar solo, pero en este tipo de proyectos definitivamente necesitas al grupo, sino, no sacas al proyecto en el tiempo que te dijeron. Es bien difícil, pero aquí se necesita el grupo" (Experto en contenidos)".

"...de todos vas aprendiendo desde aspectos teóricos como aspectos de la forma en que se desenvuelve cada rol de las personas de tu núcleo, de tu célula de producción con las tesistas, voy viendo una forma de interactuar con los profesores, voy viendo algunos aspectos que recomiendan cuando nos reunimos entonces 
también ellos aportan y eso me enriquece a mí. Con los profesores es el trabajo directo con ellos y me va haciendo conocer cada vez tener conocimientos de ese tema" (Experto en diseño instruccional)

"A mi esta experiencia me enriquece mucho en muchos sentidos, como profesora, en mi quehacer pedagógico, con mis creencias epistemológicas, filosóficas de la práctica educativa yo siento un enriquecimiento ahí porque veo nuevas potencialidades, nuevas formas que me permite pasado mañana transferir hacia las prácticas que tengo en la educación a distancia" (Experto en investigación en innovación educativa)

\subsection{Elementos de la gamificación basada en retos aplicada en xMOOC.}

El diseño la innovación educativa gamificación basada en retos para xMOOCenergía estuvo limitada por factores tecnológicos, económicos, de tiempo y de recursos humanos. No obstante, esas limitaciones se transformaron en un reto positivo, que impulsaron la creatividad, proactividad, flexibilidad y perseverancia de los equipos interdisciplinarios, atributos de las personas innovadoras (Gallardo y Lozano, 2017). En la Figura 45 se puede apreciar de manera gráfica como a pesar de esas limitaciones se generó un producto innovador y significativo para los xMOOC-energía. 


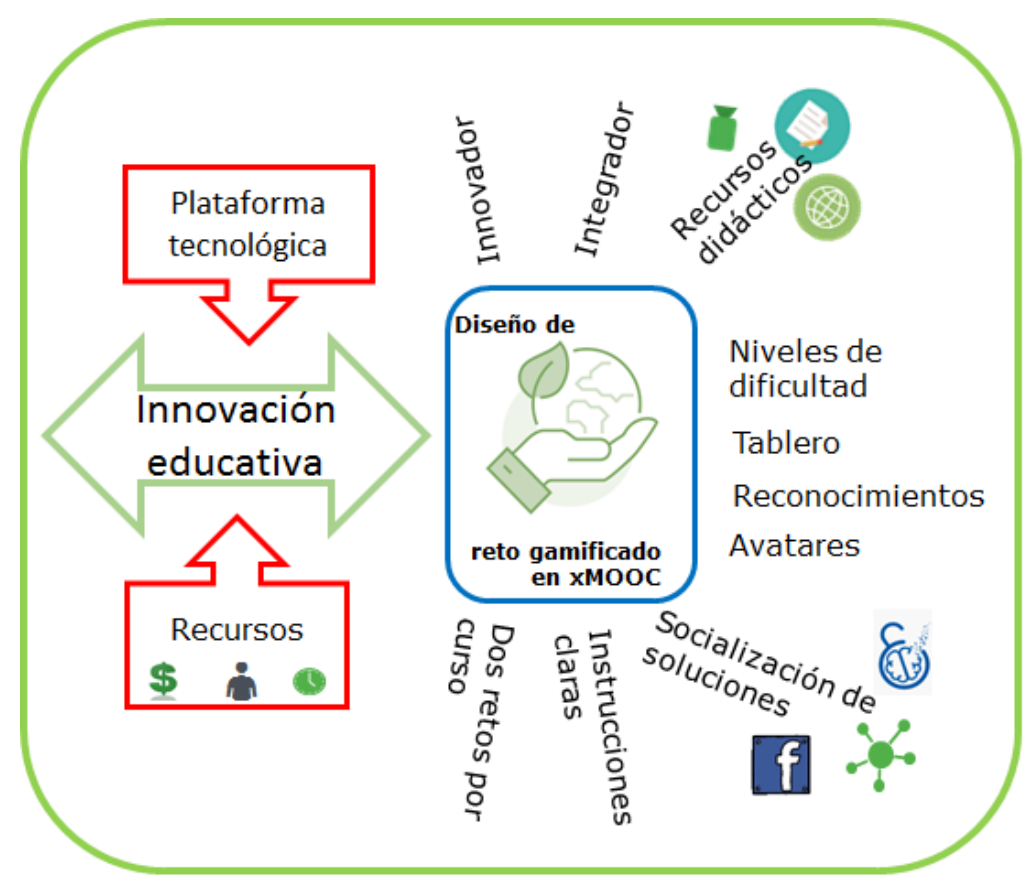

Figura 45. Trabajo colaborativo, interdisciplinario y vinculación en el sub-proyecto xMOOC-energía (Elaboración propia).

El diseño general de la Gamificación consistió en un reto que integró diversos temas del curso y de interés actual, es decir, que fuera innovador en este sentido también. Al mismo tiempo se buscó que tuviera la característica de respuesta inmediata ya que se trata de un curso masivo, no obstante, los retos de los cursos se enriquecieron con recursos didácticos como videos, secciones para saber más e infográficos.

La dinámica de la gamificación consistió en que el participante, una vez que estuviera enterado de que trata el reto y qué se le solicita, tendría tres oportunidades para resolverlo. Si lo resuelve a la primera oportunidad tendría un trofeo de oro como reconocimiento, si lo resuelve a la segunda tendría un trofeo de plata y si fuera a la 
tercera, tendría un trofeo de bronce. Por esto, la dinámica es emotiva, ya que supone que ganar un trofeo provoca algún tipo de emoción y engancha al participante (Kocadere y Caglar, 2015; Yildirim, 2017).

Luego, los trofeos son publicados en un tablero, el cual puede ser visto por cualquier usuario del curso. Por esta razón, también es una dinámica social, ya que se socializan los reconocimientos obtenidos por los participantes (Hanus y Fox, 2015; Mekler et al., 2015; Kyewski \& Krämer, 2018.). Las mecánicas fueron el reto diseñado por los expertos del curso xMOOC-energía, las oportunidades para responder y el sistema de reconocimientos. Los componentes, fueron los trofeos mostrados en el tablero.

A partir de las necesidades educativas en torno a la temática sustentabilidad energética se desarrollaron doce cursos mostrados en la Tabla 70, en la cual también se muestra el reto gamificado correspondiente a cada uno. Para esta investigación se utilizó el curso Energías convencionales, limpias y su tecnología, el cual está centrado al desarrollo, bienestar, sustentabilidad e independencia de las sociedades modernas, así como en la utilización y administración adecuada de los diferentes recursos energéticos.

\section{Tabla 71}

Cursos XMOOC energía desarrollados dentro del subproyecto Innovación abierta, interdisciplinaria y colaborativa para formar en sustentabilidad energética a través de MOOCs 


\begin{tabular}{|c|c|}
\hline Curso & Nombre del reto gamificado \\
\hline $\begin{array}{l}\text { La reforma energética y sus oportunidades } \\
\text { https://energialab.tec.mx/es/la-reforma-energetica-y-sus- } \\
\text { oportunidades }\end{array}$ & $\begin{array}{l}\text { Oportunidad de negocio en el sector } \\
\text { energético. }\end{array}$ \\
\hline $\begin{array}{l}\text { Energía, pasado, presente y futuro } \\
\text { https://energialab.tec.mx/es/energia-pasado-presente-y- } \\
\text { futuro }\end{array}$ & $\begin{array}{l}\text { ¿En qué fuente de energía renovable } \\
\text { conviene invertir? }\end{array}$ \\
\hline $\begin{array}{l}\text { Ahorro de energía } \\
\text { https://energialab.tec.mx/es/ahorro-energia }\end{array}$ & Ahorro de energía en un mini súper \\
\hline $\begin{array}{l}\text { Distribución de la energía eléctrica } \\
\text { https://energialab.tec.mx/es/distribucion-de-la-energia- } \\
\text { electrica }\end{array}$ & Producción de energía limpia \\
\hline Transmisión de energía eléctrica & $\begin{array}{l}\text { Predicción de demandas de energía } \\
\text { eléctrica }\end{array}$ \\
\hline $\begin{array}{l}\text { Smart grid: fundamentos técnicos } \\
\text { https://energialab.tec.mx/es/smart-grid-fundamentos- } \\
\text { tecnicos }\end{array}$ & $\begin{array}{l}\text { ¿Cómo se eligen correctamente los } \\
\text { equipos de actualización de las } \\
\text { subestaciones eléctricas? }\end{array}$ \\
\hline $\begin{array}{l}\text { Smart grid: redes eléctricas del futuro } \\
\text { https://energialab.tec.mx/es/smart-grid-las-redes- } \\
\text { electricas-del-futuro }\end{array}$ & $\begin{array}{l}\text { Actualizar o no las redes eléctricas a } \\
\text { smart grid }\end{array}$ \\
\hline $\begin{array}{l}\text { Energías convencionales, limpias y su tecnología } \\
\text { https://energialab.tec.mx/es/energias-convencionales- } \\
\text { limpias-y-su-tecnolog\%C3\%ADa }\end{array}$ & $\begin{array}{l}\text { Combustibles para iluminación en } \\
\text { caso de emergencia }\end{array}$ \\
\hline $\begin{array}{l}\text { Energía Eléctrica } \\
\text { https://energialab.tec.mx/es/energia-electrica }\end{array}$ & $\begin{array}{l}\text { Uso de celdas solares para ahorro de } \\
\text { energía }\end{array}$ \\
\hline $\begin{array}{l}\text { Mercados de Carbono } \\
\text { https://energialab.tec.mx/es/mercado-carbono }\end{array}$ & $\begin{array}{l}\text { Cálculo de reducción de emisiones } \\
\text { de } \mathrm{CO} 2\end{array}$ \\
\hline $\begin{array}{l}\text { Mercados de Energía } \\
\text { https://energialab.tec.mx/es/mercados-energia }\end{array}$ & Energía distribuida. \\
\hline $\begin{array}{l}\text { La nueva industria eléctrica en México } \\
\text { https://energialab.tec.mx/es/la-nueva-industria-electrica- } \\
\text { en-mexico }\end{array}$ & Potencia-energía \\
\hline
\end{tabular}

Los cursos se clasificaron en básicos, teóricos, prácticos y especializados, por esta razón el nivel de dificultad de cada reto, se diseñó de manera congruente al tipo de curso y al público dirigido. Para el curso ECLyT, el reto consistió en, ver un video sobre tres tipos de combustibles, los cuales podrían ser utilizados en una situación de 
emergencia en la que era necesario obtener calor e iluminación contaminando lo menos posible.

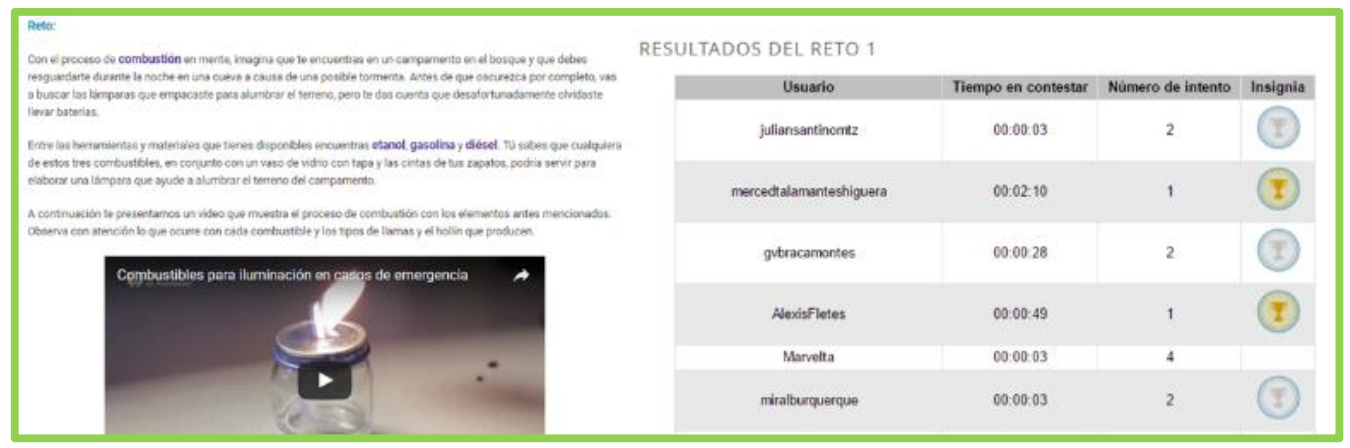

Figura 46. Imagen parcial del reto gamificado "Combustibles para iluminación en caso de emergencia" del curso ECLyT.

En la Figura 46 se puede observar parcialmente el reto a la izquierda de la imagen y el tablero por la derecha, en cual aparece el nombre de usuario, el tiempo utilizado en la resolución, el número de intentos y la copa ganada, es decir, el componente utilizado para reconocer el desempeño de los participantes en la actividad de manera pública.

Con base en la literatura se encontró que la gamificación contribuye a la motivación extrínseca e intrínseca (Surendeleg, 2014; Topîrceanu, 2017). La motivación intrínseca se genera al enfrentar al estudiante a retos que favorezcan la dimensión cognitiva y que al mismo tiempo tenga la oportunidad de aprender del error, de ahí la importancia de las oportunidades (Koivisto et al., 2016; Hamari, 2017). La motivación 
extrínseca se promovió al incluir reconocimientos, en este caso, el tablero y los trofeos fueron los elementos que contribuyeron a este propósito.

Al mismo tiempo, el diseño de la gamificación basada en retos, se diseñó con el propósito de favorecer a las dimensiones social y emotiva. La social con la publicación de los resultados en el tablero y la emotiva con el reconocimiento a través de los trofeos. Para Nisbet y Williams (2008), Domínguez et al. (2013) y Hamari et al. (2016) el incluir elementos que favorezcan las dimensiones, social, emotiva y cognitiva son fundamentales para asegurar el propósito didáctico por el cual fue concebido.

\subsection{Investigación y mejora continua.}

No obstante, toda innovación debe evaluarse para reconocer que está cumpliendo su papel innovador (García-Peñalvo, 2015; Rincón-Flores, Gallardo y Fuente, 2018), de mejorar lo que ya se hace y en qué medida. Pues implementar innovaciones educativas va más allá de incluir algo novedoso (García-Peñalvo, García de Figuerola y Merlo, 2010; Ramírez-Montoya, 2012). Por ello para evaluar la innovación el grupo de expertos en investigación educativa juega un papel de gran relevancia. Así que, para evaluar a la gamificación basada en retos como estrategia innovadora se aplicó una prueba piloto a los participantes de los XMOOC-energía, con la idea de conocer, entre otras cosas, los aspectos de mejora de esta estrategia. Por ejemplo, dentro de los resultados se encontró como respuesta recurrente, la de mejorar la 
claridad de las instrucciones, punto que estuvo claro para los equipos de expertos, pero no para los estudiantes.

Aunque parece un comentario sencillo, es de gran importancia para el desarrollo eficiente del reto gamificado, pues la gamificación basada en retos es una estrategia que recientemente se incorpora en la educación y más aún en los ambientes xMOOC en donde el proceso de aprendizaje es autorregulado y autodirigido. Por ello, este resultado fue tan relevante, por tal motivo fue considerado en la siguiente emisión del curso, así como algunos otros que resultaron viables didácticamente y tecnológicamente.

Para obtener esta información, se aplicó un cuestionario después del reto gamificado (Apéndice III), el cual fue respondido de manera voluntaria por 612 participantes de 1057 que realizaron el reto. El instrumento se aplicó en el curso ECLyT que se lanzó por primera vez en marzo del 2017 en el cual se incluyó una pregunta abierta sobre su opinión del reto con el propósito de obtener fortalezas y áreas de mejora para la estrategia de gamificación basada en retos.

De las 612 respuestas solamente 376 se relacionaron con el reto gamificado. Las 376 respuestas fueron ordenadas en tres categorías sobre el reto: opinión general, contenido y diseño. Para ello, la agrupación se realizó con base en la frecuencia de la 
respuesta, luego dentro de cada categoría se establecieron subcategorías. En la Tabla

71 se pueden leer algunas de las respuestas más recurrentes de los estudiantes.

\section{Tabla 72}

Algunas respuestas de los participantes del curso ECLyT impartido en la primera emisión.

El reto me pareció un claro ejemplo de la aplicación de los combustibles que en la vida diaria puede que se llegue a llevar a cabo, puesto que es importante tener noción de sus efectos de cada compuesto.

Me pareció un ejercicio muy apropiado para rectificar los conocimientos adquiridos y motivar la búsqueda de soluciones.

Más ejercicios de estos dentro del curso, me obligó a recordar situaciones prácticas e imaginarme cada evento, ventajas y desventajas de cada uno.

Me pareció una actividad muy interesante y bonita. A mí me ayudó mucho el análisis de las preguntas de comprensión que venían después del video y antes de las opciones del reto.

Reflexioné sobre ellas y relacioné lo visto en el video, las lecturas, el planteamiento del reto, que debía iluminar espacio cerrado durante la noche, etc.

Al obtener la respuesta correcta mostrar algún material didáctico que refuerce la razón de esa respuesta.

Es importantísimo el reconocimiento. Por favor seguir implementándolo.

Que tenga un cronómetro, para sentir la presión, y ahí sí, sentirme motivado para contestar lo más rápido posible y sentirme retado.

Justificar mi respuesta o proponer otras soluciones.

Mayor dificultad.

Los resultados completos se mostraron a los cuatro equipos de expertos

involucrados en este proyecto con el propósito de evaluar a la estrategia de

Gamificación basada en retos en su papel de innovador. Este ejercicio permitió

evaluar las acciones a tomar con base en las limitaciones de recursos económicos y

tecnológicos. En la Figura 49 se resaltan los aspectos de mejora encontrados y

sugeridos para que fueran incluidos en el reto gamificado. 


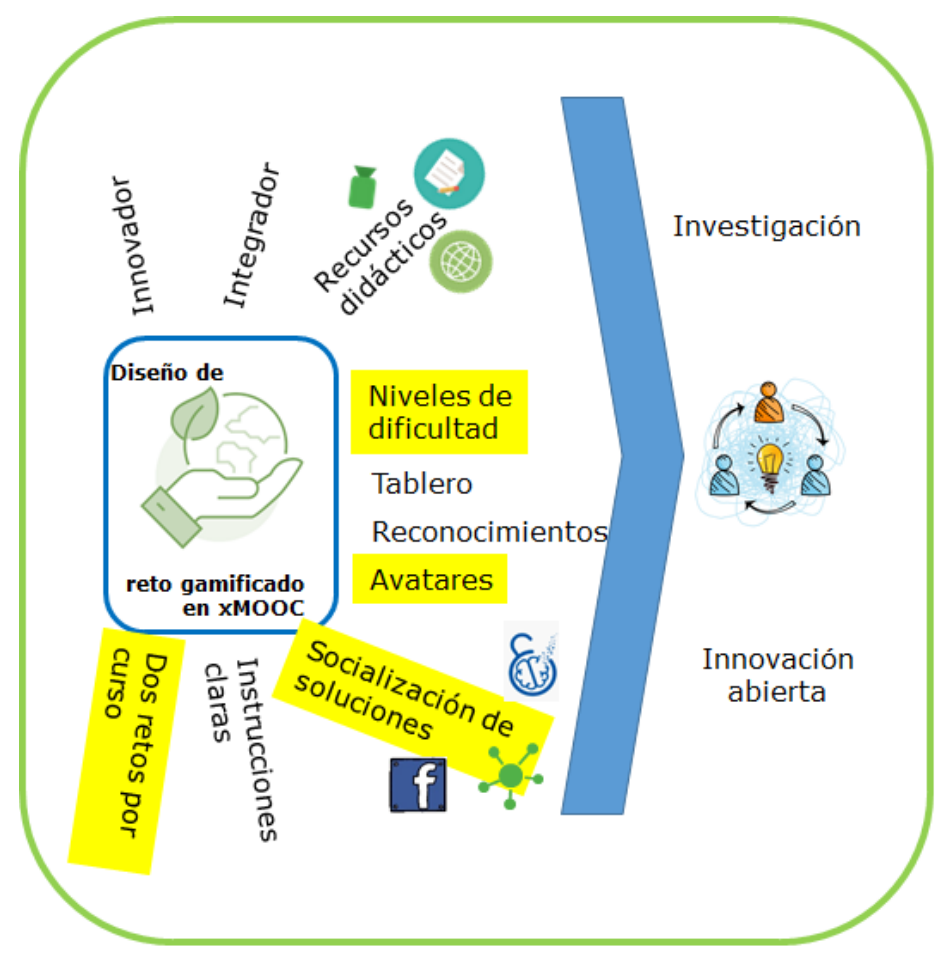

Figura 47. Evaluación y mejora continua de la innovación didáctica Gamificación basada en retos en xMOOC-energía (Elaboración propia).

En la Figura 49 se muestra que otra sugerencia recurrente fue que una parte del reto fuera abierto y que pudieran socializar sus propuestas alternativas en espacios interactivos. Por esta razón en el curso ECLyT impartido en septiembre del 2017 se volvió a aplicar el instrumento, aunque esta vez mejorado, en el que se pidió que el participante desarrollara una propuesta de solución alternativa al reto gamificado.

Aunque responder el cuestionario es una actividad voluntaria, se obtuvieron 140 respuestas alternativas al reto. Las cuales fueron evaluadas con una rúbrica sobre evaluación de innovación previamente diseñada con base en la revisión de la literatura sobre innovación educativa, ver Apéndice VII. 
Por otro lado, en la Tabla 72 se muestran algunas de las respuestas alternativas

al reto gamificado del curso ECLYT.

Tabla 73

Algunas respuestas alternativas al reto gamificado del curso ECLYT.

Agregar la posibilidad de que puedan utilizarse biocombustibles como métodos de iluminación, asumiendo que en el planteamiento del problema se den las condiciones para dicha posibilidad.

El bioetanol es un biocombustible que no es muy costoso de mantener, creo es una muy buena opción para iluminación en caso de un apagón.

Uso de bio-diésel

En vez de utilizar combustible inflamable para iluminación de emergencia preferiría hacer uso de sistemas con baterías recargables mediante dinamo.

Una alternativa al reto sería que, al no contar con gasolina, diésel o bioetanol, qué otro combustible podría usarse para iluminación y calor considerando que se estaría en un lugar donde abundan materiales como hojarasca, leña y otro tipo de residuos vegetales combustibles que cumplirían las mismas funciones, aunque con el inconveniente del humo y el ollín.

Instalación de paneles solares en lugares sin acceso a red eléctrica

Podríamos usar ciertas resinas en lugar de los combustibles, ya que como sabemos la vecinal copal tiene una buena combustión.

Utilizar una lámpara solar

Llevar pelets de biomasa.

realizar la iluminación que sea más limpia mediante plantas como el nopal

Aunque los participantes sabían que sus respuestas no iban a ser leídas por otros, solo por el investigador, se obtuvieron 140 respuestas de diversos estudiantes en cuanto a nivel educativo y edad. Por lo que este ejercicio muestra que crear espacios en los que los participantes puedan socializar sus propuestas alternativas al reto gamificado de manera auto-gestionada puede ser muy positivo.

Por lo que, si la plataforma tecnológica donde se encuentra montado el xMOOC, no permitiera espacios para la comunicación entre los participantes debido a la automatización y la masividad, se sugiere incluir redes sociales o Laboratorios 
Ciudadanos. En los que los estudiantes puedan establecer redes de comunicación en la que ellos puedan gestionar esta dinámica preestablecida como parte del diseño pedagógico de la Gamificación basada en retos.

Por ejemplo, Facebook es una red social que inicialmente fue creada para fines recreativos pero que, actualmente es utilizada para fines comerciales y académicos, convirtiéndose en una innovación tecnológica de alto impacto en educativo (Reyes y Hernández, 2017). Los laboratorios ciudadanos es la reunión de una colectividad para el desarrollo de la innovación a través del trabajo colaborativo e interdisciplinario (Yañez, Ramírez-Montoya y García-Peñalvo, 2017).

Así que, tanto Facebook como los Laboratorios Ciudadanos son ejemplos de espacios que actualmente se encuentran disponibles gracias a la tecnología y que pueden utilizarse como espacios para el trabajo colectivo, con el propósito de crear redes en las que se genere innovación abierta para la solución de problemáticas, abriendo espacios para la participación colaborativa e interdisciplinaria en la construcción del conocimiento.

Otra opción, es la capitalización de la función de los Repositorios Abiertos como medio para dar visibilidad a los productos innovadores generados por los participantes. Los repositorios abiertos se caracterizan por ofrecer un conjunto de servicios web 
centralizados, con el objetivo de organizar, gestionar, preservar y divulgar materiales digitales (González, Glasserman, Ramírez-Montoya y García-Peñalvo, 2017).

Así, al contar con espacios sistematizados como los repositorios abiertos, se contribuye al movimiento abierto (Ramírez-Montoya y García-Peñalvo, 2015), poniendo a disposición de otros usuarios, el conocimiento generado a partir de las diversas propuestas alternativas de solución de los retos que se desarrollaron en los espacios abiertos como Facebook o los Laboratorios Virtuales.

Al mismo tiempo, la generación del nuevo conocimiento se sumaría a la dinámica de la innovación abierta. Por otro lado, aunque el xMOOC se perfiló para personas con preparatoria terminada o mayores de 17 años, los datos arrojaron un elevado número de personas de niveles profesional, maestría y doctorado, en conjunto. Quizá por esto, otra respuesta recurrente fue que en el xMOOC hubiera más retos gamificados y que éstos tuvieran un mayor número de preguntas con niveles progresivos de dificultad. Esto puede favorecer aún más a la dimensión cognitiva, aunque también se debe considerar que éstos deben dosificarse para sostener el interés durante el curso, este hallazgo fue encontrado en los estudios de Hanus y Fox (2015) y Domínguez et al. (2013). Así, las otras dimensiones, la social y la emotiva no se verían disminuidas o afectadas. Por esta razón, se sugiere que sean máximo dos retos en un XMOOC cuya duración en promedio sea de seis semanas. 
Otro punto importante es el uso de avatares, ya que permiten el anonimato de los estudiantes, lo que podría mejorar la participación y el desempeño de quienes se sientan amenazados debido a la publicación de su resultado en el tablero. Esto puede favorecer aún más a la dimensión emotiva, al mismo tiempo que favorece la inclusión ante la diversidad de usuarios, en este tipo de actividades.

\subsection{Modelo de innovación educativa incremental para el diseño de Gamificación basada en retos para ambientes XMOOC.}

Como resultado de la presente investigación, en la Figura 48 se muestra el modelo de innovación educativa, de manera completa y generalizada para el diseño de la gamificación basada en retos en ambientes XMOOC. El modelo corresponde a una innovación incremental dado que crea un valor sobre un producto o servicio que ya existe, añadiéndole nuevas mejoras. El modelo parte de una base conceptual ya existente, en ese caso la literatura desarrollada en los campos de la gamificación y de los MOOC. 


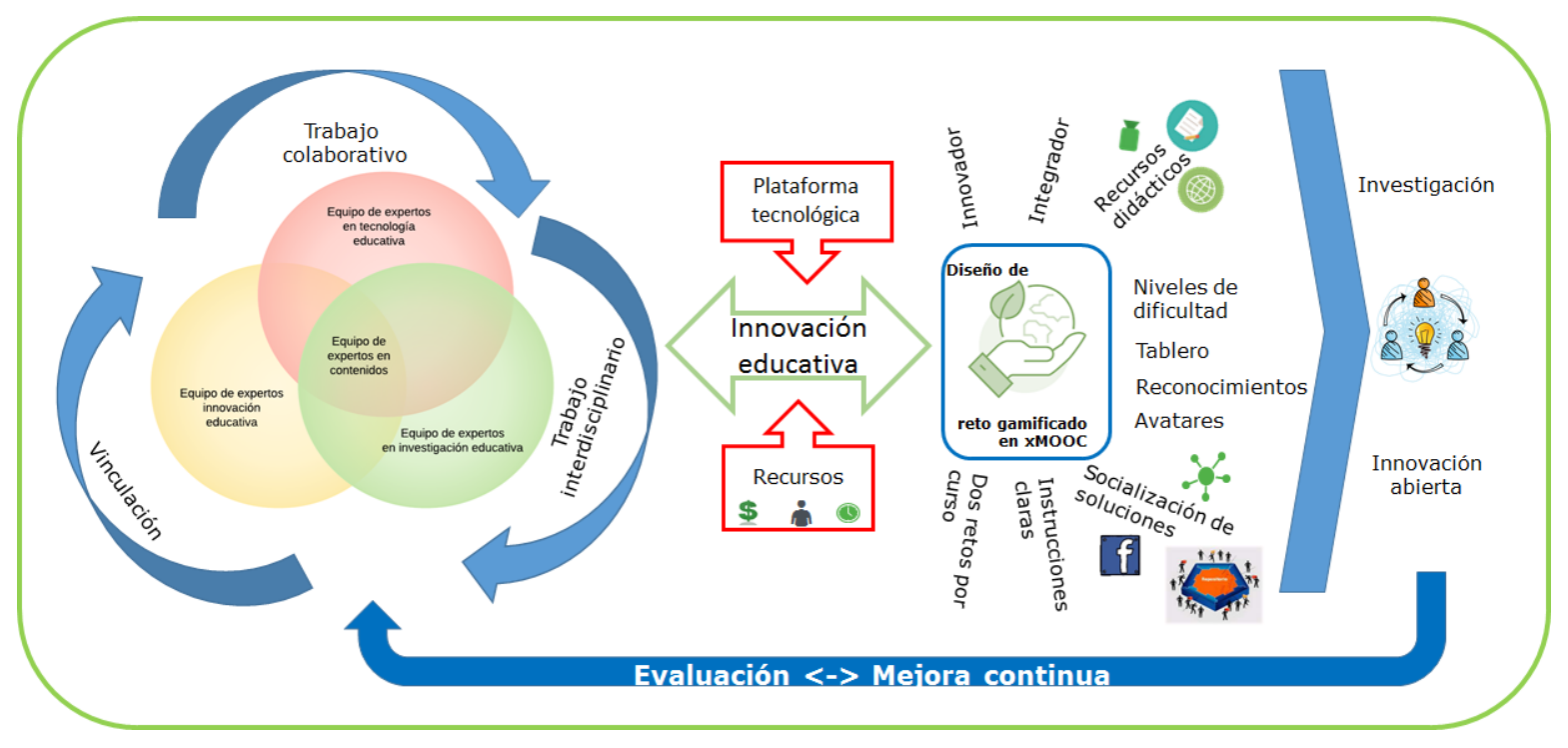

Figura 48. Modelo de innovación educativa incremental para el diseño de Gamificación basada en retos para xMOOC (Elaboración propia).

Se puede observar en la Figura 48 que los resultados obtenidos una vez que terminó la dinámica de gamificación basada en retos, los cuales se obtuvieron a partir de los productos generados de la innovación abierta y de la investigación educativa, abonan nuevo conocimiento al proceso de diseño, desarrollo, implementación y evaluación, contribuyendo así a la mejora continua.

El modelo resalta la importancia del trabajo colaborativo, interdisciplinario y vinculado como agentes potenciadores de la innovación educativa, que enfrentan de manera conjunta, creativa y proactiva las limitaciones tecnológicas y de recursos que se puedan suscitar. Así, bajo esta dinámica se desarrolla el modelo de gamificación basada en retos para $\mathrm{xMOOC} \mathrm{o} \mathrm{cualquier} \mathrm{otra} \mathrm{estrategia} \mathrm{didáctica} \mathrm{innovadora} \mathrm{para}$ este tipo de ambientes educativos. Particularmente para la gamificación basada en 
retos en $\mathrm{xMOOC}$ se sugiere que se proporcionen espacios para la socialización de las propuestas alternativas al reto. Estos espacios pueden ser redes sociales como Facebook o Laboratorios Virtuales, así mismo que las propuestas enriquecidas derivadas de la dinámica de la innovación abierta, se puedan resguardar y ser visibles dentro de otros espacios, como los Repositorios Abiertos.

También se propone que la estrategia didáctica en ambientes xMOOC, sea evaluada a través de la investigación científica de tal forma que provea de insumos significativos para la mejora continua. Y que ello permita contribuir al campo científico sobre estrategias innovadoras en MOOCs de manera ordenada y sistematizada, estableciendo pilares de conocimiento abierto para los nuevos investigadores. Finalmente, los resultados revelaron que la gamificación basada en retos es una innovación que mejora significativamente el proceso formativo en ambientes $\mathrm{xMOOC}$ y aunque este modelo se generó en un contexto particular como lo fue el energético, se puede replicar en otros cursos masivos, abiertos y en línea, incluso en la educación a distancia. El alcance de su adaptación dependerá de los recursos tecnológicos, económico y humanos, que estén a disposición.

No obstante, resulta alentador que la gamificación enriquezca a este tipo de cursos, los XMOOC, y que puedan alcanzar a una gran cantidad de personas en todo el mundo. Propiciando que la democratización del aprendizaje vaya más allá del 
modelo tradicional que consiste en ver videos y tomar examen, dando paso a una conectividad gestionada y regulada por los mismos participantes, en donde el punto de partida sea la resolución de un reto que surgió a partir de una problemática real.

En este capítulo se presentó un modelo para el diseño de estrategias didácticas innovadoras, como la gamificación, en ambientes MOOC. El propósito es ofrecer una estructura que sea transferible a otros contextos y que sirva para diseñar y aplicar cualquier otra estrategia innovadora en este tipo de ambiente educativo.

A continuación, se presenta el cierre de este trabajo de investigación, mostrando las conclusiones más importantes, así como una serie de recomendaciones que ofrecen nuevos caminos a la investigación educativa. 


\section{CONCLUSIONES}

En este capítulo se presentan las conclusiones de la presente investigación tomando como guía a la pregunta de estudio, así como a sus preguntas derivadas, a los objetivos y a los supuestos de investigación, con la finalidad de exponer el alcance logrado con este estudio. También se exponen las aportaciones al campo científico del área de conocimiento y se establecen las bases para posibles líneas de investigación.

\subsection{Sobre la pregunta de investigación general.}

En el capítulo 1 se estableció la pregunta de investigación, la cual quedo definida como: ¿Cuál es la relación entre la gamificación basada en retos y el nivel de innovación alcanzado por los participantes en cuanto a temas de energía y sustentabilidad en los Cursos Masivos Abiertos del Sector Energético? Al respecto se encontró lo siguiente:

1) Aunque los participantes se precibieron más innovadores al final del curso, la evidencia mostró que menos del 12\% de los que conformaron la muestra, desarrollaron una propuesta alternativa al reto gamificado. Esto quiere decir que el participante se percibió con capacidad innovadora pero quizás, podrían incluirse espacios de discusión y colaboración en los que ellos puedan socializar sus propuestas y recibir retroalimentación de sus compañeros. De esta manera se estarían ofreciendo espacios 
en los que los usuarios de este tipo de $\mathrm{MOOC}$ puedan desarrollar competencias para la innovación (Vila, Dávila y Mora 2010; Bi y Yang, 2015; Hoyle y Deschaine, 2016).

2) Si bien es cierto que la participación en la propuesta alternativa del reto gamificado fue baja, en esa porción se encontraron propuestas que en promedio se quedaron en el nivel 1 de impacto y como del tipo de innovación incremental. Lo cual resulta positivo porque aunque sea a menor escala el participante ofreció una alternativa que mejora lo que ya se hace en su entorno inmediato. Al mismo tiempo, la mayor parte de las propuestas fueron claras y fundamentadas en conocimiento del curso.

3) Se encontró que los hombres se situaron más en un nivel de innovación experto-adaptativo mientras que las mujeres en un nivel de experto-rutinario, según el modelo de Schwartz, Bransford y Sear (2005). Es decir ellos mostraron en sus propuestas que estaban fundamentadas en conocimiento y que fueron de mayor impacto que las propuestas de las mujeres.

4) Los niveles educativos de profesional y maestría tuvieron un mayor nivel de innovación en las cuatro categorías (impacto, claridad, conocimiento y tipo). Por lo que un hallazgo importante es que a mayor nivel educativo, mayor nivel de educación, en otras palabras, a mayor conocimiento, mayor nivel de innovación. 
5) Aunque el curso xMOOC ECLyT se posicionó como una innovación de alto impacto, clara, fundamentada en conocimiento y del tipo disruptivo, ya que llegó a un gran número de usuarios y la tasa terminal fue de más del triple que la tasa promedio mundial (Armstrong 2014, Bartolomé y Steffens, 2015), el RG se posicionó como una innovación del tipo incremental, debido al costo y a las limitaciones relacionadas a la infraestructura tecnológica que cada plataforma tiene, no obstante la Gamificación en ambientes MOOC, especialmente en $\mathrm{XMOOC}$, es una estrategia didáctica potencialmente disruptiva (Baker, Bujak y DeMilos, 2012; Marín, 2015).

\subsection{Sobre las preguntas subordinadas.}

Al inicio de la investigación, se establecieron tres preguntas subordinadas a la pregunta de investigación:

1. ¿Cuál fue la influencia de la gamificación basada en retos en los participantes en cuanto a las dimensiones cognitiva, social y emotiva?

2. ¿De qué manera la gamificación basada en retos contribuyó en el aumento de la tasa terminal con respecto a la que se ha registrado "normalmente" en los estudios internacionales?

3. ¿De qué manera la gamificación basada en retos contribuyó en el desempeño de los participantes en la evaluación final? 
La influencia de la gamificación basada en retos con respecto a las dimensiones cognitiva, social y emotiva, se encontró que los hombres estuvieron más de acuerdo con que el RG favoreció a los aspectos cognitivos, sociales y emocionales que las mujeres. No obstante, con respecto a la dimensión cognitiva, las mujeres estuvieron más de acuerdo con que la retroalimentación inmediata favoreció el análisis de su respuesta mientras que los hombres estuvieron más de acuerdo con que el RG ayudó a comprender mejor los temas. Por lo que los retos gamificados deberían diseñarse para que el estudiante pueda aplicar su conocimiento y para adquirir nuevos. Al mismo tiempo, se destaca que, en la gamificación, la retroalimentación inmediata juega un papel importante en el proceso metacognitivo del usuario, por lo que esta es una ventaja que debería potencializarse en los cursos autodirigidos como los xMOOC y en general en cualquier ambiente de aprendizaje.

Con respecto a la dimensión social, los hombres se mostraron más a favor con ver sus resultados y los de sus compañeros en un tablero que las mujeres, es decir, se evidenció su naturaleza competitiva. Mientras que las mujeres con el solo hecho de saber que los resultados se mostrarían en el tablero se sintieron motivadas a resolverlo de la mejor manera. Estos hechos nos permiten concluir que el aspecto social de la gamificación debería siempre orientarse hace una competencia constructiva, en la que 
todos los usuarios tengan la misma oportunidad de ganar con la finalidad de incrementar y sostener la motivación.

Finalmente, con respecto a la dimensión emotiva, los hombres expresaron tener más una emoción del logro al haber realizado correctamente el RG mientras que las mujeres se sintieron motivadas positivamente con el hecho de tener varias oportunidades para resolverlo correctamente. Por lo que el diseño de un sistema gamificado que incluya dinámicas, mecánicas y componentes adecuados, como el uso de tableros o trofeos, tal y como se usaron en el xMOOC ECLyT, contribuye a aumentar el compromiso (engagement) y la motivación extrínseca.

Con respecto a la segunda pregunta, aunque los resultados no fueron contundentes, la gamificación basada en retos pudo contribuir en tasa terminal (12.89\%), la cual fue superior a la encontrada en estudios internacionales (5\%). Se observó que la cantidad de participantes que hicieron el RG fue ligeramente mayor que el número de participantes que aprobaron el curso. Al mismo tiempo, se encontró que todas las actividades del curso a excepción de la Práctica estuvieron relacionadas entre sí, por otro lado, las opiniones de los participantes con respecto al RG fueron favorables, por lo tanto, casi se puede asegurar que el RG favoreció el resultado de la tasa terminal. 
Finalmente, la gamificación basada en retos contribuyó en la mejora del desempeño de los participantes en la evaluación final, pues se encontró que el RG y la evaluación final estuvieron correlacionadas, resultado que fue soportado por las opiniones de los participantes con respecto al aspecto cognitivo, por lo que se puede decir que la relación entre el RG y la evaluación final fue positiva.

\subsection{Sobre los objetivos e hipótesis.}

El objetivo de la investigación consistió en: valorar el impacto de la gamificación basada en retos que giran en torno a problemáticas sobre temas de energía y sustentabilidad, a partir de uno de los cursos masivos abiertos del sector energético, con la finalidad de proponer un modelo de evaluación de la gamificación para fortalecer la innovación abierta en los MOOC.

Al respecto se obtuvo lo siguiente:

a) A partir de la literatura revisada se elaboró una rúbrica de evaluación de la innovación, la cual se aplicó tanto a las propuestas alternativas del RG como a la misma Gamificación. En donde se encontró que las propuestas de los participantes son innovadoras, claras, fundamentadas y al menos del tipo incremental, aunque se destacaron algunas de alto impacto y disruptivas. Lo que resultó alentador, especialmente por tratarse de un curso que aborda el tema de energías limpias. 
b) La estrategia de Gamificación basada en retos en sí misma es una innovación disruptiva porque entendiendo los principios de la gamificación se puede aplicar en cualquier entorno educativo, no obstante, en un ambiente de innovación abierta como los MOOC, particularmente los $\mathrm{xMOOC,} \mathrm{puede} \mathrm{resultar} \mathrm{costoso} \mathrm{el} \mathrm{desarrollo}$ tecnológico de la aplicación, así como embeberla en la plataforma que soporta al xMOOC, por lo tanto, en este sentido se considera como una innovación incremental.

c) La valoración el impacto de la gamificación basada en retos que giran en torno a problemáticas sobre temas de energía y sustentabilidad, se dio en diversos aspectos, tales como el desempeño de los participantes reflejado en la tasa terminal y en la calidad de sus aportaciones alternativas al reto. Al mismo tiempo, generó una dinámica de innovación educativa en la que el trabajo colaborativo e interdisciplinario fueron clave en el desarrollo, aplicación y evaluación de la estrategia. De tal forma que la riqueza de la experiencia vivida y de la información obtenida, se desarrolló un modelo que ofrece una estructura para el desarrollo, implementación y evaluación de estrategias didácticas innovadoras, como la gamificación, en ambientes MOOC. Además, este modelo permite el fortalecimiento de la innovación abierta que abona de manera significativa a la sociedad del conocimiento. 
Con respecto a la hipótesis, en el capítulo 1 se establecieron las siguientes hipótesis, las cuales tienen relación con los hallazgos presentados en las secciones anteriores a este capítulo.

1) Hipótesis nula

La gamificación basada en retos desarrollada en un entorno masivo abierto potencia niveles de innovación más altos para la solución de problemáticas reales que giran en torno a las opciones energéticas autosustentables.

2) Hipótesis alternativa

La gamificación basada en retos desarrollada en un entorno masivo abierto no potencia niveles de innovación más altos para la solución de problemáticas reales que giran en torno a las opciones energéticas autosustentables.

La gamificación basada en retos, tal y como se presentó en el xMOOC ECLyT no puede potenciar directamente la innovación en termas de energía ya que es un reto cuyas respuestas son de opción múltiple y de una sola respuesta como solución. No obstante, al agregar la opción de aportar una solución alternativa se encontraron propuestas innovadoras que proponen recursos bionergéticos como el biodisel, bioetanol o biogás, así como la utilización de páneles solares portátiles. Esto muestra que partiendo de un diseño de RG autodirigido puede sentar las bases para potenciar 
la innovación siempre y cuando se establezcan espacios de interacción en el cual se puedan compartir y retroalimentar, aunque sea entre los mismos participantes, este tipo de propuestas. Por lo que la hipótesis nula es aceptada bajo un escenario en el que el participante pueda proponer sus propias soluciones al reto gamificado.

\subsection{Sobre los supuestos de la investigación.}

Al inicio de la investigación se establecieron tres supuestos de investigación los cuales se presentan a continuación y se irán comentando uno por uno.

Supuesto 1. La estrategia de gamificación basada en retos fortalece el diseño didáctico de los XMOOC ya que sitúa al participante en un ambiente andragógico menos conductista y más orientado al fortalecimiento y construcción de su aprendizaje.

Con respecto a este supuesto se encontró que el RG tuvo una participación similar a la tasa terminal, es decir, casi la totalidad de los participantes aprobados hicieron el RG. Por otro lado, los estudiantes consideraron que el RG ayudó a que aplicaran los temas del curso, a analizar la respuesta e incluso a investigar, así que a pesar de que se trató de un RG limitado por ser autodirigido sí favoreció la construcción de su aprendizaje.

Supuesto 2. La estrategia de gamificación basada en retos es una estrategia didáctica innovadora ya que contribuye a mejorar la tasa terminal y a que los 
estudiantes tengan una participación activa durante el curso, es decir, mejora el diseño conductista de los XMOOC.

La tasa terminal obtenida en el curso ECLyT y el porcentaje de participantes que hicieron el RG establece una relación positiva entre la participación activa durante el curso y la participación en el RG, por lo que casi se puede asegurar que esta estrategia motivó la participación activa. No obstante, aún se debe profundizar más sobre esta relación.

Supuesto 3. La estrategia de gamificación basada en retos contribuye a que los participantes logren un nivel medio a alto de innovación, motivados por la temática del reto gamificado y la aplicación de los conocimientos adquiridos durante el curso xMOOC energía.

Como ya se comentó en la sección anterior, el RG tal y como se llevó a cabo en el xMOOC ECLyT no contribuyó directamente a lograr algún nivel de innovación, no obstante sentó las bases y formó parte del conocimiento previo al momento de aportar las soluciones alternativas.

\subsection{Aporte científico}

Recordemos que la presente investigación se enmarcó en el proyecto Laboratorio Binacional cuyo objetivo es crear un sector energético competitivo y de clase mundial. Para ello se definieron doce subproyectos en los uno de ellos consistió 
en el desarrollo de doce $\mathrm{xMOOC}$ para educar de manera masiva y gratuita sobre temas de energia y sustentabilidad a la comunidad de habla hispana de México y Latinoamérica.

Uno de los objetivos de este subproyecto, en el cual se contextualizó la presente investigación, fue que los xMOOC energía incluyeran estrategias didácticas innovadoras como la gamificación, con la finalidad de motivar a los participantes a mantenerse activos durante el curso (Barak, Watted y Haick, 2015; Hew, 2016) , para aumentar la tasa terminal promedio mundial (Borrás-Gené, Martínez-Nuñez y FidalgoBlanco, 2016) y para contribuir positivamente en la arquitectura pedagógica de este tipo de cursos (García, Tenorio y Ramírez-Montoya, 2015; Fernández-Díaz, RodríguezHoyos y Calvo, 2016).

Así que a partir de los resultados obtenidos a continuación se presentan los aportes al campo del conocimiento:

La gamificación basada en retos es una estrategia innovadora incremental en los xMOOC que favorece positivamente el enganche y el desempeño de los participantes, gracias al ambiente de competencia constructiva generado por el reto, el uso del tablero de liderazgo, las oportunidades y los trofeos. Y, a pesar de que el diseño sea autodirgido, contribuyó en mejorar el diseño instruccional haciendolo más 
ameno y menos conductista, al mismo tiempo que potenció a los aspectos cognitivos, sociales y emocionales de los estudiantes.

En este sentido, un MOOC corresponderá a una innovación disruptiva si en su diseño didáctico se incorporan estrategias didácticas innovadoras resultado del trabajo interdisciplinario y colaborativo, así como del uso de tecnología sofisticada que contribuye en hacer asequible una educación de calidad en cualquier parte del mundo, de manera masiva y gratuita. De esta manera, el papel de los $\mathrm{MOOC}$ en el ámbito educativo continúa siendo un punto de inflexión en este sector, resolviendo diversas necesidades educativas como la del sector energético en México y Latinoamérica.

Al mismo tiempo, aunque los $\mathrm{MOOC}$ son ambientes de aprendizaje masivos y autodirigidos, se pueden propiciar espacios para la innovación abierta a través de redes sociales, laboratorios ciudadanos y espacios colaborativos virtuales, en los que de manera autodirigida los estudiantes puedan crear redes en las que se disemine el conocimiento a través del intercambio de propuestas para dar solución a diversas problemáticas del entorno, por ejemplo, de la sustentabilidad energética.

En cuanto a la estrategia didáctica de Gamificación basada en retos, ofrecer a los estudiantes varios intentos para responder correctamente en un $\mathrm{MOOC}$, favorece la meta-cognición debido al proceso reflexivo que se desarrolla al volver a intentar en 
dar con la respuesta correcta. A la vez, se fortalece la autorregulación del aprendizaje así como el flujo (flow), ya que lo impulsa a completar el reto.

Por otro lado, la retroalimentación inmediata y el uso de chances como elementos de la Gamificación en un MOOC, también genera emociones positivas de satisfacción personal en los estudiantes. De la misma manera, el uso de tableros e insignias en un ambiente $\mathrm{MOOC}$ motiva positivamente la participación de los estudiantes a resolver retos gamificados.

Finalmente, el trabajo colaborativo e interdisciplinario juegan un papel importante en el diseño, desarrollo, implementación y evaluación de estrategias didácticas innovadoras en un $\mathrm{MOOC}$, tal como la Gamificación basada en retos. Al mismo tiempo, ese trabajo colaborativo e interdisciplinario crea un ambiente propicio para la innovación abierta y la diseminación del conocimiento, ante las necesidades educativas de la sociedad, como es el caso de la sustentabilidad energética.

\subsection{Recomendaciones para el futuro.}

Para finalizar, y a partir de los resultados obtenidos, se presentan algunas propuestas que pueden derivar en futuras investigaciones. La primera es integrar espacios para la socialización de propuestas alternativas a los retos, a partir de las cuales los participantes puedan compartir e interactuar con otros, aunque no haya un tutor que lo regule pues se entiende que por la masividad y el carácter gratuito puede 
resultar complicado incurrir en este tipo de gasto. Con ello se esperaría que además de ampliar el conocimiento, se propicie que los estudiantes desarrollen redes que aborden temas sobre energía y sustentabilidad.

La segunda es investigar sobre las causas que propiciaron una recurrente diferencia de género, pues uno de los hallazgos colaterales de la investigación fue que el género másculino obtuvo mejores resultados que las mujeres. Incluso, el grupo de expertos en temas de energía estuvo conformado mayormente de hombres. Este es un tema en el que vale la pena adentrarse.

Una tercera recomendación es investigar sobre la relación entre el RG y la participación activa de los estudiantes durante el MOOC. Por otro lado, vale la pena estudiar porqué la actividad llamada práctica no se relacionó con alguna otra actividad del curso. Esto sugiere que su diseño no está alineado al diseño del curso.

También, se sugiere estudiar sobre la relación entre la gamificación y la neurociencia educativa, a través de la investigación interdisciplinaria, de tal manera que cada área fortalezca y enriquezca a la otra.

Finalmente, los resultados de esta investigación confirmaron que es importante considerar los aspecto cognitivos, sociales y emocionales (Williams y Nisbet, 2008; Hanus y Fox, 2015, Domínguez et al. 2013; Rincón-Flores, Ramírez-Montoya y Mena, 
2016)en el diseño de la gamificación en un curso xMOOC para que funcione de manera exitosa y active, tanto la motivación intrínseca como extrínseca (Hamari y Koivisto, 2015; Magaña-Valladares, et al., 2016; Morganti, Pallavicini, Cadel, Candelieri, Archetti y Mantovani, 2017; Hamari, 2017).

Por lo que resulta reelevante que en el diseño de este tipo de estretegia se consideren los siguientes aspectos:

1) Que el diseño del curso sea interdisciplinario con la finalidad de potenciar la creatividad e innovación (Bi y Yang, 2014; Jar, 2010; García-Valcárcel et al., 2012; García y Mena, 2016), es decir, que se involucren trres grupos de expertos: en innovación educativa, en tecnología y en contenidos. De tal manera que el grupo en innovación educativa pueda ir modelando las actividades gamificadas a partir de su conocimiento didáctico. Que el grupo de expertos en desarrollo tecnológico que pueda comprender las ventajas y desventajas de la plataforma donde se montará el MOOC y que puedan participar en el desarrollo del software que dará vida a la gamificación. Y que el grupo de expertos en los temas que se abordarán, desarrollen el diseño del contenido del RG de tal manera que propicie la aplicación del conocimiento, el análisis y la investigación, tal y como ocurrió en en el RG del xMOOC ECLyT.

2) Que la aplicación de este tipo de estrategias esté acompañada de un grupo de investigadores educativos que permitan evaluar el papel innovador de la estrategia 
de tal manera que los resultados permitan fortalecerla o mejorarla. Al mismo tiempo que puedan mostrar a la comunidad científica los hallazgo para que este tipo de estrategias pueda ser incorporada en otros MOOC.

3) Gracias a la naturaleza autodirigida del RG no hay manera de evidenciar que se potencia el nivel de innovación de los participantes, por lo que se sugiere crear espacios de interacción en los que los estudiantes puedan socializar sus propuestas y aprender de otras, consideramos que no es necesario que haya un tutor, ellos mismos se podrían gestionar de manera voluntaria. En la presente investigación se evidenció que los participantes hicieron sus aportaciones a pesar de que sabían que no se evaluarían ni que otros las leerían.

Por otro lado, después de la revisión de la literatura y durante la investigación se desarrollaron dos instrumentos que pueden ser utilizados por otros investigadores interesados en la gamificación en ambientes MOOC. Uno de ellos evalúa las dimensiones cognitivas, sociales y emocionales con respecto a la gamificación y el otro es una rúbrica que evalúa el nivel de innovación a partir de cuatro rubros (Eckerl y Kezer, 2003; Jamiesan y Clark, 2002; García-Fanjón y Rodríguez,2003 y Schwartz et al., 2005).

Resumiendo, el aporte científico más importante de esta investigación es el diseño y la aplicación exitosa de la gamificación basada en retos en un MOOC masivo 
y autodirigido, lo que sítua a la estrategia como innovadora y al xMOOC-energía como una innovación disruptiva. Lo que permitió desarrollar un modelo de diseño de gamificación basada en retos así como un modelo de evaluación de la estrategia, el cual se puede extender a cualquier otra estrategia innovadora dentro de un curso masivo abierto y en línea. 


\section{APÉNDICE}

\section{APÉNDICE I. MUESTRA DE ÍTEMS UTILIZADOS EN EL MAPPING}

Descripción: El apéndice muestra las referencias de las publicaciones utilizadas para el desarrollo del mapping de Gamificación en MOOC. Son un total de 30 referencias de bases de datos Scopus o WOS.

A1] Berkling K., El-Husseny A., Latt D., Petrov C., Waigand A. and Walther J. (2016). GamES MOOC - Conceptual Ideas and First Steps Towards Implementation of a MOOC for Children. In Proceedings of the 8th International Conference on Computer Supported Education, CSEDU, 405412. DOI: $10.5220 / 0005857304050412$

[A2] Borrás-Gené, O., Martínez-Nuñez, M., \& Fidalgo-Blanco, Á. (2016). New Challenges for the motivation and learning in engineering education using gamification in MOOC. International Journal of Engineering Education, 32(1), 501-512. Retrieved from http://www.scopus.com/inward/record.url?eid=2-s2.0-84959358012\&partnerlD=tZOtx3y1

[A3] Buchem, I., Merceron, A., Kreutel, J., Haesner, M., \& Steinert, A. (2015). Gamification designs in Wearable enhanced learning for healthy ageing. Proceedings of 2015 International Conference on Interactive Mobile Communication Technologies and Learning, IMCL 2015, (November), 9-15. https://doi.org/10.1109/IMCTL.2015.7359545

[A4] Cain, J., Conway, J. M., Divall, M. V, Erstad, B. L., Lockman, P. R., Ressler, J. C., Nemire, R. E. (2014). AACP REPORTS Report of the 2013-2014. American Journal of Pharmaceutical Education, 78(10).

[A5] Chan, M. M. (2016). MOOCS \& Gamification, Oportunidades y Desafíos, (October). https://doi.org/10.13140/2.1.2851.7761

[A6] Chang, J., \& Wei, H. (2016). Exploring Engaging Gamification Mechanics in Massive Online Open Courses. Educational Technology \& Society, 19(2), 177-203.

[A7] Chauhan, J., Taneja, S., \& Goel, A. (2016). Enhancing MOOC with Augmented Reality, Adaptive Learning and Gamification. Proceedings of the 2015 IEEE 3rd International Conference on MOOCs, Innovation and Technology in Education, MITE 2015, 348-353.

https://doi.org/10.1109/MITE.2015.7375343

[A8] Chou, T. L., \& Chen, S. (2015). The effects of progress bars on diverse learning styles in webbased learning. Proceedings - IEEE 15th International Conference on Advanced Learning Technologies: Advanced Technologies for Supporting Open Access to Formal and Informal Learning, ICALT 2015, 493-494. http://doi.org/10.1109/ICALT.2015.141

[A9] Ciussi, M. (2016). Designing a game-based MOOC on a smartphone application: key challenges. 10th European Conference on Games Based Learning (pp 960-967). 
[A10] Corpeño, E., Corpeño, E., Quan, A., \& Lemus, A. (MAY 2015). Designing and Executing a Gamified Hands-On MOOC for Technology Enthusiasts. International Workshop on Massive Open Online Courses.

[A11] Cózar-Gutiérrez, R., \& Sáez-López, J. M. (2016). Game-based learning and gamification in initial teacher training in the social sciences: an experiment with MinecraftEdu. International Journal of Educational Technology in Higher Education, 13(1), 2. http://doi.org/10.1186/s41239-016-0003-4

[A12] Freire, M., Martínez-Ortiz, I., Moreno-Ger, P., \& Fernández-Manjón, B. (2015). Requirements for educational games in MOOCs. IEEE Global Engineering Education Conference, EDUCON, 2015-April (March), 993-997. http://doi.org/10.1109/EDUCON.2015.7096094

[A13] Borrás-Gené, O., Martínez-Núñez,M., \& Fidalgo-Blanco, Á. (2014). Gamification in MOOC: Challenges, Opportunities and Proposals for Advancing MOOC Model. In Proceedings of the Second International Conference on Technological Ecosystems for Enhancing Multiculturality (pp. 215-220). https://doi.org/10.1145/2669711.2669902

[A14] Gomez-Galvez, P., Suarez Mejias, C., \& Fernandez-Luque, L. (2015). Social media for empowering people with diabetes: Current status and future trends. Conference Proceedings : ... Annual International Conference of the IEEE Engineering in Medicine and Biology Society. IEEE Engineering in Medicine and Biology Society. Annual Conference, 2015(978), 2135-2138. http://doi.org/10.1109/EMBC.2015.7318811

[A15] González-González, C. S., Collazos, C. A., \& García, R. (2016). Desafío en el diseño de MOOCs: incorporación de aspectos para la colaboración y la gamificación. Revista de Educación a Distancia (RED), (48). https://doi.org/10.6018/red/48/7

[A16] Grünewald, F., Meinel, C., Totschnig, M., \& Willems, C. (2013). Designing MOOCs for the Support of Multiple Learning Styles. In D. Hernández-Leo, T. Ley, R. Klamma, \& A. Harrer (Eds.), Scaling up Learning for Sustained Impact: 8th European Conference, on Technology Enhanced Learning, EC-TEL 2013, Paphos, Cyprus, September 17-21, 2013. Proceedings (pp. 371-382). in book, Berlin, Heidelberg: Springer Berlin Heidelberg. https://doi.org/10.1007/978-3-642-40814-4_29

[A17] Hammais, E., Ketamo, H., \& Koivisto, A. (2014). Mapping the energy: A gamified online course. 8th European Conference on Games Based Learning (Ecgbl 2014), 1, 176-181. Retrieved from http://www.scopus.com/inward/record.url?eid=2-s2.084923548590\&partnerID=40\&md5=6d4ba4a0ba909373a3811 fd8c61d37ad

[A18] Krause, M., Mogalle, M., Pohl, H., \& Williams, J. J. (2015). A Playful Game Changer: Fostering Student Retention in Online Education with Social Gamification. Proceedings of the 2nd ACM Conference on Learning @ Scale (L@S'15), (October 2016), 95-102. https://doi.org/10.1145/2724660.2724665

[A19] Liyanagunawardena, T. R., Lundqvist, K. Ø., \& Williams, S. A. (2015). Who are with us: MOOC learners on a FutureLearn course. British Journal of Educational Technology, 46(3), 557569. https://doi.org/10.1111/bjet.12261

[A20] Magaña-Valladares, L., González-Robledo, M. C., Rosas-Magallanes, C., Mejía-Arias, M. Á., Arreola-Ornelas, H., \& Knaul, F. M. (2016). Training Primary Health Professionals in Breast Cancer 
Prevention: Evidence and Experience from Mexico. Journal of Cancer Education, 1-7. https://doi.org/10.1007/s13187-016-1065-7

[A21] Markovic, L., \& Sofronijevic, A. (2016). Building a Gamified System for Caputring MOOC Related Data: Smart City Learning Community as its Most Precious Source of Intangible Cultural Heritage. Proceedings - 2015 International Conference on Culture and Computing, Culture and Computing 2015, 175-182. https://doi.org/10.1109/Culture.and.Computing.2015.45

[A22] Mesquita, M. A. A., Toda, A. M., \& Brancher, J. D. (2014). BrasilEduca - An Open-Source MOOC platform for Portuguese speakers with gamification concepts. IEEE Frontiers in Education Conference, (October), 446-449. https://doi.org/10.1109/FIE.2014.7044063

[A23] Ramirez-Donoso, L., Perez-Sanagustin, M., Neyem, A., \& Rojas-Riethmuller, J. S. (2016). Fostering effective collaboration in MOOCs through mobile apps. CHILECON 2015 - 2015 IEEE Chilean Conference on Electrical, Electronics Engineering, Information and Communication Technologies, Proceedings of IEEE Chilecon 2015, (1), 401-408. https://doi.org/10.1109/Chilecon.2015.7400408

[A24] Saraguro-Bravo, R. A., Jara-Roa, D. I., \& Agila-Palacios, M. (2016). Techno-instructional application in a MOOC designed with gamification techniques. 2016 3rd International Conference on eDemocracy and eGovernment, ICEDEG 2016, 176-179.

https://doi.org/10.1109/ICEDEG.2016.7461717

[A25] Staubitz, T., Woinar, S., Renz, J., \& Meinel, C. (2014). Towards Social Gamification Implementing a Social Graph in an Xmooc Platform. iCeri14 Proceedings.

[A26] Tenório, T., Bittencourt, I. I., Isotani, S., Pedro, A., \& Ospina, P. (2016). A gamified peer assessment model for on-line learning environments in a competitive context. Computers in Human Behavior, 64, 247-263. https://doi.org/10.1016/j.chb.2016.06.049

[A27] Vaibhav, A., \& Gupta, P. (2015). Gamification of MOOCs for increasing user engagement. Proceedings of the 2014 IEEE International Conference on MOOCs, Innovation and Technology in Education, IEEE MITE 2014, 290-295. https://doi.org/10.1109/MITE.2014.7020290

[A28] Voulgari, I., \& Sampson, D. G. (2014). Applying lessons learnt from massively multiplayer online games (MMOGs) to massive open online courses (MOOCs). 14th IEEE International Conference on Advanced Learning Technologies, ICALT, 14-15.

https://doi.org/10.1109/ICALT.2014.14

[A29] Warden, C. A., Stanworth, J. O., \& Chang, C. C. (2016). Leveling up: Are non-gamers and women disadvantaged in a virtual world classroom? Computers in Human Behavior, 65, 210-219. https://doi.org/10.1016/j.chb.2016.07.033

[A30] Willems, C., Fricke, N., Meier, S., Meissner, R., Rollmann, K. a., Voelcker, S. \& Meinel, C. (2014). Motivating the Masses - Gamified Massive Open Online Courses on Openhpi.

EDULEARN14 Proceedings, 4042-4052. Retrieved from

http://library.iated.org/view/WILLEMS2014MOT 


\section{APÉNDICE II}

\section{APÉNDICE II. CUADRO DE TRIPLE ENTRADA.}

\section{Descripción: El apéndice muestra el cuadro de triple entrada, el cual estableció la}

relación de los instrumentos con los constructos y teóricos de la literatura.

\begin{tabular}{|c|c|c|c|c|c|c|c|}
\hline $\begin{array}{l}\text { Instrumentos y fuentes } \\
\text { de informacion }\end{array}$ & \begin{tabular}{|l} 
Cuestionario \\
Inicio-Final
\end{tabular} & $\begin{array}{l}\text { Cuestionario } \\
\text { dimensiones de } \\
\text { la Gamificación }\end{array}$ & $\begin{array}{l}\text { Analíticas } \\
\text { Ed-X }\end{array}$ & $\begin{array}{l}\text { Cuestionario } \\
\text { cualitativo sobre } \\
\text { aspectos de } \\
\text { mejora del RG }\end{array}$ & $\begin{array}{l}\text { Nivel de } \\
\text { innovación de la } \\
\text { estrategia RG en } \\
\text { un } \\
\text { xMOOC/Rúbrica }\end{array}$ & $\begin{array}{l}\text { Nivel de } \\
\text { innovación de } \\
\text { los } \\
\text { participantes/ } \\
\text { Rúbrica } \\
\end{array}$ & Autores \\
\hline \multirow{2}{*}{\multicolumn{8}{|c|}{$\begin{array}{l}\text { Constructos/Categorias } \\
\text { 1) Innovación }\end{array}$}} \\
\hline & & & & & & & \\
\hline $\begin{array}{l}\text { a) Nivel de innovación } \\
\text { participantes }\end{array}$ & $\mathrm{x}$ & & & & $\mathrm{x}$ & $\mathbf{x}$ & 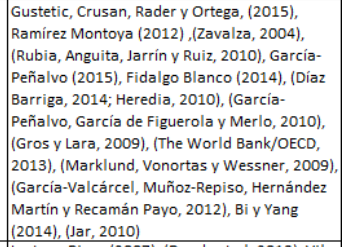 \\
\hline $\begin{array}{l}\text { b) Nivel de innovación de } \\
\text { la estrategia }\end{array}$ & $\mathrm{x}$ & & & & $\mathrm{x}$ & & $\begin{array}{l}\text { Lester y yiore (2007), (Dande et al, 2013), Vila, } \\
\text { Dávila y Mora, (2010), vila y Pérez (2013). } \\
\text { Garcí-Fanjóny y Rodriguez 2011, Zavalza y } \\
\text { Zavalzza } 2012\end{array}$ \\
\hline c) Tipo de innovación & $\mathrm{x}$ & & & $\mathbf{x}$ & $\mathrm{x}$ & $\mathrm{x}$ & \begin{tabular}{|l|} 
Schwartz, Bransford y Sears (2005) Jamieson \\
y Clark (2002), Romero, Rébori y Camio, \\
(2010), Rejeb tet al (2010), García Fanjon y \\
Rodriguez (2011), Eckel y Kezar (2003) \\
\end{tabular} \\
\hline \multicolumn{8}{|l|}{ 2) MOOC } \\
\hline $\begin{array}{l}\text { a) Diseño didáctico b) } \\
\text { Fortalezas yáreas de } \\
\text { oportunidad c) } \\
\text { Caractaristicas }\end{array}$ & $\mathrm{x}$ & $\mathrm{x}$ & $\mathrm{x}$ & $\mathrm{x}$ & $\mathrm{x}$ & $\mathrm{x}$ & $\begin{array}{l}\text { Andrews (2011), King y Lakhani (2013), } \\
\text { Aguaded, (2013), Bartolomé-Pina y Steffens, } \\
\text { (2015), Siemens (2005, 20122), Borrás, } \\
\text { Matínez y Fidalgo Blanco (2014) y González, } \\
\text { Collazzos y García (2016), Fidalago-Blanco, Sein- } \\
\text { Echaluce y García-Peñallvo (2013), Chauhan } \\
\text { (2014), Chiappe-Laverde, Hine y Martinez- } \\
\text { Silva (2015) }\end{array}$ \\
\hline \multicolumn{8}{|l|}{ 3) Gamificación } \\
\hline a) Participación/Género & $\mathrm{x}$ & & $\mathrm{x}$ & & & & $\begin{array}{l}\text { Koivisto y Hamari (2014), Albuquerque et } \\
\text { al.(2017), Tettegah, McCreery y } \\
\text { Blumberg (2016), Lenhart (2008), Warde, } \\
\text { Stanworth y Chang (2016) }\end{array}$ \\
\hline b) Relación de variables & $\mathrm{x}$ & $x$ & $\mathrm{x}$ & $x$ & $\mathrm{x}$ & $\mathbf{x}$ & \begin{tabular}{|l|} 
Galvis, Mariño, Trech y Recamán, 2013), \\
Mayer (2016), Hanus y Fox (2015), Rodriguez \\
y Santiago (2015), Dicheva, Dichev, Agre y \\
Angelova, 2015, Surendeleg, Murwa, Yun y \\
Kim, 2014, Lee y Hammer, 2011, Dicheva y y \\
Dichev (2015), Koivisto, Multisilta, Niemi, \\
Kataj isto \& Erickson, 2016, Werbach y Hunter \\
(2012), , Kocadere y Caglar, 2015, Kapp (2012), \\
Werbach y Hunter, 2015, Shonfeld (2010), Tu \\
et al (2016) , Bunchball (2012)
\end{tabular} \\
\hline c) Dimensión emotiva & & $\mathrm{x}$ & & $x$ & & & \begin{tabular}{|l|} 
Hanus y Fox (2015), Rodríguez y Santiago \\
(2015), Dicheva, Dichev, Agre y Angelova, \\
2015, Surendeleg, Murwa, Yun y Kim, 2014, \\
Lee y Hammer, 2011, Dicheva y Dichev (2015), \\
Koivisto, Multisilta, Niemi, Katajisto \& \\
Erickson, 2016, Werbach y Hunter (2012), \\
Kocadere y Caglar, 2015, Kapp (2012), \\
Werbach y Hunter (2015) \\
\end{tabular} \\
\hline & & & & & & & $\begin{array}{l}\text { Hanus y Fox (2015), Rodríguez y Santiago } \\
\text { (2015), Dicheva, Dichev, Agre y Angelova, } \\
\text { 2015, Surendeleg, Murwa, Yun y Kim, 2014, } \\
\text { Lee y Hammer, 2011, Dicheva y Dichev (2015), } \\
\text { Bunchball (2012) }\end{array}$ \\
\hline d) Dimensión Social & & $\mathrm{x}$ & & $\mathrm{x}$ & & & \\
\hline e) Dimensión cognitiva & & $\mathrm{x}$ & & $\mathrm{x}$ & & & \begin{tabular}{|l|} 
Villalustrey yel Moral (2014), (Pasin y \\
Giroux, 2011), (Fullagar, Knight y Sovern, \\
2013; Borgers y Sproedt, 2015), Dominguez et \\
al (2013), Lee y Hammer (2011) y Nisbety \\
Williams (2009), Pulos y Sneider (1994), \\
Vaihav v Gupta (2014), Rincón, Ramirez- \\
Montoya y Mena (2016)
\end{tabular} \\
\hline
\end{tabular}




\section{APÉNDICE II}

\section{APÉNDICE III. CUESTIONARIO DE INICIO Y FINAL}

Descripción: Los cuestionarios se aplicaron al inicio y al final del curso, para propósitos de investigación. Las ligas se colocaron en el Xmooc A TRAVÉS DE LA PLATAFORMA Suvery Monkey.

\section{-CUESTIONARIO INICIAL}

Instrucciones

Estimado participante: este cuestionario tiene como objetivo recopilar datos de identificación y de tu experiencia previa en este tipo de cursos. Por favor, responde todas y cada una de las preguntas que se plantean en este cuestionario. La información que proporciones será manejada de manera confidencial. Asumimos que, al responder esta encuesta, manifiestas tu acuerdo de que la información proporcionada pueda ser utilizada por los organizadores de los MOOC para mejorar la experiencia de aprendizaje. Gracias por participar en esta encuesta. Tus comentarios son muy importantes para nosotros.

I.Datos de identificación

1.Nombre(s)

2.Apellido(s)

3.Dirección de correo electrónico (usar aquella con la que entras a la plataforma del MOOC)

4.Género

Femenino Masculino

5.Fecha de nacimiento

Fecha

DDMM/AAAA

6.País de residencia

7.Estado (sólo en los casos en que el participante resida en México)

8.Nivel máximo de estudios terminados.

Bachillerato (o grados 10, 11 y 12) Carrera técnica

Licenciatura Maestría Doctorado

Otro (especifique)

9.Si tiene carrera técnica, licenciatura, maestría o doctorado, elija la opción que describe mejor la disciplina de sus estudios.

Ingenierías y sistemas computacionales

Ciencias naturales (física, química, biología, etc.) 
Ciencias sociales (sociología, relaciones internacionales, etc.) Humanidades y Filosofía

Administración de empresas (mercadotecnia, finanzas, etc.) Derecho

Ciencias de la salud (medicina, enfermería, etc.) Arte, Arquitectura, etc.

Otro (especifique)

10.Ocupación principal (en caso de que sean aplicables dos o más opciones, elegir la que implique mayor tiempo de dedicación).

Estudiante de licenciatura

Estudiante de posgrado

Empleado de tiempo completo

Empleado de tiempo parcial

Negocio propio

Jubilado

Desempleado Otro (especifique)

11.Experiencia previa con MOOC.

Es la primera vez que me inscribo a un MOOC.

Ya me había inscrito en al menos un MOOC, pero no lo(s) terminé.

He participado en un MOOC y lo terminé.

He participado en dos MOOC y los terminé.

He participado en tres o más MOOC y los terminé.

12. ¿Conocías al Tecnológico de Monterrey antes de este curso?

Sí, y fue una de las razones para inscribirme al curso.

Sí, pero no influyó en mi decisión de inscribirme al curso.

No conocía al Tecnológico de Monterrey antes de este curso.

13.Nombre del MOOC en el que estás inscrito

II. Intereses y motivaciones para estudiar el MOOC

14. ¿Cuál de las siguientes opciones describe mejor tu interés al inscribirte en este curso?

Por curiosidad (saber en qué consiste un MOOC)

Porque quiero tener contacto con otros estudiantes interesados en el tema. Tengo amigos en el curso.

El curso se relaciona con mi programa académico. El curso se relaciona con mi trabajo.

Las habilidades y conocimientos que proporciona el curso me ayudarán a conseguir un mejor trabajo. Otro (especifique).

15. ¿Cuál es tu nivel de compromiso con este curso?

Planeo realizar todas las actividades y exámenes ya que estoy interesado en el certificado. 
Planeo realizar todas las actividades y exámenes para completar el curso, aunque no tenga el certificado.

Planeo ver todas las sesiones, realizar algunas actividades y algunos exámenes, pero no estoy interesado en terminar el curso.

Sólo estoy interesado en consultar algunos videos y los materiales del curso.

Tengo interés en saber de qué se trata el curso, pero no planeo ver las sesiones ni realizar las actividades.

Otro (especifique).

16. Creo que este curso ayudará a satisfacer las necesidades de formación que me llevaron a inscribirme en él.

Muy de acuerdo

De acuerdo

En desacuerdo

Muy en desacuerdo

17.Creo que este curso ayudará a mejorar mi desarrollo profesional (actual o futuro).

Muy de acuerdo

De acuerdo

En desacuerdo

Muy en desacuerdo

18. Creo que este curso podrá mejorar mis oportunidades de trabajo o de negocio (actuales o futuras).

Muy de acuerdo

De acuerdo

En desacuerdo

Muy en desacuerdo

19.Creo que este curso me facilitará establecer relaciones profesionales con personas que tengan intereses afines a los míos.

Muy de acuerdo

De acuerdo

En desacuerdo

Muy en desacuerdo

20.Creo que este curso mejorará mi formación académica.

Muy de acuerdo

De acuerdo

En desacuerdo

Muy en desacuerdo

21.Creo tener la constancia para concluir con éxito este curso. 
Muy de acuerdo

De acuerdo

En desacuerdo

Muy en desacuerdo

22.Creo tener las habilidades (de estudio, de uso de TIC, etc.) necesarias para concluir con éxito este curso.

Muy de acuerdo

De acuerdo

En desacuerdo

Muy en desacuerdo

\section{Conocimientos previos}

23. Creo tener las competencias necesarias para usar herramientas digitales tales como navegadores de Web, correo electrónico, herramientas de Office, etc.

Muy de acuerdo

De acuerdo

En desacuerdo

Muy en desacuerdo

24.Creo tener las competencias necesarias para estudiar este curso a través de una plataforma tecnológica.

Muy de acuerdo

De acuerdo

En desacuerdo

Muy en desacuerdo

25.Creo tener las competencias necesarias para conseguir información relevante sobre los temas de este curso.

Muy de acuerdo

De acuerdo

En desacuerdo

Muy en desacuerdo

26. Creo tener las competencias necesarias para usar las redes sociales con fines académicos.

Muy de acuerdo

De acuerdo

En desacuerdo

Muy en desacuerdo 
27. Creo que actualmente cuento con una noción general de los contenidos del curso al que estoy inscrito.

Muy de acuerdo

De acuerdo

En desacuerdo

Muy en desacuerdo

28. Creo tener cierta experiencia práctica en el área de energía.

Muy de acuerdo

De acuerdo

En desacuerdo

Muy en desacuerdo

Cierre de la encuesta

Muchas gracias por tu participación al responder esta encuesta. La información proporcionada será de mucha utilidad para nosotros.

\section{- CUESTIONARIO FINAL}

Instrucciones

Estimado participante: este cuestionario tiene por objetivo recopilar información sobre la experiencia de aprendizaje que tuviste en este curso. Por favor, responde todas y cada una de las preguntas que se plantean en este cuestionario. La información que proporciones será manejada de manera confidencial. Asumimos que, al responder esta encuesta, manifiestas tu acuerdo de que la información proporcionada pueda ser utilizada por los organizadores de los MOOC para mejorar la experiencia de aprendizaje. Gracias por participar en esta encuesta. Tus comentarios son muy importantes para nosotros.

I. Datos de identificación

1. $\quad$ Nombre(s)

2. Apellido(s)

3. Dirección de correo electrónico (usar aquella con la que entras a la plataforma del curso MOOC)

4. Nombre del MOOC que estás concluyendo.

II. Intereses y motivaciones al haber estudiado el MOOC

5. Este curso satisfizo las necesidades de formación que me llevaron a inscribirme en él.

Muy de acuerdo

De acuerdo

En desacuerdo 
Muy en desacuerdo

6. Después de haberlo tomado, estoy convencido que este curso ayudará a mejorar mi desarrollo profesional.

Muy de acuerdo

De acuerdo

En desacuerdo

Muy en desacuerdo

7. Después de haberlo tomado, estoy convencido que este curso mejorará mis oportunidades de negocio Muy de acuerdo

De acuerdo

En desacuerdo

Muy en desacuerdo

8. Creo que este curso me facilitó establecer relaciones profesionales con personas que tienen intereses afines a los míos.

Muy de acuerdo

De acuerdo

En desacuerdo

Muy en desacuerdo

9. Creo que este curso mejoró mi formación académica.

Muy de acuerdo

De acuerdo

En desacuerdo

Muy en desacuerdo 
10. Creo que tuve la constancia suficiente para concluir con éxito este curso.

Muy de acuerdo

De acuerdo

En desacuerdo

Muy en desacuerdo

11. Creo que tuve las habilidades necesarias (de estudio, de uso de TIC, etc.) para concluir con éxito este curso.

Muy de acuerdo

De acuerdo

En desacuerdo

Muy en desacuerdo

III. Conocimientos adquiridos

12. Creo que este curso me permitió mejorar las competencias digitales con las que ya contaba (navegadores de Web, correo electrónico, herramientas de Office, etc.)

Muy de acuerdo

De acuerdo

En desacuerdo

Muy en desacuerdo

13. Creo que este curso me permitió desarrollar las competencias necesarias para usar adecuadamente la plataforma tecnológica.

Muy de acuerdo

De acuerdo

En desacuerdo

Muy en desacuerdo

14. Creo que este curso me permitió desarrollar las competencias necesarias para conseguir información relevante sobre los temas estudiados.

Muy de acuerdo 
De acuerdo

En desacuerdo

Muy en desacuerdo

15. Creo que este curso me permitió desarrollar las competencias necesarias para usar las redes sociales con fines académicos.

Muy de acuerdo

De acuerdo

En desacuerdo

Muy en desacuerdo

16. Creo que este curso me permitió adquirir los conocimientos básicos de los contenidos estudiados.

Muy de acuerdo

De acuerdo

En desacuerdo

Muy en desacuerdo

17. Después de haberlo tomado, estoy convencido que este curso me permitirá desarrollar experiencia práctica en el área de energía.

Muy de acuerdo

De acuerdo

En desacuerdo

Muy en desacuerdo

Cierre de la encuesta

Muchas gracias por tu participación al responder esta encuesta. La información proporcionada será de mucha utilidad para nosotros. 


\section{APÉNDICE IV}

\section{APÉNDICE IV. CUESTIONARIO SOBRE DIMENSIONES DE LA GAMIFICACIÓN (INSTRUMENTO PILOTO).}

Descripción: Este instrumento se aplicó para obtener información sobre las dimensiones cognitiva, social y emotiva, con el propósito de conocer su relación con la famificación.

Percepciones sobre reto gamificado

Estimado participante:

A través de este medio solicitamos tu apoyo para llevar a cabo un estudio que tiene como propósito mejorar el proceso enseñanza-aprendizaje de un curso MOOC.

La información recabada es para propósitos académicos, únicamente y se te asegura que no se utilizará ningún dato personal en ningún informe o publicación que se genere a partir del estudio. Tus respuestas serán tratadas en forma estrictamente confidencial.

Agradecemos tu valiosa participación en este estudio.

POLÍTICAS DE PRIVACIDAD:

https://tec.mx/es/politicas-de-privacidad-del-tecnologico-de-monterrey

AVISO DE PRIVACIDAD:

https://tec.mx/es/avisos-de-privacidad

* Required

Escribe tu usuario o correo del curso Energías convencionales, limpias y su tecnología. *

Your answer

1) La retroalimentación inmediata por parte de la platafoma en la actividad del reto gamificado "Combustibles para iluminación en caso de emergencia" me dieron oportunidad de analizar mejor mi respuesta antes de volver a responder. *

Totalmente de acuerdo

De acuerdo

En desacuerdo

Totalmente en desacuerdo 
2) Resolver el reto gamificado "Combustibles para iluminación en caso de emergencia" me ayudó a comprender mejor los temas relacionados a esta actividad. *

Totalmente de acuerdo

De acuerdo

En desacuerdo

Totalmente en desacuerdo

3) El nivel de dificultad del reto "Combustibles para iluminación en caso de emergencia" me pareció adecuado a mis conocimientos sobre el tema. *

Totalmente de acuerdo

De acuerdo

En desacuerdo

Totalmente en desacuerdo

4) El reto "Combustibles para iluminación en caso de emergencia" favoreció mi desempeño en el examen final.

Totalmente de acuerdo

De acuerdo

En desacuerdo

Totalmente en desacuerdo

5) El tablero de liderazgo me motivó positivamente a resolver el reto "Combustibles para iluminación en caso de emergencia". *

Totalmente de acuerdo

De acuerdo

En desacuerdo

Totalmente en desacuerdo

6) Ver anticipadamente los resultados de mis compañeros en el tablero de liderazgo me motivó a concentrarme más en el reto "Combustibles para iluminación en caso de emergencia". *

Totalmente de acuerdo

De acuerdo

En desacuerdo 
Totalmente en desacuerdo

7) El haber obtenido una insignia de trofeo de oro, plata o bronce en el reto me hizo sentir muy bien. *

Totalmente de acuerdo

De acuerdo

En desacuerdo

Totalmente en desacuerdo

8) ¿Qué sugieres para mejorar la actividad del reto "Combustibles para iluminación en caso de emergencia" ? $*$

Your answer

9) El haber tenido varias oportunidades para resolver correctamente el reto "Combustibles para iluminación en caso de emergencia"me hizo sentir motivado para resolverlo otra vez. *

Totalmente de acuerdo

De acuerdo

En desacuerdo

Totalmente en desacuerdo 


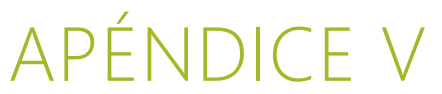

APÉNDICE V. CUESTIONARIO SOBRE DIMENSIONES DE LA GAMIFICACIÓN (INSTRUMENTO MODIFICADO).

Descripción: este es el instrumento del apéndice IV que fue modificado.

Percepciones sobre reto gamificado: Oportunidad de negocio en el sector energético

Estimado participante:

A través de este medio solicitamos tu apoyo para llevar a cabo un estudio que tiene como propósito mejorar el proceso enseñanza-aprendizaje de un curso MOOC, particularmente el estudio se centrará en el reto "Oportunidad de negocio en el sector energético"

La información recabada es para propósitos académicos, únicamente y se te asegura que no se utilizará ningún dato personal en ningún informe o publicación que se genere a partir del estudio. Tus respuestas serán tratadas en forma estrictamente confidencial.

Agradecemos tu valiosa participación en este estudio.

POLÍTICAS DE PRIVACIDAD:

https://tec.mx/es/politicas-de-privacidad-del-tecnologico-de-monterrey

AVISO DE PRIVACIDAD:

https://tec.mx/es/avisos-de-privacidad

* Required

Escribe tu usuario o correo del curso La Reforma Energética y sus Oportunidades. *

Your answer

Selecciona tu género *

Hombre

Mujer

Selecciona tu nivel de estudios *

Preparatoria

Estudios técnicos

Universitario (licenciatura o ingeniería) 
Maestría

Doctorado

Selecciona tu actividad actual *

Estudio

Trabajo

Estudio y trabajo

Selecciona tu edad *

Entre 16 y 20 años

Entre 21 y 30 años

Entre 31 y 40 años

Entre 41 y 50 años

Entre 51 y 60 años

Mas de 60 años

Other:

1) La retroalimentación inmediata por parte de la platafoma en la actividad del reto gamificado "Oportunidad de negocio en el sector energético" me dieron oportunidad de analizar mejor mi respuesta antes de volver a responder. *

Totalmente de acuerdo

De acuerdo

En desacuerdo

Totalmente en desacuerdo

2) Resolver el reto gamificado "Oportunidad de negocio en el sector energético" me ayudó a comprender mejor los temas relacionados a esta actividad. *

Totalmente de acuerdo

De acuerdo

En desacuerdo

Totalmente en desacuerdo

3) El nivel de dificultad del reto gamificado me pareció adecuado a mis conocimientos sobre el tema. * 
Totalmente de acuerdo

De acuerdo

En desacuerdo

Totalmente en desacuerdo

4) El reto gamificado favoreció mi desempeño en el examen final. *

Totalmente de acuerdo

De acuerdo

En desacuerdo

Totalmente en desacuerdo

5) Ver el tablero de liderazgo me motivó positivamente a resolver el reto gamificado. *

Totalmente de acuerdo

De acuerdo

En desacuerdo

Totalmente en desacuerdo

6) Ver los resultados de mis compañeros y el mío en el tablero de liderazgo me hizo sentir motivado para resolver más ejercicios de este tipo. *

Totalmente de acuerdo

De acuerdo

En desacuerdo

Totalmente en desacuerdo

7) Me hubiera gustado resolver el reto gamificado de manera colaborativa. *

Totalmente de acuerdo

De acuerdo

En desacuerdo

Totalmente en desacuerdo

8) Me hubiera gustado que mis compañeros leyeran mi propuesta alternativa al reto gamificado.

Totalmente de acuerdo

De acuerdo 
En desacuerdo

Totalmente en desacuerdo

9) El haber obtenido una insignia de trofeo de oro, plata o bronce en el reto me hizo sentir muy bien. *

Totalmente de acuerdo

De acuerdo

En desacuerdo

Totalmente en desacuerdo

10) El haber tenido varias oportunidades para resolver correctamente el reto gamificado me motivó positivamente para resolverlo otra vez. *

Totalmente de acuerdo

De acuerdo

En desacuerdo

Totalmente en desacuerdo

11) Resolver correctamente el reto gamificado me hizo sentir muy bien.

Totalmente de acuerdo

De acuerdo

En desacuerdo

Totalmente en desacuerdo

12) Competir para ganar un trofeo me provocó una emoción positiva

Totalmente de acuerdo

De acuerdo

En desacuerdo

Totalmente en desacuerdo

13) ¿De qué manera resolver el reto gamificado contribuyó a tu aprendizaje?

Your answer

14) ¿De qué manera afectó tu desempeño en el reto gamificado cuando supiste que tu resultado aparecería en un tablero de liderazgo? 
Your answer

15) ¿Qué tipo de emoción sentiste cuando recibiste un trofeo por haber respondido correctamente el reto gamificado?

Your answer

16) Escribe una propuesta o solución alternativa al reto gamificado "Oportunidad de negocio en el sector energético". *

Your answer

17) ¿Qué sugieres para mejorar la actividad del reto gamificado “Oportunidad de negocio en el sector energético"? *

Your answer 


\section{APÉNDICE VI}

\section{APÉNDICE VI. FORMATO PARA LA SOLICITUD DE ARCHIVOS DE DATOS DE}

\section{LA PLATAFORMA MEXICOX PARA LA PRIVACIDAD DE DATOS.}

Descripción: Este apéndice muestra el formato para la protección de datos de los participantes.

Formato de solicitud de entrega de archivos de datos de la Plataforma MéxicoX

Nombre del solicitante: Elvira Guadalupe Rincón Flores

Nombre de los cursos: La reforma energética y sus oportunidades, Energias convencionales, limpias y su tecnologia, Mercados de energía: oportunidades de negocio, La nueva industria eléctrica en México, Ahorro de energía, Energía eléctrica: conceptos y principios básicos, Mercados de carbono: una forma de mitigar el cambio climático, Energía: pasado, presente y futuro. Número de impartición: 02

Proyecto: Laboratorio Binacional para la Gestión Inteligente de la Sustentabilidad Energética y la Formación Tecnológica.

Archivos:

Student_profile_info.csv

Problema_grade_report.csv

Grade_report.csv

Privacidad de los datos y políticas de uso

Es responsabilidad del equipo docente (profesor, tutor), y administradores, el buen uso y resguardo de los datos sensibles del alumno como: identificación personal (ID), nombre del alumno, dirección de correo electrónico y otros datos de índole personal, de los cuales tienen acceso por el uso de los archivos de la plataforma MéxicoX.

El uso y manejo de estos archivos es para propósitos académicos, únicamente. Es responsabilidad del equipo docente y de los investigadores conocer y aplicar las políticas de privacidad y uso de la información del Tecnológico de Monterrey.

- POLÍTICAS DE PRIVACIDAD

- AVISO DE PRIVACIDAD

Está prohibido:

- Compartir información de identificación personal u otros datos con terceros sin la aprobación previa del alumno.

- Contactar al alumno sin previa autorización.

Fecha de solicitud: 3 de noviembre del 2017

Firma del solicitante:

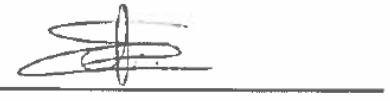




\section{APÉNDICE VII}

\section{APÉNDICE VII. RÚBRICA PARA ANÁLISIS SIGNIFICATIVO DE LAS}

\section{RESPUESTAS ALTERNATIVAS AL RETO GAMIFICADO.}

Descripción: Este apéndice muestra la rúbrica que se diseñó con base en la literatura para evaluar las propuestas de innovación de los participantes, la cual fue dada como solución alternativa al reto.

Rúbrica de evaluación de innovación potencial, elaboración propia con base en los modelos de Eckerl y Kezer (2011), García Fanjón y Rodríguez, (2010), y Lozano-Rodríguez y Gallardo (2017) y Schwartz et al., (2005).

\begin{tabular}{|c|c|c|c|}
\hline Atributos & Nivel 1 & Nivel 2 & Nivel 3 \\
\hline Impacto & $\begin{array}{l}\text { Se observa una relativa } \\
\text { ventaja con respecto a } \\
\text { lo que ya se hace, } \\
\text { tiene una baja } \\
\text { profundidad y baja } \\
\text { extensión, es decir, su } \\
\text { influencia es mínima. }\end{array}$ & $\begin{array}{l}\text { Se percibe que la } \\
\text { innovación mejora lo } \\
\text { que ya se hace e } \\
\text { impacta el entorno } \\
\text { inmediato del } \\
\text { participante. }\end{array}$ & $\begin{array}{l}\text { Se percibe que la } \\
\text { innovación mejora lo } \\
\text { que ya se hace y su } \\
\text { impacto va más allá } \\
\text { del entorno inmediato } \\
\text { del participante, como } \\
\text { puede ser su } \\
\text { comunidad, su ciudad } \\
\text { o su país. }\end{array}$ \\
\hline Claridad & $\begin{array}{l}\text { La propuesta resulta } \\
\text { compleja porque no es } \\
\text { comprensible o } \\
\text { aplicable. }\end{array}$ & $\begin{array}{l}\text { Se comprende en qué } \\
\text { consiste la propuesta } \\
\text { pero su aplicación no } \\
\text { es factible u } \\
\text { observable. }\end{array}$ & $\begin{array}{l}\text { Se comprende en qué } \\
\text { consiste la propuesta, } \\
\text { su aplicación es } \\
\text { factible y observable. }\end{array}$ \\
\hline Conocimiento & $\begin{array}{l}\text { Aunque sea una nueva } \\
\text { idea no se puede } \\
\text { considerar como } \\
\text { innovadora ya que } \\
\text { carece de fundamento } \\
\text { teórico. }\end{array}$ & $\begin{array}{l}\text { La propuesta está } \\
\text { fundamentada } \\
\text { teóricamente pero no } \\
\text { fue desarrollada } \\
\text { acorde a las } \\
\text { necesidades del } \\
\text { entorno. }\end{array}$ & $\begin{array}{l}\text { La propuesta está } \\
\text { fundamentada } \\
\text { teóricamente y es } \\
\text { compatible a los } \\
\text { valores y necesidades } \\
\text { del entorno. }\end{array}$ \\
\hline Tipo de innovación & $\begin{array}{l}\text { La propuesta } \\
\text { corresponde a una } \\
\text { Innovación Incremental } \\
\text { o Evolutiva, ya que } \\
\text { mejora lo que ya se } \\
\text { hace. }\end{array}$ & $\begin{array}{l}\text { La propuesta } \\
\text { corresponde a una } \\
\text { Innovación Incremental } \\
\text { y Abierta ya que } \\
\text { además de mejorar lo } \\
\text { que ya se hace, se } \\
\text { desarrolló dentro de } \\
\text { una dinámica de } \\
\text { innovación abierta. }\end{array}$ & $\begin{array}{l}\text { La propuesta } \\
\text { corresponde a una } \\
\text { Innovación Disruptiva } \\
\text { y/o Abierta, pues } \\
\text { además de ser } \\
\text { revolucionaria es } \\
\text { económica y simple, es } \\
\text { decir, está al alcance } \\
\text { de una gran cantidad }\end{array}$ \\
\hline
\end{tabular}


de personas. Pudo

generarse en una

dinámica de

Innovación Abierta.

\begin{tabular}{|c|c|c|c|}
\hline Tipo de innovador & $\begin{array}{l}\text { Innovador novato, ya } \\
\text { que a partir de la } \\
\text { propuesta se muestra } \\
\text { que reconoce } \\
\text { oportunidades para el } \\
\text { cambio y la mejora a } \\
\text { través de la innovación } \\
\text { pero no se encuentra } \\
\text { inmerso en el proceso } \\
\text { de experimentación y } \\
\text { divulgación de manera } \\
\text { formal. }\end{array}$ & $\begin{array}{l}\text { Innovador en proceso, } \\
\text { ya que hay evidencia } \\
\text { de involucramiento } \\
\text { dentro de la dinámica } \\
\text { del proceso de } \\
\text { innovación, en cuanto } \\
\text { a experimentación y } \\
\text { divulgación de manera } \\
\text { formal. }\end{array}$ & $\begin{array}{l}\text { Innovador experto, } \\
\text { existe evidencia de } \\
\text { que el sujeto dirige y } \\
\text { evalúa los proyectos } \\
\text { de innovación de } \\
\text { otros. }\end{array}$ \\
\hline
\end{tabular}




\section{APÉNDICE VIII}

\section{APÉNDICE VIII. RESPUESTAS SINTETIZADAS DE LAS ENTREVISTAS A}

\section{EXPERTOSEX.}

Descripción: La tabla muestra el condensado de las respuestas a las entrevistas a los expertos sobre el papel innovador del reto gamificado aplicado en el xMOOC energía.

\begin{tabular}{|c|c|c|c|}
\hline \multirow{3}{*}{ EXPERTOS } & & \multicolumn{2}{|l|}{ PREGUNTAS } \\
\hline & $\begin{array}{l}\text { ¿Cuál fue el costo del desarrollo } \\
\text { del reto gamificado? Es decir, el } \\
\text { desarrollo del tablero qué costo } \\
\text { tuvo. }\end{array}$ & $\begin{array}{l}\text { Con base en la pregunta anterior, } \\
\text { ¿puedes decir que la innovación } \\
\text { se puede aplicar en cualquier otro } \\
\text { MOOC de la institución o en } \\
\text { cualquier otra plataforma } \\
\text { (Coursera, Edx, etc) }\end{array}$ & $\begin{array}{l}\text { Desde tu perspectiva y experiencia con } \\
\text { los MOOC, ¿crees que el reto } \\
\text { gamificado sea una estrategia } \\
\text { innovadora en el tipo xMOOC? }\end{array}$ \\
\hline & $\begin{array}{l}\text { El costo del desarrollo tecnológico } \\
\text { se puede integrar por a) la compra } \\
\text { del espacio en servidor de } \\
\$ 3,000.00 \text { pesos por tres años, b) } \\
\text { las horas hombre de desarrollo } \\
\text { tecnológico y desarrollo } \\
\text { instruccional que fueron } \\
\text { alrededor de } 100 \text { horas y } 60 \text { horas } \\
\text { respectivamente }\end{array}$ & $\begin{array}{l}\text { Con un previo análisis el tablero sí } \\
\text { se pudiera adaptar para otras } \\
\text { plataformas }\end{array}$ & $\begin{array}{l}\text { Con base en las definiciones de } \\
\text { innovación, yo pienso que es } \\
\text { innovación incremental. }\end{array}$ \\
\hline Diseñador instruccional & $\mathrm{x}$ & Si es posible & $\begin{array}{l}\text { Desde mi punto de vista, el reto sí es } \\
\text { una innovación disruptiva, pero cuando } \\
\text { tiene las características que se le } \\
\text { imprimen en las experiencias i; las } \\
\text { actividades que realizamos en los } \\
\text { MOOC llevan como títulos "retos" pero } \\
\text { por las limitantes de la plataforma y la } \\
\text { característica de los cursos no se } \\
\text { cumplen con las características } \\
\text { deseadas. }\end{array}$ \\
\hline Desarrollador tecnológico & $\mathrm{x}$ & $\begin{array}{l}\text { El concepto es aplicable en } \\
\text { cualquier otro MOOC, pero el } \\
\text { desarrollo debe ser compatible } \\
\text { con la plataforma, pues no todas } \\
\text { las plataformas permiten la } \\
\text { interacción de sus datos con } \\
\text { procesos externos como es el caso } \\
\text { del Tablero. }\end{array}$ & $\begin{array}{l}\text { Considero que si es una estrategia de } \\
\text { innovadora debido a la aplicación de } \\
\text { gamificación con un número de } \\
\text { participantes tan alto y por la } \\
\text { visualización de resultados a todos los } \\
\text { participantes logrando así la motivación } \\
\text { entre ellos. }\end{array}$ \\
\hline Profesor & $x$ & $\mathrm{x}$ & $\begin{array}{l}\text { Sí es innovador aunque podría } \\
\text { mejorarse. }\end{array}$ \\
\hline Investigador & $\mathrm{x}$ & $\begin{array}{l}\text { La estrategia didáctica se puede } \\
\text { aplicar en otros MOOC, tanto } \\
\text { xMOOC como cMOOC. }\end{array}$ & Es una estrategia incremental. \\
\hline
\end{tabular}




\section{APÉNDICE IX}

APÉNDICE IX. TRANSCRIPCIONES DE LAS ENTREVISTAS REALIZADAS A EXPERTOS.

Descripción: el apéndice IX muestra las transcripciones de las entrevistas con respecto al trabajo interdisciplinario en el desarrollo de los XMOOC energía.

\section{A) Entrevista a experto en contenidos.}

\begin{tabular}{|l|l|}
\hline \multicolumn{2}{|l|}{ ENTREVISTA \# 1} \\
\hline $\begin{array}{l}\text { ROL: } \\
\text { Coordinador de MOOC } \\
\text { (Experto en contenido) }\end{array}$ \\
\hline MOOC que coordinó & Experto en temas de sustentabilidad energética \\
\hline Coordina entrevista & Energías convencionales, limpias y su tecnología \\
\hline Equipo de entrevista & Dr. Antonio Valdivia \\
\hline Fecha & $\begin{array}{l}\text { Mgtr. Ruth Minga } \\
\text { Mgtr. Gioconda Riofrio }\end{array}$ \\
\hline Hora: & Miércoles 22 de febrero \\
\hline Ubicación: & $14: 30$ \\
\hline
\end{tabular}

1. El rol con el que usted participó en el curso fue el de experto en contenido. ¿Con quién más trabajó, con qué otros participantes? ¿Qué roles cumplían este equipo con el que trabajó?

El equipo estuvo cambiando durante el proceso. El MOOC que me tocó a mí en particular empezamos muy atrasados porque había un profesor encargado que no pudo participar, entonces ya todos iniciaron y yo inicié con más de un mes de retraso. Me asignaron a una persona experta que le llaman Diseñador Instruccional y esa persona cambió durante el proceso, cambió porque se saturó con trabajo con otros MOOC en los que estaba trabajando. Yo tuve tres diseñadores que me estuvieron apoyando.

\section{¿Alguna otra persona del equipo?}

En términos generales las personas muy profesionales, la mayoría del tiempo Gaby Ábrego, muy intensa porque trabajaba conmigo hasta dos veces por semana y siempre me estaba recordando de las fechas límites. Después con las últimas personas también bien, pero fue menos tiempo con las que trabajé con ellas. Respecto a la gente por ejemplo del estudio también muy profesionales, se ve que tienen mucha experiencia, me ayudaban mucho porque yo nunca había hecho grabaciones previas. Había trabajado en transmisiones satelitales donde no hay script, donde no tiene que salir todo a la perfección, en vivo es diferente. Acá tiene que salir muy bien todo, entonces ellos se encargaban de ayudarme y no sé identificar a las personas porque siempre que iba a grabar eran diferentes. Eran del equipo de producción, la persona que medía los tiempos y coordinaba, siempre lo cambiaban, pero todos muy bien, muy profesionales. 
Y de Diseño Gráfico ahí tengo varios comentarios que son oportunidades. Nos daban una plantilla y esa plantilla es un poquito incómoda de manejar porque al final me quedaban documentos extremadamente grandes y es muy difícil manejarlos por correo electrónico o en la nube, entonces era bastante complicado y otro punto es que se supone que estas personas nos iban a apoyar para hacer animaciones para hacer dibujos y cosas de ese estilo, pero nunca tuve una comunicación directa. Al principio Gaby me sugirió algunos lugares donde la gente encargado de diseño tomaba imágenes y que trate de ver si hay imágenes que se puedan utilizar. Yo hacía mis diseños. Tomaba imágenes y le agregaba algunas cosas, pero nunca tuve contacto con ellos, yo se los mandaba y les decía esto es lo que quiero, estas imágenes tienen estos números, localícenmelas. Nunca hubo un proceso de retroalimentación, que me digan profesor aquí ya está el producto final, cree que esté bien o cree que esté mal, pero creo que fue por la cuestión de los tiempos, estábamos demasiado apurados y me imagino que ellos confiaban que lo que estaban haciendo estaba bien porque nunca me pidieron que diera el visto bueno, o a lo mejor yo hice tan bien el trabajo que ellos no batallaron.

Las áreas de oportunidad son en la plantilla porque cuando tú estás redactando lo que vas a decir a la hora de la grabación, hay imágenes y animaciones que ya estaban en una base de datos que ellos nos dijeron que de ahí escogiéramos y era muy difícil para mí insertar en el documento. La plantilla no está bien hecha, por eso se me ocurrió a la hora de estar redactando abrir un paréntesis, poner un numerito de la imagen y luego anexarla al documento. Cualquier persona que trabaja en diseño, puede diseñar mejor esa plantilla que sea más fácil de manejarla.

\section{Entonces, ¿se puede decir que estas son áreas de mejora para futuros proyectos?}

Como a mí me tocó desarrollar varios módulos, en los últimos ya no batallé, porque ya sabía cómo hacerlo. Es más todo lo que eran los dibujos yo hacía una presentación en ppt en donde ponía todos los diagramas y animaciones y en el documento general nada más lo describía y les decía les voy a anexar el archivo adjunto y de ahí saquen las imágenes.

\section{Tengo entendido que este trabajo multidisciplinario para desarrollar un curso, es la primera experiencia que están teniendo. En este caso es la primera experiencia suya trabajando con diferentes personas. ¿Cómo cree que le ha impactado en su quehacer docente, para planificar un curso, como crecimiento personal y profesional?}

A mí me gustó la experiencia, yo creo que si los profesores se animan a participar es una muy buena

experiencia en todos los aspectos, incluso te abre posibilidades para tus mismos cursos que no son en línea, de adaptar algunas cuestiones, de mejorar algunos materiales que tú ya tienes porque cuando tu trabajas en un mooc la información tiene que ser muy directa, muy concisa y los expertos por lo general nos gusta detallar demasiado las cosas, entonces aquí tienes que hacer un juicio de qué es lo relevante, que lo tengo que decir en un tiempo limitado, o sea los videos no pueden ser más largos de seis minutos. 
Entonces se puede decir que ese punto de vista de otras personas, por ejemplo la persona que hace los videos le está dando una directriz de seis minutos, estos son los lineamientos, ¿se puede decir que le enriqueció su perspectiva para desarrollar cursos?

3. En cuanto al trabajo que se dio, cómo compara con el trabajo autónomo. El tener toda la libertad en comparación de trabajar con un equipo. Le cambió la perspectiva, prefiere el trabajo autónomo.

Hay ocasiones en las que es mejor trabajar solo, pero en este tipo de proyectos definitivamente necesitas al grupo, sino, no sacas al proyecto en el tiempo que te dijeron. Es bien difícil, pero aquí se necesita el grupo. Si siento que todavía hay muchas ineficiencias, porque veo que hay mucha gente, entonces a mí no me quedaba claro el rol de todos esos participantes, sé que están metidos en muchos proyectos y esa es la razón de que existan, pero no me quedaba claro quién era el responsable, el encargado.

4. Puede decir que este tipo de trabajo fue un reto? ¿Qué le pareció?

Fue un reto. A mí me gustan los retos, es una experiencia más.

5. Ahora en base a lo que comentaba, considera usted que debería integrarse un equipo con todos los actores, con la gente que no conoció, que no tuvo comunicación directa o que continuamente se fueran integrando en el desarrollo del curso. ¿Cómo considera usted?

Creo que es necesario tener una visión global desde el principio. En mi caso yo me incorporé tarde al proyecto, a lo mejor por eso faltó esa parte, de que no conocía cómo funcionaba inicialmente todo el grupo, entonces mi recomendación es que cuando una persona planee un tipo de este curso mooc es que el que está coordinando el mooc, le pongan un auxiliar que sea emergente, en el caso de que alguien deja, que le dé continuidad, porque si lo dejan como en este caso y había que retomar después de un tiempo, se acumula el trabajo y había responsabilidad, había que cumplir con las fechas y a eso no le preguntan si entró tarde al proyecto. Se reportan y hay que acabarlo. Es demasiado estrés.

En cuando a esas vicisitudes que comenta. En la dinámica para el resultado, ¿cómo cree que fue el liderazgo, en la organización de tareas, se solventó rápidamente?

Ahí le daría el mérito a mi jefe, el Dr. Alberto Mendoza dijo hay que hacer un plan para resolver el problema. Me dijo cuenta con mi apoyo, entonces todo el grupo de enfoque, los profesores se comprometieron a apoyarnos y me dio la autoridad de poderles pedir que nos apoyaran. Fue clave el papel de él como líder. 
Entonces nada más que esté bien definido el líder y que este líder tenga autoridad sobre las personas que están apoyando en el proyecto.

6. En relación con los contenidos del curso, cómo visualiza usted que está dirigido para unos participantes que tienen un alto conocimiento en energía, medio.

A nosotros nos dijeron que tenía que ser para una persona que tenía un nivel de educación de preparatoria para arriba, entonces dijimos todo el contenido que vamos a desarrollar es para una persona que salió de preparatoria, eso no quiere decir que alguien de secundaria no lo pueda entender. Si hay material muy digerible incluso para los muchachos de secundaria, pero no está diseñado así. Alguien que trabaja en el sector legal y que anda haciendo algo de energía lo puede tomar y se puede enterar de cómo está la situación de energía. Si hay un experto por ejemplo en combustibles fósiles, también lo puede tomar para que vea el punto de vista de otros expertos. Para mí es un curso que va dirigido a la sociedad, a cualquier persona que esté interesado en saber más de la energía, porque hay mucha desinformación. La energía se ha politizado demasiado, de hecho todas las guerras están relacionadas con la energía, entonces lo mejor es informar y así se pensó este curso para cualquier persona.

7. Estos cursos que inicialmente se ofertaron, son autodirigidos, es decir, no tienen la presencia de un tutor que les apoye. Su opinión muy personal respecto al tema que se está impartiendo ¿Considera que amerita una retroalimentación permanente a los participantes o está bien el enfoque planteado?

Como estamos arrancando yo creo que ahora si debe haber una persona que esté cerca, para ver si está avanzando como nosotros habíamos diseñado el curso. Sé que hay gente que está en el doctorado y que está tratando de hacer ese seguimiento. El ciclo pasado se me pidió que sugiera una persona que pueda estar al pendiente de las contribuciones, sugerí alguna persona pero no sé si está trabajando o no. Tengo entendido que le están dando seguimiento. Desde mi punto de vista se le debe hacer seguimiento ahora.

¿Este seguimiento usted lo recomendaría para la interacción que surge para los foros de discusión?

$\mathrm{Si}$

Retroalimentación general que pueda dar.

Me sentí estresado, pero volvería a participar. Ahora ya sé y es más fácil. Se le dedica mucho tiempo porque tienes que estar pensando en lo que piensa la persona que está leyendo, es difícil. Me tomó tres meses, dos fueron muy duros porque tuvimos que conseguir gente que nos apoyara del mismo grupo de enfoque para tener material y luego revisarlos. Hubo un profesor que nos ayudó con la parte de energía eólica y cuando le dijimos de la idea se enamoró del proyecto, nos dijo si les apoyo, pero cuando nos mandó el material era un libro. Ahí lo que tuvimos que hacer es tomar el material de él, seleccionar lo importante y luego tuvimos que ponerlo alcanzable para el alumno. Se necesita ser un experto para hacer que el maestro 
que conceptualizó la idea no sienta que fue inútil lo que el hizo. Todo lo que había dicho lo pusimos, pero lo aterrizamos, lo bajamos de nivel para que lo pudiera entender un muchacho de preparatoria en el tiempo a como estaba diseñado. Entonces le tuvimos que dedicar mucho tiempo a eso, porque cuanto tú lo haces es más fácil.

Tengo que ver el curso, soy bien crítico y no me gustan que las cosas salgan mal. Me gustó mucho la experiencia y si me volvieran a invitar yo diría que sí, nada más que esté desde el principio.

\section{B) Experto en diseño instruccional}

\begin{tabular}{|c|c|}
\hline $\begin{array}{l}\text { ROL: } \\
\text { Diseño Instruccional }\end{array}$ & Diseñador instruccional \\
\hline Coordina entrevista & Dr. Antonio Valdivia \\
\hline Equipo de entrevista & $\begin{array}{l}\text { Maestra Elvira Rincón } \\
\text { Mgtr. Roberto Carlos Cuenca } \\
\text { Mgtr. Ruth Minga } \\
\text { Mgtr. Gioconda Riofrio }\end{array}$ \\
\hline Fecha & Jueves 23 de febrero \\
\hline Hora: & $12: 00$ \\
\hline Ubicación: & Edificio CEDES Sala de Juntas 1 \\
\hline
\end{tabular}

\section{1. ¿Cuál es su trabajo como diseñador instruccional?}

Podemos hablar de diferentes roles de diseñadores instruccionales en varias empresas, pero en el Tec de Monterrey se trata de conocer por nuestra cuenta el modelo pedagógico o el modelo instruccional con el que partimos. Los DI somos los que orientamos al profesor a llevar a cabo su curso, teniendo en cuenta las disponibilidades tecnológicas y la herramienta o la plataforma en la que se va a impartir, así como el modelo pedagógico y haciendo un balance con el contenido. Podríamos decir, nos basamos mucho o tenemos que desarrollar ese aspecto del technological pedagogical content knowledge (tpack) porque debemos hacer un balance entre esto, que el contenido se pueda interpretar por los estudiantes y tener un balance entre los aspectos didácticos y pedagógicos con lo tecnológico. Mi misión es esa.

\section{En esta experiencia de cursos $M O O C$ ¿Con quién más trabajó, con qué otros participantes? ¿Qué roles cumplían este equipo con el que trabajó?}

Aquí un DI lo que tenemos son células de producción entonces nosotros tenemos una comunicación constante con el experto en contenido porque es quien nos va a estar dando la materia prima que es el contenido en bruto. También tenemos mucho contacto con la arquitecta pedagógica que es la persona que diseñó el modelo y que nos hace sugerencias o que nosotros podemos acercarnos a preguntarle si esto se puede hacer o no. Tenemos contacto con los diseñados gráficos ya que ellos se van a encargar de los efectos visuales, con los encargados de programación web ya que todo se monta en una plataforma y también con las personas de producción audiovisual tanto con productores como pos productores. 


\section{¿En esta experiencia específica de los MOOC han trabajado todos juntos en reunión o por partes?}

Depende de qué es el punto que se quiere abordar. Por ejemplo el diseño del curso tiene muchas etapas, en primera es un trabajo directo con los profesores entonces de cierta manera se invita a reuniones a algunas personas expertas en producción de video, de producción audiovisual, de diseñadores gráficos, para que también vayan aportando y ellos vayan haciendo recomendaciones de cómo se puede ver mejor, de cómo se van a implementar los videos, pero no en todas las sesiones de trabajo vamos a estar todos juntos porque somos un equipo muy grande, multidisciplinario. Entonces como vamos avanzando, primero es el desarrollo del contenidos, después es ir haciendo elementos como guiones de video, después se producen y se editan, hay otras etapas en las que como DI te llega el contenido, lo trabajamos le damos esa forma ese sentido para que vaya de acuerdo al modelo y se dan todas las instrucciones en un documento o en un documento que se llama guion master que es el guion de DI. A partir de eso nosotros hacemos las instrucciones para mandarlo con el diseñador gráfico y el programador web para que ellos vayan identificando "de este componente me está pidiendo que haga un pdf, de este un html con interactividad y de este que haga una infografía". Entonces se les va dando las instrucciones y trabajamos de manera asíncrona, a distancia, aunque estamos en un mismo edificio no estamos en la misma sala. La comunicación es por correo electrónico más que nada.

\section{En su opinión en esta forma de trabajar en equipo cómo considera que es más adecuado o que observaciones tiene en cuanto a comenzar a trabajar todos desde un inicio o que se vayan integrando. ¿Cuál sería su opinión sobre esta dinámica?}

Bueno hay que ver si se puede o no por los espacios en las instalaciones en las que estamos, no podríamos traernos a los de producción audiovisual y que cada proyecto de Tec tuviera una celula de producción en conjunto, por las mismas instalaciones. Si es ideal que estemos de manera cercana, que podamos entablar comunicación de manera directa y resolver dudas de manera más ágil, obviamente le daría más fluidez a la producción y al diseño, pero a veces tenemos horarios distintos, entonces no se puede. Creo que es buena la forma de trabajo que tenemos, porque se ha realizado muchas actividades, muchos proyectos se realizan así, no es necesario hacerlo de forma presencial y esto sirve también para tener evidencias, si yo mando un correo electrónico a uno de los diferentes roles me respaldo; yo pedí esto y está trabajando de otra manera. Si nada más me comunico con las personas de manera directa puede que se nos olvide. Entonces las dos opciones son válidas dependiendo del equipo, cada una necesita desarrollar diferente competencias. La comunicación es esencial y darse a entender bien.

4. En cuanto a la participación en el equipo de trabajo, cómo es el liderazgo en diseño de tareas, organización del equipo, etc. 
Hay una persona que se encarga de esas situaciones, es la administradora de proyectos y aparte está la líder de proyecto. Hay muchos roles en este tipo de proyecto, entonces la líder de proyecto lleva un control general de todo este proyecto en este caso es Mónica Bilbao, que va viendo los tiempos los avances, los detalles que van surgiendo como los podemos resolver y la administradora del proyecto es la que lleva el control de que está haciendo cada rol, es la que manda las órdenes de producción cuando se tiene que hacer un video. Tiene que hacer una solicitud para que nos den un espacio de tiempo, nos den un productor y equipo para realizarlo, entonces es parte de su tarea, el administrar todos esos aspectos.

\section{Áreas de oportunidad, ventajas como participante...}

Las personas que están encargadas tienen amplia experiencia, porque han pasado por los roles de DI y han ido escalando y conocen como es este sistema. En la etapa 1 hubo una situación en la que nos atrasamos en tiempos, entonces nos quedamos con dos meses para realizar los cursos, sin embargo esta fue una situación más que nada de CONACYT y el Tec, entonces la administradora del proyecto y la líder estaban en espera de que nos den una respuesta clara, porque no podíamos comenzar a realizar algo sin haberse dado ya la autorización. Entonces nos enfrentamos en un reto de sacar un curso con todas las complicaciones que conlleva un MOOC de energía en dos meses y se logró el objetivo, entonces estas personas tuvieron una buena forma de resolver las cosas, haciendo uso de recursos tanto humanos materiales y de espacios, pero lo supieron resolver. Las áreas de oportunidad siempre va a haber hay detalles obviamente que por las premuras de tiempo va a haber como falta de comunicación, pero creo que si teniendo el tiempo todo esto fluye de manera eficaz.

\section{5. ¿Cómo cree que le ha impactado en lo personal y profesional?}

Yo tengo una formación de investigación educativa, soy maestro en esa área. Cuando llegué aquí entré en otro proyecto, entonces es muy diferente tanto la redacción, la forma de escribir en educación a distancia, es muy diferente a la forma como estaba acostumbrado a redactar, utilizando citas, formato APA, utilizando un lenguaje más profesional y aquí se busca algo más coloquial, hacerlo más ameno para personas que a veces no tienen los conocimientos que están buscando adquirir. Eso fue el primer choque y fue enriquecedor para mí, porque estoy interesado en estos temas, siempre me interesó el tema de los MOOC, incluso hace un año tuve una ponencia acerca de este tema, entonces era algo que me llamaba la atención. Cuando me llamaron a este proyecto me puso contento porque puedo llevar a la práctica, esas cuestiones teóricas las puedo ver reflejada en cuestiones prácticas. Entonces para mí ha sido algo muy interesante. Mi plan a futuro es estudiar un doctorado entonces me siento enriquecido en estos temas porque puedo llevar a la práctica no nada más el tema de los MOOC sino aspectos pedagógicos y didácticos, como aprendizaje basado en retos, estrategias didácticas, uso de videos, uso de elementos visuales multimedios para desarrollar conocimientos, entonces en el aspecto profesional me he sentido muy satisfecho con miras a seguir avanzando seguir creciendo. 
Ser DI te brinda un montón de información porque para saberlo plasmar en un curso, primero para enseñarlo a alguien más, primero lo tienes que conocer tú, con la experiencia del mooc me quedo con conocimientos de los recursos energéticos y en este curso que estoy llevando estoy comprendiendo cosas sobre sistemas eléctricos, conceptos como voltaje, corriente, potencia. Empiezas a desarrollar un bagaje cultural en los temas que desarrollas. A mí me encanta esta profesión es muy reconfortante porque vas aprendiendo mucho, no te estancas.

\section{Alguna observación general de la experiencia que ha tenido en este proyecto.}

En particular que podría mencionar como DI es que estamos en un punto intermedio entre lo que el profesor a veces quiere, lo que la plataforma nos permite y lo que el cliente nos pide, entonces a veces es complicado y uno tiene que buscar las formas más amenas de solucionarlo para no llegar a tener choques con los diferentes roles con los que intervienes, necesitas tener desarrollado una competencia comunicativa eficaz y tener la capacidad para saber hasta donde puedes tomar decisiones, hasta donde puede consultar con otras personas, en qué momentos puedes intervenir y en que momentos necesitas el apoyo de alguien más. Entonces es un reto al que nos enfrentamos en estos cursos por la cantidad de gente que está involucrada, en estos en particular el rol del DI también tiene una modificación porque tienes que interactuar con las necesidades a veces de los tesistas, de la gente de la Escuela de Educación, con lo cambios que van pidiendo y aparte con lo que ya está establecido y lo que pide el experto. Entonces si es un reto, pero se me ha hecho muy interesante.

6. En este proceso como DI cuales han sido los aspectos más positivos del trabajo interdisciplinario en las células.

Hay bastantes, porque de todos vas aprendiendo desde aspectos teóricos como aspectos de la forma en que se desenvuelve cada rol de las personas de tu núcleo, de tu célula de producción con las tesistas, voy viendo una forma de interactuar con los profesores, voy viendo algunos aspectos que recomiendan cuando nos reunimos entonces también ellos aportan y eso me enriquece a mí. Con los profesores es el trabajo directo con ellos y me va haciendo conocer cada vez tener conocimientos de ese tema. Algo muy importante es que nosotros como DI no llegamos a imponer cómo vamos a hacer el trabajo, porque cada profesor es distinto; en este grupo que tenemos hay dos personas grandes de edad y otro que es más joven, sin embargo, el más joven es el que menos utiliza la tecnología y tienes que buscar las estrategias para lograr tu objetivo a partir de esas características, de su forma de trabajo y de interacturar entonces con cada uno de ellos vas desarrollando habilidades distintas.

En lo particular con mi célula de producción siento que aprendo mucho de la arquitecta que tiene un bagaje y también aprendo de diseño gráfico me voy imaginando cómo plasmarlo y considero mucho el aspecto gráfico, el aspecto visual porque es sumamente importante en la Educación a Distancia. La verdad se aprende todo. 
7. ¿Si tuviera la oportunidad de mejorar el trabajo interdisciplinario como DI que mejoraría?

Esos roles deben tener en claro cómo van a hacer la producción, entonces hay veces en las que se van haciendo adecuaciones y primero tienen que ponerse de acuerdo los especialistas, la arquitecta, los líderes, los clientes, con el departamento de diseño gráfico, de producción audiovisual para que a partir de eso nosotros podamos darles las recomendaciones a los profesores. Yo recomendaría que primero ellos trabajen ese aspecto de cómo piensan que va a quedar, para después nosotros poderle decir al profesor esto es lo que se está pidiendo, porque a veces se hace de una manera distinta estás trabajando con el profesor, lo traes al profesor y empiezas a trabajar y te dicen que al final así no era que estaban apenas desarrollando algo. Entonces creo que la comunicación en el flujo de trabajo es algo que se debe tomar muy en cuenta.

8. Al tener usted el rol de cuidar el modelo pedagógico del curso, estuvo tal vez la planificación y el desarrollo mismo con base en alguna teoría, enfoque de aprendizaje en particular.

Si en particular lo que me baso es a seguir el modelo establecido, la planeación y el diseño se hizo por arquitectura pedagógica y si se tomó en cuenta, por la herramienta que se está trabajando y por el diseño mismo tiende a ser conductista pero se busca aspectos constructivistas aunque sean limitados, pero se busca que se desarrollen. Un mooc siempre va a buscar que haya interacción entre estudiantes, entonces por eso se ha propuesto el uso de diferentes herramientas como son los foros de discusión, el networking así como la evaluación practica de evaluación entre pares, en donde los estudiantes hacen una actividad práctica y después cumplen el rol de evaluadores, evalúan las tareas de sus compañeros entonces llega a haber cierta interacción en la medida de lo posible.

9. Entonces con esta interacción y como modelo pedagógico ¿estaría encaminado hacia unas competencias, hacia unos objetivos o hacia unos resultados de aprendizaje que puedan encaminar de mejor manera? y ¿cuál sería la evidencia que ustedes tienen que el participante aprendió algo?

Está enfocado hacia objetivos. Medir una competencia a distancia en este caso es difícil entonces no podemos arriesgarnos. Cada curso tiene un objetivo general y cada tema tiene objetivos particulares. La forma en que nosotros vamos analizando si el estudiante está complementando estos objetivos es a través de las evaluaciones de tema o ejercicios que se van realizando. Cada tema tiene una evaluación así como un ejercicio de repaso que no se evalúa, es más que nada para que el estudiante refuerce los conocimientos y después si hay una evaluación al final de cada tema en la que el estudiante obtiene un puntaje a partir de las respuestas que dé. En el tema 3 empieza el ejercicio de evaluación entre pares y esto se entrega en la semana 5 del curso, entonces este se realiza o se diseña a partir del objetivo del curso, entonces el estudiante al realizar esta actividad pues está demostrando que está cumpliendo con el objetivo o parte 
del objetivo del curso. En el tema 6 hay un ejercicio de reto en el que se implementa gamificación y que también se obtiene a partir del objetivo, por ejemplo si en la semana 5 no se cumplió el objetivo en su totalidad la semana 6 se puede utilizar para irlo cumpliendo, así como en la semana 4 hay un ejercicio de una situación contextualizada en la que se le plasma al estudiante un caso en la que él tiene que asumir un rol, una decisión, entonces se va buscando el cumplimiento del objetivo a lo largo del curso a través de estos instrumentos que aportan valor a su calificación.

¿Se esperaría aprendizaje en la interacción de los foros de discusión?

Se esperaría pero como no hay tutor no podemos llevar un control como tal. Lo que se hace es darles unos temas de discusión para que sea libre su participación y ellos puedan desarrollar esa interacción, esa construcción del conocimiento social y al final se da una respuesta de lo que el tutor consideró como válido.

\section{C) Experto en innovación educativa e investigación}

\begin{tabular}{|l|l|}
\hline \multicolumn{2}{|l|}{ ENTREVISTA \# 3} \\
\hline $\begin{array}{l}\text { ROL: } \\
\text { Coordinación general del diseño de } \\
\text { los MOOC y Experta en Educación. } \\
\text { (Experto en contenido) }\end{array}$ & Investigadora en innovación educativa. \\
\hline MOOC que coordinó & Energías convencionales, limpias y su tecnología \\
\hline Coordina entrevista & Dr. Antonio Valdivia \\
\hline Equipo de entrevista & $\begin{array}{l}\text { Mgtr. Ruth Minga } \\
\text { Mgtr. Gioconda Riofrio }\end{array}$ \\
\hline Fecha & Miércoles 24 de febrero \\
\hline Hora: & $14: 30$ \\
\hline Ubicación: & Aulas 4 - Piso 1.5 \\
\hline
\end{tabular}

Rol en el curso MOOC:¿Cuál fue el rol que tuvo usted en el proceso y en diseño de los cursos y con quienes trabajaba en las reuniones, regularmente quiénes eran los participantes y qué roles tenían estas personas con quienes se reunía usted?

Tuve dos roles, un rol fue en la coordinación general de todo el diseño de los cursos MOOC, desde el inicio toda la estructura, entonces fue el trabajo con el equipo de IDEA donde están todos los productores, diseñadores y también los de energía; entonces, principalmente en ese rol era un rol macro, el gran paraguas; y ya concretamente en el diseño de uno de los cursos estuve trabajando con el experto de energía, Luis Serra, y estaban ahí los diseñadores instruccionales, productores. Esas reuniones se dieron a cabo en la distancia porque Luis está en la ciudad de México y yo estaba en Monterrey, todos estábamos distribuidos y mi rol ahí era escuchar cómo se estaba dando la instrucción para el experto en contenido y yo hacía mis intervenciones en mi papel de investigadora de innovación educativa, haciendo hincapié en determinadas cuestiones que debían tener los videos, los materiales, en su caso también la 
gamificación, las estrategias que iban a estar ahí, entonces ese era mi rol metiendo los tips para la innovación educativa.

1. Tengo entendido que esta es una nueva dinámica de trabajo que se presentó precisamente durante este proyecto, es una forma de innovación en cuanto a lo que es la dinámica de trabajo y contrario a como anteriormente tenía el Tecnológico de Monterrey y ha estado desarrollando los cursos que era más unidireccional, sobre esta base de trabajo en equipo me puede decir su perspectiva en cuanto a cómo ha impactado el trabajo en equipo, se ha enriquecido, qué cambios a áreas de oportunidad

Si fue un cambio porque normalmente estábamos acostumbrados a que era el diseñador instruccional con el experto pero ahora entramos un tercer componente que somos los de innovación educativa; entonces fue un cambio para los tres entes y digamos que las dificultades que yo encontraba era más del lado del equipo de diseño instruccional como para aceptar este tercer componente que del experto en contenido, como que para él era más normal que estuviera, pero a los del equipo de diseño instruccional, ya sea que se les olvidaba este tercer componente que entrábamos ahora y tanto es así que en las reuniones las agendaban y las acordaban con el experto en contenido y luego me informaban a mi como para de innovación, esta es la fecha de reunión, y yo le decía no, somos los tres componentes los que debemos llegar a hacer los acuerdos, entonces esas dificultades estaban.

Luego otra de las dificultades es que el equipo de diseño lo veo muy acostumbrado a las estructuras que llegan a establecer y les cuesta trabajo hacer cambio para hacer nuevos agregados que es lo que se necesita de parte de la innovación educativa, unas integraciones, unas modificaciones, recursos diferentes, estrategias diferentes y a ellos les cuesta más pensarlo, ahí yo veía la dificultad más en el equipo de diseño más que en el experto en contenido, no encontré dificultad en él en este cambio de diseño.

2. Cómo se trabajó precisamente este cambio de paradigma en función de trabajo, cómo se negoció

Se estableció por las necesidades del proyecto; el proyecto en sí al ser un proyecto de energía, de una temática muy específica, un gran acierto que tuvo es integrar el área de la investigación educativa y al entrar el equipo de investigación educativa y concretamente en la temática de innovación educativa, ese fue un desprendimiento, o sea fue como una necesidad del proyecto que provocó ese cambio en la forma de diseñar los cursos para tener las condiciones a su vez, posteriormente, para hacer esos estudios que requerimos.

3. Eso en cuanto a lo que es la tarea. En cuanto a la dinámica de grupo qué cambios hubo, o resistencias, motivaciones, la adaptación fue rápido.

Si, fue rápido, fue como muy normal, no hubo ninguna resistencia, fuer un elemento de que llegó establecido, vamos a funcionar de esta manera y entonces una aceptación sin resistencia 
y ya fue en el camino cuando no se entendía la dinámica y supongo que en la etapa 2 esto va a ser más transparente, más continuo; en la etapa 1 al ser el momento del cambio es cuando las dinámicas se veían de esta manera.

4. Con respecto precisamente a esta dinámica, en esta experiencia cómo considera usted que sea mejor en una práctica, integrar paulatinamente participantes de diferentes roles a lo que es el trabajo o desde un inicio.

Desde un inicio si, y creo que sería un acierto el argumentar la necesidad de estos tres componentes y que todos estemos en el entendido y los procedimientos pero fue algo que aprendimos todos cuando ya se dio la dinámica, el hecho que íbamos a funcionar de esta manera, en lo personal yo lo tenía muy claro, pero el otro componente de IDEA no lo tenía tan claro, lo había aceptado pero no sabía que estábamos en el mismo nivel de implicación los tres equipos dentro del diseño.

5. Cómo ha impactado su quehacer profesional, su perspectiva personal respecto a la forma de trabajar.

Siento que me ha enriquecido porque esa conversación de los tres elementos en un área tan distante para nosotros como es la energía, acostumbrados a lo que estábamos haciendo temáticamente en innovación educativa viene a ser un enriquecimiento para mí, es nueva mirada, nueva forma de construir las experiencias de aprendizaje a partir de la incorporación de un área de conocimiento completamente nueva y diferente.

6. Como profesora experta en el desarrollo de cursos, este se puede decir que es un nuevo modelo de trabajo donde se involucran profesores de otras áreas, la gente de innovación educativa, la gente propiamente del diseño instruccional IDEA, se podría exportar al campus para un quehacer propiamente de la formación docente para trabajar en nuevos cursos

Sí, yo creo que enriquecería mucho el proceso porque, hace un momento te acabo de hablar de mi enriquecimiento, quizá cuando los entrevisten a ellos el hecho de que los profesores de energía sepan cómo se les puede investigar lo que ellos están haciendo en una experiencia formativa también se descubren nuevas posibilidades para enriquecer sus áreas formativas y lo mismo en el área de diseño instruccional esa es mi perspectiva, entonces considero que se puede exportar, que sería muy benéfico porque nos ayudaría mucho a dar seguimiento, evaluación transversal a las innovaciones educativas que se estén haciendo.

7. Y en la experiencia, cómo en función del liderazgo, cómo transmitir esta nueva dinámica de trabajo, todos pensamos distinto, cada quien en su área tiene una forma de trabajar, cómo trabajar esa nueva cultura 
Creo que un elemento sustancial es documentar el proceso que estamos llevando a cabo para con evidencias nosotros poder argumentar en el momento que hiciéramos la propuesta de cambio hacia otros, entonces algo sustancial es esa documentación, esa investigación en el proceso, esa documentación que pasado mañana cuando lo presentemos no hablemos así no más de, fue muy positivo, sino aquí están los datos, de qué fue lo que provocó esta nueva manera de trabajar.

Desde mi perspectiva el liderazgo argumentado, el liderazgo sólido con experiencias y con evidencia empírica es lo nos puede llevar a una mayor aceptación y seguimiento de otros en las experiencias MOOC.

8. Se puede decir que hemos hablado del aprendizaje que se ha tenido y tengo entendido que va para una segunda etapa y posteriormente a lo mejor una tercera en este proyecto de energía, pero en la dinámica de trabajo, en la cultura qué retos ve para seguir avanzado en este nuevo modelo de hacer las cosas.

Pues los retos que yo encuentro es el tiempo, los profesores y todos estamos súper saturados y entonces el principal reto sería en ese aspecto.

Otro reto lo encuentro en el significado de mejora que puede traer para la experiencia, el tener conocimiento sobre el enriquecimiento que se puede llevar a cabo, entonces la falta de conocimiento es un reto y el llegar a convencerte, si no tienes ese conocimiento va a ser difícil el que se ejecute.

Otro reto lo encuentro en la coordinación para el trabajo colaborativo de los tres; no me refiero a posturas de estar en contra de compartir con otros, sino en la conversación que se tiene que tener para construir juntos, ahí es el reto, una cultura de colaboración, es el reto que tenemos que trabajar no solo en esta experiencia sino en todas en donde se incorporan innovaciones o cosas nuevas.

\section{OTRAS PREGUNTAS}

Entendemos que los cursos MOOC son un subproyecto del gran proyecto presentado a CONACYT, en este sentido se ha incluido en los cursos el área de innovación educativa, es está una fortaleza para haber presentado ante el organismo superior y haber aceptado el financiamiento de este proyecto, además que otros elementos estuvieron presentes para argumentar y lograr ese financiamiento.

Creo que por una parte fue lo de innovación educativa y otro que le interesaba mucho a CONACYT era la formación en el tema, entonces el hecho de los cursos masivos que ellos vieron también como un área innovadora, de poder llegar a miles y miles de participantes con la temática tan necesaria como es la energía ahí es donde le vieron el potencia y les gustó mucho. Formar y certificar a técnicos lo vieron como una posibilidad muy valiosa. 
Sí se pueden implementar, actualmente están como educación continua, entonces son como cursos aislados pero por ejemplo en lo personal, en mi curso, que es de maestría en tecnología educativa, el curso que yo doy se llama Teoría y práctica de la educación a distancia y se lo estoy poniendo a los alumnos el hecho de que se inscriban en esos cursos y se le daría puntos extras el que apruebe. Yo lo incorporo de esa manera porque era como una motivación y les dije a los alumnos van aprender al ser alumnos en esa experiencia lo que ustedes van a construir en este curso, en el curso ellos tienen que diseñar una experiencia a distancia, un pequeño MOOC y para esa construcción les sirve ver otra experiencia y vivirla para que no cometan errores que están acá o sigan ejemplos de buenas prácticas de lo de los cursos.

Tengo conocimiento que otros colegas de los de energía se los están poniendo, no dentro del plan de estudios pero sí como un elemento; si su curso dura cuatro unidades, una unidad es este curso MOOC.

\section{De la conversación con expertos en contenido, se observa una gran motivación por este trabajo para emprender y continuar con este tipo de actividades a futuro. Qué cree usted que ha influenciado para que ellos tengan esa alta motivación, los expertos en contenido.}

La motivación que ellos tienen creo que es porque descubrieron nuevas formas de hacer llegar lo que ellos enseñan. Ellos son súper profesores en presencial y algunos de ellos a distancia, pero los cursos $\mathrm{MOOC}$ son diferentes a los cursos a distancia, entonces encuentran una manera diferente de enseñar y un alcance mucho más grande que lo que están haciendo en presencial como en esos cursos a distancia. Su motivación estaría por ahí, llegar a miles y miles que les llevaría años y años hacerlo de manera presencial e incluso con los de distancia. El poder estar con más participantes, poder llegar a todo el mundo, de una manera abierta, cosa que no te da los cursos a distancia que están cerrados en blackboard solo para los alumnos de la institución y para los que están inscritos presencialmente.

9. Finalmente, si quiere compartirnos cómo impacto esta experiencia a su quehacer, a su persona

A mi esta experiencia me enriquece mucho en muchos sentidos, como profesora, en mi quehacer pedagógico, con mis creencias epistemológicas, filosóficas de la práctica educativa yo siento un enriquecimiento ahí porque veo nuevas potencialidades, nuevas formas que me permite pasado mañana transferir hacia las prácticas que tengo en la educación a distancia.

Por el lado de la investigación esta experiencia es muy motivante por todo lo que implica, poder generar nuevas maneras, nuevas formas, nuevas estrategias y ver relaciones a través de los participantes que lo estén llevando a cabo. También representa un reto en la investigación educativa por lo difícil que tenemos en la deserción, el hecho de que no terminan y no 
podemos dar seguimiento puntual a ciertos participantes pero si nos va a dar a la investigación educativa, datos valiosos que podemos aportar en el área temática.

En el área personal el participar en esta experiencia me deja un mayor conocimiento de escucha de asertividad, de buscar nuevas formas para lograr juntos el objetivo. 


\section{APÉNDICE X. PRODUCCIÓN CIENTÍFICA}

Rojas-López, A. Rincón-Flores, E.G.,Ramírez-Montoya, M.S., Mena, J. \& García-Peñalvo (In Press). Engagement in the course of Programming in Higher Education through the use of Gamification. Universal Access in the Information Society (UAIS).

Rincón-Flores, E.G, Mena, J., Ramírez, R. \& Ramírez-Montoya, M.S. (In Press). The use of gamification in a MOOC about energy: Effects and predictive models for participants' learning. Australasian Journal of Educational Tecnnology (AJET).

Mena, J, Rincón-Flores, E.G. \& Ramírez-Montoya, M.S. (2018). The Use of Gamification as a Teaching Methodology in a MOOC About the Strategic Energy Reform in México. En Di Masco, T., Vittorini, P., Gennari, R., De la Prieta, F., Rodríguez, S., Temperini, M., Azambuja-Silveira, R., Popescu, E., \& Lancia, L. (Eds), Methodologies and Intelligent Systems for Technology Enhanced Learning, 8th International Conference, 29-36. Toledo, Spain. Springer Link. Disponible en: xxxx

Rojas-López, A., \& Rincón-Flores, E. G. (2018). Gamification as Learning Scenario in Programming Course of Higher Education. Springer International Publishing AG, part of Springer Nature 2018, 1, 200-210.

Rincon-Flores, E.G., Gallardo, K. \& Fuente, J.M.d.I. (2018). Strengthening an Educational Innovation Strategy: Processes to Improve Gamification in Calculus Course through Performance Assessment and Meta-evaluation. IEJMEMathematics Education, 13(1), 1-11

Rincon-Flores, E.G, Ramírez-Montoya, M.S., \& Serra, L.A. (2017) Gamificación basada en retos en el MOOC La reforma energéntica y sus oportunidades. In M.S. Ramírez-Montoya, \& A. Mendoza-Domínguez (Eds.), Innovación y sustentabilidad energética Formación con MOOCs e investigación educativa (pp. 55-70). Madrid, España: Narcea.

Rincón-Flores, E. G., Ramírez-Montoya, M. S., \& Mena, J. J.. (2016a). Challenge-based gamification and its impact in teaching mathematical modeling. En F. J. GarcíaPeñalvo, the Fourth International ConferenceProceedings of the Fourth International Conference on Technological Ecosystems for Enhancing Multiculturality - TEEM '16. Salamanca, SpainNew York, New York, USA: ACM Press. doi:10.1145/301243010.1145/3012430.3012605 
Rincón-Flores, E. G., Ramírez-Montoya, M. S., \& Mena, J. J.. (2016b). Challenge-based gamification as a teaching' open educational innovation strategy in the energy sustainability area. En F. J. García-Peñalvo, the Fourth International

ConferenceProceedings of the Fourth International Conference on Technological Ecosystems for Enhancing Multiculturality - TEEM '16. Salamanca, SpainNew York, New York, USA: ACM Press. doi:10.1145/301243010.1145/3012430.3012658

Rincón-Flores, E. G., Ramírez-Montoya, M. S., \& Mena, J. J.. (2016c). Problem-based Gamification on sustainable energy 's MOOCs. Proceedings of the 9th annual International Conference of Education, Research and Innovation. presentado en 11/2016, https://library.iated.org/publications/ICERI2016: IATED. doi:

10.21125/iceri.2016 


\section{REFERENCIAS}

\section{REFERENCIAS}

Abramovich, S. (2016). Understanding digital badges in higher education through assessment. On the Horizon, 24 (1), pp.126-131. https://doi.org/10.1108/OTH-082015-0044

Acaso, M. [FundaciónTelefónicaMX]. (2014, junio 19). La educación disruptiva. [Archivo de video]. Recuperado de https://www.youtube.com/watch?v=-cbcYxp49Os

Acaso, M., \& Manzanera, P. (2015). Esto no es una clase. Investigando la educación disruptiva en los contextos educativos formales. Barcelona, España: Editorial

Admiraal, W., Huizenga, J., Akkerman, S., \& Dam, G.(2011). The concept of flow in collaborative game-based learning. Computers in Human Behavior, 27(3), 11851194. https://doi.org/10.1016/j.chb.2010.12.013Ariel.

Aguaded-Gómez, J. (2013). La revolución MOOCs, ¿una nueva educación desde el paradigma tecnológico?. Comunicar, XXI (41) Recuperado de http://www.redalyc.org/articulo.oa?id=15828675001

Aguaded-Gómez, I., \& Medina-Salguero, R. (2015). Criterios de calidad para la valoración y gestión de MOOC/ Quality criteria for the valuation and management of MOOC. Revista Iberoamericana de Educación a Distancia, 18(2), 119-143. Retrieved from http://search. proquest.com/docview/1701876963?accountid=15299\%5Cnhttp://s earch. . roquest.com/docview/1701876963? accountid=15299

Aguilera, M., Alejo, F., Eduardo, Navarrete, J. Torres, R. (2014). Consideraciones sobre la Reforma de la Industria Petrolera en México Considerations on the Reform of the Oil Industry in Mexico. Economía UNAM, 11(33), 110-137. https://doi.org/10.1016/S1665-952X(14)72184-X

Alcorn, B., Christensen, G. \& Emanuel, E.J. (2014). Who Takes MOOCs? New Republic. Recuperado de http://goo.gl/TqYtnE.

Alemán de la Garza, L., Sancho Vinuesa, T., \& Gomez Zermeño, M. G. (2015).

Indicators of pedagogical quality for the design of a Massive Open Online 
Course for teacher training. RUSC. Universities and Knowledge Society Journal, 12(1), 104. https://doi.org/10.7238/rusc.v12i1.2260

Alpizar-Castro, I., \& Rodríguez-Monroy, C. (2016). Review of Mexico's energy reform in 2013: Background, analysis of the reform and reactions. Renewable and Sustainable Energy Reviews, 58, 725-736. https://doi.org/10.1016/j.rser.2015.12.291

Alraimi, K. M., Zo, H., \& Ciganek, A. P. (2014). Understanding the MOOCs continuance: The role of openness and reputation. Computers \& Education, 80, 28-38. https://doi.org/10.1016/j.compedu.2014.08.006

Alsawaier, R. S. (2018). The Effect of Gamification on Motivation and Engagement. The International Journal of Information and Learning Technology, 35(1), 56-79. https://doi.org/10.1108/IJILT-02-2017-0009

Ambadkar, R., Vyas, A., \&Bhargava J. (2015). Changing Accounting Education in India Through MOOCs. International Journal of Economic and Business Review, EPRA, 3(7) 149-153.

Amo, D., Casán, M.J. \& Alier, M. (2013). Approaches for quality in pedagogical and design fundamentals in MOOCs. Teoría de la Educación en la Sociedad de la información, TESI, 15(1), 70-89.

Andrés, L., Oanes, E. y Stefani, G. (2014). Transformaciones lúdicas. Un estudio preliminar sobre tipos de juego y espacios lúdicos. Interdisciplinaria,31() 39-55. Recuperado de http://www.redalyc.org/articulo.oa?id=18031545003

Apple. (2010). Challenge Based Learning: A Classroom Guide. Apple Inc, 1-40. Recuperado de http://www.apple.com/br/education/docs/CBL Classroom Guide Jan 2011.pdf

Armstrong, L. (2014). 2013- The Year of Ups and Downs for the MOOCs. Changing Higher Education. Recuperado de http://goo.gl/SqwGWn

Attali, Y., \& Arieli-Attali, M. (2015). Gamification in assessment: Do points affect test performance? Computers \& Education, 83, 57-63. http://doi.org/10.1016/j.compedu.2014.12.012

Awwal, N., Alom, M., \& Care, E. (2015). Game design for learning to solve problems in a collaborative environment. In Proceedings of the European Conference on Games-based Learning, pp. 25-33. Retrieved from 
http://www.scopus.com/inward/record.url?eid=2-s2.084955132225\&partnerID=tZOtx3y1

Barak, M., Watted, A., \& Haick, H. (2016). Motivation to learn in massive open online courses: Examining aspects of language and social engagement. Computers \& Education, 94, 49-60. https://doi.org/10.1016/j.compedu.2015.11.010

Barrientos del Monte, F., \& Añorve-Añorve, D. (2014). Mexico 2013: Agreements, reforms and social discontent. Revista de Ciencia Política (Santiago), 34, 221-247.

Bartolomé, A.R. \& Steffens, K. (2015). Are MOOCs Promising Learning Environments? Comunicar, 44, 91-99. http://dx.doi.org/10.3916/C44-2015-10

Baturay, M. H. (2015). An Overview of the World of MOOCs. Procedia - Social and Behavioral Sciences, 174, 427-433. https://doi.org/10.1016/j.sbspro.2015.01.685

BBC Mundo. (2011, Noviembre 29). El polémico crudo de Canadá que muy pocos quieren. BBC. Recuperado de http://www.bbc.com/mundo/noticias/2011/11/111129_petroleo_alquitran_canada_ am.shtml

Benlamri, R., \& Klett, F. (2015). Emerging trends for open access learning. Research and Practice in Technology Enhanced Learning, 10(1), 1-7. https://doi.org/10.1186/s41039-015-0010-4

Bi, Y., \& Yang, L. (2014). University Interdisciplinary Research Organizations in the Process of Collaborative Innovation: Advantages, Difficulties and Strategies. International Journal of Higher Education, 4(1), 71-76. http://doi.org/10.5430/ijhe.v4n1p71

Blum, W. and Leiß, D. (2007). How do students' and teachers deal with modelling problems? In: Haines, C. et al. (Eds.), Mathematical Modelling: Education, Engineering and Economics. Chichester: Horwood , 222-231

Bogers, M., \& Sproedt, H. (2012). Playful Collaboration (or Not): Using a Game to Grasp the Social Dynamics of Open Innovation in Innovation and Business Education. Journal of Teaching in International Business, 23(2), 75-97. http://doi.org/10.1080/08975930.2012.718702

Borrás-Gené, O., Martínez-Nuñez, M., \& Fidalgo-Blanco, Á (2014). Gamification in MOOC: Challenges, Opportunities and Proposals for Advancing MOOC Model. In Proceedings of the Second International Conference on Technological 
Ecosystems for Enhancing Multiculturality (pp. 215-220).

https://doi.org/10.1145/2669711.2669902

Borrás-Gene, O., Martínez-Nuñez, M., \& Fidalgo-Blanco, Á. (2016). New Challenges for the motivation and learning in engineering education using gamification in MOOC. International Journal of Engineering Education, 32(1), 501-512. Retrieved from http://www.scopus.com/inward/record.url?eid=2-s2.084959358012\&partnerID=tZOtx3y1

Bravo, E., Amante, B., Simo, P., Enache, M., \& Fernandez, V. (2011). Video as a new teaching tool to increase student motivation. IEEE Global Engineering Education Conference (EDUCON), Amman, 638-642. https://doi.org/10.1109/EDUCON.2011.5773205

Breslow, L. I. of T., Pritchard, D. E. (Massachusetts I. of T., DeBoer, J. (Massachusetts I. of T., Stump, G. S. (Massachusetts I. of T., Ho, A. D. (Massachusetts I. of T., \& Seaton, D. T. (Massachusetts I. of T. (2012). Studying Learning in the Worldwide Classroom Research into edX's First MOOC. Research \& Practice in Assessment, (March 2012), 5-15. Retrieved from http://files.eric.ed.gov/fulltext/EJ1062850.pd

Buckley, P., \& Doyle, E. (2014). Gamification and student motivation. Interactive Learning Environments, 0(0). https://doi.org/10.1080/10494820.2014.964263

Bunchball. (2012). Gamificaiton 101: An Introduction to Game Dynamics. Retrieved from www.bunchball.com

Burke, B. (Noviembre, 2012). Gamification 2020: What is the future of gamification?. Recuperado de http://www.gartner.com/analyst/26081

Cabero-Almenara, J. (2015). Visiones Educativas Sobre Los Mooc. RIED. Revista Iberoamericana de Educación a Distancia, 18(2), 39-60. https://doi.org/http://dx.doi.org/10.5944/ried.18.2.13718

Caponetto,I., Earp, J., \& Ott, M. (2014). Gamification and Education: A Literature Review. Proceedings of the European Conference on Games Based Learning, 7(October), 50-57. Retrieved from http://search.ebscohost.com/login.aspx?direct=true \&db=eue \&AN=99224935\&s ite=ehost-live

Carbonell, M. (2013, Agosto 9). La reforma energética tomada en serio. Recuperado de http://www.miguelcarbonell.com/articulos_periodicos/La_reforma_energ_tica_to mada_en_serio.shtml 
Caride, J A; Pose, H M; Gradaílle, R; Caballo, M B; (2014). Los Massive Open On Line Courses (MOOCS) como extensión universitaria. Profesorado. Revista de Currículum y Formación de Profesorado, 18() 43-61. Recuperado de http://www.redalyc.org/articulo.oa?id=56730662004

Casas Anguita, J., Repullo Labrador, J. R., \& Donado Campos, J. (2003). La encuesta como técnica de investigación. Elaboración de cuestionarios y tratamiento estadístico de los datos (I). Atención Primaria, 31(8), 527-538. https://doi.org/10.1016/S0212-6567(03)70728-8

Casilda, R. (2002). Energía y desarrollo económico en América Latina. Boletín económico del ICE, (2750), 31-44.

Caballo, M. B., Caride, J. A., Gradaille, R., y Pose, H. (2014). Los massive open on line courses (MOOCs) como extensión universitaria. Profesorado. Revista de curriculum y formación del profesorado, 18 (1), 43-61.

Castaño, C., y Cabero, J. (2013). Enseñar y aprender en entornos m-learning. Madrid:Síntesis.

Castaño Garrido, C. M., Maiz Olazabalaga, I., \& Garay Ruiz, U. (2015). Percepción de los participantes sobre el aprendizaje en un MOOC. RIED: Revista Iberoamericana de Educación a Distancia, 18(2), 197-221. https://doi.org/10.5944/ried.18.2.13444

CEEPYS, Centro de estudios de energía, política y sociedad. 29/07/2015. "Canadá y las arenas bituminosas". [En línea] < http://ceepys.org.ar/blog/canad\%C3\%A1-ylas-arenas-bituminosas>

Chan, M. M. (October, 2016). MOOCS \& Gamification, Oportunidades y Desafíos, https://doi.org/10.13140/2.1.2851.7761

Chauhan, A. (2014). Massive Open Online Courses (MOOCS): Emerging trends in assessment and accreditation. Digital Education Review, 25(1), 7-18.

Conole, G. (2016). MOOCs as disruptive technologies: strategies for enhancing the learner experience and quality of MOOCs. RED. Revista de Educación a Distancia. 50(2). Recuperado de http://www.um.es/ead/red/50

Connolly, T. M., Boyle, E. A., MacArthur, E., Hainey, T., \& Boyle, J. M. (2012). A systematic literature review of empirical evidence on computer games and 
serious games. Computers \& Education, 59(2), 661-686.

http://doi.org/10.1016/j.compedu.2012.03.004

Contreras Espinosa, R. (2016). Presentación. Juegos digitales y gamificación aplicados en el ámbito de la educación. RIED. Revista Iberoamericana de Educación a distancia, 19(2), 27-33. doi:http://dx.doi.org/10.5944/ried.19.2.16143

Corbalán Yuste, F. (1996). Estrategias utilizadas por los alumnos de secundaria en la resolución de juegos. SUMA 23, 21-32. Recuperado de: https://revistasuma.es/IMG/pdf/23/021-032.pdf

Corbalán, F. (2000). Algunos aspectos de matemáticas recreativas. En A. M. Cejas (coord.) Las matemáticas del siglo XX, una mirada en 101 artículos (pp. 121-124). España: Nivola.

Corpeño, E., Quan, A., \& Lemus, A. (Mayo, 2014). Designing and Executing a Gamified Hands-On MOOC for Technology Enthusiasts Designing and Executing a Gamified Hands-On MOOC for Technology Enthusiasts. V Congreso Internacional Sobre Calidad y Accesibilidad de la Formación Virtual.

Coughlan, S., (2013). Harvard plans to boldly go with 'Spocs'. Retrived January 27, 2014, from http://etcjournal.com/2013/09/26/spocs-are-mooc-game-changers/

Chamoso, J., Durán, J., García, J., Martín, J., \& Rodriguez, M. (2004). Análisis y experimentación de juegos como instrumentos para enseñar matemáticas. SUMA, 47, 47-58.

Chauhan, A. (2014). Massive Open Online Courses (MOOCS): Emerging trends in assessment and accreditation. Digital Education Review, 25(1), 7-18.

Chang, J., \& Wei, H. (2016). Exploring Engaging Gamification Mechanics in Massive Online Open Courses, Educational Technology \& Society, 19, 177-203.

Chang, K. E., Wu, L. J., Weng, S. E., \& Sung, Y. T. (2012). Embedding game-based problem-solving phase into problem-posing system for mathematics learning. Computers and Education, 58(2), 775-786. http://doi.org/10.1016/j.compedu.2011.10.002

Cheng, M. T., She, H. C., \& Annetta, L. A. (2015). Game immersion experience: Its hierarchical structure and impact on game-based science learning. Journal of Computer Assisted Learning, 37(3), 232-253. http://doi.org/10.1111/jcal.12066 
Chesbrough,H., Vanhaverke, W. y West, J. (2008). Open Innovation: Researching A New Paradigm, United States: Oxford University Press.

Chiappe-Laverde, A., Hine, N., \& Martínez-Silva, J. A. (2015). Literature and Practice: A Critical Review of MOOCs. Comunicar, 22(44), 09-18. http://doi.org/10.3916/C44$\underline{2015-01}$

Chou, K. (Agosto, 2013). Top 10 Marketing Gamification Cases You Won't Forget. Recuperado de http://sumo.ly/dhll via @yukaichou

Christensen, C. M. (2012). Disruptive innovation. En M. Soegaard y R. F. Dam (Ed.), Encyclopedia of human-computer interaction. Recuperado de: http://www. interaction-design.org/encyclopedia/ disruptive_innovation.html

Christensen, C., Michael, R., and McDonald, R. (2015). "What Is Disruptive Innovation?" Harvard Business Review, 93(12), 44-53.

Christensen, C., Johnson, C., and Horn, M. (2016). Disrupting Class: How Disruptive Innovation Will Change the Way the World Learns. United States: McGraw Hill.

Coldwell, P. [tecdemonterreyvideos]. (2017, enero 25). Energía para la sustentabilidad. [Archivo de video]. Recuperado de https://www.youtube.com/watch?v=OyFo742ONZU

CONACYT (2018). "Laboratorio Binacional para la Gestión Inteligente de la Sustentabilidad Energética y la Formación Tecnológica" financiado a través de Fondo CONACYT SENER de Sustentabilidad Energética (S0019201401). México: CONACYT.

Creswell, J. W, Plano Clark, V. L., Guttmann, M. L. and Hanson, E. E. (2003). Advanced mixed methods research design. En A.Tashakkori and C. Teddlie (Eds.).

Handbook of mixed methods in social and behavioral research (pp. 209-240). Thousand Oaks, CA: Sage.

Creswell, J. W. (2007). Qualitative inquiry research design. Choosing among five approaches (2a. ed). California, Estados Unidos: Sage.

Csikszentmihalyi, M. (1997). Finding flow: The psychology of engagement with everyday life. The masterminds series. New York: Basic Books. 
Csikszentmihalyi, M. (1990). Flow: The Psychology of Optimal Experience, (1st Harper Perennial Modern Classics ed., Harper Perennial modern classics), Harper Perennial: New York, NY.

Cunningham, R. (2003). La energía, historia de sus fuentes y transformación. Petrotecnia, 7.

Dande, P. R., Ashutosh, A., Ajgaonkar, N., Parkhi, B., Tyagi, D., Tanay, C., \& Parekh, D. (2013). Innovation models in education. Proceedings of the 2013 IEEE International Conference in $\mathrm{MOOC}$, Innovation and Technology in Education, MITE 2013, 353-356. http://doi.org/10.1109/MITE.2013.6756366

Deci, E.L. and Ryan, R.M. (2008), "Facilitating optimal motivation and psychological well-being across life'sdomains", Canadian Psychology/Psychologie Canadienne, 49(1), pp. 14-23, available at: https://doi.org/10.1037/0708-5591.49.1.14

De la cruz, G., Chung, G. y Baker, E. (2010). Validity evidence for games as assessment environments. National Center for Research on Evaluation, Standards, and Student Testing: UCLA.

De Miguel, I. (septiembre, 2016), Innovación evolutiva vs Innovación disruptiva. Innovacionpymes. Recuperado de https://innovacionpymes.com/innovacion-evolutiva-vs-innovacion-disruptiva/

Del Moral-Perez, M. E., \& Villalustre-Martinez, L. (2015). MOOC: Digital ecosystems for the construction of ple in higher education. Ried-Revista Iberoamericana De Educacion a Distancia, 18(2), 87-117. http://doi.org/10.5944/ried.18.2.13353

Dennis, M. (2012). The Impact of MOOCs on Higher Education. College and University, 88(2), 24-30.

Deterding, S., Khaled, R., Nacke, L., \& Dixon, D. (2011). Gamification: toward a definition. Chi 2011, 12-15. http://doi.org/978-1-4503-0268-5/11/0

Díaz Barriga, F. (2014). Programa TIC y Educación Básica: Las políticas TIC en los sistemas educativos de América Latina. Caso México. Retrieved from http://www.unicef.org/argentina/spanish/educacion Integracion TIC sistemas f ormacion docente.pdf

Díaz-Bravo, L., Torruco-García, U., Martínez-Hernández, M., \& Varela-Ruiz, M. (2013). La entrevista, recurso flexible y dinámico. Investigación En Educación Médica, 2(7), 162-167. https://doi.org/10.1016/\$2007-5057(13)72706-6 
Dichev, C., \& Dicheva, D. (2017). Gamifying education: what is known, what is believed and what remains uncertain: a critical review. International Journal of Educational Technology in Higher Education 14(1) https://doi.org/10.1186/s41239-017-0042-5

Dicheva, D., Dichev, C., Agre, G., \& Angelova, G. (2015). Gamification in education: A systematic mapping study. Educational Technology and Society, 18(3), 75-88. Retrieved from http://www.scopus.com/inward/record.url?eid=2-s2.084938082996\&partnerlD=tZOtx3y1

Deulofeu, J. (2001). Una recreación matemática: historias, juegos y problemas: Barcelona: Planeta.

Domínguez, A., Saenz-De-Navarrete, J., De-Marcos, L., Fernández-Sanz, L., Pagés, C., \& Martínez-Herráiz, J. J. (2013). Gamifying learning experiences: Practical implications and outcomes. Computers and Education, 63, 380-392. http://doi.org/10.1016/j.compedu.2012.12.020

Domínguez, C. y Macías-Ordóñez, R. (2004). "El que no transa no avanza": la ciencia mexicana en el espejo. En: M. Aluja y A. Birke (Coords.), El papel de la ética en la investigación científica y la educación superior (2a. ed.). Distrito Federal, México: Fondo de Cultura Económica.

Dzeng, R. J., Lin, K. Y., \& Wang, P. R. (2014). Building a construction procurement negotiation training game model: Learning experiences and outcomes. British Journal of Educational Technology, 45(6), 1115-1135. http://doi.org/10.1111/bjet.12189

Echevarría R. (2011). Ética y coaching ontológico. Santiago de Chile: JC Sáez Editor.

Eckel, P. \& Kezar, A. (2011). Taking the reins, institutional transformation in higher education. United States: Rowman \& Littlefiel Publishers.

Egan, M. (2016, Julio 7). Estados Unidos tiene más reservas de crudo que Arabia Saudita y Rusia. CNN, sección Economía. Recuperado de http://cnnespanol.cnn.com/2016/07/07/estados-unidos-tiene-mas-reservas-decrudo-que-arabia-saudita-y-rusia/\#0

Energy, R. (2007). Renewable Energy Road Map. Renewable energies in the 21st century: building a more sustainable future. Journal of International Wildlife Law Policy, 12(1), 1-20. https://doi.org/10.1080/13880290902938435 
Faiella, F., \& Ricciardi, M. (2015). Gamification and learning: A review of issues and research. Journal of E-Learning and Knowledge Society. Italian e-Learning Association.

Fernández-Díaz, E., Rodríguez-Hoyos, C., \& Calvo Salvador, A. (2017). The Pedagogic Architecture of MOOC: A Research Project on Educational Courses in Spanish. The International Review of Research in Open and Distributed Learning, 18(6), 1835. https://doi.org/10.19173/irrodl.v18i6.2964

Fidalgo-Blanco, Á. (2014). Editorial "innovación conocimiento" Teoría de La Educación Sociedad de La Información (TESI), 15(3), 1-4.

Fidalgo-Blanco, Á., Sein-Echaluce, M. L., Borras-Gene, O. \& García-Peñalvo, F. J. (2014). Educación en abierto: Integración de un MOOC con una asignatura académica. Teoría de La Educación Sociedad de La Información (TESI), 15(3), 233255.

Fidalgo-Blanco, Á., Sein-Echaluce, M. L., \& García-Peñalvo, F. J. (2013). Coperative MOOC. An integration between $\mathrm{CMOOC}$ and XMOOC. II Congreso Internacional Sobre Aprendizaje, Innovación Y Competitividad (CINAIC 2013), (Cinaic), 481-486.

Fidalgo-Blanco, Á., Sein-Echaluce, M. L., \& García-Peñalvo, F. J. (2016). From massive access to cooperation: Lessons learned and proven results of a hybrid $\mathrm{xMOOC/CMOOC}$ pedagogical approach to MOOCs. International Journal of Educational Technology in Higher Education (ETHE), 13, 24. doi:10.1186/s41239016-0024-z

Flores, C. y Silva, H. (2010). Uma proposta para relacionar arte e educação matemática. Revista Latinoamericana de Investigación en Matemática Educativa, 13() 337-354. Recuperado de http://www.redalyc.org/articulo.oa?id=33519249005

Frankfurt School and UNEP. (2016). Global Trends in Renewable Energy, 1-84. Retrieved from http://fs-unep centre.org/sites/default/files/publications/globaltrendsinrenewableenergyinvest ment2016lowres_0.pdf

Fredricks, J. A., Blumenfeld, P. C., \& Paris, A. H. (2004). School Engagement : Potential of the Concept, State of the Evidence. Review of Educational Research Spring 74(1), 59-109. 
Friman, H. (2017). New Trends in the Higher Education: Renewable Energy at the Faculty of Electrical Engineering. Energy Procedia, 115, 18-28. https://doi.org/10.1016/j.egypro.2017.05.003

Fullagar, C.J., Knight, P.A. and Sovern, H.S. (2013) Challenge/Skill Balance, Flow, and Performance Anxiety. Applied Psychology: An International Review, 62, 236-259. http://dx.doi.org/10.1111/j.1464-0597.2012.00494.x

Galvis, A. (2013). Educación en la era de la información. In A. Galvis(Ed.), Ambientes educativos CLIC-creativos, lúdicos, interactivos y colaborativos-para aprender en la era de la información (pp. 1-10). Bogotá, Colombia: Ediciones Uniandes.

Galvis, A., Mariño, O., Trech, M. y Recamán, B. (2013). Juegos, acertijos y creatividad. In A. Galvis(Ed.), Ambientes educativos CLIC-creativos, lúdicos, interactivos y colaborativos-para aprender en la era de la información (pp. 35-48). Bogotá, Colombia: Ediciones Uniandes.

García, A. \& Mena, J. (2016). Information Technology as a way to support Collaborative learning: what in-service teachers think, know and do. Journal of Information Technology Research, 9 (1), 1-17

García, F. (2002). El cuestionario, recomendaciones metodológicas para el diseño de cuestionario. México: Limusa.

García-Aretio, L. (2015). MOOC: ¿tsunami, revolución o moda pasajera? RIED. Revista Iberoamericana de Educación a Distancia, 18 (1), 9-21. Recuperado de http://ried.utpl.edu.ec/sites/default/files/files/pdf/v\%2018-1/editorial.pdf.

García-Aretio, L. (2016). El juego y otros principios pedagógicos. Su pervivencia en la educación a distancia y virtual. RIED. Revista Iberoamericana de Educación a distancia, 19(2), 9-23. doi:http://dx.doi.org/10.5944/ried.19.2.16175

García-Holgado, A. (2018). Análisis de integración de soluciones basadas en software como servicio para la implantación de Ecosistemas Tecnológicos Educativos (Tesis doctoral). Universidad de Salamanca, España.

García-Manjón, J.V y Rodríguez, J. (2011). El ABC de la innovación. España: Netbiblo.

García-Peñalvo, F. J. (2015). Mapa de tendencias en Innovación Educativa. Teoría de La Educación Sociedad de La Información (TESI), 16(4), 6-23.

https://doi.org/10.14201/eks2015164623 
García-Peñalvo, F. J., García de Figuerola, C., \& Merlo, J. A. (2010). Open knowledge: challenges and facts. Online Information Review, 34(4), 520-539. http://doi.org/10.1108/14684521011072963

García-Peñalvo, F. J., Fidalgo-Blanco, A., \& Sein-Echaluce, M. L. (2017). Los MOOC: Un análisis desde una perspectiva de la innovación institucional universitaria. La Cuestión Universitaria, 9, 117-135.

García-Peñalvo, F. J., Fidalgo-Blanco, Á., \& Sein-Echaluce, M. L. (2018). An adaptive hybrid MOOC model: Disrupting the MOOC concept in higher education. Telematics and Informatics, 35, 1018-1030. doi:10.1016/j.tele.2017.09.012

García-Valcárcel, Muñoz-Repiso, A., Hernández Martín, A., \& Recamán Payo, A. (2012). La metodología del aprendizaje colaborativo a través de las TIC: una aproximación a las opiniones de profesores y alumnos. Revista Complutense de Educacion, 23(1), 161-188. http://doi.org/10.5209/rev_RCED.2012.v23.n1.39108

Gökcen, N. (2014). Homo Ludens in Gilead: The Handmaid's Tale Revisited. Journal of social sciences institute 18(2) 139-155. https://kuldoc.com/download/homoludens-in-gilead-the-handmaids-tale-revisited5943eec81723dd6b995598dc pdf

González-González, C., Río, N. G., \& Navarro-Adelantado, V. (2018). Exploring the Benefits of Using Gamification and Videogames for Physical Exercise: a Review of State of Art. International Journal of Interactive Multimedia and Artificial Intelligence, InPress(InPress), 1. https://doi.org/10.9781/ijimai.2018.03.005

González-González, C. S., Collazos, C. A., \& García, R. (2016). Desafío en el diseño de MOOCs: incorporación de aspectos para la colaboración y la gamificación. Revista de Educación a Distancia (RED), (48). http://doi.org/10.6018/red/48/7

González, L., Glasserman, L., Ramírez-Montoya, M.S., García-Pañalvo, F. (2017). Repositorios como soportes para diseminar experiencias de innovación educativa. In M.S. Ramírez-Montoya, \& R. Valenzuela (Eds.), Innovación educativa, investigación, formación, vinculación y visibilidad (pp. 259-270). Madrid, España: Narcea.

Granic, I., Lobel, A., \& Engels, R. C. M. E. (2014). The benefits of playing video games. American Psychologist, 69(1), 66-78. https://doi.org/10.1037/a0034857 
Griffith-Jones, S., Spratt, S., Andrade, R., Griffith-Jones, E. (2017). Investment in renewable energy, fossil fuel prices and policy implications for Latin America and the Caribbean. United Nations: Financing for Development Series, https://doi.org/10.1093/oxfordhb/9780199560103.003.0005

Gros Salvat, B., \& Lara Navarra, P. (2009). Estrategias De Innovación En La Educación Superior: El Caso De La Universitat Oberta De Catalunya. Revista Iberoamericana de Educación, 49(49), 223-245. Retrieved from file:///C:/Users/ROSALBA/Downloads/rie49a09.pdf

Gruman, J., Holmes-Rovner, M., French, M.E., Jeffres, D., Sofaer, S., Shaller, D. and Prager, D.J. (2010), "From patient education to patient engagement: implications for the field of patient education", Patient Education and Counseling, 78(3), 350356.

Guerrero, M., Glasserman, L. D. y Ramírez, M. S. (2017). Conexión de aprendizajes con recursos abiertos en un MOOC: percepciones y prácticas. CPU-e, Revista de Investigación Educativa, 25, 61-82. Recuperado de http://revistas.uv.mx/index.php/cpue/article/view/2705/pdf 18

Guijosa, Ch. (Febrero, 2018). Aumenta el uso de cursos de paga en plataformas MOOC. Observatorio de innovación educativa. https://observatorio.itesm.mx/edu-news/aumentan-cursos-pagados-en-mooc

Guo, P., Wang, T., Li, D., \& Zhou, X. (2016). How energy technology innovation affects transition of coal resource-based economy in China. Energy Policy, 92, 1-6. https://doi.org/10.1016/j.enpol.2016.01.026

Gustetic, J. L., Crusan, J., Rader, S., \& Ortega, S. (2015). Outcome-driven open innovation at NASA. Space Policy, 1-7. http://doi.org/10.1016/j.spacepol.2015.06.002

Hamari, J. (2015). Computers in Human Behavior Do badges increase user activity? A field experiment on the effects of gamification. Computers in Human Behavior, 1-10. https://doi.org/10.1016/j.chb.2015.03.036

Hamari, J., Shernoff, D. J., Rowe, E., Coller, B., Asbell-Clarke, J., \& Edwards, T. (2016). Challenging games help students learn: An empirical study on engagement, flow and immersion in game-based learning. Computers in Human Behavior, 54, 170-179. http://doi.org/10.1016/j.chb.2015.07.045 
Hanus, M. D., \& Fox, J. (2015). Assessing the effects of gamification in the classroom: A longitudinal study on intrinsic motivation, social comparison, satisfaction, effort, and academic performance. Computers \& Education, 80, 152-161. http://doi.org/10.1016/j.compedu.2014.08.019

Heredia, Y. (2010, junio). Incorporación de tecnología educativa en educación básica: dos escenarios escolares en México. Ponencia presentada en el XI Encuentro Internacional Virtual Educa, Santo Domingo, República Dominicana.

Hernández-Carranza, E. E., Romero-Corella, S. I., \& Ramírez-Montoya, M. S. (2015). Evaluation of Digital Didactic Skills in Massive Open Online Courses: a Contribution to the Latin American Movement. Comunicar, 22(44), 81-90. http://doi.org/10.3916/C44-2015-09

Hernández-Pozas y Neri, J. (2017). Innovación educativa con grupos multidisciplinarios y multiculturales: retos y soluciones. In M.S. RamírezMontoya, \& R. Valenzuela (Eds.), Innovación educativa, investigación, formación, vinculación y visibilidad (pp. 179-198). Madrid, España: Narcea.

Herzig, P., Ameling, M., Wolf, B., \& Schill, A. (2015). Implementing Gamification: Requirements and Gamification Platforms. In T. Reiners \& C. L. Wood (Eds.), Gamification in Education and Business (pp. 431-450). inbook, Cham: Springer International Publishing. http://doi.org/10.1007/978-3-319-10208-5_22

Hew, K. F. (2016). Promoting engagement in online courses: What strategies can we learn from three highly rated MOOCS. British Journal of Educational Technology, 47(2), 320-341. https://doi.org/10.1111/bjet.12235

Hew, K. F., \& Cheung, W. S. (2014). Students' and instructors' use of massive open online courses (MOOCs): Motivations and challenges. Educational Research Review, 12, 45-58. https://doi.org/10.1016/j.edurev.2014.05.001

Hew, K. F., Huang, B., Chu, K. W. S., \& Chiu, D. K. W. (2016). Engaging Asian students through game mechanics: Findings from two experiment studies. Computers and Education, 92-93, 221-236.

Hickey, D. (October, 2013). xMOOC, cMOOC, DOCC or BOOC: What's in a name? [Web log post]. Retrieved from http://remediatingassessment.blogspot.com/2013/10/xmooc-cmooc-docc-orbooc-whats-in-name.html 
Hills, J. M., \& Michalena, E. (2017). Renewable energy pioneers are threatened by EU policy reform. Renewable Energy, 108, 26-36. https://doi.org/10.1016/j.renene.2017.02.042

Hood, N., Littlejohn, A., \& Milligan, C. (2015). Context counts: How learners' contexts influence learning in a MOOC. Computers \& Education, 91, 83-91. https://doi.org/10.1016/j.compedu.2015.10.019

Hone, K. S., \& El Said, G. R. (2016). Exploring the factors affecting MOOC retention: A survey study. Computers \& Education, 98, 157-168. https://doi.org/10.1016/j.compedu.2016.03.016

Hou, H. T., \& Li, M. C. (2014). Evaluating multiple aspects of a digital educational problem-solving-based adventure game. Computers in Human Behavior, 30 , 29-38. https://doi.org/10.1016/j.chb.2013.07.052

Howe, K. R., \& Moses, M. S. (1999). Chapter 2: Ethics in Educational Research. Review of Research in Education, 24(1), 21-59. https://doi.org/10.3102/0091732X024001021

Hoyle, J., \& Deschaine, M. E. (2016). An interdisciplinary exploration of collegiate internships. Education + Training, 58(4), 372-389. https://doi.org/10.1108/ET-10$\underline{2015-0098}$

Huizinga, J. (2012). Homo Ludens. Madrid: Alianza. http://dx.doi.org/ 10.5117/9789089640031

Huotari, K., \& Hamari, J. (2011). Gamification" from the perspective of service marketing. CHI 2011 Workshop Gamification, (January), 11-15. http://doi.org/table of contents ISBN: 978-1-4503-1637-8 doi>10.1145/2393132.2393137

Jar, A. M. (2010). Trabajo interdisciplinario e interinstitucional: ser o no ser. Revista Argentina de Microbiología, 42() Recuperado de http://www.redalyc.org/articulo.oa?id=213014884001

Johnson, B. \& Christensen, L. (2000). Educational research: Quantitative and qualitative approaches. Boston: Allyn \& Bacon.

Johnson, M., \& Liber, O. (2008). The Personal Learning Environment and the human condition: from theory to teaching practice. Interactive Learning Environments, 16(1), 3-15. http://doi.org/10.1080/10494820701772652 
Johnson, C. I., \& Mayer, R. E. (2010). Applying the self-explanation principle to multimedia learning in a computer-based game-like environment. Computers in Human Behavior, 26(6), 1246-1252. http://doi.org/10.1016/j.chb.2010.03.025

Johnson, B. \& Onwuegbuzie, A. (2004). Mixed Methods Research: A Research Paradigm Whose Time Has Come. Educational Researcher, 33(14), 14-26. https://doi.org/10.3102/0013189X033007014

Johnson, B. \& Turner, L. (2003). Data collection strategies in mixed methods research. En A.Tashakkori and C. Teddlie (Eds.). Handbook of mixed methods in social and behavioral research (pp. 297-320). Thousand Oaks, CA: Sage.

Jolliffe, I. T. (2012). Principal Component Analysis and Factor Analysis. In: Principal Component Analysis. Springer Series in Statistics. Springer, New York, NY

Jonker, G. \& Harmsen, J. (2013). Ingeniería para la sostenibilidad, guía práctica para el diseño sostenible. Reverté: España.

Jordan, K. (2013). MOOCs Completion Rates: The Data. (http:// - goo.gl/73AxVf) (1512-2013).

Juárez, G. H., \& Carballo, M. M. R. (2016). Learning gains, motivation and learning styles in a gamified class. International Journal of Engineering Education, 32(1), 438-447. Retrieved from http://www.scopus.com/inward/record.url?eid=2-s2.084959386316\&partnerID=tZOtx3y1

Kafai, Y. B., \& Burke, Q. (2015). Constructionist Gaming: Understanding the Benefits of Making Games for Learning. Educational Psychologist, 50(4), 313-334. http://doi.org/10.1080/00461520.2015.1124022

Kapp, K. M. (2012). The gamification of learning and instruction: game-based methods and strategies for training and education. San Francisco, USA: Wiley.

Kaplan, A. M., \& Haenlein, M. (2016). Higher education and the digital revolution: About MOOCs, SPOCs, social media, and the Cookie Monster. Business Horizons, 59(4), 441-450. https://doi.org/10.1016/j.bushor.2016.03.008

Kandpal, T. C., \& Broman, L. (2014). Renewable energy education: A global status review. Renewable and Sustainable Energy Reviews, 34, 300-324. https://doi.org/10.1016/j.rser.2014.02.039 
Kebritchi, M., Hirumi, A., \& Bai, H. (2010). The effects of modern mathematics computer games on mathematics achievement and class motivation. Computers \& Education, 55(2), 427-443. http://doi.org/10.1016/j.compedu.2010.02.007

Kerlinger, F. \& Lee, H. (2002). Investigación del Comportamiento. Métodos de investigación en Ciencias Sociales. Cuarta edición. México: MacGraw-Hill.

Keusch, F., \& Zhang, C. (2017). A Review of Issues in Gamified Surveys. Social Science Computer Review, 35(2), 147-166. https://doi.org/10.1177/0894439315608451

King, B. A., \& Lakhani, K. R. (2013). Using Open Innovation to Identify the Best Ideas. MIT Sloan Management review, 55(1).

Kitchenham, B., Pretorius, R., Budgen, D., Brereton, O. P., Turner, M., Niazi, M., \& Linkman, S. (2010). Systematic literature reviews in software engineering-A tertiary study. Information and Software Technology, 52(8), 792-805. https://doi.org/10.1016/j.infsof.2010.03.006

Kocadere, S. A., \& Çağlar, Ş. (2015). The design and implementation of a gamified assessment. Journal of E-Learning and Knowledge Society, 17(3), 85-99. Retrieved from http://www.scopus.com/inward/record.url?eid=2-s2.084943247812\&partnerID=tZOtx3y1

Koivisto, J., \& Hamari, J. (2014). Demographic differences in perceived benefits from gamification. Computers in Human Behavior, 35, 179-188. http://doi.org/10.1016/j.chb.2014.03.007

Koivisto, J.-M., Multisilta, J., Niemi, H., Katajisto, J., \& Eriksson, E. (2016). Learning by playing: A cross-sectional descriptive study of nursing students' experiences of learning clinical reasoning. Nurse Education Today, 45, 22-28. http://doi.org/10.1016/j.nedt.2016.06.009

Krause, M., Mogalle, M., Pohl, H., \& Williams, J. J. (2015). A Playful Game Changer: Fostering Student Retention in Online Education with Social Gamification . Proceedings of the 2nd ACM Conference on Learning @ Scale (L@S'15), (October 2016), 95-102. https://doi.org/10.1145/2724660.2724665

Kyewski, E., \& Krämer, N. C. (2018). To gamify or not to gamify? An experimental field study of the influence of badges on motivation, activity, and performance in an 
online learning course. Computers \& Education, 118, 25-37.

https://doi.org/10.1016/j.compedu.2017.11.006

Laboratorio Binacional para la Gestión Inteligente de la Sustentabilidad Energética y la Formación Tecnológica (2017). Retrieved desde http://energialab.com/cursos/

Labrador, E. (2016). Unir Gamificación y Experiencia de Usuario para mejorar la experiencia docente. RIED. Revista Iberoamericana de Educación a Distancia, 19, 12. https://doi.org/http://dx.doi.org/10.5944/ried.19.2.15748

Lee, J., \& Hammer, J. (2011). Gamification in Education: What, How, Why Bother? Academic Exhange Quarterly, 15(2).

Lenhart, A., Kahne, J., Middaugh, E., Rankin Macgill, A., Evans, C., \& Vitak, J. (2008). Teens, Video Games, and Civics: Teens' gaming experiences are diverse and include significant social interaction and civic engagement. Pew Internet \& American Life Project, 1-64. http://doi.org/10.1016/j.chembiol.2006.01.005

Lincoln, Y. y Guba, E. (1985). Naturalistic inquiry. Beverly Hills, California, Estados Unidos: Sage.

Liyanagunawardena, T., Williams, S., \& Adams, A. (2013). The impact and Reach of MOOCs: A Developing Countries' Perspective. eLearning Papers, (33), 1-8. Recuperado desde http://elearningeuropa.info/sites/default/files/asset/Indepth_33_1.pdf

Lester, R. and Piore, M. (2004). Innovation: The Missing Dimension. Cambridge, USA: Harvard University Press.

López, J.L.[tecdemonterreyvideos]. (2017a, enero 4). Petróleo y su energía. [Archivo de video]. Recuperado de https://www.youtube.com/watch?v=y6PdyL0xAAg\&t=148s

López, J.L.[tecdemonterreyvideos]. (2017b, enero 4). ¿Cómo y dónde está la energía?. [Archivo de video]. Recuperado de https://www.youtube.com/watch?v=9BMWKI7cQmQ\&t=293s

López-Meneses, E., Vázquez-Cano, E., \& Román-Graván, P. (2015). Analysis and Implications of the Impact of MOOC Movement in the Scientific Community: JCR and Scopus (2010-13). Comunicar, 22(44), 73-80. http://doi.org/10.3916/C44$\underline{2015-08}$ 
Lozano Rodríguez, A. y Gallardo, K. (2017). Taxonomía de competencias para la innovación educativa. In M.S. Ramírez-Montoya, \& R. Valenzuela (Eds.), Innovación educativa, investigación, formación, vinculación y visibilidad (pp. 85104). Madrid, España: Narcea.

Lozano Rodriguez, A. y Herrera Bernal, J.A. (2013). Diseño de programas educativos basados en competencias. Monterrey: Editorial Digital del Tecnológico de Monterrey.

Lucassen, G., \& Jansen, S. (2014). Gamification in Consumer Marketing - Future or Fallacy? Procedia - Social and Behavioral Sciences, 148(2011), 194-202. http://doi.org/10.1016/j.sbspro.2014.07.034

Maican, C., Lixandroiu, R., \& Constantin, C. (2016). Interactivia.ro - A study of a gamification framework using zero-cost tools. Computers in Human Behavior,61, 186-197. Elsevier Ltd.

Mälkki, H., \& Paatero, J. V. (2015). Curriculum planning in energy engineering education. Journal of Cleaner Production, 106, 292-299.

https://doi.org/10.1016/j.jclepro.2014.08.109

Marín, V. (2015). La gamificación educativa. Una alternativa para la enseñanza creativa. Digital Education Review, 27, 5-8. Recuperado de http://revistes.ub.edu/index.php/der/article/view/12486/pdf 1

Margaryan, A., Bianco, M., \& Littlejohn, A. (2015). Instructional quality of Massive Open Online Courses (MOOCs). Computers and Education, 80, 77-83. https://doi.org/10.1016/j.compedu.2014.08.005

Marklund, G., Vonortas, N., y Wessner, Ch. (2009). The innovation imperative:National Innovation Strategies in the global economy. Great Britain, England: Edward Elgar Publishing Limited.

Martin, T., Rivale, S. D., \& Diller, K. R. (2007). Comparison of student learning in challenge-based and traditional instruction in biomedical engineering. Annals of Biomedical Engineering, 35(8), 1312-1323. https://doi.org/10.1007/s10439-0079297-7

Mathews, J. (2016). China's renewable energy revolution - can it save the world? Energy Post, 1-13. Retrieved from http://www.energypost.eu/chinas-continuingrenewable-energy-revolution-can-save- 
world/\%5Cnpapers3://publication/uuid/67CBB4F7-C27A-4C97-BBABB558FDED0AF1

Mayer, R. E. (2015). On the Need for Research Evidence to Guide the Design of Computer Games for Learning. Educational Psychologist, 50(4), 349-353. http://doi.org/10.1080/00461520.2015.1133307

Mayorga, J. (2017, marzo 5). Así es como Alemania le dice adiós al carbón y transita hacia las energías renovables. Animal Político. Recuperado de http://www.animalpolitico.com/2017/03/alemania-energias-renovables/

Meister, J. (2015), "MOOCs emerge as disruptors to corporate learning", Forbes, 10 June, avalaible at:

http://www.forbes.com/sites/jeannemeister/2015/06/10/moocs-emerge-asdisruptors-to-corporate-learning/2/\#568fb6324e6d (accessed 6 Febrero 2017)

Mekler, E. D., Brühlmann, F., Opwis, K., \& Tuch, A. N. (2013). Do points, levels and leaderboards harm intrinsic motivation? Proceedings of the First International Conference on Gameful Design, Research, and Applications - Gamification '13, 66-73.

Mekler, E. D., Brühlmann, F., Tuch, A. N., \& Opwis, K. (2015). Towards understanding the effects of individual gamification elements on intrinsic motivation and performance. Computers in Human Behavior, 1-10.

https://doi.org/10.1016/j.chb.2015.08.048

Méndez-García, C.(2015). Diseño e implementación de cursos abiertos masivos en línea (MOOC): expectativas y consideraciones prácticas. Revista de Educación a Distancia, (39), 1-19. Retrieved from http://www.um.es/ead/red/39

Mendoza, A. [tecdemonterreyvideos]. (2016a, noviembre 18). ¿Cuáles combustibles han sido usados por la humanidad en los últimos mil años?. [Archivo de video]. Recuperado de https://www.youtube.com/watch?v=9XpxN8YkhqM\&feature=youtu.be

Mendoza, A. [tecdemonterreyvideos]. (2016b, diciembre 7). El mundo actual visto bajo la perspectiva de una tercera revolución industrial. [Archivo de video]. Recuperado de https://www.youtube.com/watch?v=ri54glebb9I\&feature=youtu.be 
Mercado-Varela, M., Fernández, K., Lavigne, G. y Ramírez, M. (2018). Enseñanza y difusión sobre el uso de recursos educativos abiertos con MOOC: un estudio de caso. CPU-e Revista de Investigación Educativa, 26.

MexicoX.(2017). Recuperado de http://mexicox.gob.mx/

Montalvo, T. (2016, Marzo 24). ¿Qué países invierten más en energías renovables? México entra al top 10 mundial. Animal Político. Recuperado de http://www.animalpolitico.com/2017/02/robo-combustible-mexico/

Mora, A., Riera, D., González, C., \& Arnedo-Moreno, J. (2017). Gamification: a systematic review of design frameworks. Journal of Computing in Higher Education, 29(3), 516-548. https://doi.org/10.1007/s12528-017-9150-4

Morales, I. [tecdemonterreyvideos]. (2016, noviembre 25). Razones de la Reforma Energética. [Archivo de video]. Recuperado de https://www.youtube.com/watch?v=vQk5My8mTSY

Mota, R., \& Oliveira, J. F. (2014). Combining innovation and sustainability: an educational paradigm for human development on earth. Brazilian Journal of Science and Technology, 1(1), 2. https://doi.org/10.1186/2196-288X-1-2

Mouaheb, H., Fahli, A., Moussetad, M., \& Eljamali, S. (2012). The Serious Game: What Educational Benefits? Procedia - Social and Behavioral Sciences, 46, 5502-5508. https://doi.org/10.1016/j.sbspro.2012.06.465

Muellner, L. (2015). Anotaciones y el héroe griego antiguo: Pasado, presente y futuro. (Spanish). Annotations and the Ancient Greek Hero: Past, Present, and Future. (English), Comunicar, 22(44), 45-53. https://doi.org/10.3916/C44-2015-05

Mundo-Hernández, J., De Celis Alonso, B., Hernández-Álvarez, J., \& De Celis-Carrillo, B. (2014). An overview of solar photovoltaic energy in Mexico and Germany. Renewable and Sustainable Energy Reviews, 31, 639-649. https://doi.org/10.1016/j.rser.2013.12.029

Muñiz-Rodríguez, L., Alonso, P., \& Rodríguez-Muñiz, L. J. (2014). El uso de los juegos como recurso didáctico para la enseñanza y el aprendizaje de las Matemáticas: estudio de una experiencia innovadora. Revista Iberoamericana de Educación Matemática (39), 19-34. 
Nakamura, J., \& Csikszentmihalyi, M. (2002). The concept of flow. In C. R. Snyder \& S. J. Lopez (Eds.), Handbook of positive psychology (pp. 89-105). Oxford: Oxford University Press

Neri, L., Noguez, J. y Alanís, G. (2017). La importancia de un auténtico trabajo colaborativo para la innovación educativa. In M.S. Ramírez-Montoya, \& R. Valenzuela (Eds.), Innovación educativa, investigación, formación, vinculación y visibilidad (pp. 159-177). Madrid, España: Narcea.

Nisbet, S., \& Williams, A. (2009). Improving students' attitudes to chance with games and activities. Australian Mathematics Teacher, 65(3), 25-37.

Noguera, I. (2015). How millenials are changing the way we learn: the state of the art of ICT integration in education. RIED, 18(2), 45-65. Retrieved from http://revistas.uned.es/index.php/ried/issue/viewlssue/879/99

Noreña, A. L., Alcarz-Moreno, N., Rojas, J. G., \& Rebolledo-Malpica, D. (2012). Aplicabilidad de los criterios de rigor y éticos en la investigación cualitativa. Aquichan, 12(3), 263-274.

Observatorio de Innovación Educativa del Tecnológico de Monterrey (2014, Mayo). MOOC. Reporte EduTrends. Recuperado desde https://observatorio.itesm.mx/edutrendsmooc/Xing

Ocetkiewicz, I., Tomaszewska, B., \& Mróz, A. (2017). Renewable energy in education for sustainable development. The Polish experience. Renewable and Sustainable Energy Reviews, 92-97. https://doi.org/10.1016/j.rser.2017.05.144

OECD.(Octubre, 2015). The innovation imperative. Recuperado de https://www.oecd.org/sti/the-innovation-imperative-9789264239814-en.htm

Olsson, U. (2016). Open courses and MOOCs as professional development - is the openness a hindrance? Education + Training, 58(2), 229-243. http://doi.org/10.1108/ET-01-2015-0006

Onwuegbuzie, A. J. (2003). Expanding the framework of internal and external validity in quantitative research. Research in the Schools, 10(1), 71- 90.

Onwuegbuzie, A. \& Teddlie, Ch. (2003). A framework for analyzing data in mixed methods research. En A.Tashakkori and C. Teddlie (Eds.). Handbook of mixed methods in social and behavioral research (pp. 351-384). Thousand Oaks, CA: Sage. 
Pasin, F., \& Giroux, H. (2011). The impact of a simulation game on operations management education. Computers and Education, 57(1), 1240-1254. http://doi.org/10.1016/j.compedu.2010.12.006

Pedreira, O., García, F., Brisaboa, N., \& Piattini, M. (2014). Gamification in software engineering - A systematic mapping. Information and Software Technology, 57, 157-168. http://doi.org/10.1016/j.infsof.2014.08.007

Pérez, P. y Vila, L. (2013). La adquisición de competencias para la innovación productiva en la universidad española. Revista de Educación, (361), 429-455. http://doi.org/10.4438/1988-592X-RE-2013-361-228

Petersen, R. (Mayo, 2013). 21 Las empresas que utilizan gamificación para obtener resultados Mejor Negocio. Recuperado de: http://blog.heyo.com/21-companiesusing-gamification-to-get-better-business-results/?lang=es via @heyo

Ping (2013). The Latest Development and Application of Massive Open Online Course: From $\mathrm{CMOOC}$ to XMOOC. Recuperado desde http://en.cnki.com.cn/Article en/CJFDTOTAL-XDYC201303005.htm

Pulos, S. \& Sneider, C. (1994). Designing and evaluating effective games for teaching science and mathematics: An illustration form coordinate geometry. Focus on Learning Problems in Mathematics, 16(3), 23-42.

Probst, O. [tecdemonterreyvideos]. (2017, enero 10). Impacto ambiental y social. [Archivo de video]. Recuperado de https://www.youtube.com/watch?v=Q7|Fn8En1X0

Ramírez-Donoso, L., Rojas-Riethmuller, J. S., Pérez-Sanagustín, M., Neyem, A., \& Alario-Hoyos, C. (2017). MyMOOCSpace: A cloud-based mobile system to support effective collaboration in higher education online courses. Computer Applications in Engineering Education, 25(6), 910-926. https://doi.org/10.1002/cae.21843

Ramírez-Fernández, M. B. (2015). La Valoración De Mooc: Una Perspectiva De Calidad. RIED. Revista Iberoamericana de Educación a Distancia, 18(2), 171-195. Retrieved from http://revistas.uned.es/index.php/ried/article/view/13777

Ramírez-Montoya, M.S. (2012). Modelos y estrategias de enseñanza para ambientes innovadores. México: Editorial Digital. Tecnológico de Monterrey. 
Ramírez-Montoya, M.S. (2015). Acceso abierto y su repercusión en la Sociedad del Conocimiento : Reflexiones de casos prácticos en Latinoamérica. Educational Knowledge Society EKS, 16(1), 103-118. http://dx.doi.org/10.14201/eks2015161103118

Ramírez-Montoya, M.S. [tecdemonterreyvideos]. (2016a, julio 13). Innovación abierta, interdisciplinaria y colaborativa. [Archivo de video]. Recuperado de https://www.youtube.com/watch?v=HQbMDs2gw4Y

Ramírez-Montoya, M.S. [tecdemonterreyvideos]. (2016b, julio 25). Triangulación de instrumentos para análisis de datos. [Archivo de video]. Recuperado de https://www.youtube.com/watch?v=0OG_OLBT_VA

Ramírez-Montoya, M. S., \& García-Peñalvo, F. J. (2015). Movimiento Educativo Abierto. Virtualis, 6(12), 1-13.

Ramírez-Montoya, M. S., \& García-Peñalvo, F. J. (2018). Co-creation and open innovation: Systematic literature review. Comunicar, 26(54), 9-18. doi:10.3916/C54-2018-01

Ramírez-Montoya, M. S., García-Peñalvo, F. J., \& McGreal, R. (2018). Shared Science and Knowledge. Open Access, Technology and Education. Comunicar, 26(54), 15.

Ramírez-Montoya, M.S. \& Mena, J. (2017). In-service teachers' self perception on Digital Competence and OER use as determined by a XMOOC training course. Computers in Human Behaviour, 77, 356-364

Research GRoup of Interaction And e-Learning (GRIAL). (2018). Recuperado de https://grial.usal.es/home

Reyes, S. y Hernández, I. (2017). Comunicar la innovación: destinataios, contenidos, propósitos. In M.S. Ramírez-Montoya, \& R. Valenzuela (Eds.), Innovación educativa, investigación, formación, vinculación y visibilidad (pp. 229-243). Madrid, España: Narcea.

Rifkin, J. (2012). La tercera revolución industrial. Barcelona, España: Ediciones Paidós.

Riemer, V., \& Schrader, C. (2015). Learning with quizzes, simulations, and adventures: Students' attitudes, perceptions and intentions to learn with different types of serious games. Computers \& Education, 88, 160-168.

https://doi.org/10.1016/j.compedu.2015.05.003 
Rincon-Flores, E.G., Gallardo, K. \& Fuente, J.M. (2018). Strengthening an Educational Innovation Strategy: Processes to Improve Gamification in Calculus Course through Performance Assessment and Meta-evaluation. IEJME-Mathematics Education, 13(1), 1-11

Rincón-Flores, E. G., Ramírez-Montoya, M. S., \& Mena, J. J.. (2016a). Challenge-based gamification and its impact in teaching mathematical modeling. En F. J. GarcíaPeñalvo, the Fourth International ConferenceProceedings of the Fourth International Conference on Technological Ecosystems for Enhancing Multiculturality - TEEM '16. Salamanca, SpainNew York, New York, USA: ACM Press. doi:10.1145/301243010.1145/3012430.3012605

Rincón-Flores, E. G., Ramírez-Montoya, M. S., \& Mena, J. J.(2016b). Challenge-based gamification as a teaching' open educational innovation strategy in the energy sustainability area. En F. J. García-Peñalvo, the Fourth International ConferenceProceedings of the Fourth International Conference on Technological Ecosystems for Enhancing Multiculturality - TEEM '76. Salamanca, SpainNew York, New York, USA: ACM Press. doi:10.1145/301243010.1145/3012430.3012658

Rincón-Flores, E. G., Ramírez-Montoya, M. S., \& Mena, J. J. (2016c). Problem-based Gamification on sustainable energy 's MOOCs. Proceedings of the 9th annual International Conference of Education, Research and Innovation. presentado en 11/2016, https://library.iated.org/publications/ICERI2016: IATED. doi: 10.21125/iceri.2016

Rincon-Flores, E.G, Ramírez-Montoya, M.S., \& Serra, L.A. (2017). Gamificación basada en retos en el MOOC La reforma energéntica y sus oportunidades. In M.S. Ramírez-Montoya, \& A. Mendoza-Domínguez (Eds.), Innovación y sustentabilidad energética Formación con MOOCs e investigación educativa (pp. 55-70). Madrid, España: Narcea.

Riofrio-Calderón, G., López-Salinas, J.L., y Ramírez-Hernández, D. (2017). Mediación en el MOOC Energías convencionales, limpias y su tecnología. In M.S. RamírezMontoya, \& A. Mendoza-Domínguez (Eds.), Innovación y sustentabilidad energética Formación con MOOCs e investigación educativa (pp. 97-125). Madrid, España: Narcea.

Ricciardi, M. (2015). Je-LKS Gamification and learning : a review of, 11, 13-21.

Rodríguez, F. y Santiago, R. (2015). Gamificación: cómo motivar a tu alumnado y mejorar el clima en el aula. Barcelona, España : Grupo Oceano. 
Rojas-López, A., \& Rincón-Flores, E. G. (2018). Gamification as Learning Scenario in Programming Course of Higher Education. Springer International Publishing AG, part of Springer Nature 2018, 1, 200-210.

Rojas-López, A. Rincón-Flores, E.G.,Ramírez-Montoya, M.S., Mena, J. \& García-Peñalvo (In Press). Engagement in the course of Programming in Higher Education through the use of Gamification. Universal Access in the Information Society (UAIS).

Romero, M. C., Rébori, A. y Camio, M. I. (2010). Un Índice Para "Medir" El Nivel De Innovación Tecnológica En Empresas Intensivas En El Uso De Tecnología. Revista de Administracao e Innovacao, 7(1), 3-20.

Rosas-Flores, J. A. (2017). Elements for the development of public policies in the residential sector of Mexico based in the Energy Reform and the Energy Transition law. Energy Policy, 104(February), 253-264. https://doi.org/10.1016/j.enpol.2017.01.015

Rubia Avi, B., Anguita Martínez, R., \& Jarrín Abellán Inés Ruiz Requies, I. (2010). Educative Innovation Process in University Formation, New Productive Bests Practices in Educative Technology. Tesi, 11(113), 96-120.

Russell, J., Ainley, M. and Frydenberg, E. (2005), Issues Digest: Motivation and Engagement, Department of Education, Science and Training, Australian Government, Canberra, available at: www.dest.gov.au/sectors/school_education/publications_resources/schooling_9 0 issues_digest/

Sánchez, J., \& Olivares, R. (2011). Problem solving and collaboration using mobile serious games. Computers \& Education, 57(3), 1943-1952. https://doi.org/10.1016/j.compedu.2011.04.012

Sánchez-Carmona, A., Robles, S., \& Pons, J. (2017). A gamification experience to improve engineering students' performance through motivation. Journal of technology and science education, 7(2), 150-161. https://doi.org/10.3926/jotse.246

Sánchez-Vera, M.-M., León-Urrutia, M., \& Davis, H. (2015). Challenges in the Creation, Development and Implementation of MOOCs: Web Science Course at the University of Southampton / Desafíos en la creación, desarrollo e implementación de los MOOC: El curso de Web Science en la Universidad de Southampton. Comunicar, 22(44), 37-44. https://doi.org/10.3916/C44-2015-04 
Sailer, M., Hense, J. U., Mayr, S. K., \& Mandl, H. (2017). How gamification motivates: An experimental study of the effects of specific game design elements on psychological need satisfaction. Computers in Human Behavior, 69, 371-380. https://doi.org/10.1016/j.chb.2016.12.033

Sanabria, A. (2018). La economía del carbono una adicción de difícil tratamiento. Ciencia Politica, 13(25), 51-65.

Schonfeld. E. (Agosto, 2010). SCVNGR's Secret Game Mechanics Playdeck. Recuperado de https://techcrunch.com/tag/svngr/

Schoijet, M. (2002). Historia de la energía. Elementos: ciencia y cultura, 7(45), 51-57. http://www.elementos.buap.mx/num45/htm/51.htm

Schwartz, D. L., J. D. Bransford, and D. Sears. (2005). Innovation and efficiency in learning and transfer. In: Transfer of Learning from a Modern Multidisciplinary Perspective, edited by J. Mestre. New Jersey: Erlbaum, pp. 1-51.

Seaborn, K., \& Fels, D. I. (2015). Gamification in theory and action: A survey. International Journal of Human-Computer Studies, 74, 14-31. https://doi.org/10.1016/j.ijhcs.2014.09.006

Secretaría de energía (2015). Programa estratégico de formación de recursos humanos en materia energética. Recuperado de http://www.gob.mx/cms/uploads/attachment/file/365/PEFormacionRecursosHumanos.pdf

Secretaría de gobernación (2017). México-X te ofrece cursos gratuitos todo el año. Recuperado de https://www.gob.mx/imjuve/articulos/mexico-x-te-ofrececursos-gratuitos-todo-el-ano

Serra, A. [tecdemonterreyvideos]. (2017a, enero 9). El crimen organizado y su efecto en el subsector hidrocarburos. [Archivo de video]. Recuperado de https://www.youtube.com/watch?v=MGBXtzleW3c\&feature=youtu.be

Serra, A. [tecdemonterreyvideos]. (2017a, enero 9). Escasez de talento en el subsector hidrocarburos. [Archivo de video]. Recuperado de https://www.youtube.com/watch?v=yThDONCkFsg

Siemens, G. (2005). Connectivism. A Learning Theory for the Digital Age. ElearnSpace. (http://goo.gl/1yV7WT) (12-12-212). 
Siemens, G. (2012a). MOOCs for the Win! ElearnSpace. (http:// -goo.gl/7kJftu) (05-032012).

Skinner, E.A. and Belmont, M.J. (1993), "Motivation in the classroom: reciprocal effects of teacher behavior and student engagement across the school year", Journal of Educational Psychology, Vol. 85 No. 4, pp. 571-581.

Smith, L. M. (1990). Ethics, field studies, and the paradigm crisis. En E. Guba (Coord.) The paradigm dialog (pp. 139-157). Newbury Park, California, Estados Unidos: Sage.

Spector, J. M. (2014). Emerging educational technologies: Tensions and synergy. Journal of King Saud University - Computer and Information Sciences, 26(1), 5-10. https://doi.org/10.1016/j.jksuci.2013.10.009

Stefani, G., Andrés, L., \& Oanes, E. (2014). Transformaciones lúdicas. Un estudio preliminar sobre tipos de juego y espacios lúdicos. Interdisciplinaria, 31(1), 3955.

Sucic, B., Lah, P., \& Visocnik, B. P. (2017). An education and training program for energy managers in Slovenia - Current status, lessons learned and future challenges. Journal of Cleaner Production, 142, 3360-3369. https://doi.org/10.1016/j.jclepro.2016.10.133

Sun, Q., Xu, L., \& Yin, H. (2016). Energy pricing reform and energy efficiency in China: Evidence from the automobile market. Resource and Energy Economics, 44, 3951. https://doi.org/10.1016/j.reseneeco.2016.02.001

Surendeleg, G., Murwa, V., Yun, H. K., \& Kim, Y. S. (2014). The role of gamification in education-a literature review. Contemporary Engineering Sciences, 7(29-32), 1609-1616. http://doi.org/10.12988/ces.2014.411217

Suttie, N., Louchart, S., Lim, T., Macvean, A., Westera, W., Brown, D., \& Djaouti, D. (2012). Introducing the "Serious Games Mechanics" A Theoretical Framework to Analyse Relationships Between "Game" and"Pedagogical Aspects" of Serious Games. Procedia Computer Science, 15, 314-315. https://doi.org/10.1016/j.procs.2012.10.091

Tashakkori, A. y Teddlie, C. [Eds.]. (2003). Handbook of Mixed Methods in Social \& Behavioral Research [Manual de métodos mixtos en investigación social y del comportamiento]. Thousand Oaks: Sage Publications. 
Tay, H. Y. (2015). Setting formative assessments in real-world contexts to facilitate selfregulated learning. Educational Research for Policy and Practice, 14(2), 169-187. http://doi.org/10.1007/s10671-015-9172-5

Tecnológico de Monterrey.[tecdemonterreyvideos]. (2016, junio 23). MOOC - Cursos Masivos Abiertos en Línea. [Archivo de video]. Recuperado de https://www.youtube.com/watch?v=Ar12R 1AlEg

Tettegah, S., McCreery, M., \& Blumberg, F. (2015). Toward a Framework for Learning and Digital Games Research. Educational Psychologist, 50(4), 253-257. https://doi.org/10.1080/00461520.2015.1134330

Theisen, T. (2013). New spaces, new realities: Expanding learning any time, any place. Foreign Language Annals, 46(1), 1-2. https://doi.org/10.1111/flan.12019

The World Bank/OECD.(2013). Innovación y crecimiento: En busca de una frontera en movimiento, Foro Consultivo Científico y Tecnológico. A.C., México, D.F.

DOI: http://dx.doi.org/10.1787/9789264208339-es

Topîrceanu, A. (2017). Gamified learning: A role-playing approach to increase student in-class motivation. Procedia Computer Science, 112, 41-50. https://doi.org/10.1016/j.procs.2017.08.017

Torres-Carrion, P. V., Gonzalez-Gonzalez, C. S., \& Basurto-Ortiz, J. E. (2016). Diseño de un juego serio para la mejora de la conciencia fonológica de los niños con dislexia. 11 Congreso Colombiano de Computación, (May 2017).

Tsai, M.-J., Huang, L.-J., Hou, H.-T., Hsu, C.-Y., \& Chiou, G.-L. (2016). Visual Behavior, Flow and Achievement in Game-Based Learning. Computers \& Education, 98, 115-129. http://doi.org/10.1016/j.compedu.2016.03.011

Tseng, S.-F., Tsao, Y.-W., Yu, L.-C., Chan, C.-L., \& Lai, K. R. (2016). Who will pass? Analyzing learner behaviors in MOOCs. Research \& Practice in Technology Enhanced Learning, 11(1), 1-11. https://doi.org/10.1186/s41039-016-0033-5

Tu, C.-H., Yen, C.-J., Sujo-Montes, L., \& Roberts, G. A. (2015). Gaming personality and game dynamics in online discussion instructions. Educational Media International, 52(3), 155-172. http://doi.org/10.1080/09523987.2015.1075099

Ulrich, C., \& Nedelcu, A. (2015). MOOCs in Our University: Hopes and Worries. Procedia - Social and Behavioral Sciences, 180(November 2014), 1541-1547. https://doi.org/10.1016/j.sbspro.2015.02.304 
UNESCO. (2013). Alfabetización y Educación. Lecciones desde la Práctica Innovadora de América Latina y el Caribe. Santiago de Chile, Chile: OREALC/UNESCO

UNESCO (2017). Dar una mirada al futuro de la Educación para el Desarrollo Sostenible. Recuperado de http://www.unesco.org/new/es/education/themes/leading-the-internationalagenda/education-for-sustainable-development/dynamic-content-singleview/news/looking_into_the_future_of_education_for_sustainable_develop/

Vaibhav, A., \& Gupta, P. (2015). Gamification of MOOCs for increasing user engagement. Proceedings of the 2014 IEEE International Conference on MOOCS, Innovation and Technology in Education, IEEE MITE 2014, (February), 290-295. http://doi.org/10.1109/MITE.2014.7020290

Valenzuela, R. (2017). La innovación como objeto de investigación en educación: problemas, tensiones y experiencias. In M.S. Ramírez-Montoya, \& R. Valenzuela (Eds.), Innovación educativa, investigación, formación, vinculación y visibilidad (pp. 29-49). Madrid, España: Narcea.

Valerio, G. (2017). Redes digitales para gestionar la innovación educativa. In M.S. Ramírez-Montoya, \& R. Valenzuela (Eds.), Innovación educativa, investigación, formación, vinculación y visibilidad (pp. 247-255). Madrid, España: Narcea.

Valdivia Vázquez, J.A., Ramírez-Montoya, M.S., \& Valenzuela-González, J. R. (2018). Motivation and knowledge: Pre-Assessment and Post- Assessment of MOOC Participants From an Energy and Sustainability Project. The International Review of Research in Open and Distributed Learning, 19(4).

Valdivia Vázquez, J.A., Villegas, A.R., Farías, S.C. y Aldape, L.P. (2017) Evaluación de las experiencias en el desarrollo e implementación de MOOCs de energía. In M.S. Ramírez-Montoya, \& A. Mendoza-Domínguez (Eds.), Innovación y sustentabilidad energética Formación con MOOCs e investigación educativa (pp. 15-34). Madrid, España: Narcea.

Vázquez-Cano, E., López-Meneses, E., y Sarasola, J. L. (2013). La expansión del conocimiento en abierto: Los MOOCs. Barcelona: Octaedro, 120 pp.

Vazquez-Cano, E., \& López Meneses, E. (2015). La filosofía educativa de los MOOC y la educación universitaria. RIED, 18(2), 25-37. Retrieved from http://www.jbeplatform.com/content/journals/10.1075/sic.8.2.06yus \nhttp://publications.cetis.ac .uk/wp-content/uploads/2013/03/MOOCs-and-Open- 
Education.pdf $n$ http://publications.cetis.ac.uk/2013/667\nhttp://www.smarthighe red.com/wp-content/uploads/2013/03/

Vila, L., Dávila Quintana, C., \& Mora, J. (2010). Competencias para la innovación en las universidades de América Latina: un análisis empírico. Revista Iberoamericana De Educación Superior, 7(1). Recuperado dehttps://ries.universia.net/article/view/30

Villagrasa,S., Fonseca, D., Romo, M. and Redondo, E. "GLABS: Gamification for learning management systems," 2014 9th Iberian Conference on Information Systems and Technologies (CISTI), Barcelona, 2014, pp. 1-7. doi: 10.1109/CISTI.2014.6876878

Villalustre Martínez, L., \& Del Moral Pérez, M. E. (2015). Gamitication: Strategies to optimize learning process and the acquisition of skills in university contexts. Digital Education Review, 27, 13-31. Recuperado de http://revistes.ub.edu/index.php/der/article/view/12486/pdf 1

Villegas, A., Rivera, G., Martínez, M., Farías, S., Chacón E., González, S. (2016). Modelo Instruccional para los XMOOC de energía Sub-proyecto: Innovación abierta, interdisciplinaria y colaborativa para formar en sustentabilidad energética a través de MOOC. Laboratorio Binacional para la Gestión Inteligente de Sustentabilidad Energética y la Formación Tecnológica (Acuerdo: S0019-201401). México: Tecnológico de Monterrey (no publicado)

Warden, C. A., Stanworth, J. O., \& Chang, C. C. (2016). Leveling up: Are non-gamers and women disadvantaged in a virtual world classroom? Computers in Human Behavior, 65, 210-219. https://doi.org/10.1016/j.chb.2016.07.033

Wiesner, S. (2014). The development of technicians as a key factor for a sustainable development of renewable energies using an adapted education method based on the successful German Dual Education (Duale Ausbildung). Energy Procedia, 57(2013), 1034-1036. https://doi.org/10.1016/j.egypro.2014.10.069

Werbach, K., \& Hunter, D. (2012). For the win: How game thinking can revolutionize your business. Philadelphia, USA:Wharton Digital Press.

Werbach, K., \& Hunter, D. (2015). The gamification toolkit. Philadelphia, USA: Wharton Digital Press. 
Williams, I. (Octubre, 2015). Gamification as a content marketing tactic. Recuperado de: http://www.smartinsights.com/content-management/content-marketingcreative-and-formats/gamification-as-a-content-marketing-tactic/

Woolfolk, A. (2008). Educational Psychology. USA: Pearson.

World Council Energy. (2014). Consejo Mundial de la Energía, 16. Retrieved from https://www.worldenergy.org/wpcontent/uploads/2014/04/WEC_16_page_docu ment_21.3.14_ES_FINAL.pdf

World Energy Resources.(2016). World Energy Resources, 1, 468. https://doi.org/http://www.worldenergy.org/wpcontent/uploads/2013/09/Complete WER 2013 Survey.pdf

Wonglimpiyarat, J. (2010). Innovation index and the innovative capacity of nations. Futures, 42(3), 247-253. https://doi.org/10.1016/j.futures.2009.11.010

Xing, W., Chen, X., Stein, J., \& Marcinkowski, M. (2016). Temporal predication of dropouts in MOOCs: Reaching the low hanging fruit through stacking generalization. Computers in Human Behavior, 58, 119-129. https://doi.org/10.1016/j.chb.2015.12.007

Yañez, J., Ramírez-Montoya, M.S. y García-Peñalvo, F. (2017).Vinculación universidadsociedad para la innovación educativa: los casos de laboratorios ciudadanos. In M.S. Ramírez-Montoya, \& R. Valenzuela (Eds.), Innovación educativa, investigación, formación, vinculación y visibilidad (pp. 29-49). Madrid, España: Narcea.

Yildirim, I. (2017). Students' perceptions about gamification of education: A Q-method analysis. Egitim ve Bilim, 42(191), 235-246. https://doi.org/10.15390/EB.2017.6970

Young, J.R. (2013). What professors can learn from "hard core" MOOC students. Chronicle of Higher Education, 59(37), A4.

Zabalza Beraza, A. y Zabalza Cerdeiriña, M. (2016). Innovación y cambio en las instituciones educativas. Argentina: Homo Sapiens Ediciones.

Zhou, M. (2016). Chinese university students' acceptance of MOOCs: A selfdetermination perspective. Computers \& Education, 92-93, 194-203. http://doi.org/10.1016/j.compedu.2015.10.012 
